PNL-2494

NRC-1,3

\title{
Data Report for the NRC/PNL Halden Assembly IFA-431
}

April 1978

Prepared for the

U.S. Nuclear Regulatory Commission under a Related Services Agreement with the U.S Department of Energy

Contract Number EY-76-C-06-1830 
NOTICE

This report was prepared as an account of work sponsored by the United States Covernment. Neither the United States nor the United States Nuclear Regulatory Commission, nor any of their employees, nor any of their contractors, subcontractors, or their employees, makes any warranty, express or implied, or assumes any legal liability or responsibility for the accuracy, completeness or usefulness of any information, apparatus, product or process disclosed, or represents that its use would not infringe privately owned rights.

\author{
PACIFIC NORTHWEST LABORATORY \\ operated by \\ BATTELLE \\ for the \\ UNITED STATES DEPARTMENT OF ENERCY \\ Under Contract EY-76-C-06-1830
}

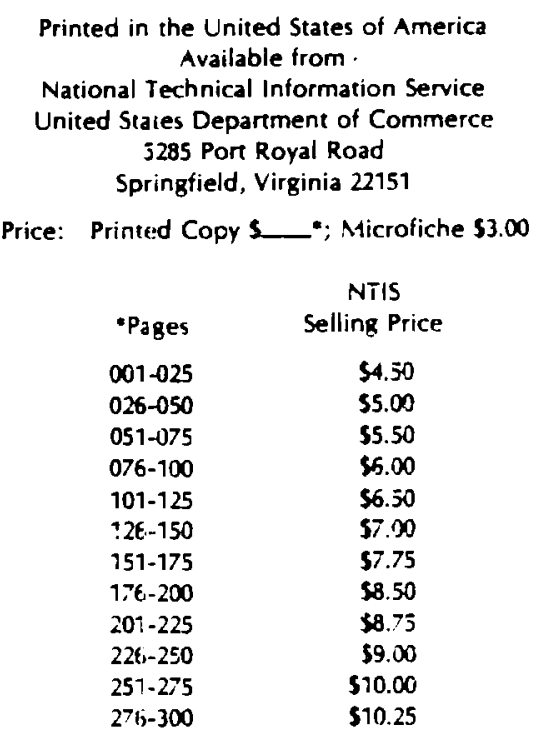




\section{9}

DARTA REPORT FOR THE NRC/PNL

HALDEN ASSEMBLY IFA-431

\section{Report to}

Fuel Behavior Research Branch

Division of Reactor Safety Research

U.S. Nuclear Regulatory Commission

by

C. R. Hann

E. R. Bradley

M. E. Cunnirigham

D. D. Lanning

R. K. Marshail

R. E. Williford

\section{Apri] 1978}

\section{BATTELLE}

Pacific Northwest Laboratories

Richland, Washington 99352

Prepared for the Nuclear Regulatory Commission under a Related Services Agreement with the U.S. Department of Energy - Contract Number EY-76-C-06-1830 
"The NRC will make available data tapes and operational computer codes on research programs dealing with postulated accidents in light water reactors. Persons requesting this information must reimburse the NRC contractors for their expenses in preparing copies of the data tapes and the operational computer codes. Requests should be submitted to the Research Support Branch, Office of Nuclear Regulatory Research, Nuclear Regulatory Commission, Washington, DC 20555."

\section{NOTICE}

This report was prepared as an account of work sponsored by the United States Government. Neither the United States nor the Energy Research and Development Administration, nor the Nuclear Regulatory Commission, nor any of their employees, nor any of their contractors, subcontractors, or their employees, makes any warranty, express or implied, or assumes any legal liability or responsibility for the accuracy, completeness or usefulness of any information, apparatus, product or process disclosed, or represents that its use would not infringe privately owned rights. 


\section{ACKNOWLEDGEMENTS}

The support of Dr. W. V. Johnston and H. H. Scott of the Fuel Behavior Research Branch is appreciated. J. A. Christensen contributed to the design and was instrumental in coordinating the final assembly, reactor loading, and, with the Halden Project staff, guiding the assembly through a successful irradiation. N. J. Wildung and W. D. Bennett produced the many data plots for this report. 
N

$b$

$+$ 


\section{CONTENTS}

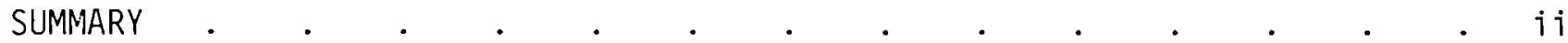

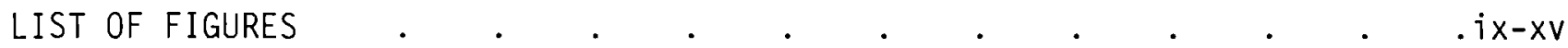
LIST OF TABLES .

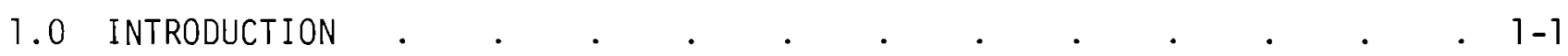

2.0 TEST RATIONALE . . . . . . . . . . . . . . . . . . . . . . $2-1$

2.1 Cross-Correlation Efforts . . . . . . . . . . . . . $2-1$

2.2 Test Facility . . . . . . . . . . . . . . . . . . $2-6$

2.3 Fuel Rod Thermal Design Parameters . . . . . . . . . 2-6

2.4 Fuel and Cladding Precharacterization . . . . . . . . 2-11

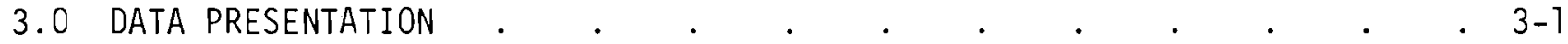

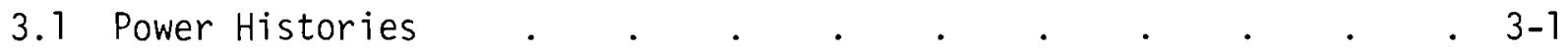

3.2 Fuel Temperature Histories . . . . . . . . . . . . . . . $3-1$

3.3 Cladding Elongation Histories . . . . . . . . . . 3-2

3.4 Rod Internal Pressure Histories . . . . . . . . . . . . . 3-2

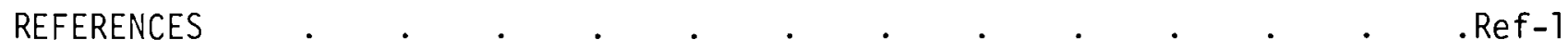
APPENDIX A - FUEL ROD AND FUEL COLUMN SCHEMATICS FOR IFA-431 • • . A-1 APPENDIX B - INSTRUMENT DESCRIPTIONS AND CALIBRATION . . . • • • . $\mathrm{B}-1$ APPENDIX C - ASSEMBLY POWER CALIBRATION $\quad . \quad$. . . . . . . . . . C-1 APPEINDIX D - DATA PROCESSING . . . . . . . . . . . . . . . . $\quad$ D-1 
5

- 


\section{SUMMARY}

This report presents the in-reactor data collected from the NRC/PNL Halden Assembly IFA-431 as a part of the program entitled "Experimental Verification of Steady State Fuel Codes," sponsored by the Fuel Behavior Research Branch of the USNRC. The purpose of this program is to reduce the uncertainties of calculating the thermal stored energy in an operating nuclear fuel rod.

This report presents fuel centerline thermocouple readings, cladding elongation monitor readings, rod internal pressure readings, and neutron detector readings. The neutron detector readings were corrected to represent rod local powers at the thermocouple locations. These data are presented in the form of plots of the variables versus time during the irradiation period from June 1975 to February 1976. Also included are descriptions of the test rationale, assembly and rod designs, test facility, instrument array and calibration, and data processing methods. Topical reports discussing specific aspects and results of the data analysis are referenced. 


\section{FIGURES}

2.1 Arrangement of Temperature Sensors, Neutron Detectors, and Fuel Relative to Reference Axial Thermal Flux Profile, IFA-431 and 432 2-3

2.2 Schematic of Instrumented Fuel Assembly--IFA-431 2-5

2.3 IFA-431 and IFA-432 Arrangements in the Flow Channel 2-7

2.4 Schematic of Rod 4 Fuel Column 2-10

2.5 IFA-431 Fuel Thermal Conductivity 95\% TD Stable, Rods 1, 2, 3, 4 2-12

3.1 Local Linear Heat Ratings at Upper Thermocouple Locations for Rods 1,3 of IFA 431 - June 1975

3.2 Local Linear Heat Ratings at Lower Thermocouple Locations for Rods 1,3 of IFA 431 - June 1975

3.3 Local Linear Heat Ratings at Upper Thermocouple Locations for Rods 2,4 of IFA 431 - June 1975

3.4 Local Linear Heat Ratings at Lower Thermocouple Locations for Rods 2,4 of IFA 431 - June 1975

3.5 Local Linear Heat Ratings at Upper Thermocouple Locations for Rods 5,6 of IFA 431 - June 1975

3.6 Local Linear Heat Ratings at Lower Thermocouple Locations for Rods 5,6 of IFA 431 - June 1975

3.7 Local Linear Heat Ratings at Upper Thermocouple Locations for Rods 1,3 of IFA 431 - July 1975

3.8 Local Linear Heat Ratings at Lower Thermocouple Locations for Rods 1,3 of IFA 431 - July 1975

3.9 Local Linear Heat Ratings at Upper Thermocouple Locations for Rods 2,4 of IFA 431 - July 1975

3.10 Local Linear Heat Ratings at Lower Thermocouple Locations for Rods 2,4 of IFA 431 - July 1975

3.11 Local Linear Heat Ratings at Upper Thermocouple Locations for Rods 5,6 of IFA 431 - July 1975

3.12 Local Linear Heat Ratings at Lower Thermocouple Locations for Rods 5,6 of IFA 431 - July 1975 
3.13 Local Linear Heat Ratings at Upper Thermocouple Locations for Rods 1,3 of IFA 431 - August 1975

3.14 Local Linear Heat Ratings at Lower Thermocouple Locations for Rods 1,3 of IFA 431 - August 1975

3.15 Local Linear Heat Ratings at Upper Thermocouple Locations for Rods 2,4 of IFA 431 - August 1975

3.16 Local Linear Heat Ratings at Lower Thermocouple Locations for Rods 2,4 of IFA 431 - August 1975

3.17 Local Linear Heat Ratings at Upper Thermocouple Locations for Rods 5,6 of IFA 431 - August 1975

3.18 Local Linear Heat Ratings at Lower Thermocouple Locations for Rods 5,6 of IFA 431 - August 1975

3.19 Local Linear Heat Ratings at Upper Thermocouple Locations for Rods 1,3 of IFA 431 - September 1975

3.20 Local Linear Heat Ratings at Lower Thermocouple Locations for Rods 1,3 of IFA 431 - September 1975

3.21 Local Linear Heat Ratings at Upper Thermocouple Locations for Rods 2,4 of IFA 431 - September 1975

3.22 Local Linear Heat Ratings at Lower Thermocouple Locations for Rods 2,4 of IFA 431 - September 1975

3.23 Local Linear Heat Ratings at Upper Thermocouple Locations for Rods 5,6 of IFA 431 - September 1975

3.24 Local Linear Heat Ratings at Lower Thermocouple Locations for Rods 5,6 of IFA 431 - September 1975

3.25 Local Linear Heat Ratings at Upper Thermocouple Locations for Rods 1,3 of IFA 431 - December 1975

3.26 Local Linear Heat Ratings at Lower Thermocouple Locations for Rods 1,3 of IFA 431 - December 1975

3.27 Local Linear Heat Ratings at Upper Thermocouple Locations for Rods 2,4 of IFA 431 - December 1975

3.28 Local Linear Heat Ratings at Lower Thermocouple Locations for Rods 2,4 of IFA 431 - December 1975 
3.29 Local Linear Heat Ratings at Upper Thermocouple Locations for Rods 5,6 of IFA 431 - December 1975

3.30 Local Linear Heat Ratings at Lower Thermocouple Locations for Rods 5,6 of IFA 431 - December 1975

3.31 Local Linear Heat Ratings at Upper Thermocouple Locations for Rods 1,3 of IFA 431 - January 1976

3.32 Local Linear Heat Ratings at Lower Thermocouple Locations for Rods 1,3 of IFA 431 - January 1976

3.33 Local Linear Heat Ratings at Upper Thermocouple Locations for Rods 2,4 of IF.4 431 - January 1976

3.34 Local Linear Heat Ratings at Lower Thermocouple Locations for Rods 2,4 of IFA 431 - January 1976

3.35 Local Linear Heat Ratings at Upper Thermocouple Locations for Rods 5,6 of IFA 431 - January 1976

3.36 Local Linear Heat Ratings at Lower Thermocouple Locations for Rods 5,6 of IFA 431 - January 1976

3.37 Local Linear Heat Ratings at Upper Thermocouple Locations for Rods 1,3 of IFA 431 - February 1976

3.38 Local Linear Heat Ratings at Lower Thermocouple Locations for Rods 1,3 of IFA 431 - February 1976

3.39 Local Linear Heat Ratings at Upper Thermocouple Locations for Rods 2,4 of IFA 431 - February 1976

3.40 Local Linear Heat Ratings at Lower Thermocouple Locations for Rods 2,4 of IFA 431 - February 1976

3.41 Local Linear Heat Ratings at Upper Thermocouple Locations for Rods 5,6 of IFA 431 - February 1976

3.42 Local Linear Heat Ratings at Lower Thermocouple Locations for Rods 5,6 of IFA 431 - February 1976

3.43 Upper Thermocouple Readings for Rods 1,3 of IFA 431 - June 1975

3.44 Lower Thermocouple Readings for Rods 1,3 of IFA 431 - June 1975

3.45 Upper Thermocouple Readings for Rods 2,4 of IFA 431 - June 1975 
3.47 Upper Thermocouple Readings for Rods 5,6 of IFA 431 - June 1975 3-26

3.48 Lower Thermocouple Readings for Rods 5,6 of IFA 431 - June $1975 \quad 3-26$

3.49 Upper Thermocouple Readings for Rods 1,3 of IFA 431 - July $1975 \quad 3-27$

3.50 Lower Thermocouple Readings for Rods 1,3 of IFA 431 - July 1975 3-27

3.51 Upper Thermocouple Readings for Rods 2,4 of IFA 431 - July 1975 3-28

3.52 Lower Thermocouple Readings for Rods 2,4 of IFA 431 - July 1975 3-28

3.53 Upper Thermocouple Readings for Rods 5,6 of IFA 431 - July 1975 3-29

3.54 Lower Thermocouple Readings for Rods 5,6 of IFA 431 - July $1975 \quad 3-29$

3.55 Upper Thermocouple Readings for Rods 1,3 of IFA 431 - August 1975 3-30

3.56 Lower Thermocouple Readings for Rods 1,3 of IFA 431 - August 1975 3-30

3.57 Upper Thermocouple Readings for Rods 2,4 of IFA 431 - August 1975 3-31

3.58 Lower Thermocouple Readings for Rods 2,4 of IFA 431 - August 1975 3-31

3.59 Upper Thermocouple Readings for Rods 5,6 of IFA 431 - August 1975 3-32

3.60 Lower Thermocouple Readings for Rods 5,6 of IFA 431 - August 1975 3-32

3.61 Upper Thermocouple Readings for Rods 1,3 of IFA 431 September 1975

3.62 Lower Thermocouple Readings for Rods 1,3 of IFA 431 September 1975

3.63 Upper Thermocouple Readings for Rods 2,4 of IFA 431 September 1975

3.64 Lower Thermocouple Readings for Rods 2,4 of IFA 431 September 1975

3.65 Upper Thermocouple Readings for Rods 5,6 of IFA 431 September 1975

3.66 Lower Thermocouple Readings for Rods 5,6 of IFA 431 September 1975

3.67 Upper Thermocouple Readings for Rods 1,3 of IFA 431 December 1975

3.68 Lower Thermocouple Readings for Rods 1,3 of IFA 431 December 1975 
3.69 Upper Thermocouple Readings for Rods 2,4 of IFA 431 December 1975

3.70 Lower Thermocouple Readings for Rods 2,4 of IFA 431 December 1975

3.71 Upper Thermocouple Readings for Rods 5,6 of IFA 431 December 1975

3.72 Lower Thermocouple Readings for Rods 5,6 of IFA 431 December 1975

3.73 Upper Thermocouple Readings for Rods 1,3 of IFA 431 January 1976

3.74 Lower Thermocouple Readings for Rods 1,3 of IFA 431 January 1976

3.75 Upper Thermocouple Readings for Rods 2,4 of IFA 431 January 1976

3.76 Lower Thermocouple Readings for Rods 2,4 of IFA 431 January 1976

3.77 Upper Thermocouple Readings for Rods 5,6 of IFA 431 January 1976

3.78 Lower Thermocouple Readings for Rods 5,6 of IFA 431 January 1976

3.79 Upper Thermocouple Readings for Rods 1,3 of IFA 431 February 1976

3.80 Lower Thermocouple Readings for Rods 1,3 of IFA 431 February 1976

3.81 Upper Thermocouple Readings for Rods 2,4 of IFA 431 February 1976

3.82 Lower Thermocouple Readings for Rods 2,4 of IFA 431 February 1976

3.83 Upper Thermocouple Readings for Rods 5,6 of IFA 431 February 1976

3.84 Lower Thermocouple Readings for Rods 5,6 of IFA 431 February 1976

3.85 Cladding Elongation Sensor Readings for Rods 1,2,5,6 of IFA 431 June 1975 
3.86 Cladding Elongation Sensor Readings for Rods 3,4 of IFA 431 - June 1975

3.87 Cladding Elongation Sensor Readings for Rods 1,2,5,6 of IFA 431 - Ju1y 1975

3.88 Cladding Elongation Sensor Readings for Rods 3,4 of IFA 431 - July 1975

3.89 Cladding Elongation Sensor Readings for Rods 1,2,5,6 of IFA 431 - August 1975

3.90 Cladding Elongation Sensor Readings for Rods 3,4 of IFA 431 - August 1975

3.91 Cladding Elongation Sensor Readings for Rods $3,4,5$ of IFA 431 - September 1975

3.92 Cladding Elongation Sensor Readings for Rods 1,2,6 of IFA 431 - September 1975

3.93 Cladding Elongation Sensor Readings for Rods 1,5 of IFA 431 - December 1975

3.94 Cladding Elongation Sensor Readings for Rods 3,4 of IFA 431 - December 1975

3.95 Cladding Elongation Sensor Readings for Rods 2,6 of IFA 431 - December 1975

3.96 Cladding Elongation Sensor Readings for Rods 1,5 of IFA 431 - January 1976

3.97 Cladding Elongation Sensor Readings for Rods 3,4 of IFA 431 - January 1976

3.98 Cladding Elongation Sensor Readings for Rods 2,6 of IFA 431 - January 1976

3.99 Cladding Elongation Sensor Readings for Rods 1,3,5 of IFA 431 - February 1976

3.100 Cladding Elongation Sensor Readings for Rods 2,4,6 of IFA 431 - February 1976

3.101 Internal Pressures for Rods 1,5,6 of IFA 431 - June 1975 3-53

3.102 Internal Pressures for Rods 1,5,6 of IFA 431 - July 1975 3-53

3.103 Internal Pressures for Rods 1,5,6 of IFA 431 - August 1975 3-54

3.104 Internal Pressures for Rods 1,5,6 of IFA 431 - September 1975 3-54 
3.105 Internal Pressures for Rods 1,5,6 of IFA 431 - December 1975

- 3.106 Internal Pressures for Rods 5,6 of IFA 431 - January 1976

3.107 Internal Pressures for Rods 5,6 of IFA 431 - February $1976 \quad 3-56$

A-1 Schematic Arrangement of Fuel Rods for IFA-431 A-1

A-2 Stack Arrangement for Rods 1 and $6 \quad$ A-2

A-3 Stack Arrangement for Rods 2, 3, and 5 A-3

A-4 Stack Arrangement for Rod 4 A-4

B-1 Schematic of Self-Powered, Beta Current Neutron Detector B-2

B-2 Schematic of $W 5 \% \operatorname{Re} / W 26 \%$ Re Thermocouples with Grounded Junction . B-4

B-3 Calibration Curve for W $5 \%$ Re/W $26 \%$ Re Thermocouples B-5

B-4 Cladding Elongation Monitor B-7

B-5 Rod 1 Extensometer Calibration Curve B-8

B-6 Rod 2 Extensometer Calibration Curve B-9

B-7 Rod 3 Extensometer Calibration Curve B-10

B-8 Rod 4 Extensometer Calibration Curve B-11

B-9 Rod 5 Extensometer Calibration Curve B-12

B-10 Rod 6 Extensometer Calibration Curve B-13

B-11 Comparison of Rod 1 and Rod 6 Extensometer Calibration
Curves

B-12 Fission Gas Pressure Transducer $\quad$ B-16

C-1 Schematic Arrangement for Assembly Power Calibration C-2

C-2 Power Calibration Data for IFA-431 C-3

D-1 Flow Diagram for Processing Halden Data D-2

D-2 Flow Diagram for Correction of Halden Rod Local Powers D-3

- D-3 Typical Axial Power Profile for IFA-431 D-5

D-4 Flow Diagram for Gap Conductance and Uncertainty Calculations D-6 


\section{TABLES}

2. 1 Design Parameters and Instrumentation for IFA-431 and IFA-432 2-2

2.2 Cross-Correlation Matrix 2-6

2.3 Operating Data for the HBWR 2-6

D-1 Typical Power Correction Factors for IFA-431 D-2 


\subsection{INTRODUCTION}

The thermal stored energy in a fuel rod is the driving function for the most severe postulated accident, the Loss-of-Coolant Accident. The Final Acceptance Criteria for Emergency Core Cooling Systems require an assessment of the stored energy during normal operation as well as a gap conductance calculation throughout the duration of the accident. Uncertainties in stored energy calculations have caused temporary derating of many commercial power plants and delayed the startup of additional plants. Many of the uncertainties can be attributed to the lack of we11-characterized data for fuel operating in the power ranges of commercial nuclear power plants. Specifically, the effects of fuel densification, fuel relocation and fission gas release on the fuel-cladding gap conductance are difficult to quantify primarily because the applicable data are extremely sparse.

Most of the calculational uncertainties can be attributed to inadequate mathematical models assembled in computer codes developed to simulate fuel rod behavior over a wide range of postulated conditions. Significant uncertainties in the calculations are associated with changes to fuel geometry, fuel-cladding gap dimensions, and internal gas compositions with their concomitant effects on the temperature distributions and gap conductance.

Two instrumented Halden Reactor fuel assemblies have been designed to focus on the above uncertainties. These experiments are providing we11-characterized experimental data under conditions which realistically simulate Light water Reactor operations. The data will be used to verify United States Nuclear Regulatory Commission fuel codes as well as provide bench mark data for commercial fuel licensing codes submitted by nuclear fuel vendors.

The two assemblies were designated IFA-431 and IFA-432 by the Halden Reactor Project and are being irradiated in the Halden Boiling Water Reactor. The first assembly, IFA-431, had a design power of $10 \mathrm{~kW} / \mathrm{ft}(328 \mathrm{~W} / \mathrm{cm})$ and reached its goal burnup of 4300 MWd/MTM in February 1976. IFA-432 has a design power of $15 \mathrm{~kW} / \mathrm{ft}(492 \mathrm{~W} / \mathrm{cm})$ and is expected to reach its goal burnup of 20,000 MWd/MTM in mid-1978. 


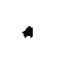




\subsection{TEST RATIONALE}

Experimental verification of computer codes provides a means to quantify uncertainties in simulating the conditions for an operating nuclear fuel rod. A collection of mathematical models (i.e., a computer code) is used to simulate the wide range of conditions postulated during an evaluation of reactor fuel safety. Any computer code that is forced to rely on a collection of empirical and semiempirical models for much of the analysis is limited and should be primarily used for interpolation. Some extrapolation can be accomplished with models based on first principles; however, well-characterized data are needed in either case to test code predictions. When these tests were designed (July 1974) very little data were available describing the effects of burnup on LWR fuel and no data were available describing the effects of fuel densification on fuel temperatures. Accordingly, a test matrix was developed (Table 2.1) and two instrumented assemblies designed to provide the data.

\subsection{CROSS-CORRELATION EFFORTS}

Much thought went into the design of the tests to ensure a means for cross correlating the data, provide as many independent checks of data validity as possible, ensure against instrument failure, ensure at least internal consistency on a relative basis, and provide some reference points to commercial plant designs as well as other fuel research programs.

One of the test design basic premises was to provide a systematic approach that would allow adequate interpolation and extrapolation with computer codes. The first step in this approach was the decision to design IFA-431 and IFA-432 as identical assemblies. An identical design enhances the ability to interpolate over a range of powers and also replicates initial conditions. For example, all the data from the IFA-431 first power ramp was duplicated with IFA-432. Identical assemblies also reduce the uncertainties associated with assembly and rod power distributions. 
TABLE 2.1. Design Parameters and Instrumentation for IFA-431 and IFA-432 IFA-431 [Peak Power - $10 \mathrm{~kW} / \mathrm{ft}(328 \mathrm{~W} / \mathrm{cm})$ ]

\begin{tabular}{|c|c|c|c|c|c|c|c|c|c|c|c|c|}
\hline \multirow{3}{*}{$\begin{array}{l}\text { Rod } \\
\text { No. }\end{array}$} & \multirow{2}{*}{\multicolumn{2}{|c|}{$\begin{array}{l}\text { Diameter } \\
\text { Pellet }\end{array}$}} & \multirow{2}{*}{\multicolumn{2}{|c|}{$\begin{array}{l}\text { Coid } \\
\text { Oiametral } \\
\text { Gap }(a)\end{array}$}} & \multicolumn{3}{|c|}{ Fuel } & \multicolumn{5}{|c|}{ Instrumentation } \\
\hline & & & & & Fill & Density & FUE & Burriup & Temper & ature & & Cladding \\
\hline & in. & $m$ & in. & $\frac{\pi n}{n}$ & Gas & & Iype(b) & $\mathrm{MHd} / \mathrm{MT}$ & Upper & Lower & Pressure & Length \\
\hline 1 & 0.4205 & 10.681 & 0.009 & 0.229 & $\mathrm{He}$ & 95 & Stable & 4,000 & $T c^{(c)}$ & TC & $P_{T}(d)$ & $E S^{(e)}$ \\
\hline 2 & 0.4145 & 10.528 & 0.015 & 0.381 & $\mathrm{He}$ & 95 & Stable & 4,000 & $T C$ & TC & - & ES \\
\hline 3 & 0.4275 & 10.858 & 0.002 & 0.051 & $\mathrm{He}$ & 95 & Stable & 4,000 & TC & TC & -- & ES \\
\hline 4 & 0.4205 & 10.681 & 0.009 & 0.229 & $x e$ & 95 & Stabie & 4,000 & $T C$ & TC & -- & ES \\
\hline 5 & 0.4205 & 10.681 & 0.009 & 0.229 & He & 92 & Stable & 4,000 & TC & TC & PT & ES \\
\hline & 0.4205 & 10.681 & 0.009 & 0.229 & $\mathrm{He}$ & 92 & Unstable & 4,000 & $T C$ & TC & PT & ES \\
\hline
\end{tabular}

IFA-432 [Peak Power - $15 \mathrm{~kW} / \mathrm{ft}(492 \mathrm{~W} / \mathrm{cm})]$

\begin{tabular}{|c|c|c|c|c|c|c|c|c|c|c|c|c|}
\hline & 0.4205 & 10.681 & 0.009 & 0.229 & $\mathrm{He}$ & 95 & Stable & 20,000 & $T C$ & TC & PT & ES \\
\hline & 0.4145 & 10.528 & 0.015 & 0.381 & $\mathrm{He}$ & 95 & Stable & $4,000^{(f)}$ & $U T^{(g)}$ & TC & -- & ES \\
\hline & 0.4265 & 10.858 & 0.003 & 0.076 & $\mathrm{He}$ & 95 & Stable & $4,000^{(f)}$ & TC & TC & -- & ES \\
\hline & 0.4205 & 10.681 & 0.009 & 0.229 & $x e$ & 95 & Stable & $4,000^{(f)}$ & $T C$ & $T C$ & -. & ES \\
\hline & 0.4205 & 10.681 & 0.009 & 0.229 & $\mathrm{He}$ & 92 & Stable & 20,000 & $T C$ & TC & PT & ES \\
\hline & 0.4205 & 10.681 & 0.009 & 0.229 & $\mathrm{He}$ & 92 & Unstable & 20,000 & $T C$ & TC & PT & ES \\
\hline & 0.4145 & 10.528 & 0.015 & 0.381 & $\mathrm{He}$ & 95 & Stable & 16,000 & -- & -- & -- & -- \\
\hline & 0.4205 & $10.58 ?$ & 0.009 & 3.229 & Ho & 95 & Stable & 16,000 & $\cdots$ & -- & -- & 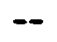 \\
\hline & 0.4225 & 10.732 & 0.007 & 0.179 & He & 95 & Stable & 16,000 & -- & - & -- & - \\
\hline
\end{tabular}

(a) Cladding for all rods has an 00 of $0.5035 \mathrm{in}$. (12.789 m) and an to of $0.4295 \mathrm{in.}(10.909 \mathrm{~mm}$ ). Dic-etral gap is clacting lo minus pellet diameter.

(b) witn respect to in-reastor densification.

(c) $T C=$ Thermoccucie

(d) $P_{\bar{T}}=$ Pressure Transducer

(e) $\varepsilon s=$ Elongation Saisor

(f) Retrovatie rods ropizced by kods 7,8 , and 9.

(g) UT = UItrasonic Thermometer

The power profile in the Haiden BWR (Figure 2.1) was also considered during the design. The top of the rod was placed at the peak, which forced the bottom of the rod to operate at 70 to $80 \%$ of the peak rod power. To take advantage of the power distribution, thermocouples were placed in the top and bottom of each rod. Previously, no tests had been run in Haiden with thermocouples penetrating both endcaps; however, Halden staff were able to develop a workable design. Thermocouples in both ends allows modelers to check the ability of various codes to extrapolate over a short power range within the same rod. If a code cannot perform these calculations adequately, calculations of the temperature distribution over an $\sim 4-m$ fuel length are also suspect. 


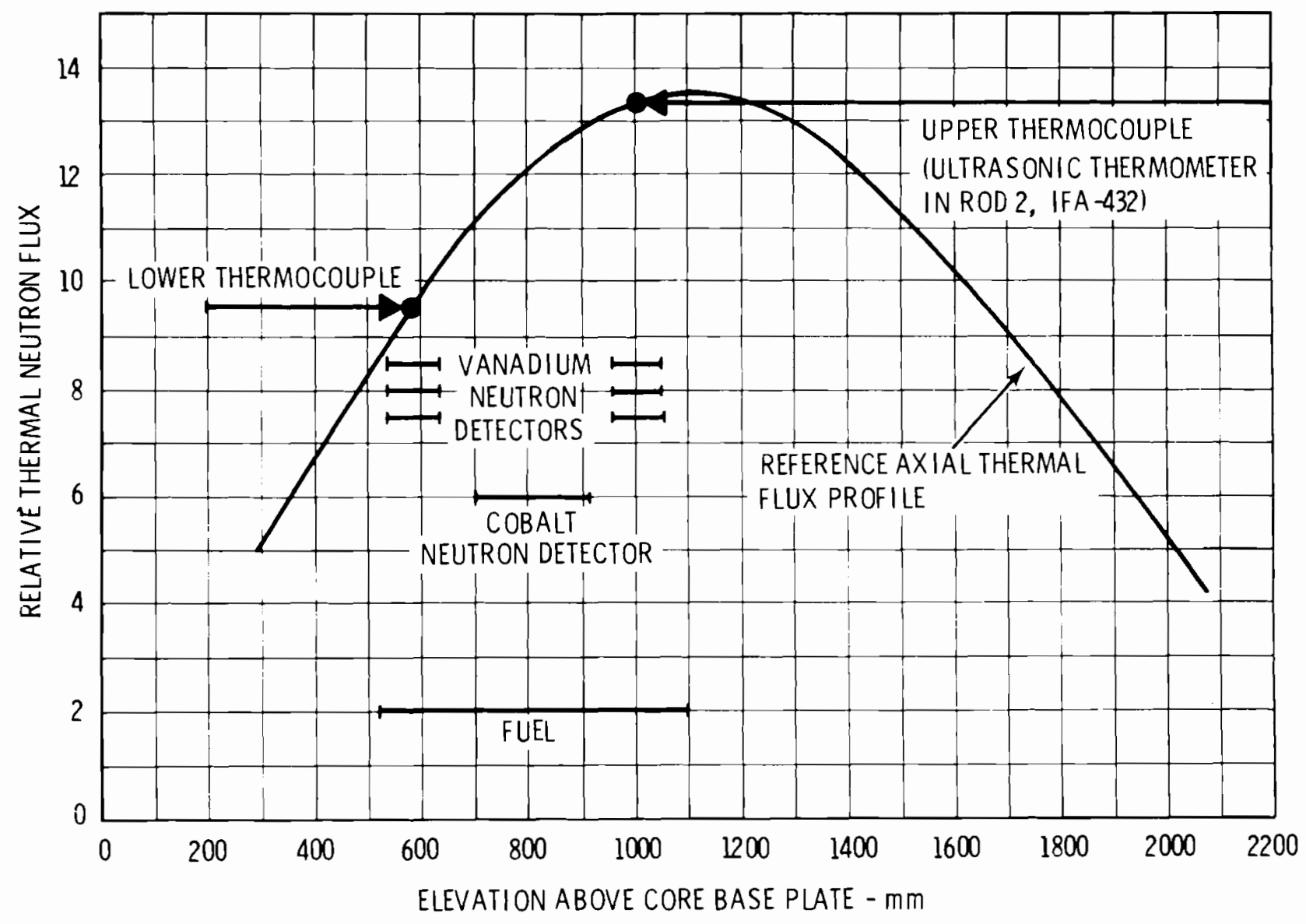

FIGURE 2.1. Arrangement of Temperature Sensors, Neutron Detectors, and Fuel Relative to Reference Axial Thermal Flux Profile, IFA-431 and 432

Using two thermocouples per rod allows modelers to interpolate between $\sim 7 \mathrm{~kW} / \mathrm{ft}$ $(230 \mathrm{~W} / \mathrm{cm})$ and $15 \mathrm{~kW} / \mathrm{ft}(492 \mathrm{~W} / \mathrm{cm})$ with tie points at $\sim 10 \mathrm{~kW} / \mathrm{ft}(328 \mathrm{~W} / \mathrm{cm})$ and $212 \mathrm{~kW} / \mathrm{ft}(394 \mathrm{~W} / \mathrm{cm})$. Single thermocouples would have provided data at only $10 \mathrm{~kW} / \mathrm{ft}(328 \mathrm{~W} / \mathrm{cm})$ and $15 \mathrm{~kW} / \mathrm{ft}(492 \mathrm{~W} / \mathrm{cm})$. Data is obtained, as a result of reactor cycling, over the entire range of 0 to $15 \mathrm{~kW} / \mathrm{ft}(492 \mathrm{~W} / \mathrm{cm})$. This should span most of the anticipated normal operating powers in commercial plants.

Reference points with commercial plants and other fuel research programs were also developed. Selection of the BWR- 6 fuel geometry, procurement of commercial quality tubing, and selection of assembly powers connects the data to commercial plants. Some of the cladding procured for this program was shipped to EG\&G (INEL) for use in their Haiden tests. Both programs also used the 
same starting powder for fuel manufacture. The length of the rods in both IFA431 and 432 were designed to be compatible with the Power Burst Facility (PBF) test trains; we11-characterized irradiated fuel is needed for a number of tests in the PBF program. Some of the fuel structures were similar to those investigated in the EEI/EPRI UO 2 fuel densification study, (1) to provide a reference point to a much larger structural characterization program.

The correct assessment of rod powers and the distribution of power within the rods is of utmost importance to assure the best possible thermal data. To attain this, seven neutron sensors were placed in each assembly (Figure 2.2). One was located in the center of the assembly, three were located at the top plane of thermocouples, and three were located at the bottom plane of thermocouples. An extensive calibration of the Vanadium sensors is conducted during the initial startup of any assembly. In addition, Rod 3 (0.051-0.076 mm gap for IFA-431 and 432, respectively) was included as an internal standard. The small gap was closed at power and thus the temperature gradient across the gap was minimized. Since the coolant temperature and fuel centerline temperatures are known, an independent check of rod power at both the top and bottom planes in the assembly was obtained. Rod powers and fuel temperatures in both assemblies were compared to assure consistent data. Each rod had a cladding elongation sensor, and Rods 1, 5, and 6 had fission gas pressure transducers.

Design assembly burnups for IFA-431 were set at 4000 MWd/MTM to ensure complete densification, minimize fuel volume changes induced by fission product swelling, and to retain the option of PIE confirmation of gap closure data obtained from low burnup rods. The second assembly, IFA-432, is a sibling to IFA-431. Three major differences exist in the design parameters. The design power is $15 \mathrm{~kW} / \mathrm{ft}(492 \mathrm{~W} / \mathrm{cm})$, the goal burnup is 20,000 MWd/MTM, and the assembly contains an option to replace three rods, allowing cross correlation with three identical rods in IFA-431.

The amount of cross-correlation that is possible is best illustrated in Table 2.2. In addition to the rod-to-rod comparisons, top-to-bottom comparisons can be made in each rod, and separate effects as a function of burnup and power can also be evaluated. 


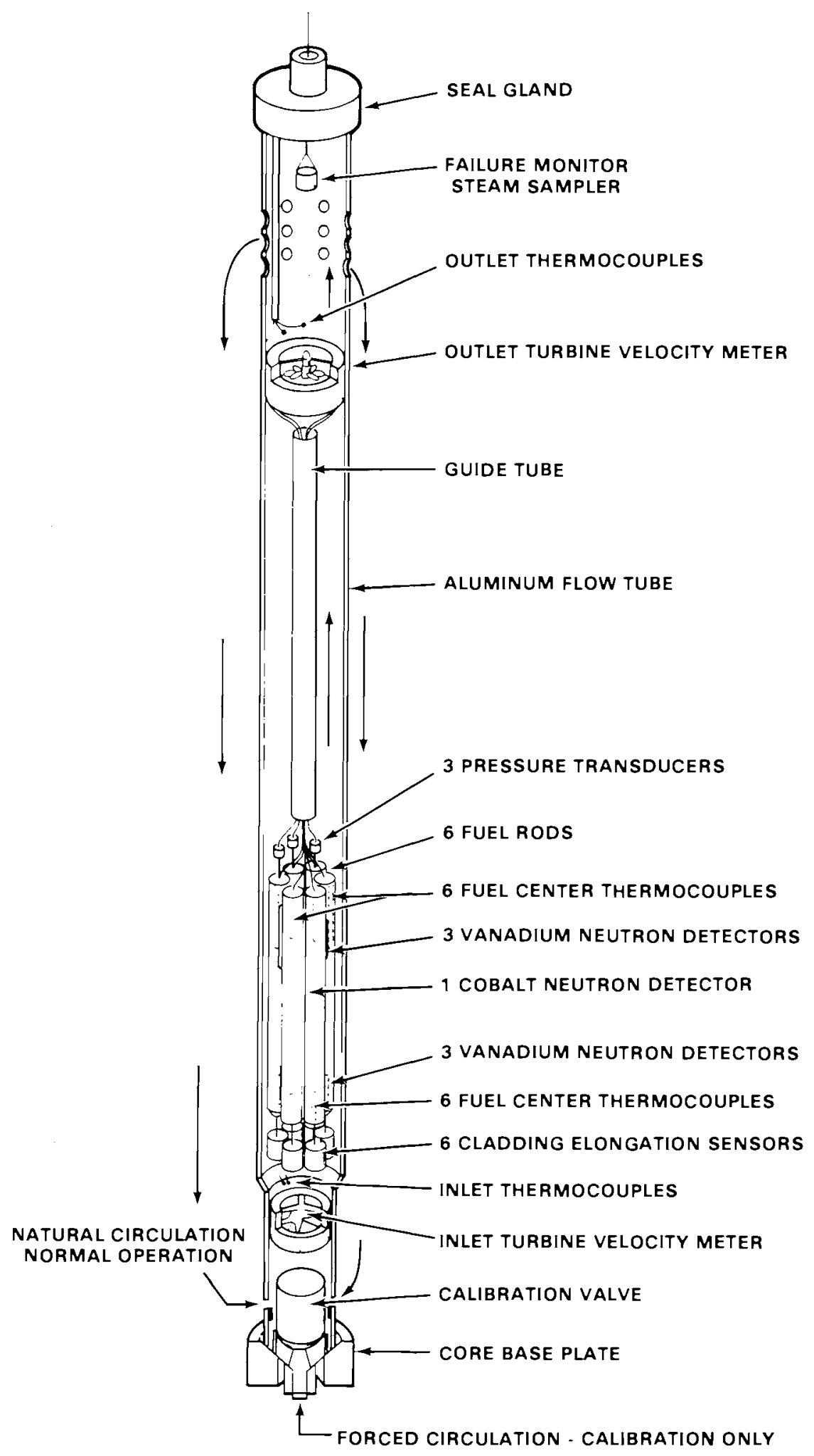

FIGURE 2.2. Schematic of Instrumented Fuel Assembly--IFA-431 
TABLE 2.2. Cross-Correlation Matrix

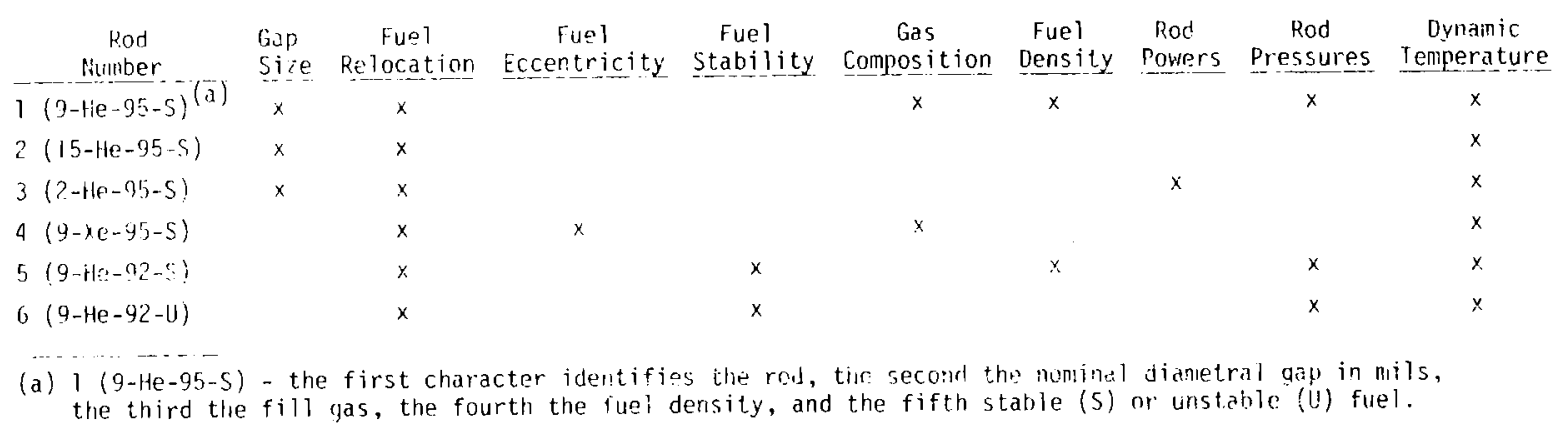

\subsection{TEST FACILITY}

The Halden Boiling Water Reactor (HBWR) uses natural circulation of heavy water for cooling. Reactor operating data are shown in Table 2.3.

\section{TABLE 2.3. Operating Data for the HBWR}

Power Level

Reactor Pressure

Heavy Water Saturation Temp.

Plenum Inlet Temp.

Thermal Flux

Fast Flux (>1 MeV)

Average Fuel Power Density
$12 \mathrm{MW}$

500 psi (34 atm)

$464^{\circ} \mathrm{F}\left(240^{\circ} \mathrm{C}\right)$

$459^{\circ} \mathrm{F}\left(237^{\circ} \mathrm{C}\right)$

$23 \times 10^{13} \mathrm{n} / \mathrm{cm}^{2}-\mathrm{sec}$

$\sim 5 \times 10^{11} \mathrm{n} / \mathrm{cm}^{2}-\mathrm{sec}$

$14.8 \mathrm{~W} / \mathrm{g}$

A schematic of the plan view of the HBWR core loading in November 1975 is shown in Figure 2.3. The locations of IFA-431 and IFA-432 are also indicated. Both half-length assemblies were charged into the bottom half of the core (Figure 2.1).

\subsection{FUEL ROD THERMAL DESIGN PARAMETERS}

\subsubsection{Contemporary Rod (Rod 1)}

It was important to obtain as many reference points as possible to crosscorrelate the data and provide avenues to extrapolate these test results to U.S. commercial nuclear fuel. Accordingly, a BWR-6 geometry, a 95\% TD pellet, 


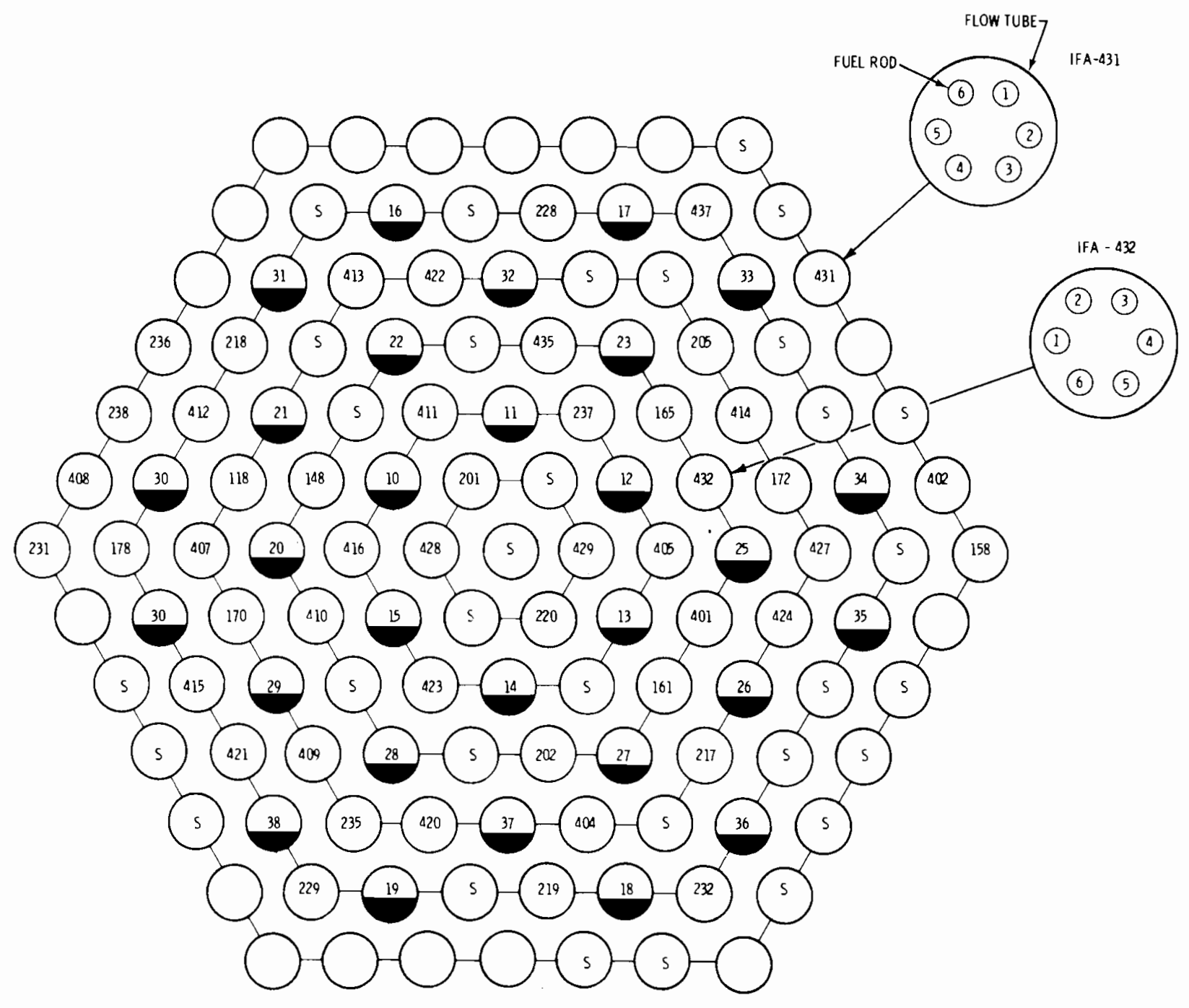

HBWR IV CORE LOADING NO. 19 DATE: NOV -75

(19) CONTRO ROD (CS 19 )

(21) INSTRUMENTED F UEL ASSEMBLY I IFA-43]

(1) STANDARD THIRD CHARGE ASSEMBLY

FIGURE 2.3. IFA-431 and IFA-432 Arrangements in the Flow Channel 
a $0.009 \mathrm{in} .(0.229 \mathrm{~mm})$ diametral gap, and helium fill gas were selected as the primary reference. In addition to minimizing the difficulty of extrapolating the data from the Halden tests to commercial plants, the larger BWR pellets tend to reduce perturbations induced by thermocouples. Cladding procurement problems were also minimized since atypical cladding dimensions are difficult to obtain from commercial sources. The $95 \%$ TD fuel density was selected to assure a densification-resistant fuel, provide a density typical of 1974 vintage fuel designs, and provide a reference point to previous thermal conductivity measurements on unirradiated fuel. Rod 1 in each assembly fulfills the above objectives.

\subsubsection{Simulated Instantaneous Densification (Rod 2)}

The major impact of fuel densification (2) was the assumption that the fuel underwent isotropic shrinkage directly proportional to the difference between the fabricated density and the terminal density. For example, a 93.5\% TD BWR fuel pellet (0.488-in. diameter) would shrink $0.00488 \mathrm{in}$. $(0.124 \mathrm{~mm})$ if the NRC criteria of a $96.5 \%$ TD terminal density were applied. Most BWR fuel rods of the above pellet size would contain an initial diametral gap of 0.011 to $0.012 \mathrm{in}$. (0.279-0.305 mm). Consequentiy, the shrinkage induced by densification would create a diametral gap of about 0.015 to $0.017 \mathrm{in}$. (0.381-0.432 mm). Consideration of tolerances ( $i . e ., \pm 0.0015 \mathrm{in}$.) on the initial gap resulted in even larger gaps. Until data became available from the EEI/EPRI UO 2 densification' program, $(1,3)$ the Halden program, (4) and individual fuel vendor programs, instantaneous densification was assumed. (2) That is, a gap of $0.016 \mathrm{in}$. $(0.406 \mathrm{~mm})$, for the example above, was assumed to exist as soon as the plant reached full power.

Accordingly, Rod 2 was designed with a 0.015-in. (0.381 mm) diametral gap to simulate instantaneous densification. The 0.015-in. gap in the BWR-6 geometry (0.4205-in. reference pellet diameter) yields a gap/diameter (G/D) ratio of 0.036 which approximates the $G / D$ ratios typically postulated for densified fuel in either the older BWR or PWR fuel designs.

\subsubsection{Internal Reference (Rod 3)}

Rod 3 was designed primarily for an independent check of rod powers. This rod contained 95\% TD fuel with an initial diametral gap of $0.002 \mathrm{in} .(0.051 \mathrm{~mm})$ (0.003 in. in IFA-432). These gaps were chosen to provide good contact at power 
and yet minimize the potential for cladding failure induced by mechanical interaction. The small gap was closed at power which produced very high gap conductances and thus minimized the temperature gradient across the fuel-cladding interface. Minimizing the temperature gradients across the gap is a good check of the effective thermal conductivity of the fuel in-reactor. Since cladding temperatures are calculable, and thermocouples indicated the fuel centerline temperatures, rod powers in the assembly could be checked. The technique that was used was based on the conductivity integral. (5)

A series of controlled power drops were requested for each assembly. Three cycles in each series consisted of a $20 \% 1$ inear drop in power over a 60-sec time interval. These tests yielded transient gap conductance data for comparison with the steady-state measurements. (6) Steady-state values were available for powers at the beginning and end of a ramp for boundary conditions. Data from the transient provided a cross-check on the steady-state data, as well as a data base for developing or verifying portions of the transient gap conductance models needed to satisfy the Final Acceptance Criteria for Emergency Core cooling System.

Rod 3 also provided an upper bound for gap conductance.

\subsubsection{Effects of Xenon and Eccentricity (Rod 4)}

Previous experiments have indicated that gap conductances are not as sensitive to different $f i 11$ gas compositions as some models would predict. In particular, Cohen et al., (7) Horn ${ }^{(8)}$ and Lawrence et al., (9) have reported that large portions of xenon must be mixed with helium before significant changes in gap conductance can be detected. In addition, analytical work had indicated that asymmetric pellet cladding gap geometries could have a significant effect on fuel temperatures and gap conductances. (10) The experimental resolution of the above was considered in the design of the NRC-RSR/PNL Halden assemblies IFA-431 and IFA-432.

To understand the anomalous thermal behavior of xenon-filled rods, we designed a rod (Number 4) that contained 95\% TD stable fuel, a 0.009-in. $(0.229 \mathrm{~mm})$ diametral gap, and xenon fill gas. Instrumented portions of the fuel column were mechanically constrained to be held concentric (near the top) 
and eccentric (near the bottom) of the rod (Figure 2.4). This was accomplished using the fuel centerline thermocouples, molybdenum rods, and oversized pellets. These oversized pellets were of Rod 3 design of each respective assembly. They had flats ground on the periphery to allow axial fill gas communication.

Results of the analysis of the data from this rod may be seen in Reference 11.

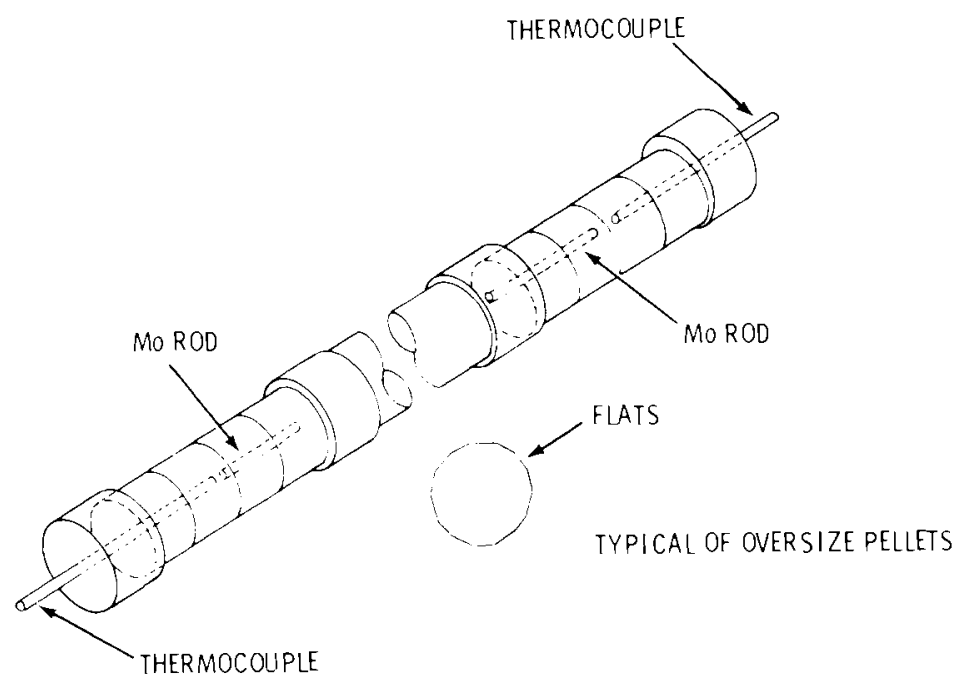

FIGURE 2.4. Schematic of Rod 4 Fuel Column

\subsubsection{Verification of Fuel Stability (Rod 5)}

Results of recent experimental work $(1,12)$ provide the technology required to fabricate low density (e.g., 92\% TD) fuel with various degrees of stability or resistance to irradiation-induced densification. New commercial designs under consideration will use low density, stable fuel. Rod 5 contained 92\% TD stable fuel and provided one means of verifying recent fuel fabrication technology with regard to the effects of fuel structures on irradiation temperatures. This rod will also be a cross-correlation with Rod 6 .

\subsubsection{Densification Kinetics (Rod 6)}

Rod 6 contains 92\% TD unstable fuel and a 0.009 in. $(0.229 \mathrm{~mm})$ gap. Unstable fuel with similar structure $(1,12)$ underwent significant densification. 
Densification models utilizing kinetic information obtained from Halden (4), terminal densities derived from the EEI/EPRI studies, (1) and resintering tests were developed to simulate time-dependent densification. Data from Rod 6 will be used to verify NRC densification models $(13,14)$ and provide a check of applicant-supplied models.

\subsection{FUEL AND CLADDING PRECHARACTERIZATION}

Extensive precharacterization of the fuel and cladding was essential to assure quality data and to reduce calculational uncertainties. Since this is presented elsewhere, ${ }^{(15)}$ only the main objectives will be discussed here.

The previous discussion describes the importance of knowing the correct power distribution. Thermal diffusivity measurements were made on each fuel type up to $1600^{\circ} \mathrm{C}$. This spans most of the fuel volume in either test. From previous experimental work, the heat capacity and density were obtained to calculate the thermal conductivity of the fuel as a function of temperature. Substitution of these data for the Lyons ${ }^{(16)}$ thermal conductance equation used in the GAPCON-THERMAL-2 ${ }^{(17)}$ pretest predictions improved the power calibration calculation using Rod 3. In addition, the thermal diffusivity data reduced the uncertainty associated with calculating gap conductances from the experimental data. The differences between the Lyons and IFA-431 precharacterization fuel thermal conductivities $(15)$ are shown in Figure 2.5 .

Establishing the initial dimensions and void volumes within the pins was also an essential part of assessing all thermal calculations. Consequently, the lengths and diameters of each pellet and the cladding for each rod were measured. Each pellet was identified with a unique number to trace pellet types and position within the rod (see Appendix A). With this information the axial distribution of gap volume and the plenum volume were known quite accurately. Pellet and cladding roundness profiles were also obtained to illustrate the departure from ideal coaxial cylinders used in most computer code models.

Geometric densities were determined for all pellets and immersion densities for a significant fraction of the pellets. A correlation was developed 


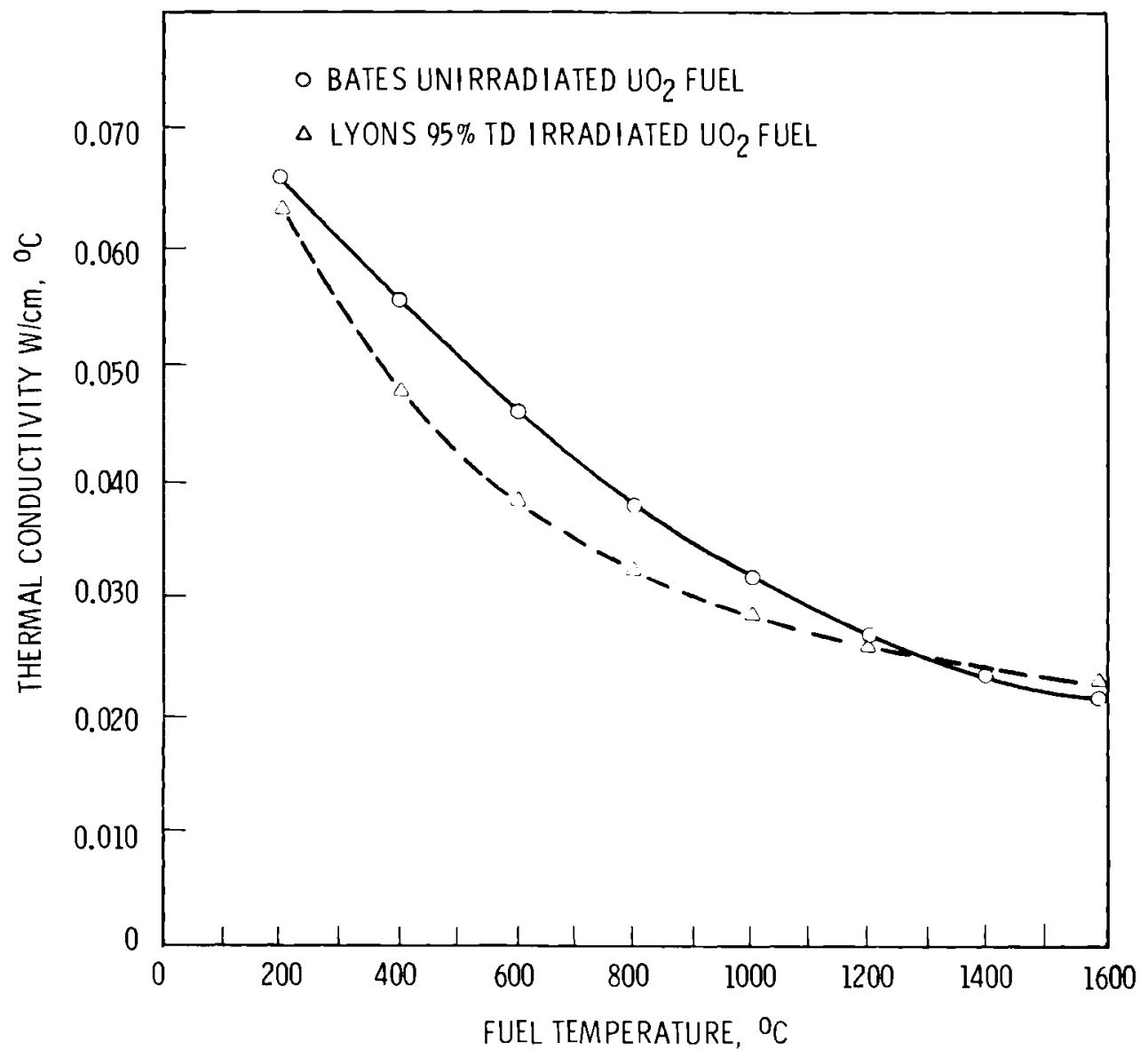

FIGURE 2.5. IFA-431 Fuel Thermal Conductivity, 95\% TD Stable, Rods 1, 2, 3, 4

relating immersion density to geometric densities. These data were used in two ways, 1) in a correction to rod powers caused by differences in mass distribution and 2) in the verification of NRC resintering models used to characterize fuel's propensity to densify. Resintering tests conducted on each fuel type are discussed in Reference 15.

The EEI/EPRI $\mathrm{UO}_{2}$ densification program ${ }^{(1)}$ demonstrated the importance of pore-size distribution measurements in characterizing the stability of various fuel types. We wanted to assure that the $95 \%$ TD stable fuel types were indeed stable. On the other hand, we wanted the $92 \%$ TD unstable fuel to undergo large 
amounts of densification in-reactor to determine the effects on fuel temperatures. Both fuel densities and pore-size distribution are being measured in a PIE (Post-Irradiation Examination) for Rod 6 at Harwe11, UK. Archive pellets from each fuel type were retained to provide a means of reducing variances associated with potential differences in examination techniques used in the pre-and post-test measurements. 


\subsection{DATA PRESENTATION}

Figures 3.1 through 3.107 show the in-reactor data collected from IFA-431 during its irradiation period from June 1975 to February 1976 plotted versus time by months. All except the rod internal pressures were obtained by the Halden IBM/1800 on-line computer data acquisition system. Data densities (versus time) vary from 15 minutes to 12 hours, depending on whether the reactor was experiencing transient (startup, power cycling) or steady state conditions.

In each figure, the rod number for each curve appears in the upper left hand corner. The relative position of the rod number corresponds to the relative position of the curve in each figure.

\subsection{POWER HISTORIES}

Figures 3.1 through 3.42 show the power histories of the upper and lower thermocouple locations for all six rods. These values were deduced from the vanadium self-powered neutron detector readings after applying correction factors to account for local mass distribution, radial flux tilt, and axial flux shape. This is described in Appendix D.

Corrections were also made for the burnup dependent depletion of ${ }^{235} \mathrm{U}$, but no plutonium buildup was considered. Both these factors are relatively small due to the low burnup achieved by the IFA-431 assembly (4300 MWd/MTM).

Note that neutron detector number six, which monitored the flux near the top of Rods 4 and 5, failed early in life. An equivalent value was calculated assuming that the upper and lower flux planes defined by the neutron detectors were parallel. This is also described in Appendix $D$.

The neutron detector readings during transient periods have not been corrected for the response lag of the detector due to incomplete saturation of the vanadium emitter. This 1 ag amounts to about 5 minutes during a power ramp, or one third of the normal data collection frequency.

\subsection{FUEL TEMPERATURE HISTORIES}

Figures 3.43 through 3.84 show the fuel centerline temperature histories for the upper and lower thermocouple locations for all six rods. These data were 
collected from the $\mathrm{W} 5 \% \mathrm{Re} / \mathrm{W} 26 \%$ Re sheathed, grounded thermocouples inserted in each end of each rod (see Appendix $B$ ).

In using these data, the reader should be aware that some anomolies have been seen between upper and lower thermocouples in the same rod, suggesting that the fuel at one end of the rod may be relatively decoupled from that at the other end. Future PNL reports will discuss these data.

\subsection{CLADDING ELONGATION HISTORIES}

Figures 3.85 through 3.100 show the cladding elongation histories for all six rods. Each rod was equipped with an LVDT-type elongation sensor of Halden design to monitor length changes throughout life. The results of the analysis of these data are discussed in Reference 18.

\subsection{ROD INTERNAL PRESSURE HISTORIES}

Figures 3.101 through 3.107 show the internal gas pressure histories for Rods 1, 5 and 6 throughout their irradiation history. These measurements were taken manually at various assembly powers using a null balance technique to complete an electrical connection in the diaphragm-type pressure transducers. The pressure reading was taken from the gas feed line that supplied the pressure to balance the transducer, which indicated gauge pressure. The data points connected by straight lines in Figures 3.101 through 3.107 indicate the number of times that the pressure data was manually collected throughout the life of the assembly. Results of the analysis of these data will be discussed in future PNL reports. 


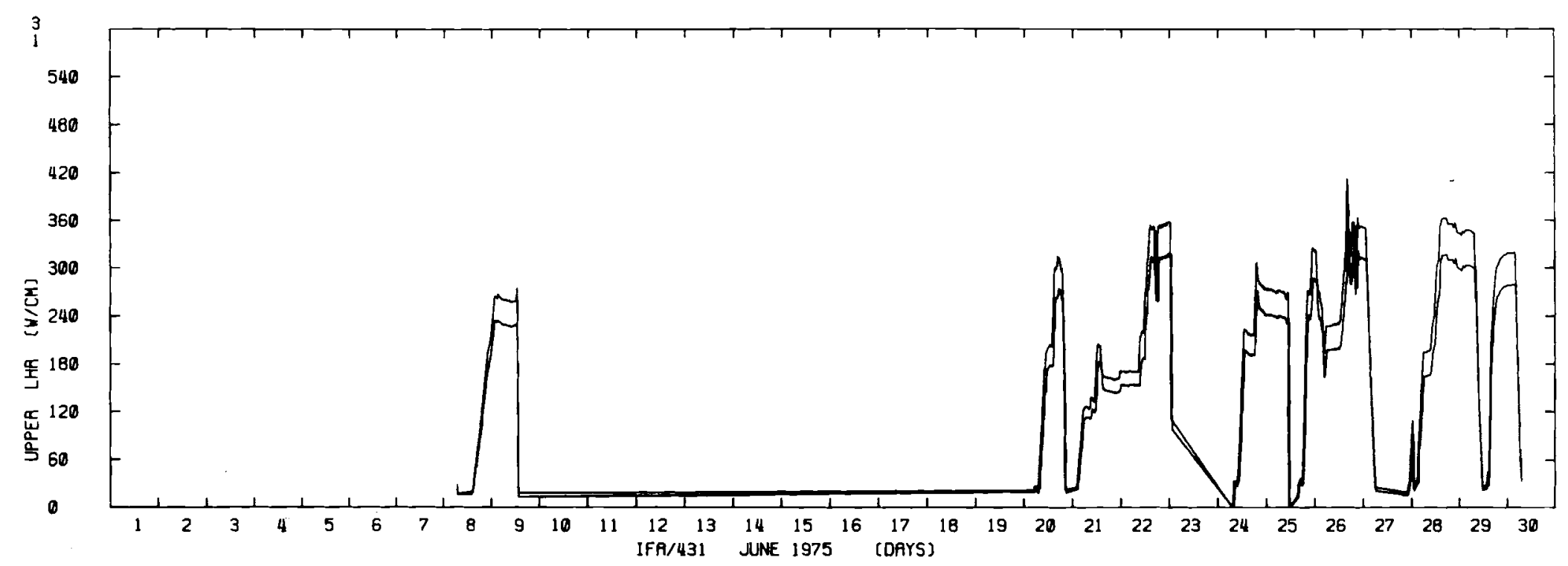

FIGURE 3.1. Local Linear Heat Ratings at Upper Thermocouple Locations for Rods 1,3 of IFA 431 - June 1975

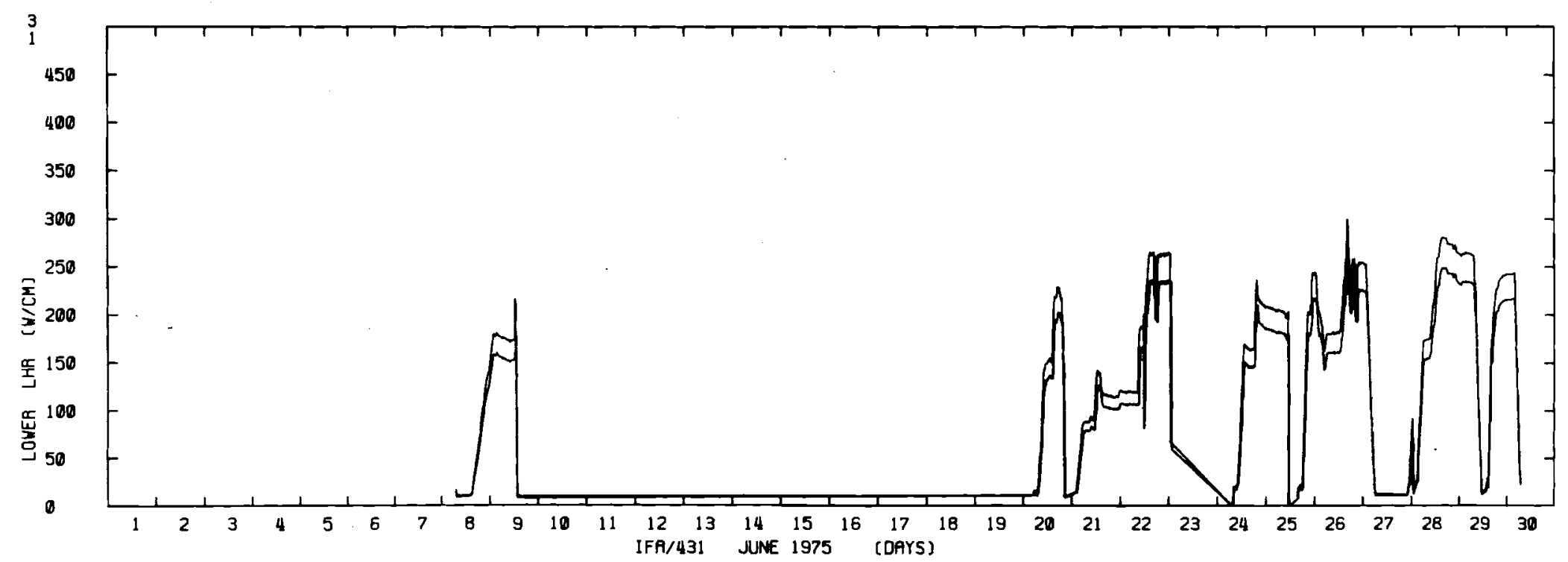

FIGURE 3.2. Local Linear Heat Ratings at Lower Thermocouple Locations for Rods 1,3 of IFA 431 - June 1975 


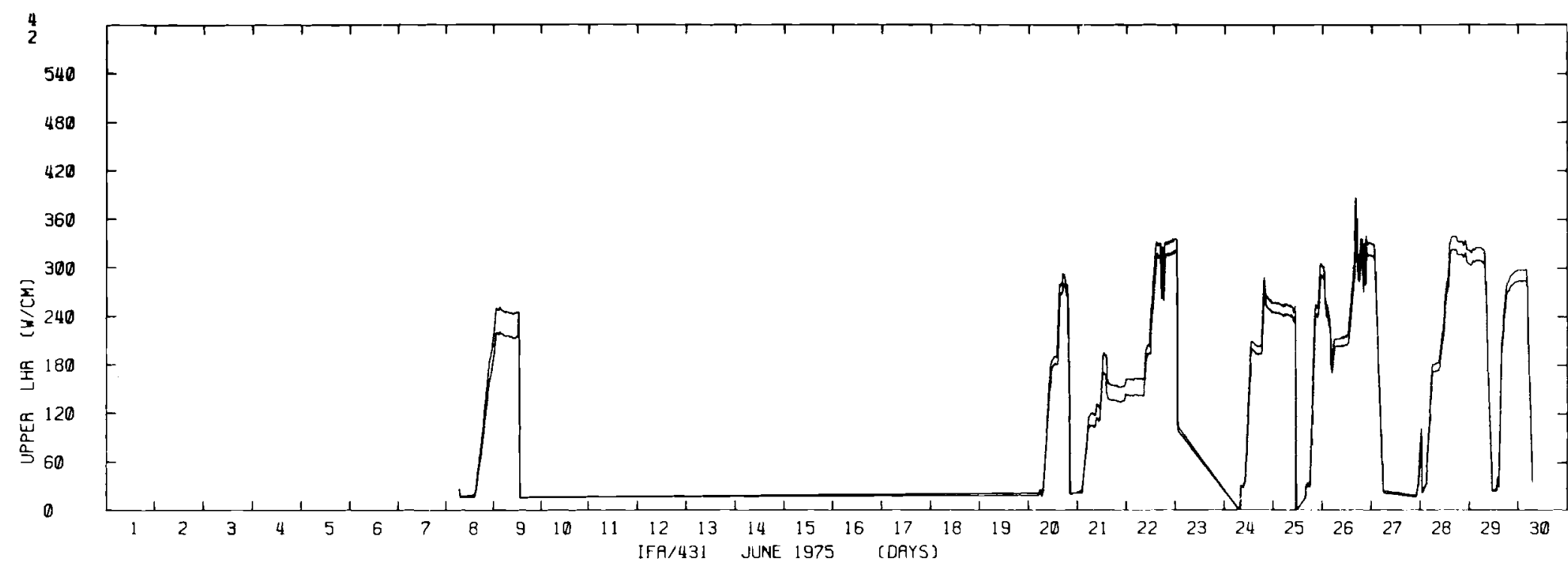

FIGURE 3.3. Local Linear Heat Ratings at Upper Thermocouple Locations for Rods 2,4 of IFA 431 - June 1975

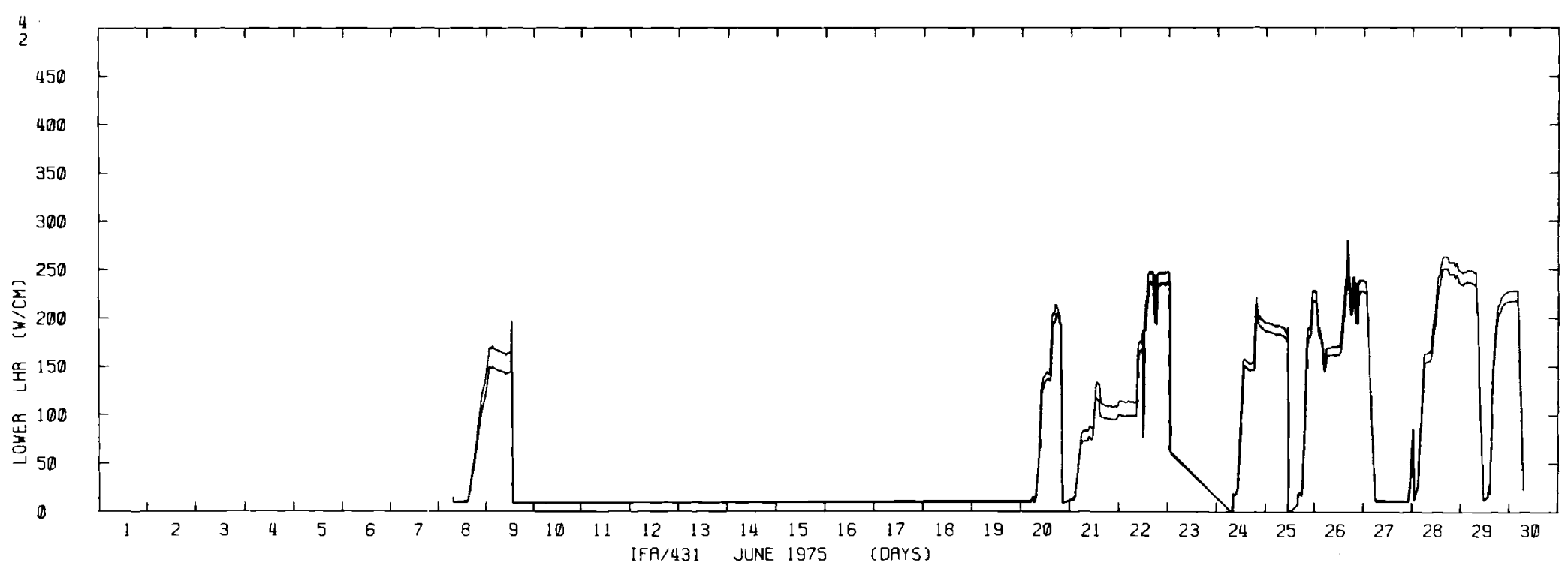

FIGURE 3.4. Local Linear Heat Ratings at Lower Thermocouple Locations for Rods 2,4 of IFA 431 - June 1975 


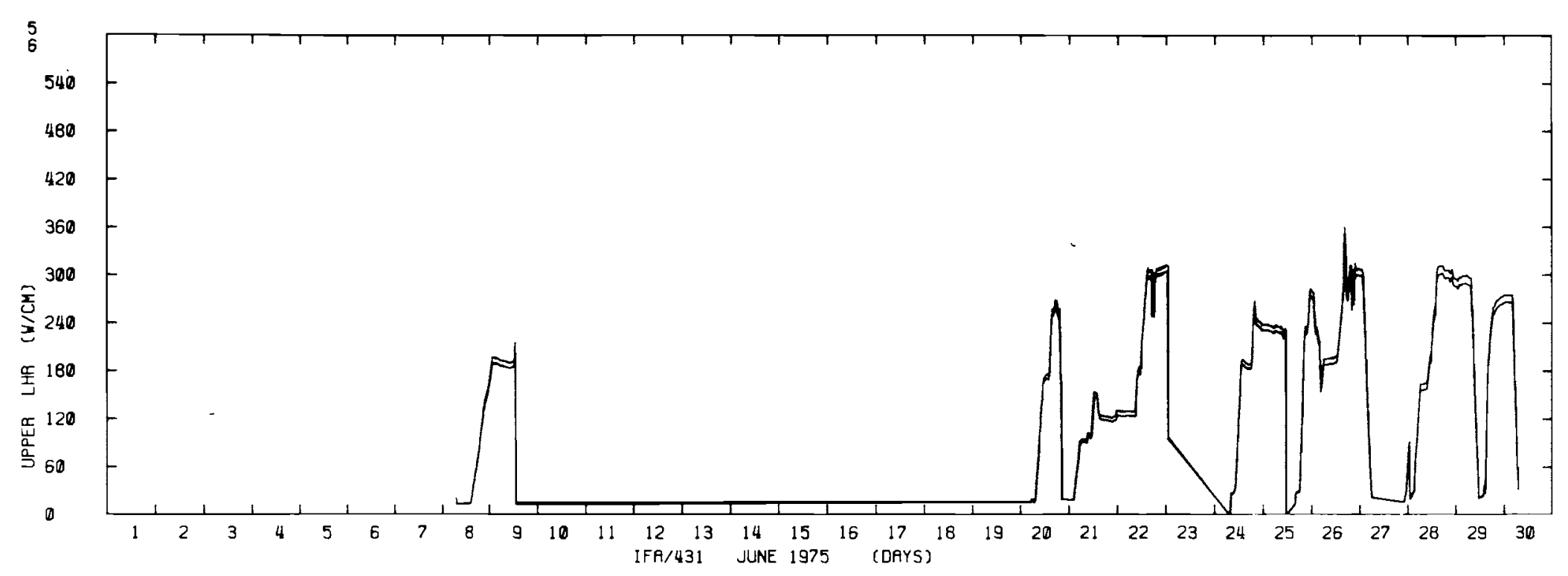

$\omega$
1
$u$

FIGURE 3.5. Local Linear Heat Ratings at Upper Thermocouple Locations for Rods 5,6 of IFA 431 - June 1975

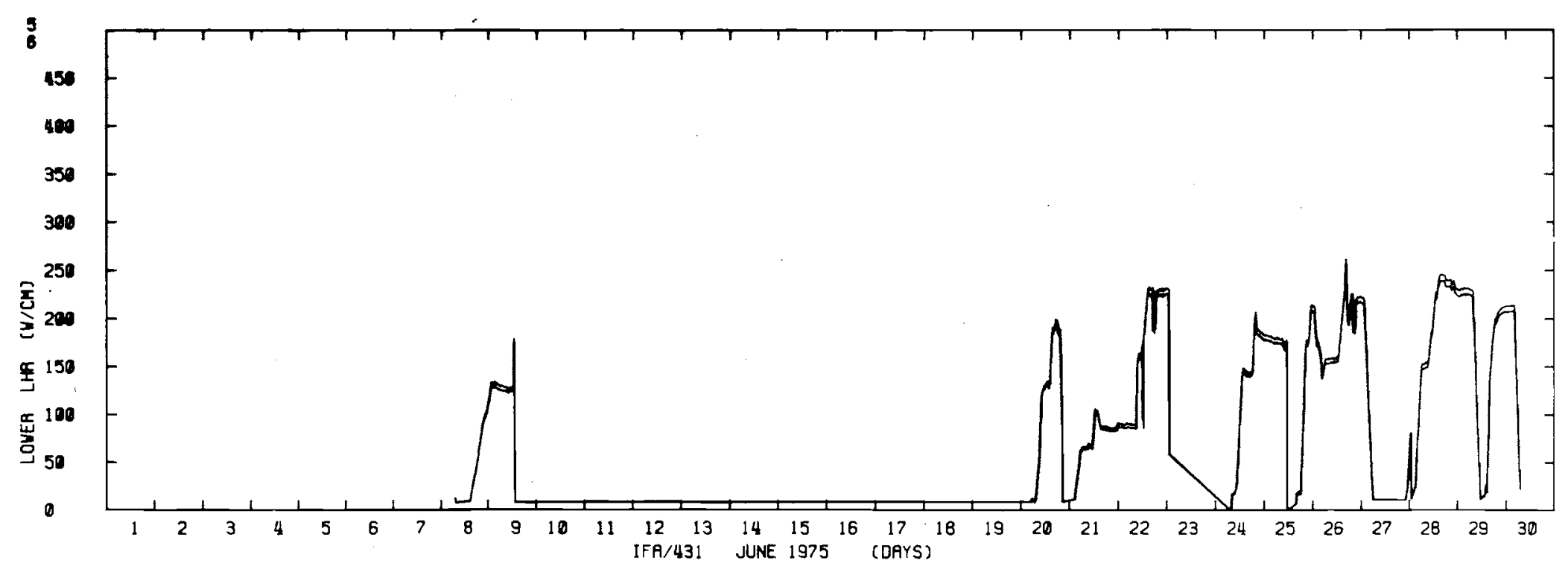

FIGURE 3.6. Local Linear Heat Ratings at Lower Thermocouple Locations for Rods 5,6 of IFA 431 - June 1975 


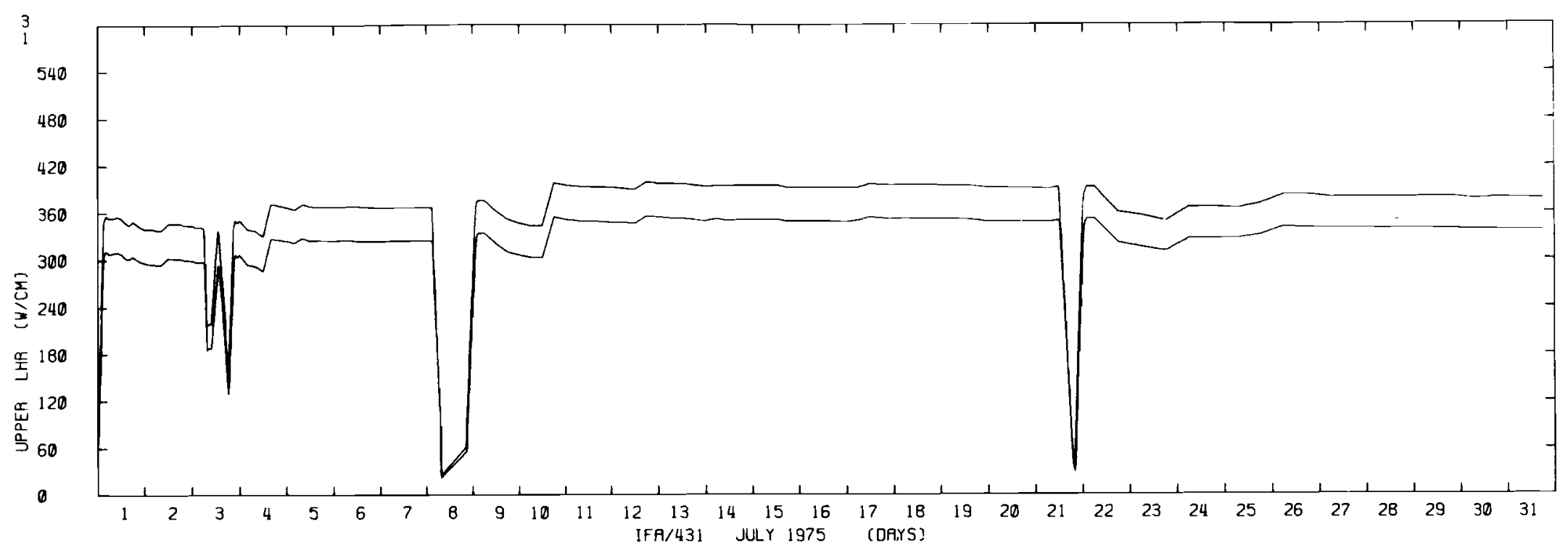

$\omega$

FIGURE 3.7. Local Linear Heat Ratings at Upper Thermocouple Locations for Rods 1,3 of IFA 431 - July 1975

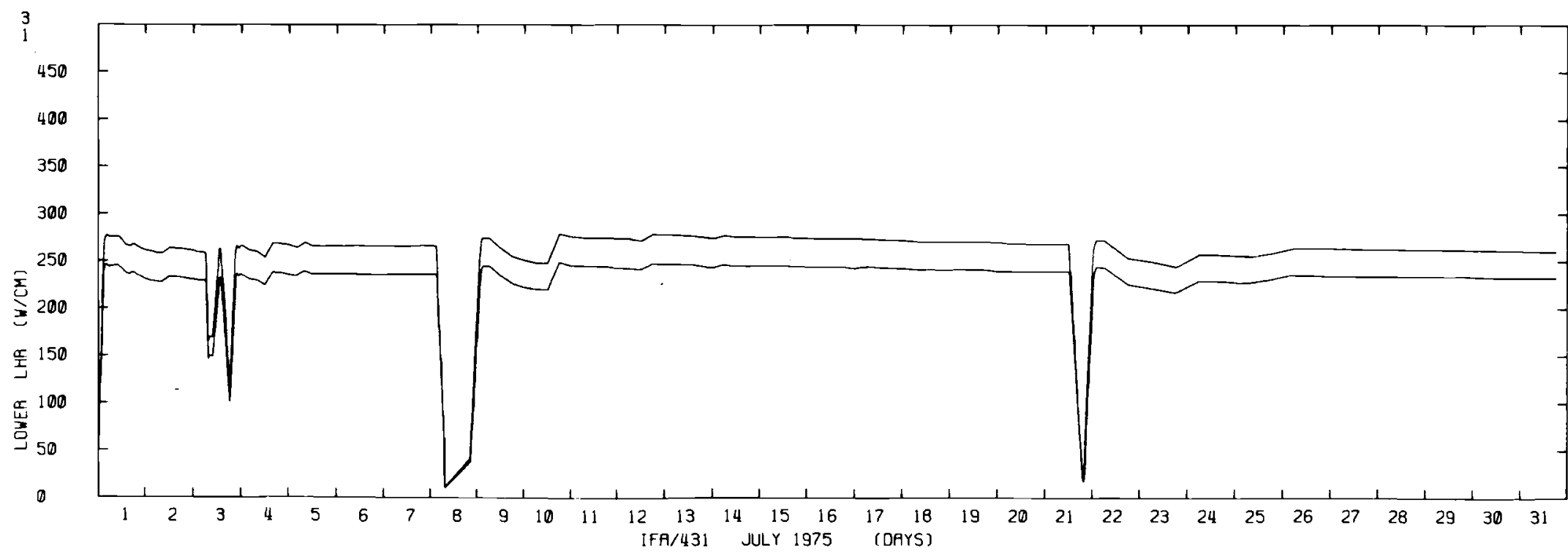

FIGURE 3.8. Local Linear Heat Ratings at Lower Thermocouple Locations for Rods 1,3 of IFA 431 - Ju1y 1975 


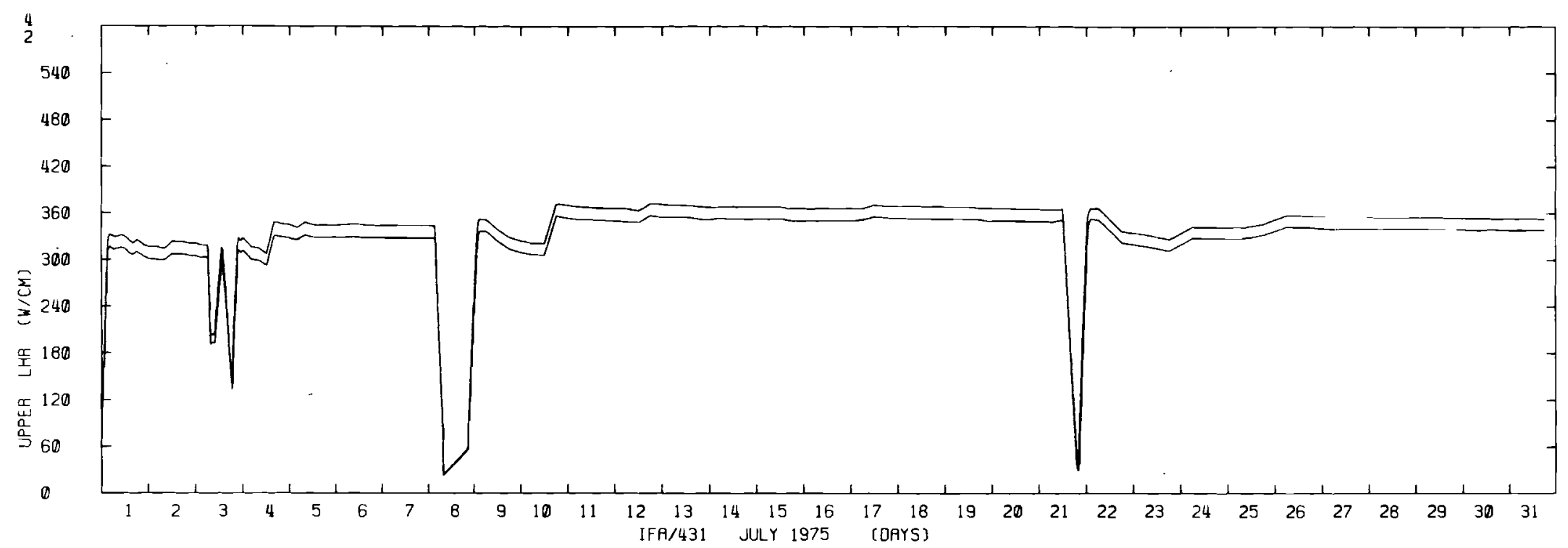

$\stackrel{\omega}{\dot{L}}$

FIGURE 3.9. Local Linear Heat Ratings at Upper Thermocouple Locations for Rods 2,4 of IFA 437 - July 1975

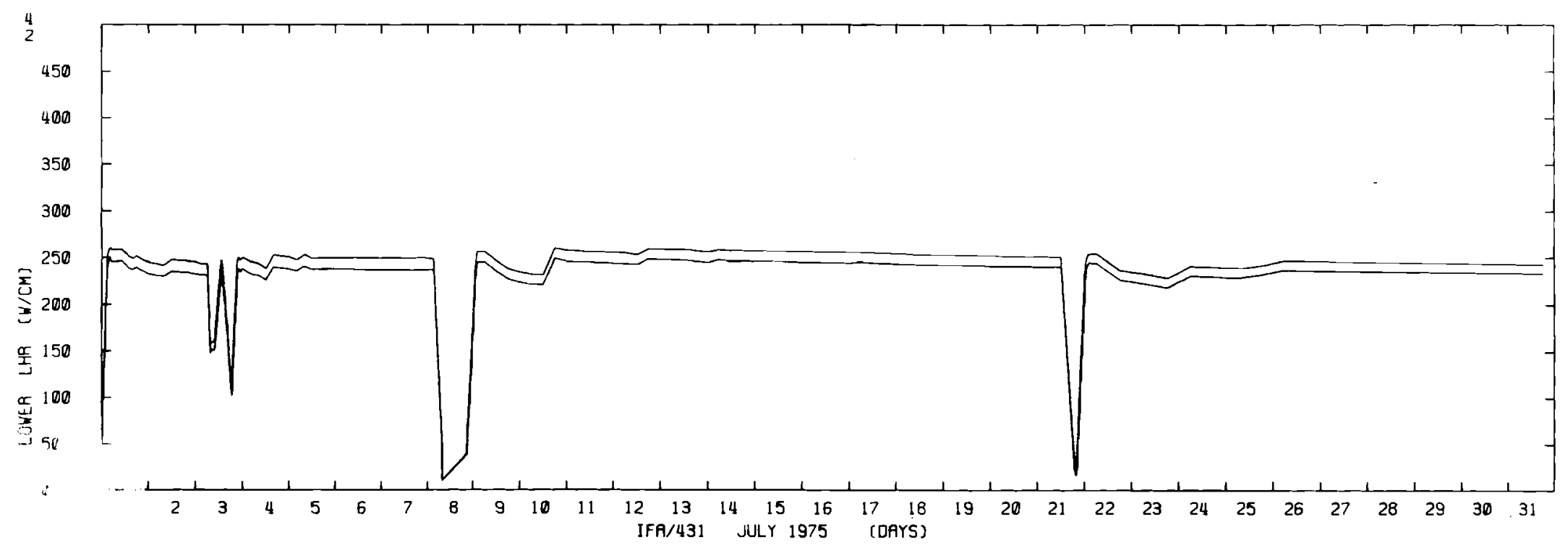

FIGURE 3.10. Local Linear Heat Ratings at Lower Thermocouple Locations for Rods 2,4 of IFA 431 - July 1975 


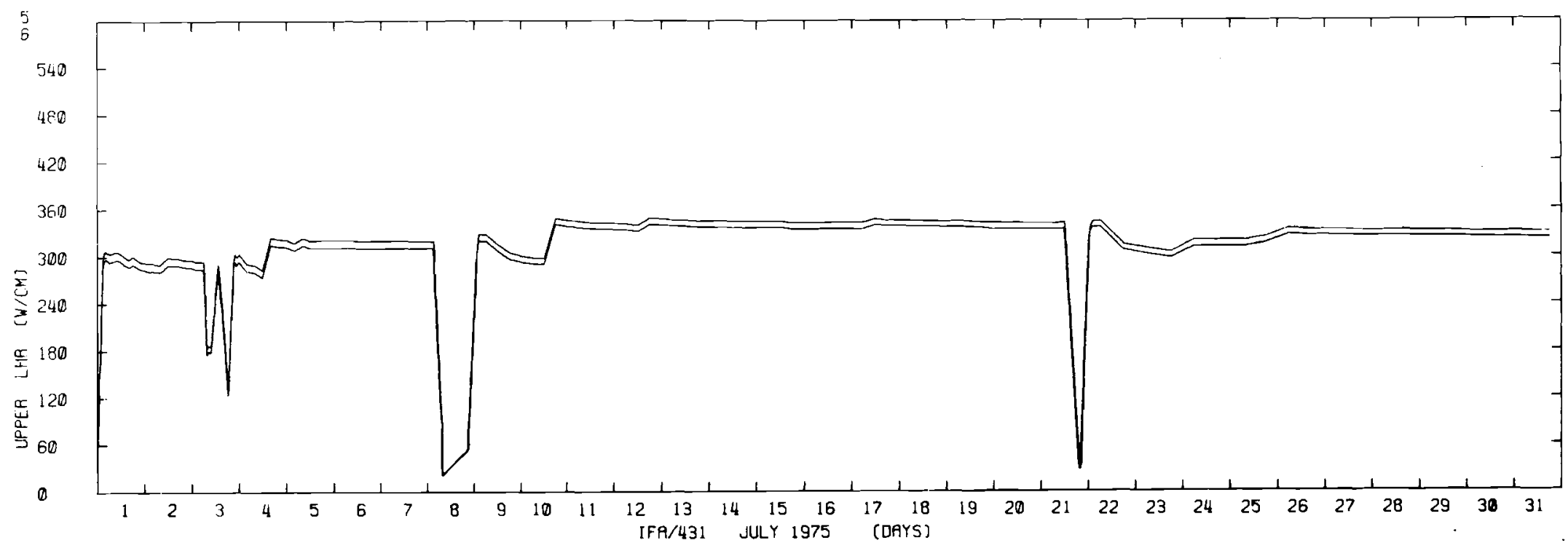

FIGURE 3.11. Local Linear Heat Ratings at Upper Thermocouple Locations fur Rods 5,6 of IFA 431 - July 1975

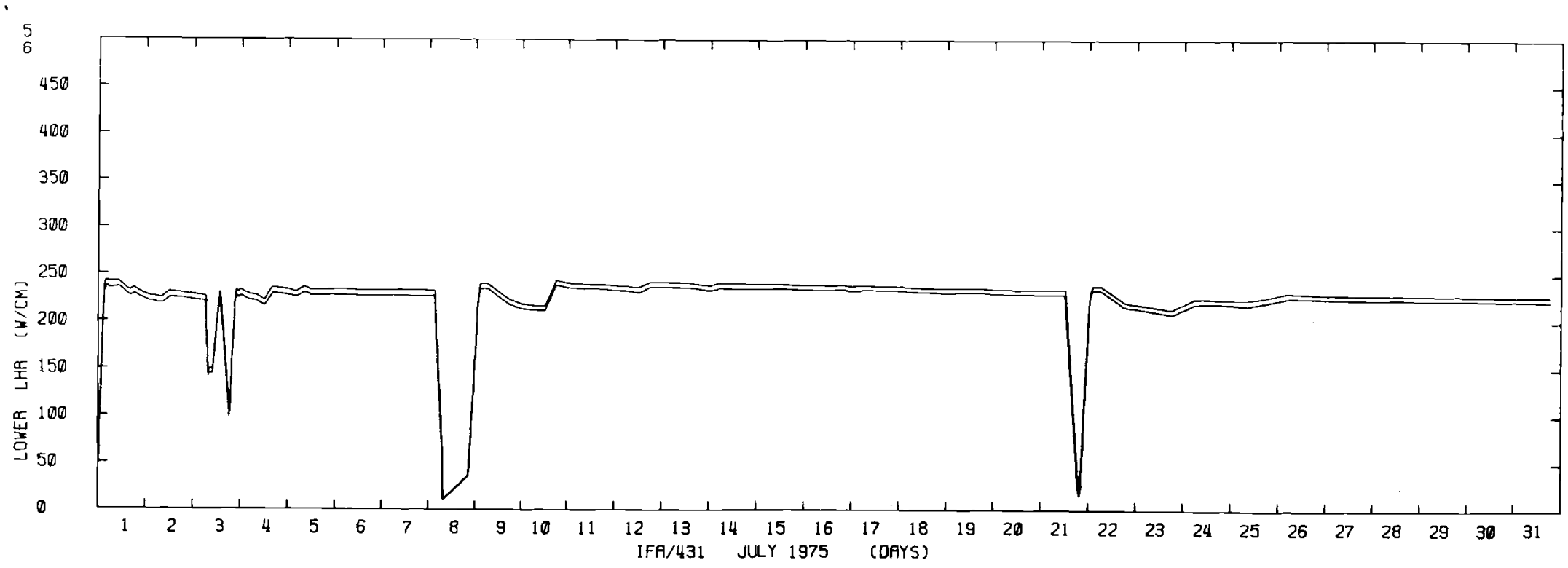

FIGURE 3.12. Local Linear Heat Ratings at Lower Thermocouple Locations for Rods 5,6 of IFA 431 - July 1975 


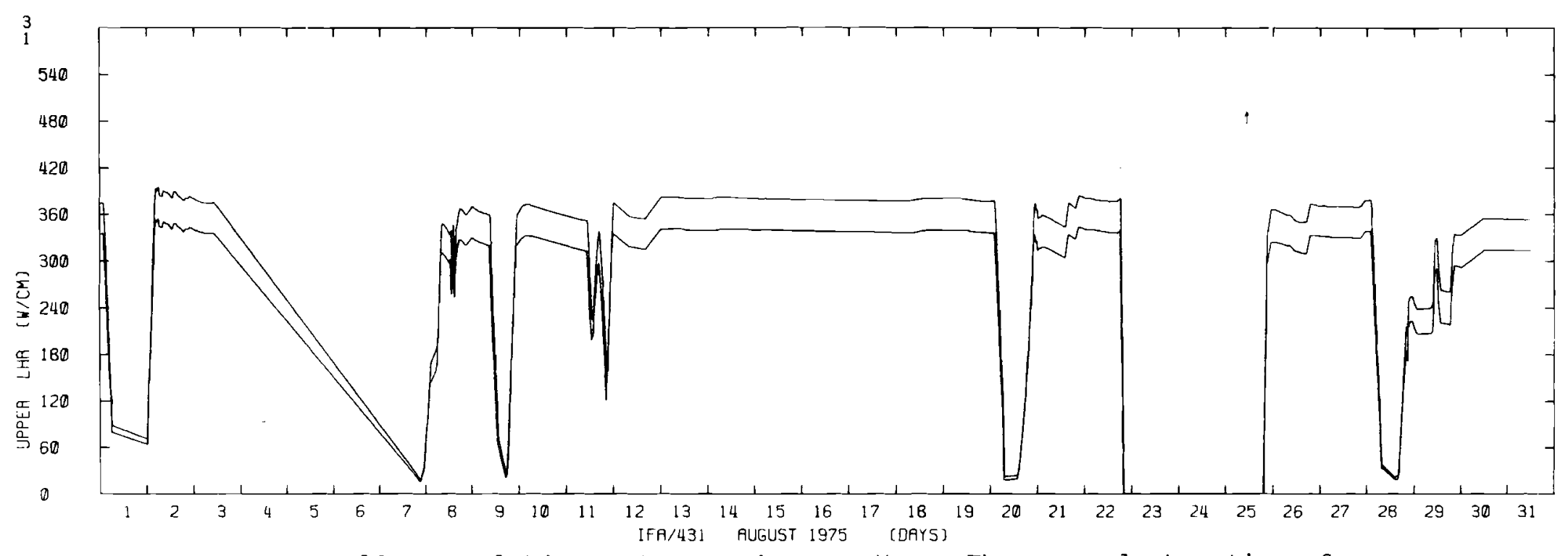

$\omega$
1
6

FIGURE 3.13. Local Linear Heat Ratings at Upper Thermocouple Locations for Rods 1,3 of IFA 431 - August 1975

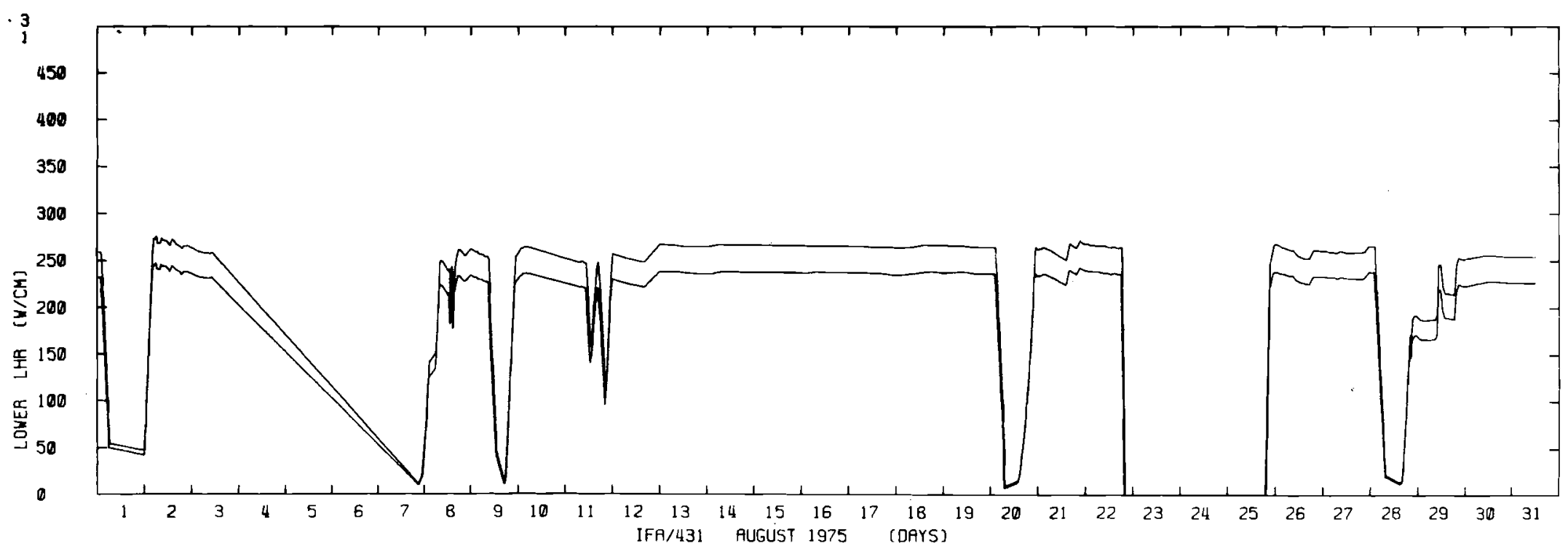

FIGURE 3.14. Local Linear Heat Ratings at Lower Thermocouple Locations for Rods 1,3 of IFA 431 - August 1975 


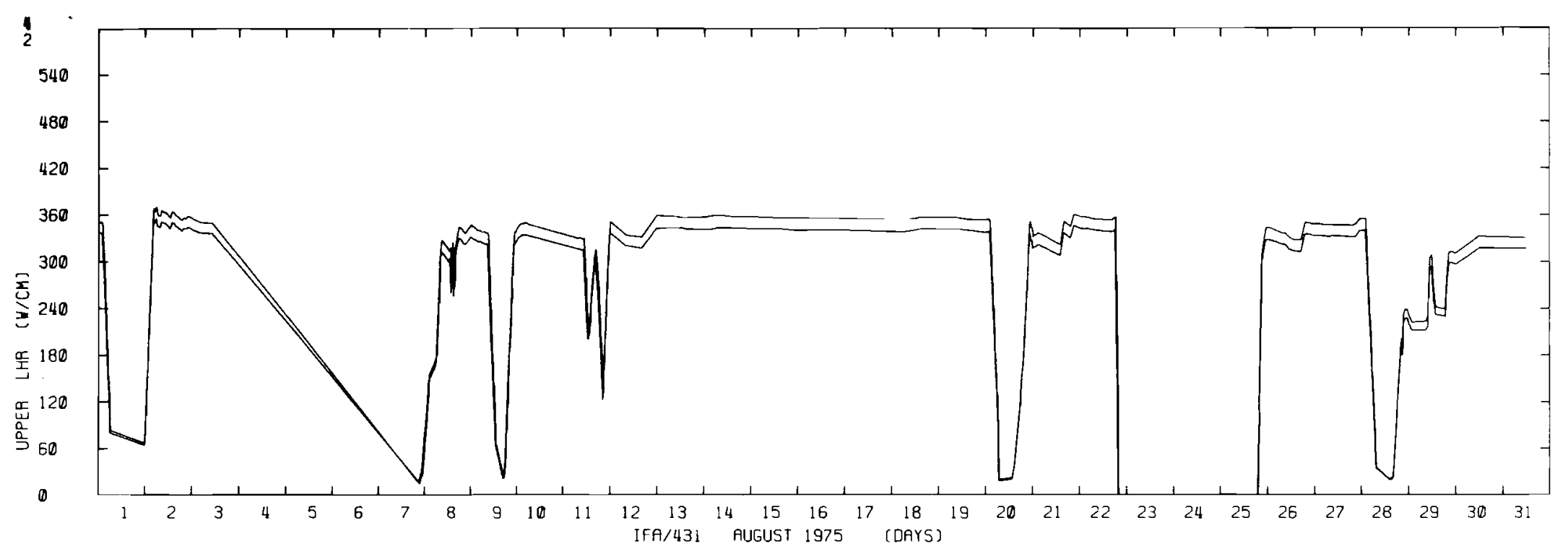

FIGURE 3.15. Local Linear Heat Ratings at Upper Thermocouple Locations for

$\omega$
$\frac{1}{0}$ Rods 2, 4 of IFA 431 - August 1975

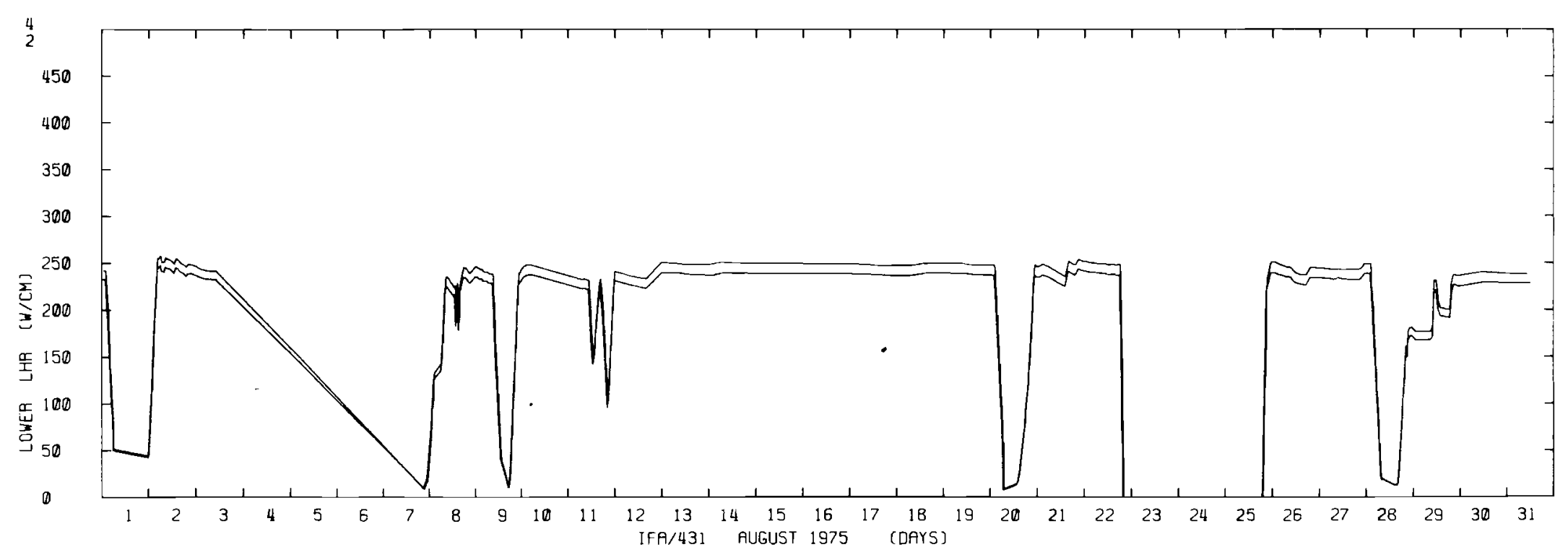

FIGURE 3.16. Local Linear Heat Ratings at Lower Thermocouple Locations for Rods 2,4 of IFA 431 - August 1975 


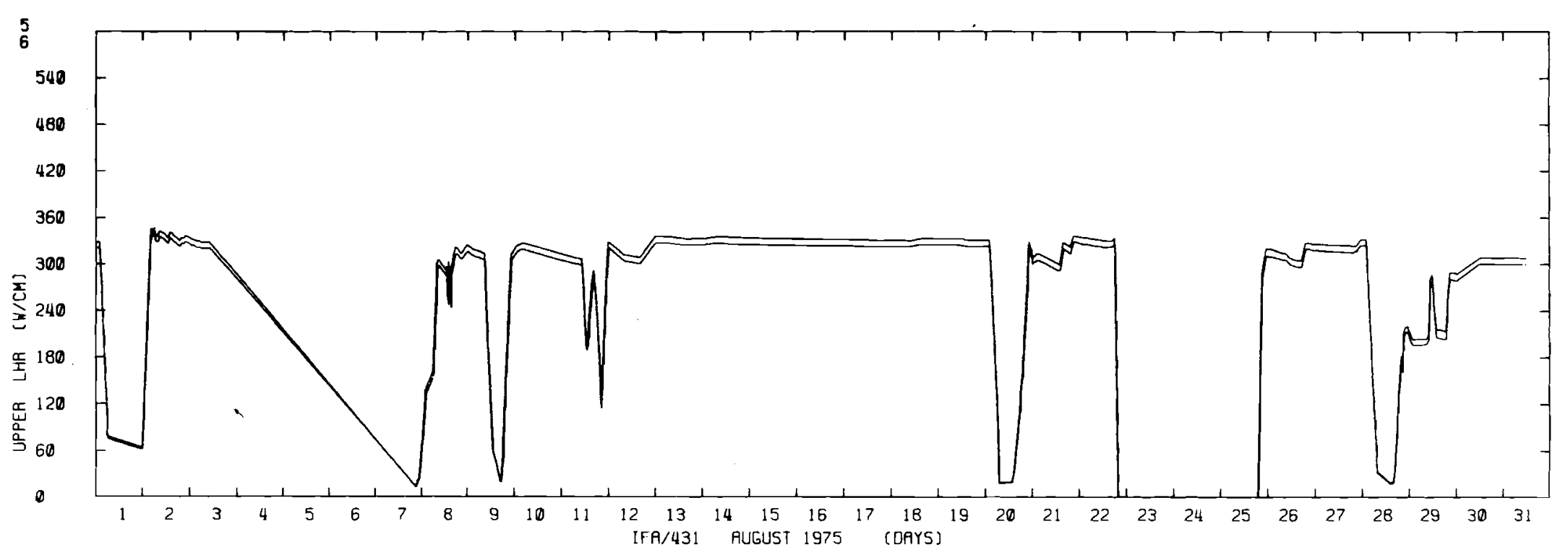

FIGURE 3.17. Local Linear Heat Ratings at Upper Thermocouple Locations for Rods 5,6 of IFA 431 - August 1975

$\stackrel{\omega}{\perp}$

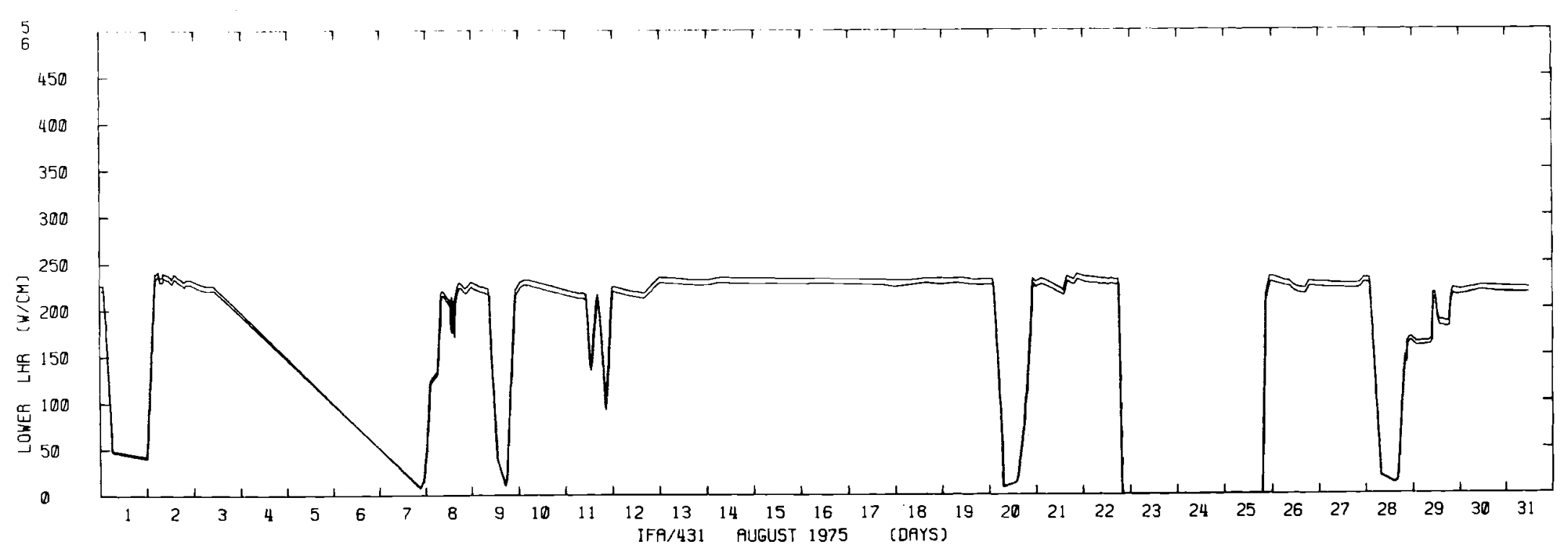

FIGURE 3.18. Local Linear Heat Ratings at Lower Thermocouple Locations for Rods 5,6 of IFA 431 - August 1975 


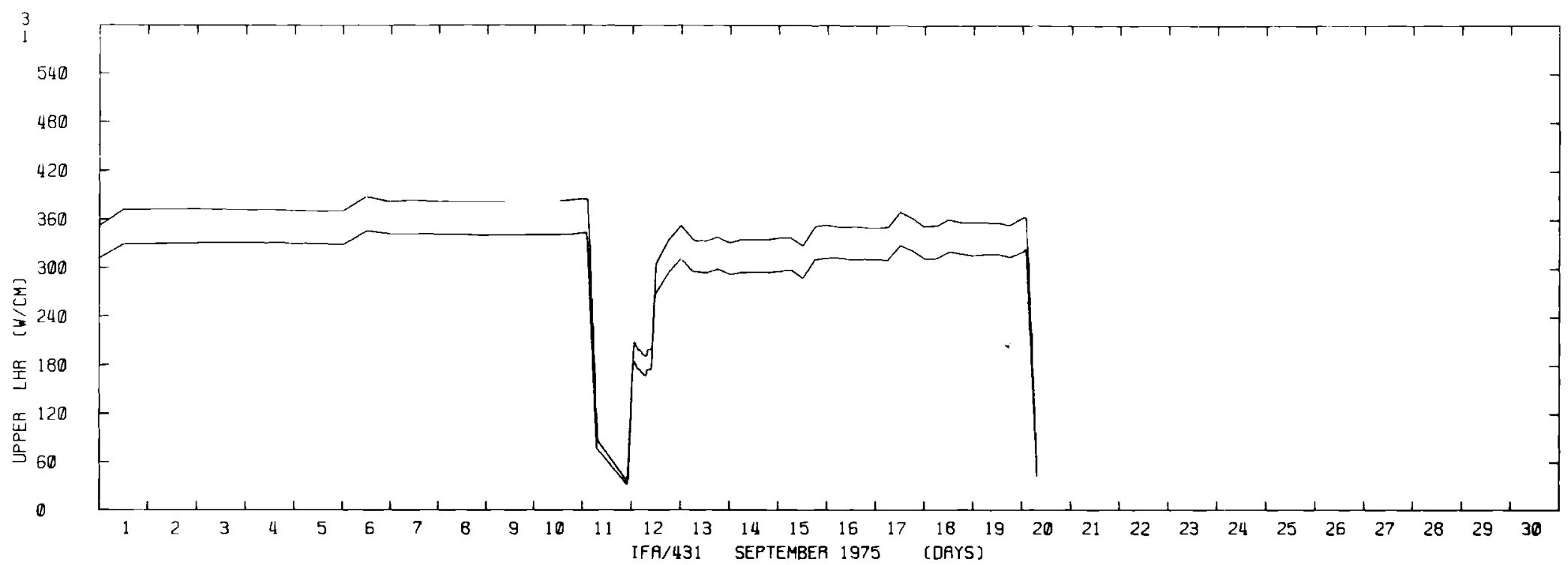

FIGURE 3.19. Local Linear Heat Ratings at Upper Thermocouple Locations for Rods 1,3 of IFA 431 - September 1975

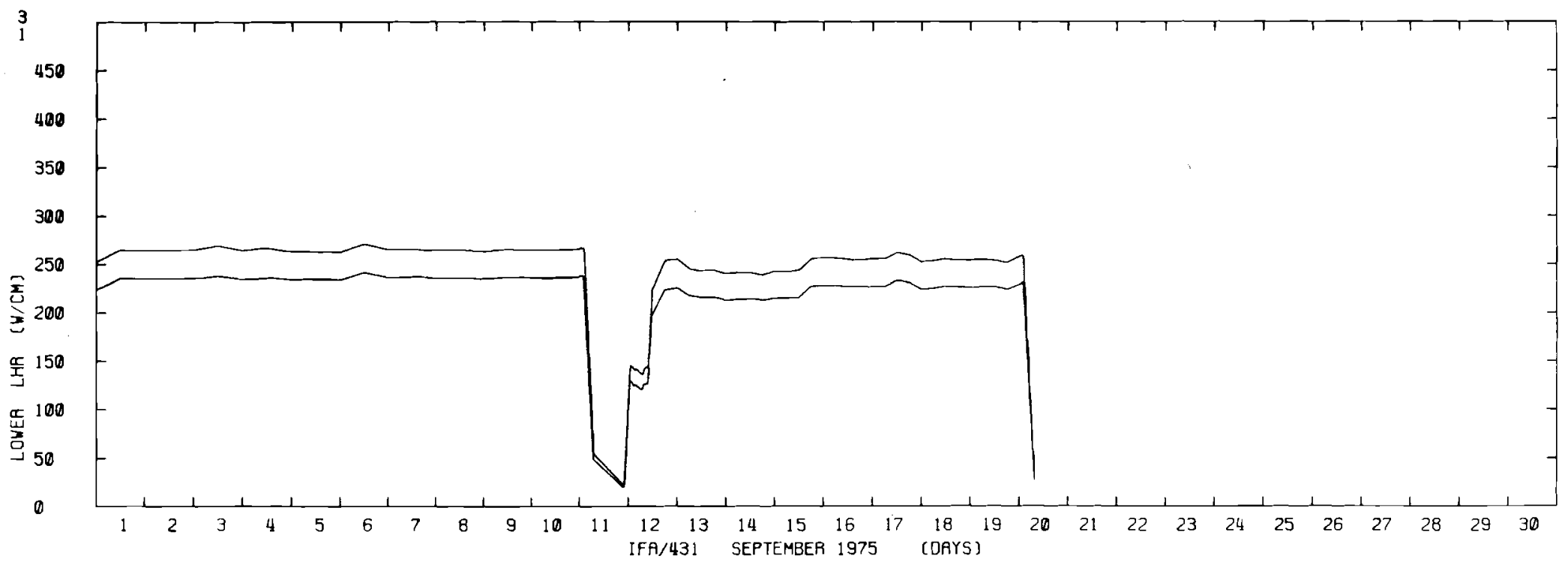

FIGURE 3.20. Local Linear Heat Ratings at Lower Thermocouple Locations for Rods 1,3 of IFA 431 - September 1975 


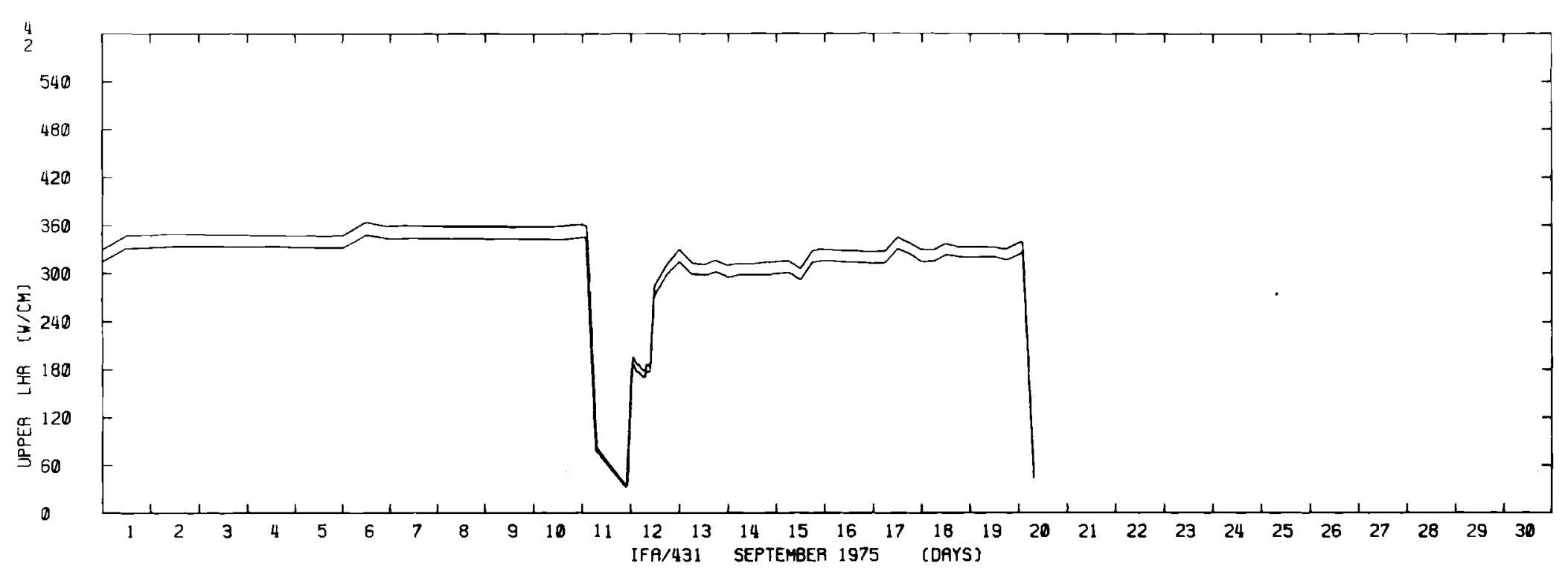

$\frac{\omega}{\omega}$

FIGURE 3.21. Local Linear Heat Ratings at Upper Thermocouple Locations for Rods 2,4 of IFA 431 - September 1975

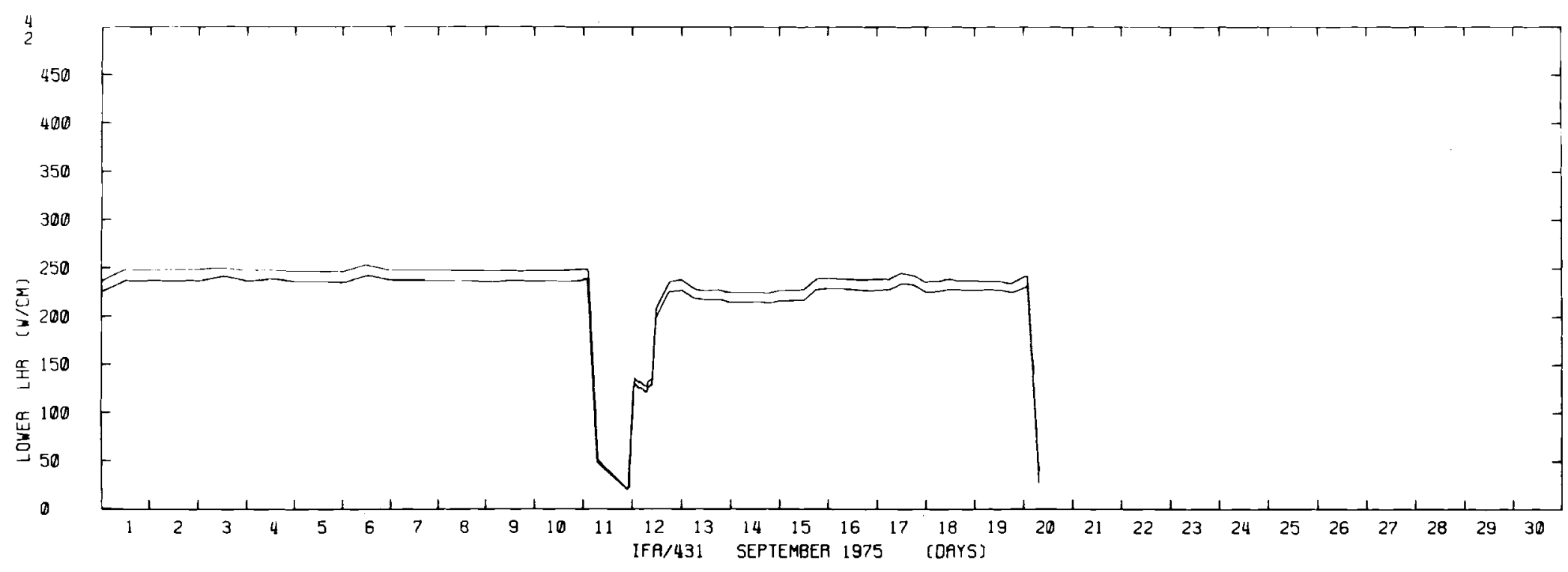

FIGURE 3.22. Local Linear Heat Ratings at Lower Thermocouple Locations for Rods 2,4 of IFA 431 - September 1975 


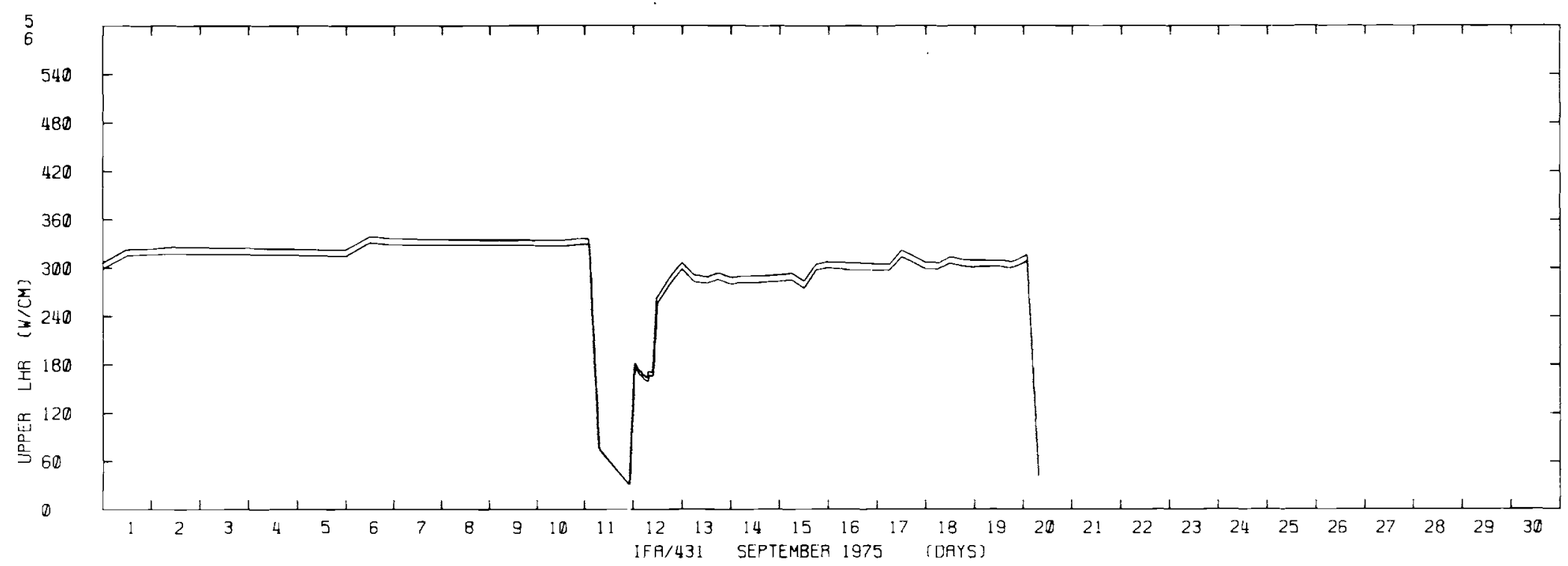

FIGURE 3.23. Local Linear Heat Ratings at Upper Thermocouple Locations for Rods 5,6 of IFA 431 - September 1975

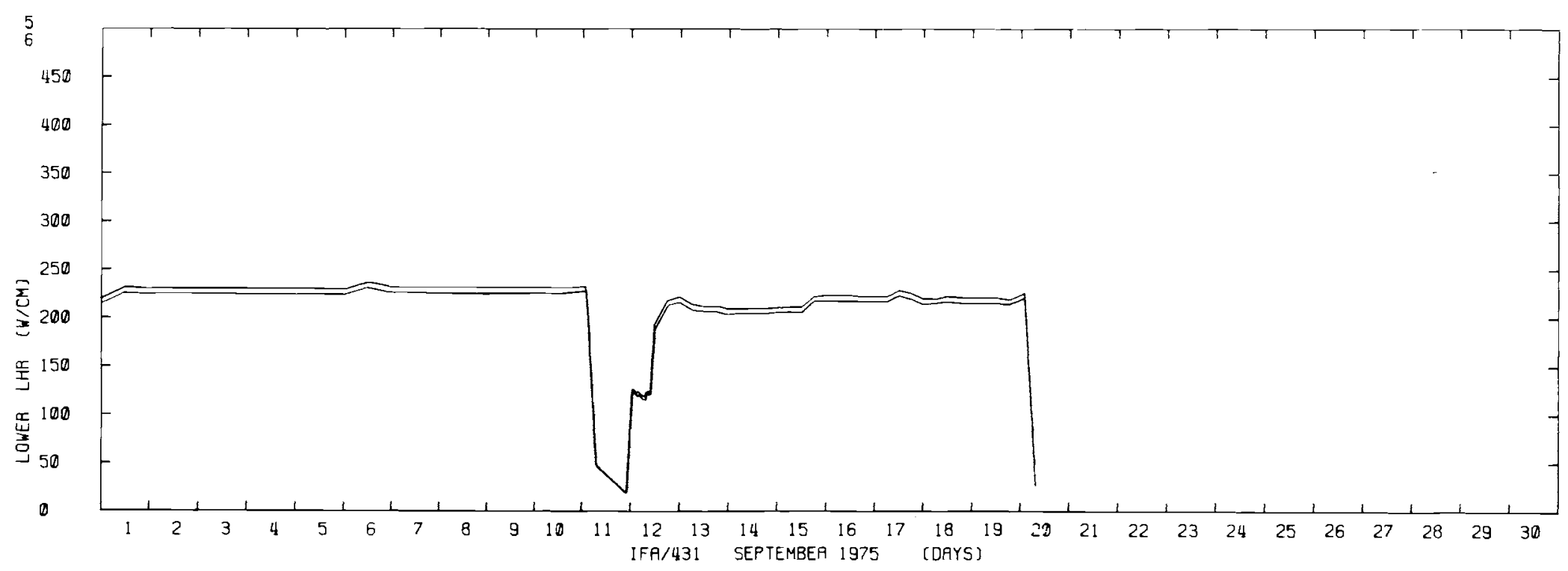

FIGURE 3.24. Local Linear Heat Ratings at Lower Thermocouple Locations for Rods 5,6 of IFA 431 - September 1975 


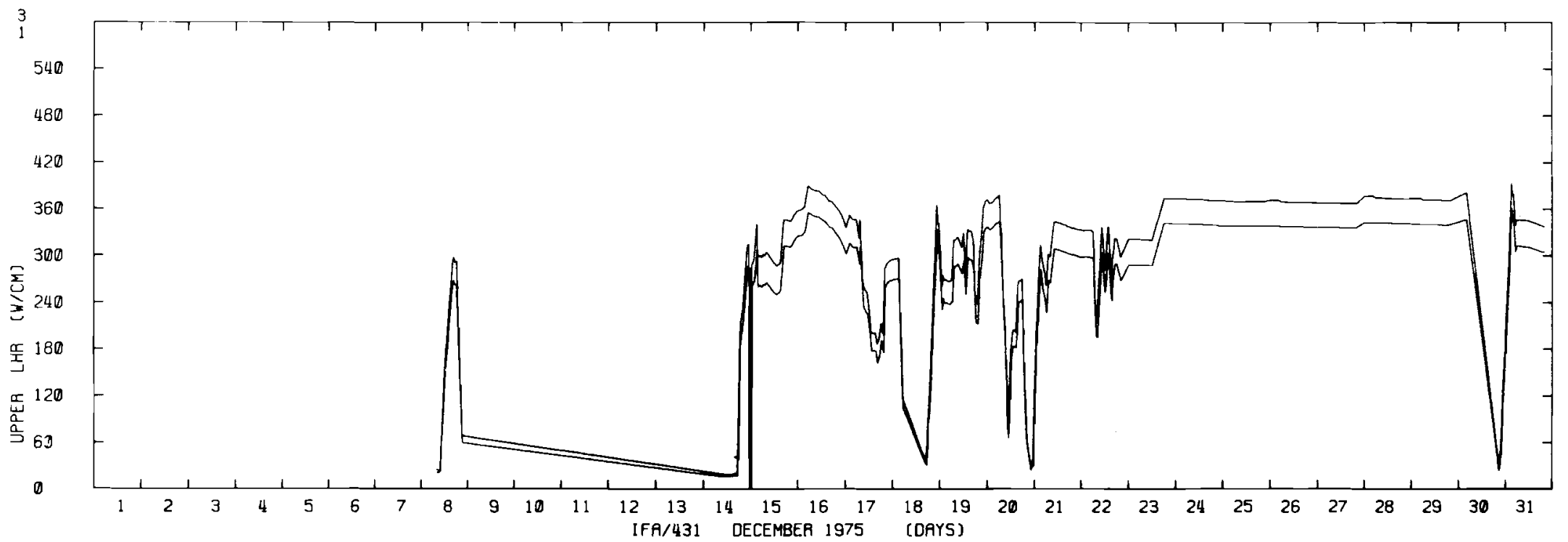

$\frac{\omega}{v}$

FIGURE 3.25. Local Linear Heat Ratings at Upper Thermocouple Locations for Rods 1,3 of IFA 431 - December 1975

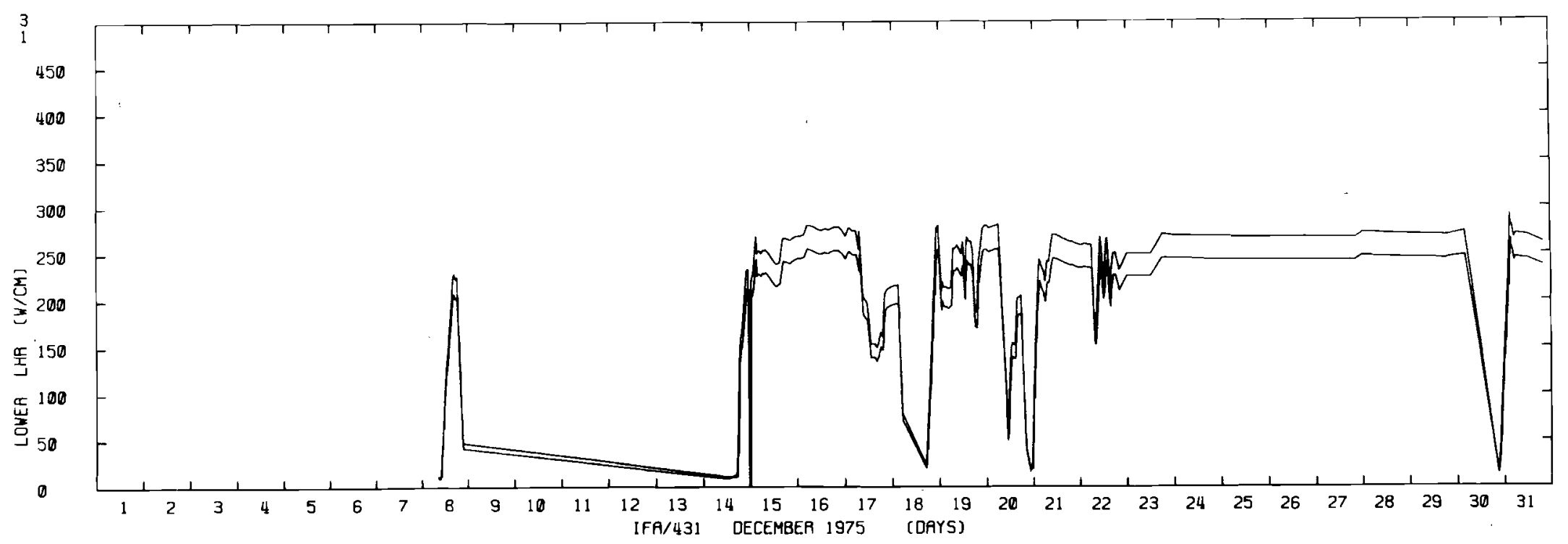

FIGURE 3.26. Local Linear Heat Ratings at Lower Thermocouple Locations for Rods 1,3 of IFA 431 - December 1975 


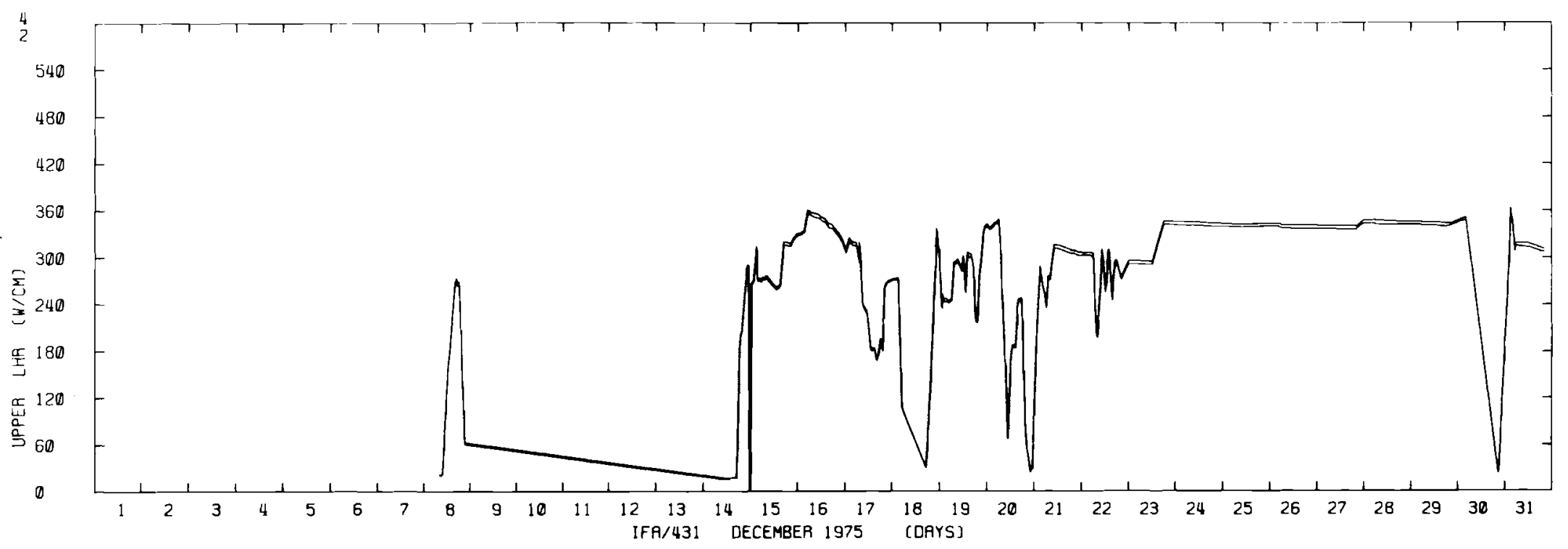

$\omega$
$\frac{1}{\sigma}$

FIGURE 3.27. Local Linear Heat Ratings at Upper Thermocouple Locations for Rods 2,4 of IFA 431 - December 1975

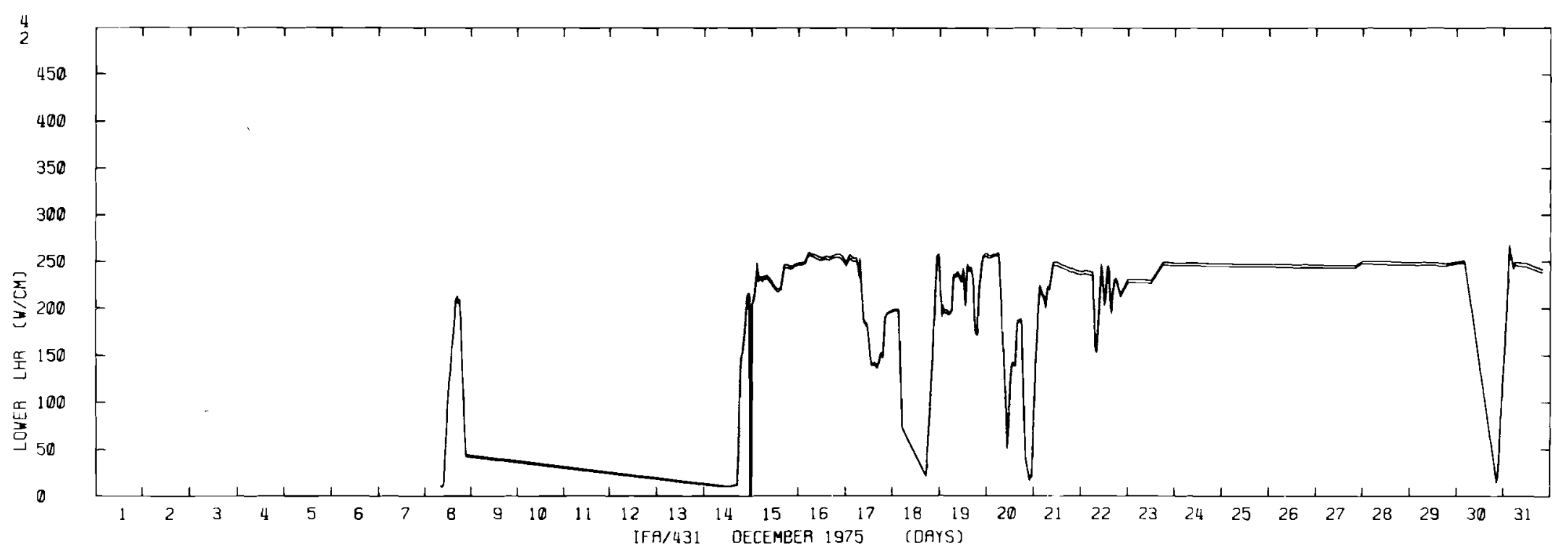

FIGURE 3.28. Local Linear Heat Ratings at Lower Thermocouple Locations for Rods 2,4 of IFA 431 - December 1975 


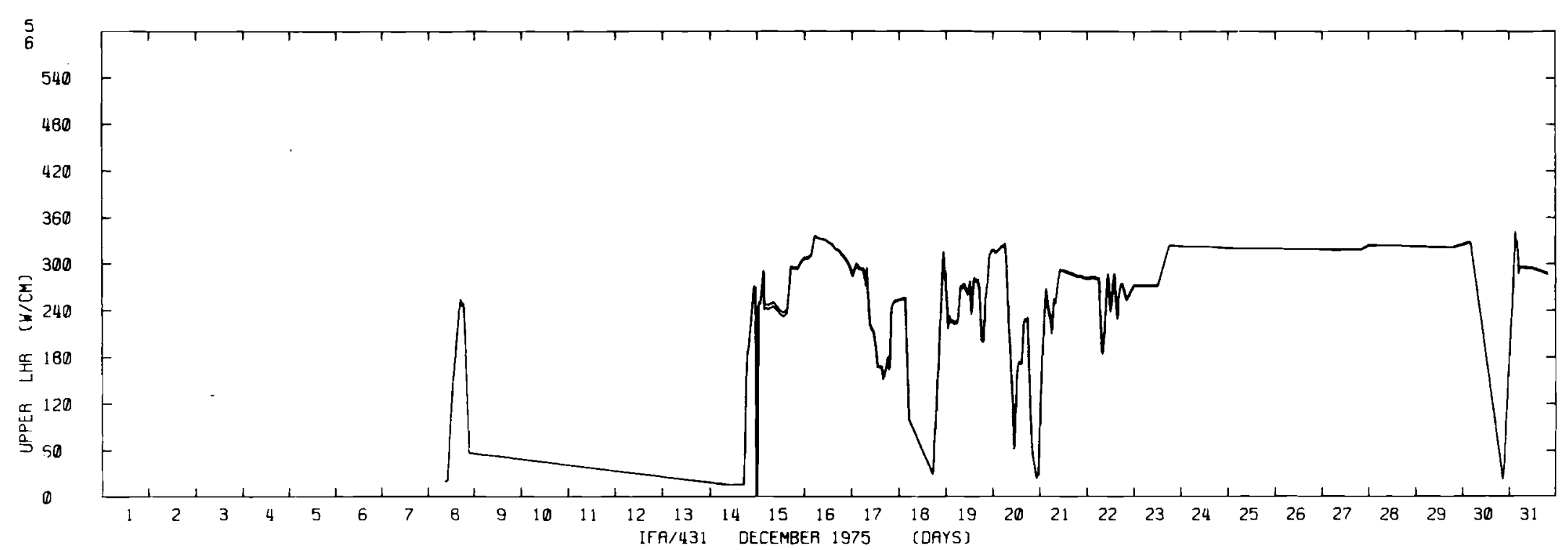

$\stackrel{w}{\stackrel{\omega}{v}}$

FIGURE 3.29. Local Linear Heat Ratings at Upper Thermocouple Locations for Rods 5,6 of IFA 431 - December 1975

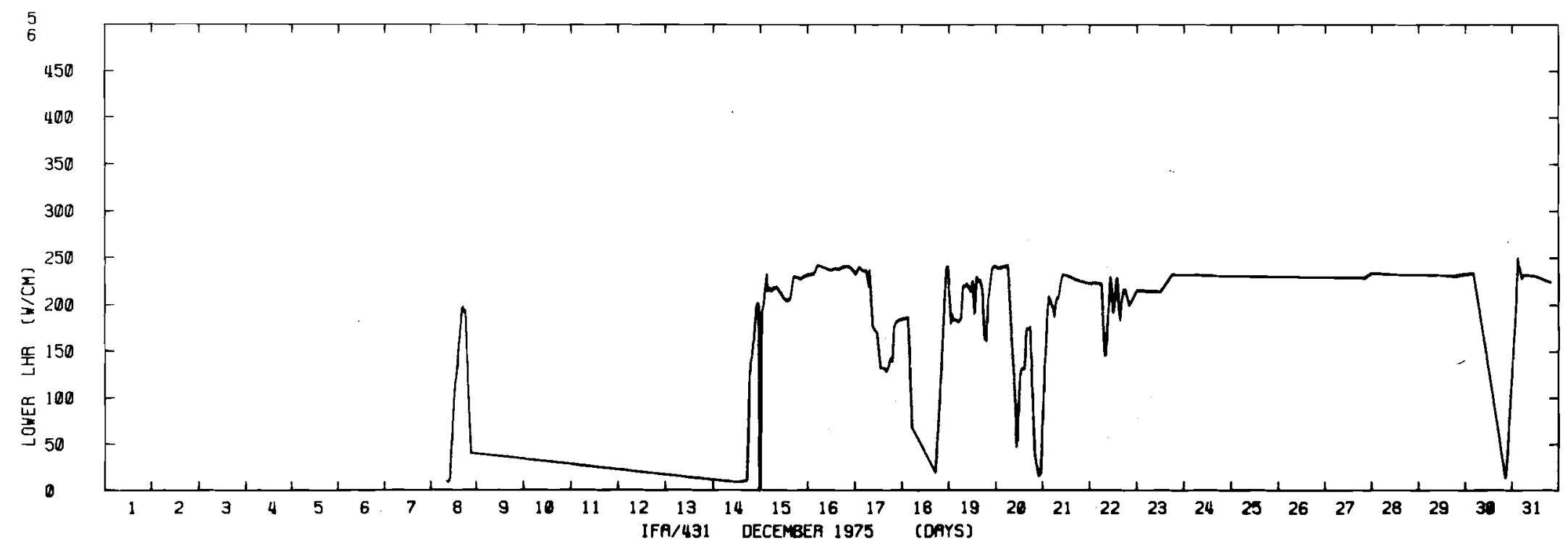

FIGURE 3.30. Local Linear Heat Ratings at Lower Thermocouple Locations for Rods 5,6 of IFA 431 - December 1975 


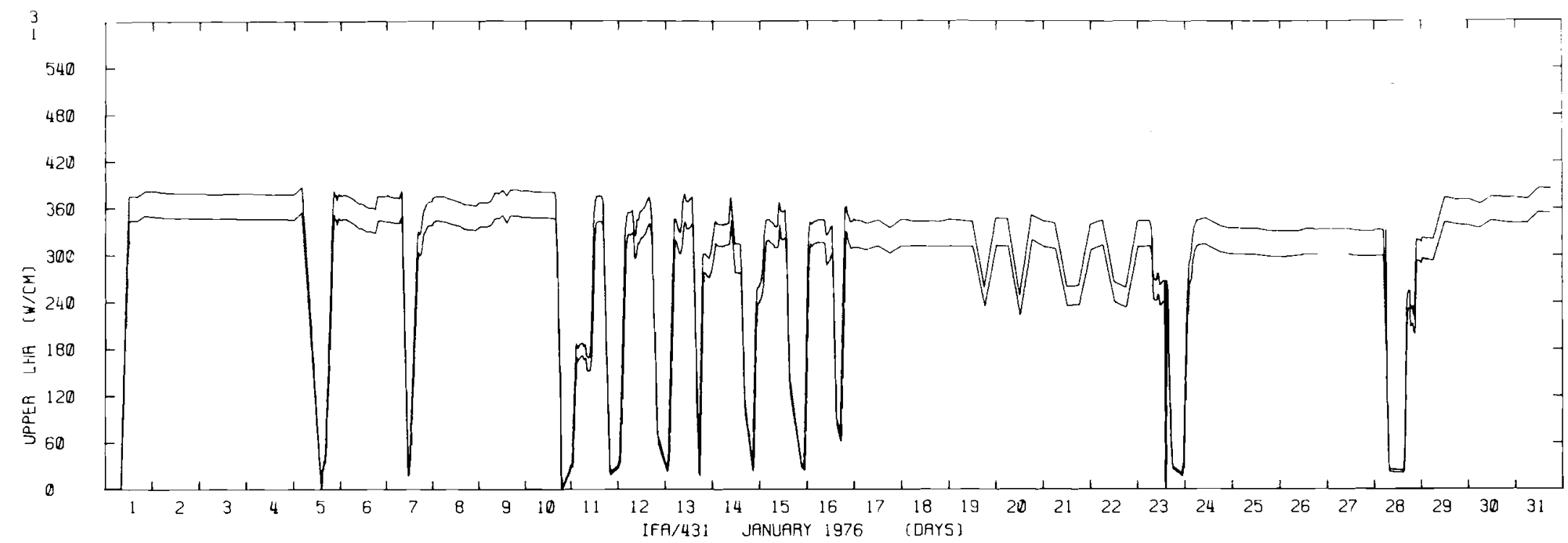

$\frac{\omega}{1}$

FIGURE 3.31. Local Linear Heat Ratings at Upper Thermocouple Locations for Rods 1,3 of IFA 431 - January 1976

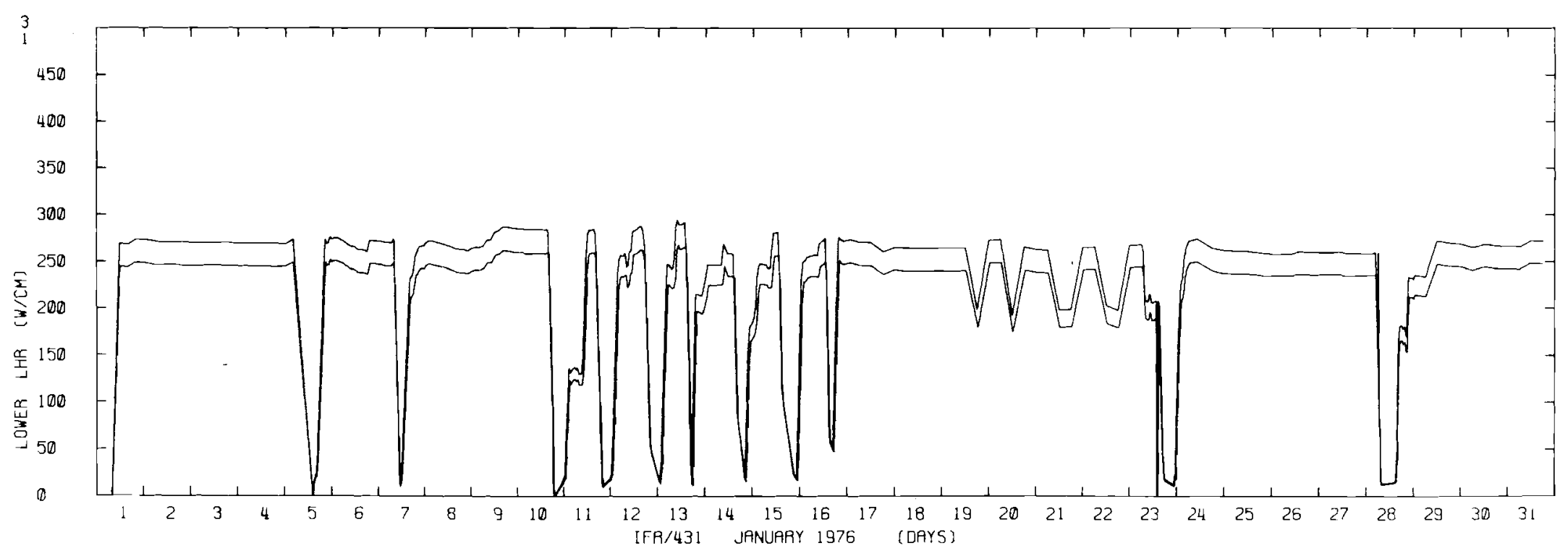

FIGURE 3.32. Local Linear Heat Ratings at Lower Thermocouple Locations for Rods 1,3 of IFA 431 - January 1976 


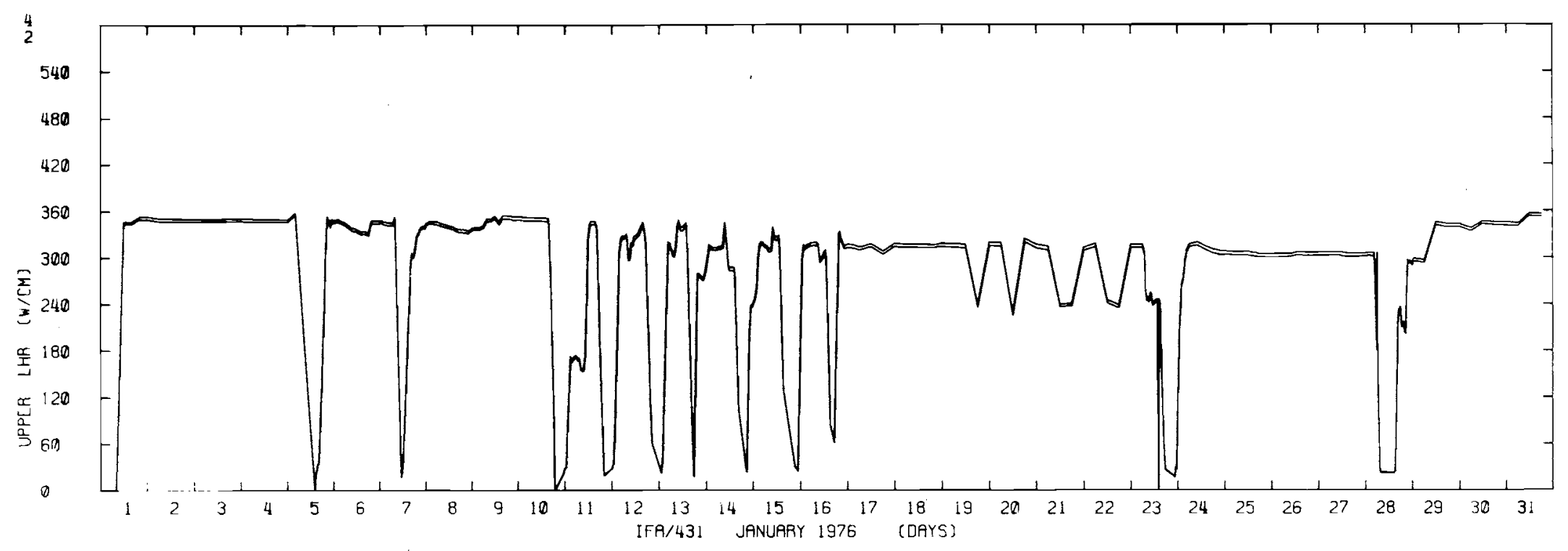

$\frac{\omega}{\omega}$

FIGURE 3.33. Local Linear Heat Ratings at Upper Thermocouple Locations for Rods 2,4 of IFA 431 - January 7976

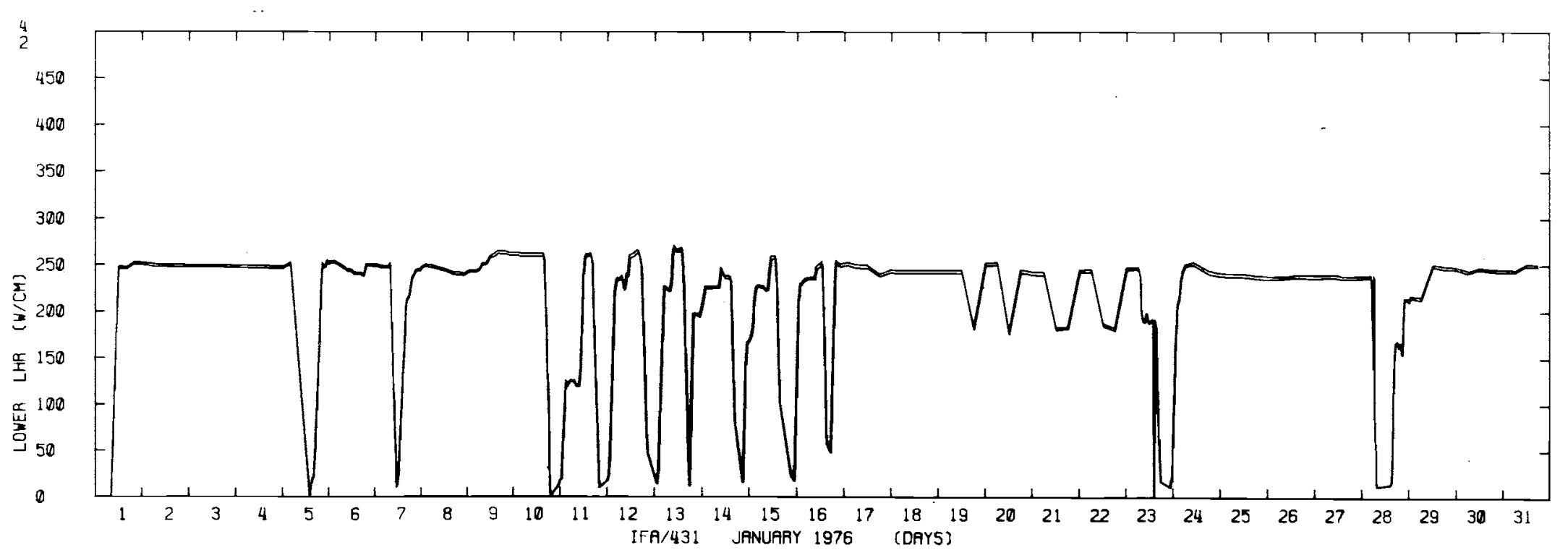

FIGURE 3.34. Local Linear Heat Ratings at Lower Thermocouple Locations for Rods 2,4 of IFA 431 - January 1976 


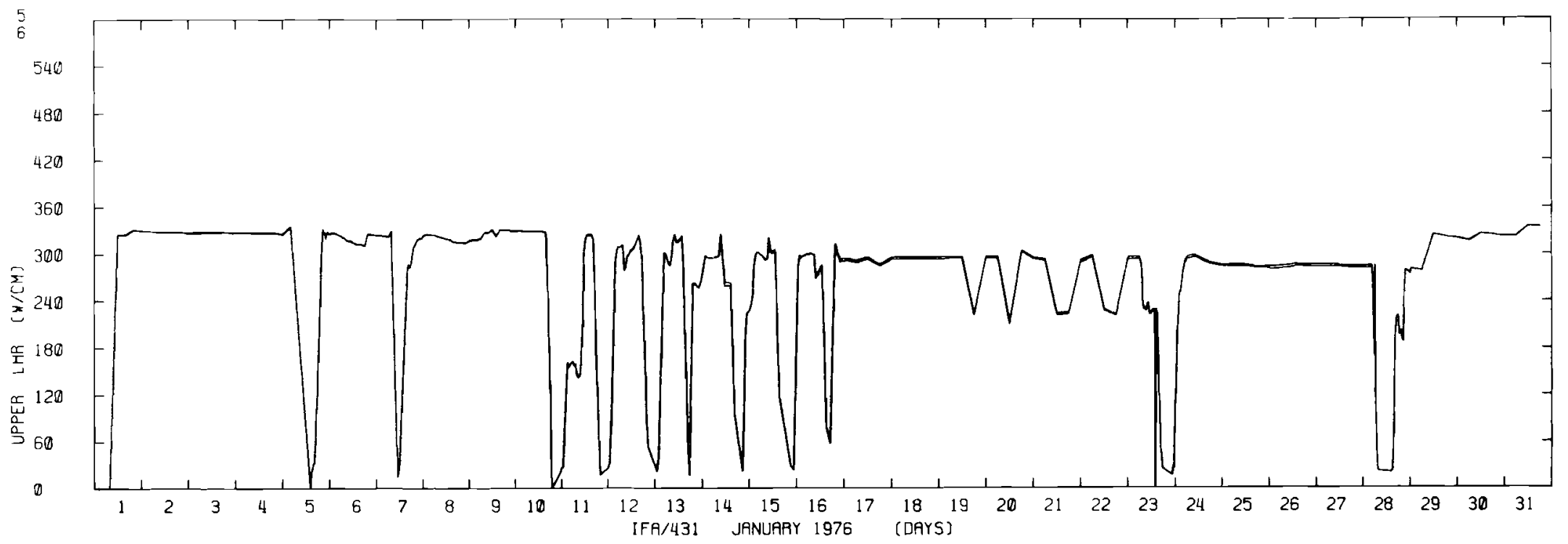

FIGURE 3.35. Local Linear Heat Ratings at Upper Thermocouple Locations for Rods 5,6 of IFA 431 - January 1976

$\omega$
$\dot{1}$
0

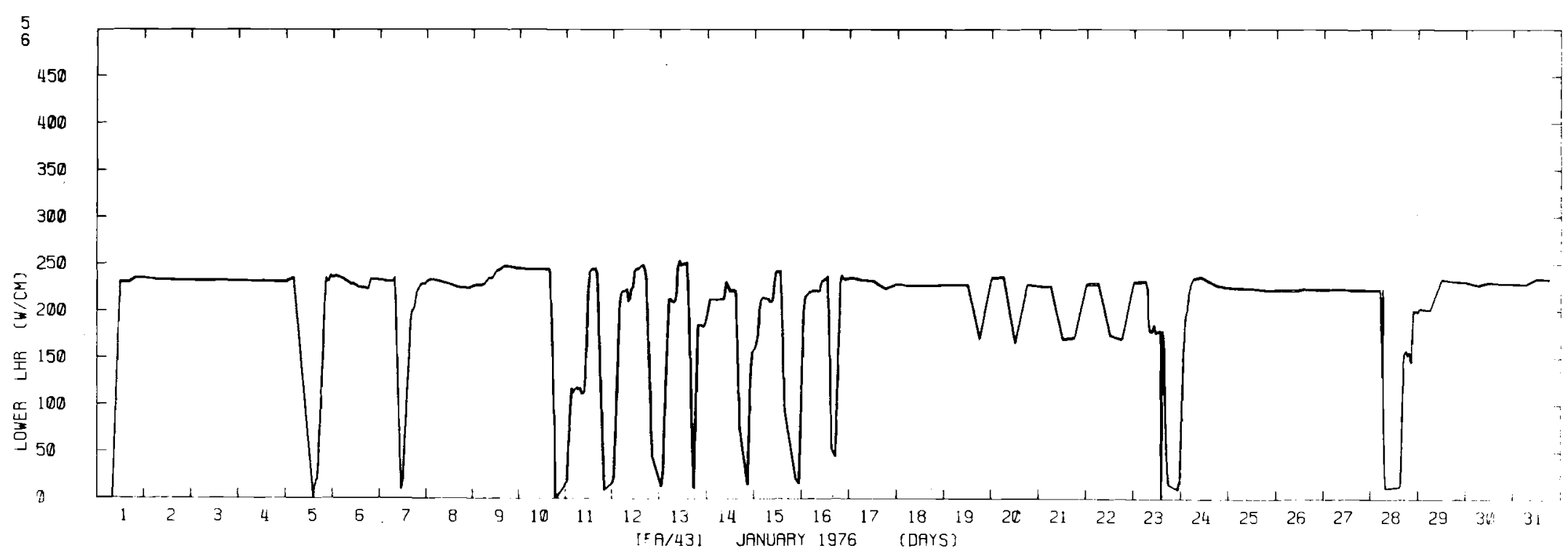

FIGURE 3.36. Local Linear Heat Ratings at Lower Thermocouple Locations for Rods 5,6 of IFA 431 - January 1976 


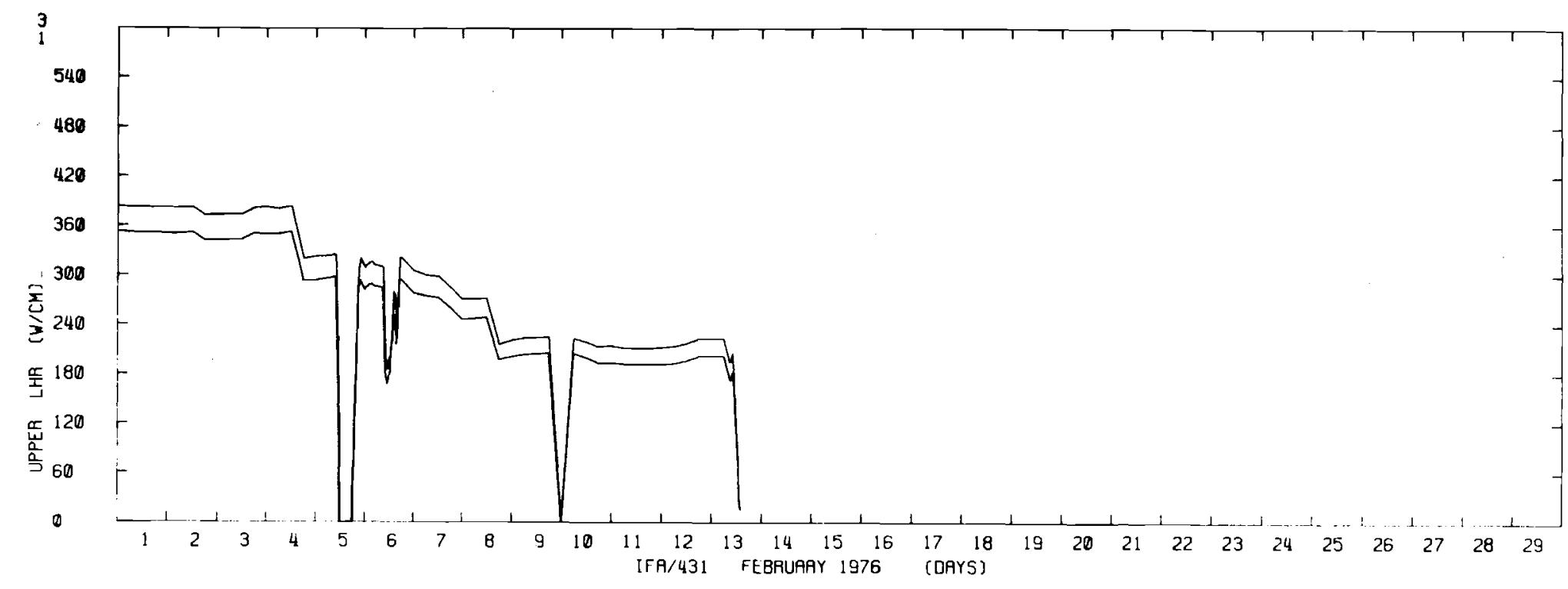

FIGURE 3.37. Local Linear Heat Ratings at Upper Thermocouple Locations for Rods 1,3 of IFA 431 - February 1976

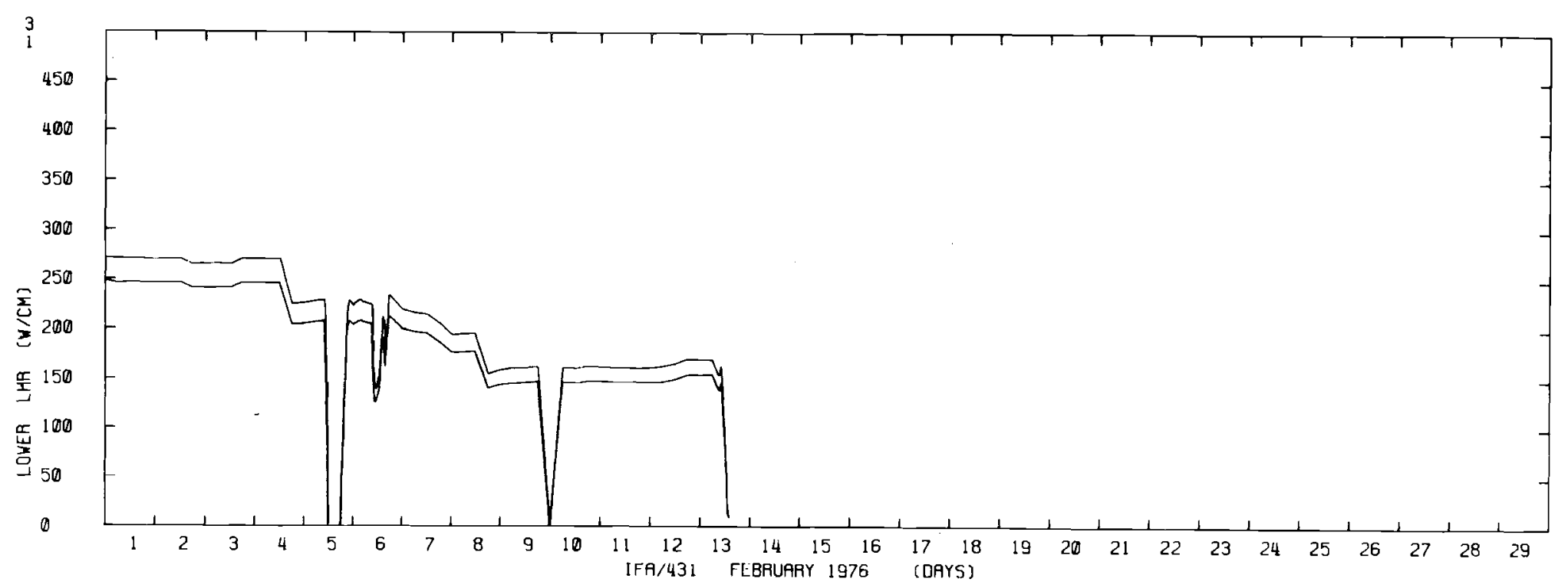

FIGURE 3.38. Local Linear Heat Ratings at Lower Thermocouple Locations for Rods 1,3 of IFA 431 - February 1976 


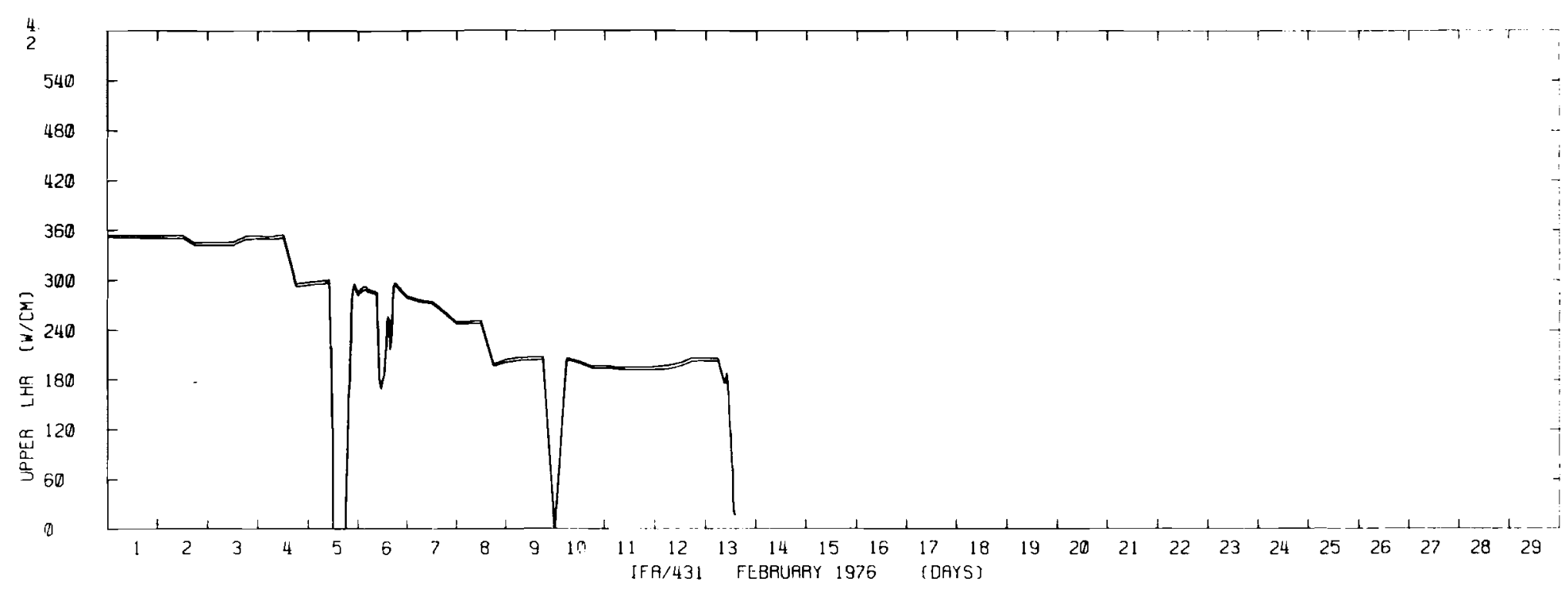

FIGURE 3.39. Local Linear Heat Ratings at Upper Thermocouple Locations for Rods 2,4 of IFA 431 - February 1976

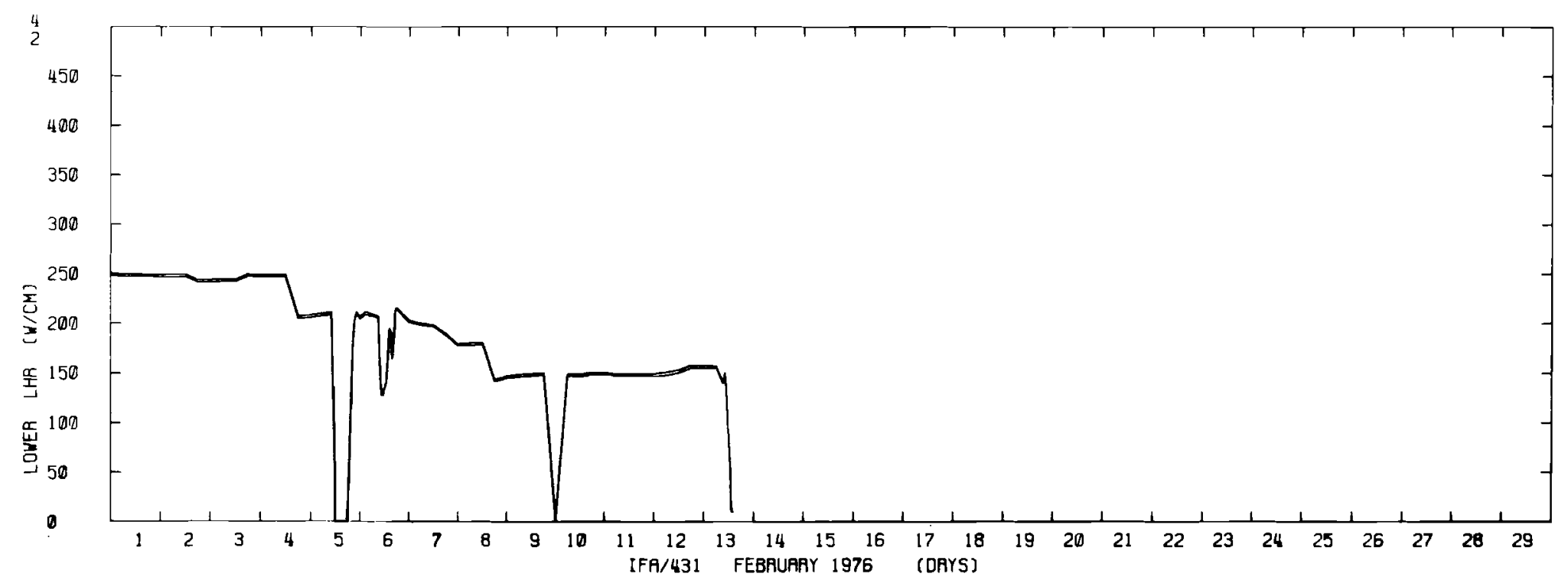

FIGURE 3.40. Local Linear Heat Ratings at Lower Thermocouple Locations for Rods 2,4 of IFA 431 - February 1976 


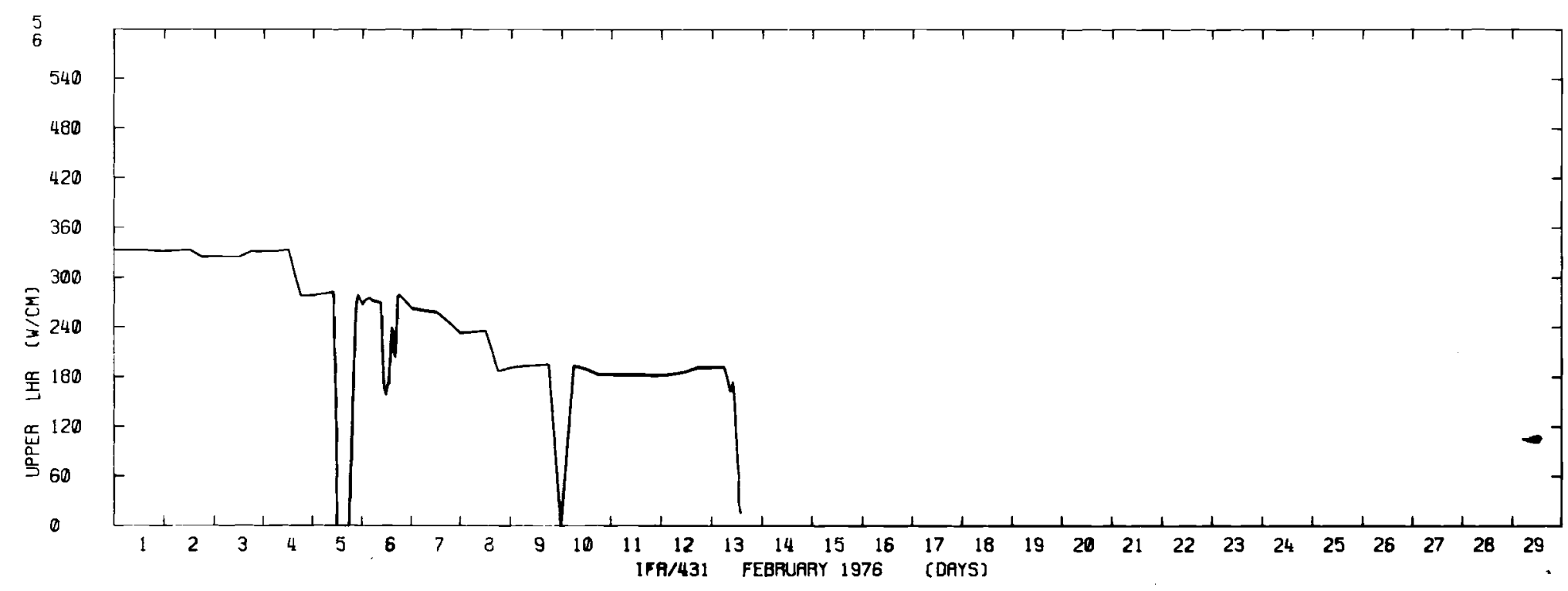

$\stackrel{\omega}{\grave{n}}$

FIGURE 3.41. Local Linear Heat Ratings at Upper Thermocouple Locations for Rods 5,6 of IFA 431 - February 1976

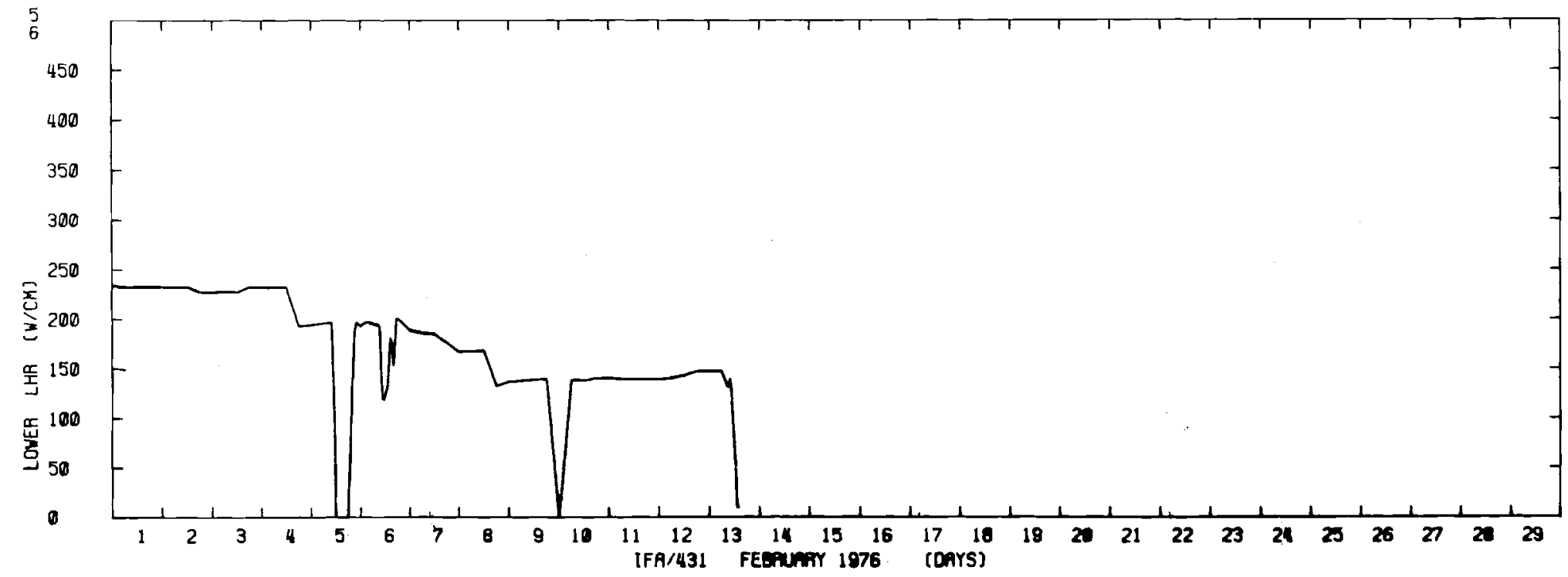

FIGURE 3.42. Local Linear Heat Ratings at Lower Thermocouple Locations for Rods 5,6 of IFA 431 - February 1976 


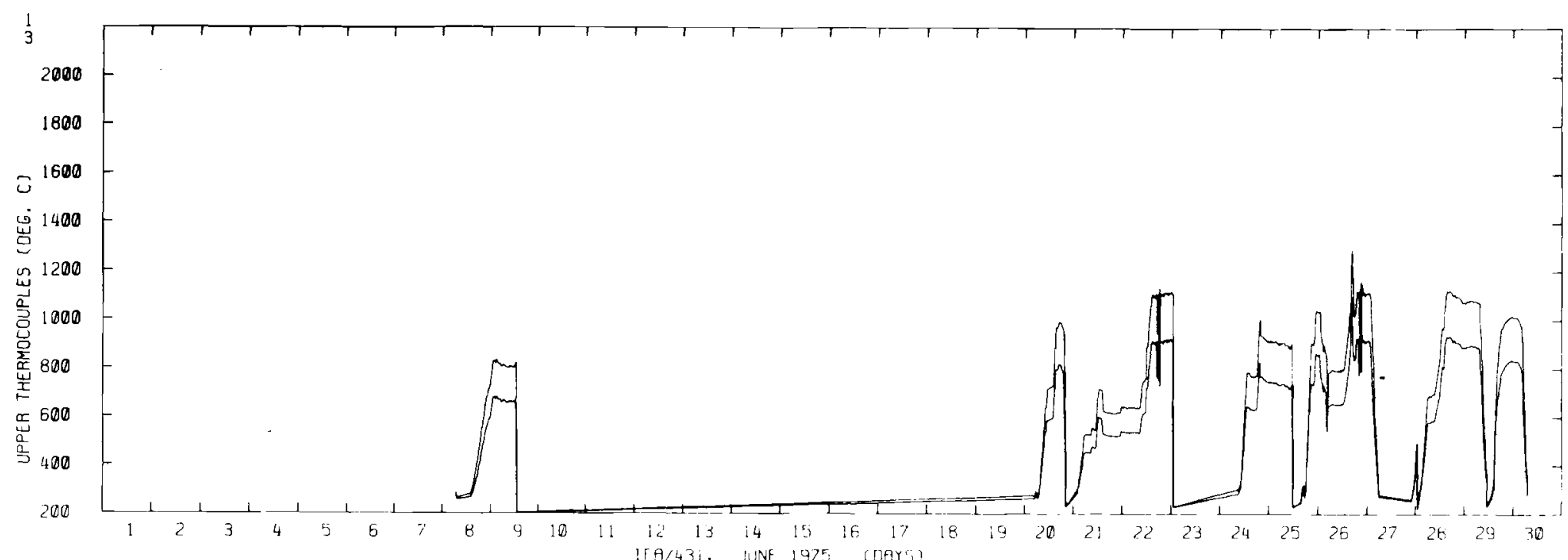

$\stackrel{\omega}{\stackrel{\Delta}{\infty}}$

FIGURE 3.43. Upper Thermocouple Readings for Rods 1,3 of IFA 431 - June 1975

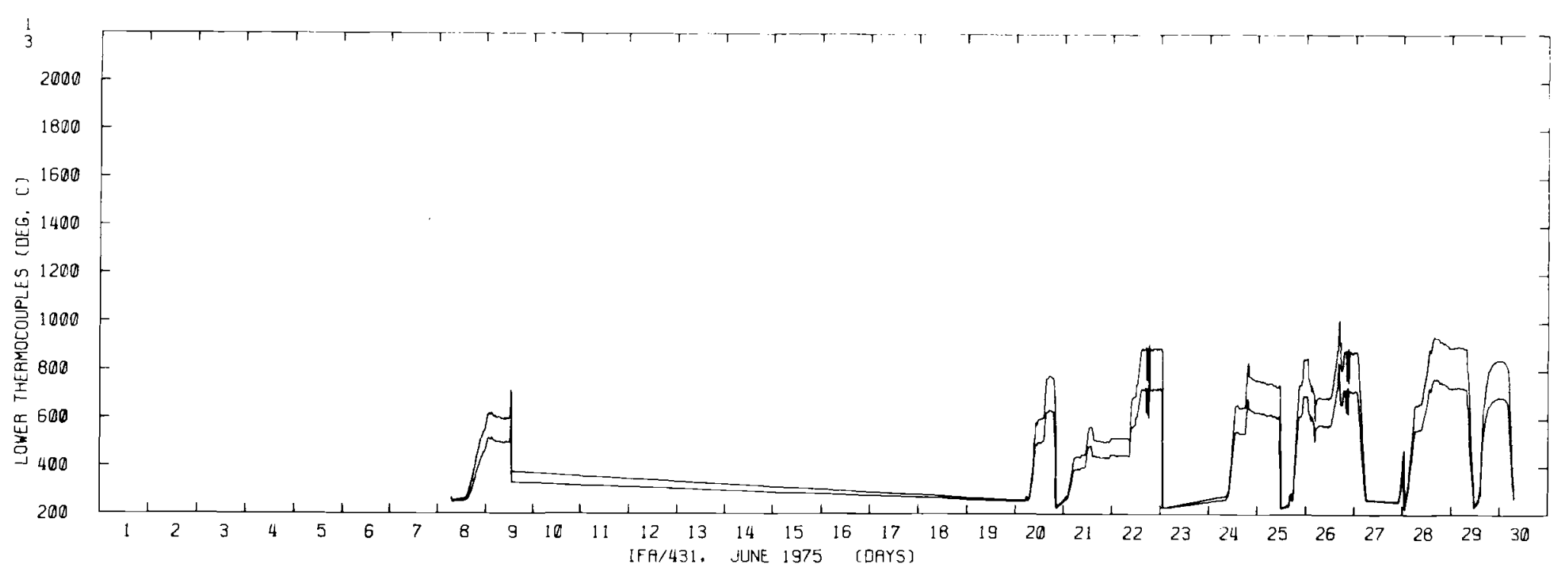

FIGURE 3.44. Lower Thermocouple Readings for Rods 1,3 of IFA 431 - June 1975 


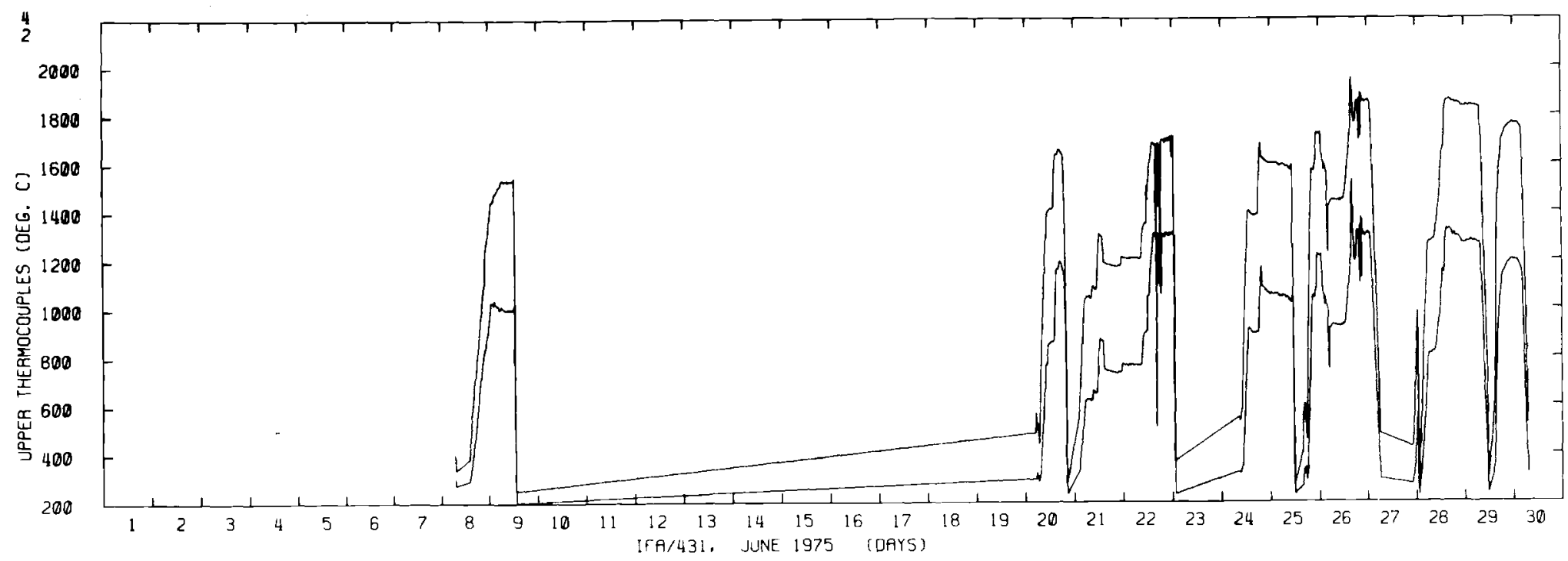

$w$
1
$\mathcal{N}$

FIGURE 3.45. Upper Thermocouple Readings for Rods 2,4 of IFA 431 - June 1975

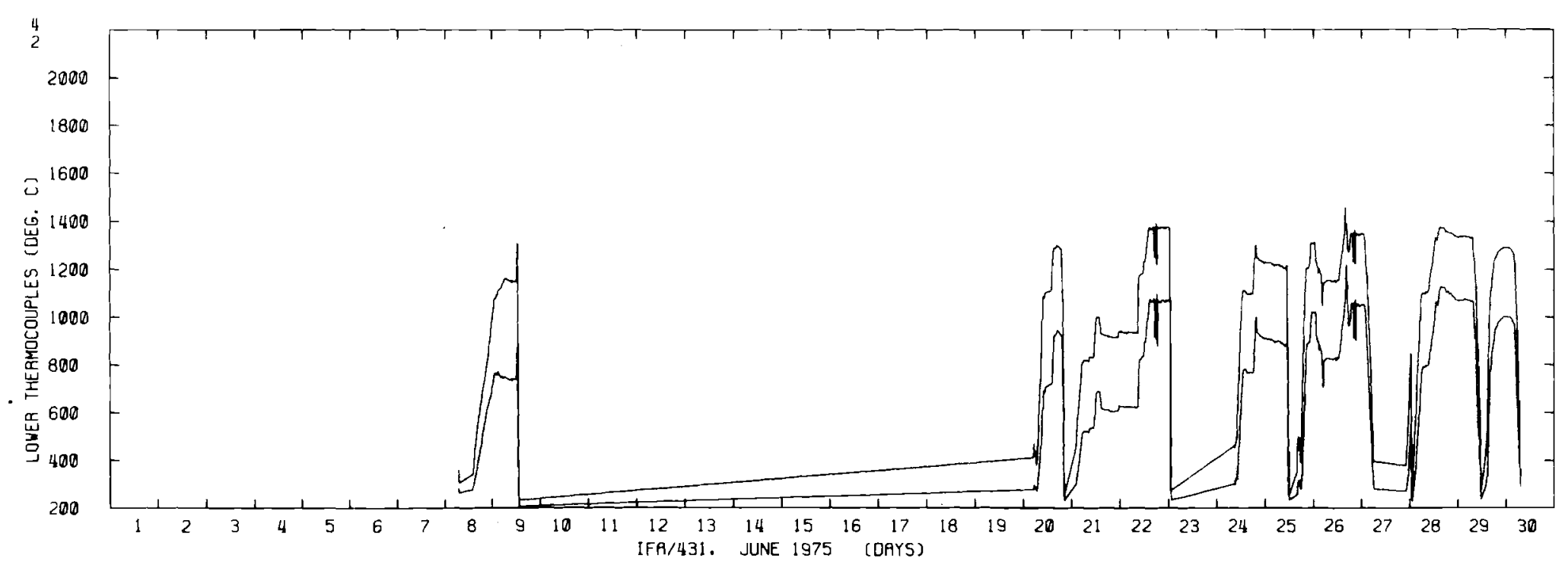

FIGURE 3.46. Lower Thermocouple Readings for Rods 2,4 of IFA 431 - June 1975 


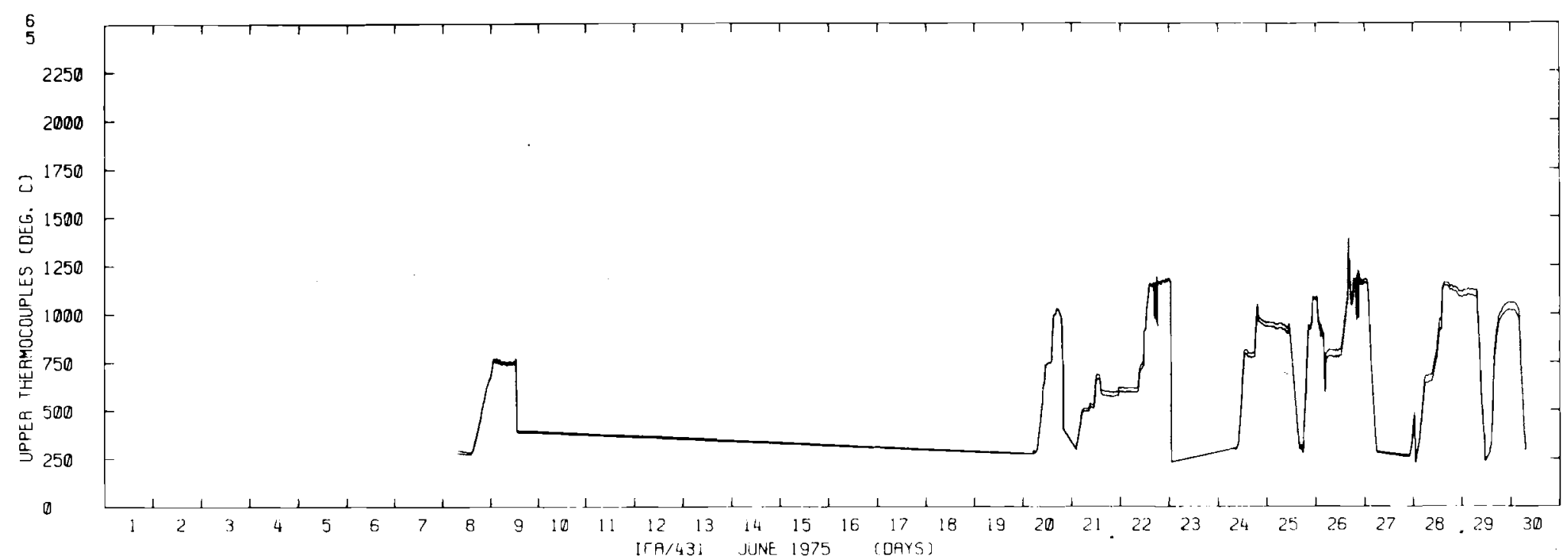

$\stackrel{\omega}{\tilde{\sigma}}$

FIGURE 3.47. Upper Thermocouple Readings for Rods 5,6 of IFA 431 - June 1975

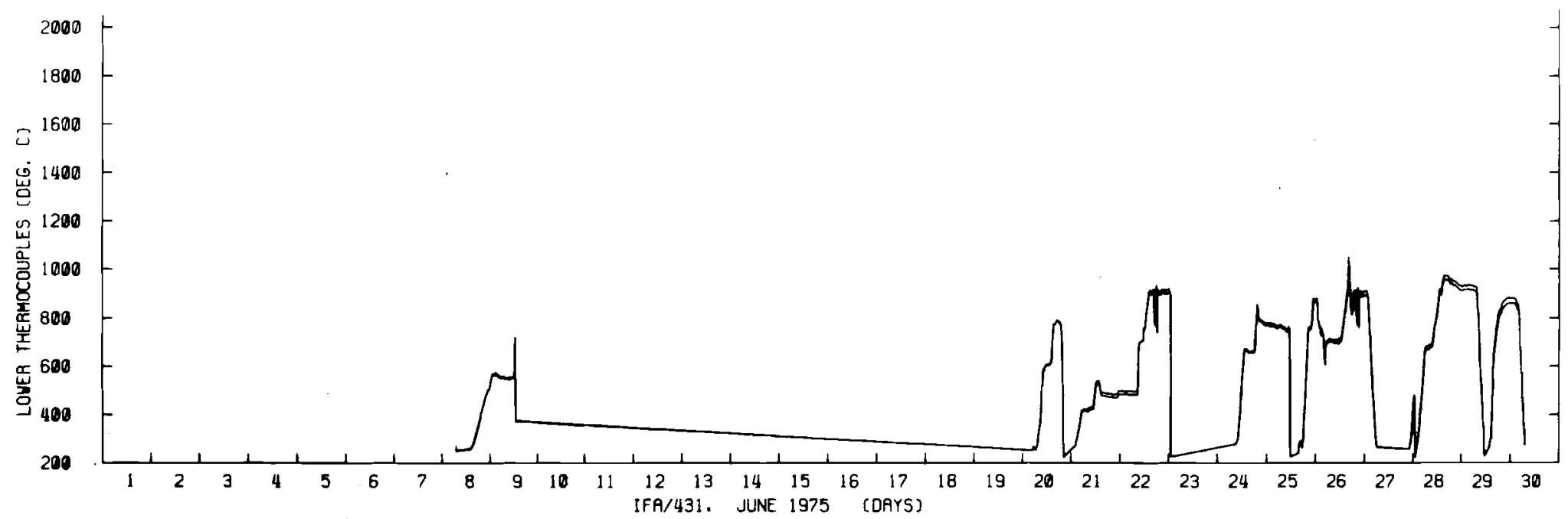

FIGURE 3.48. Lower Thermocouple Readings for Rods 5,6 of IFA 431 - June 1975 


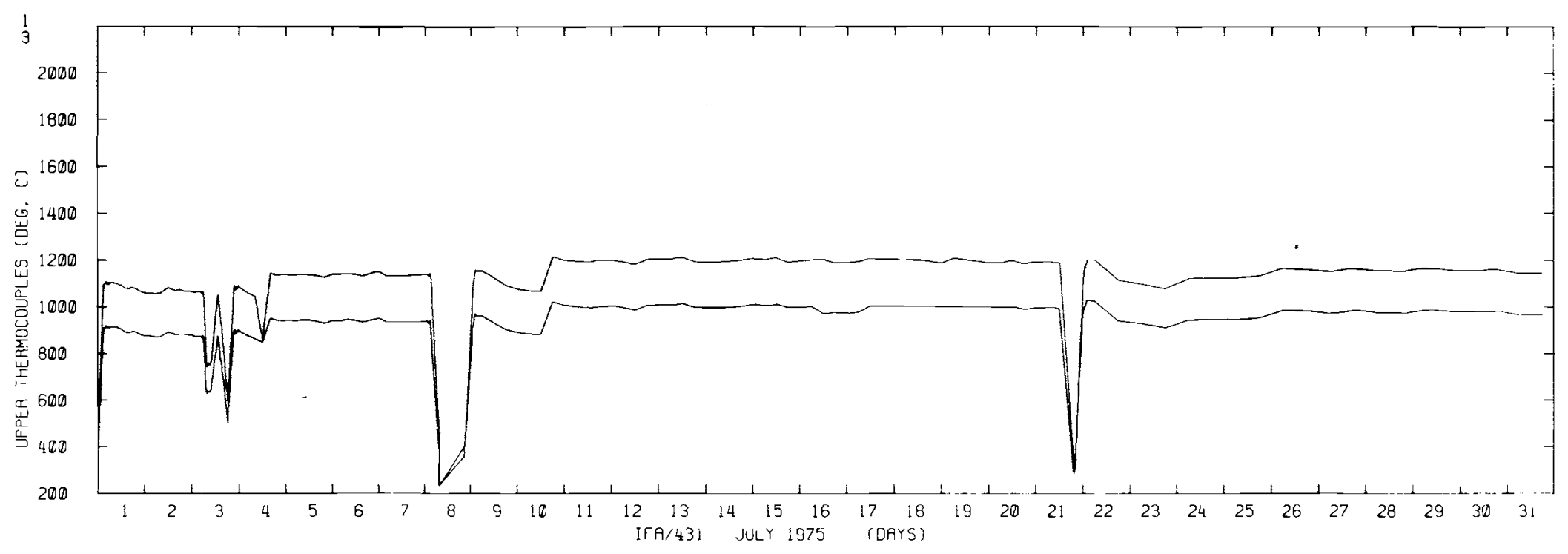

FIGURE 3.49. Upper Thermocouple Readings for Rods 1,3 of IFA 431 - July 1975

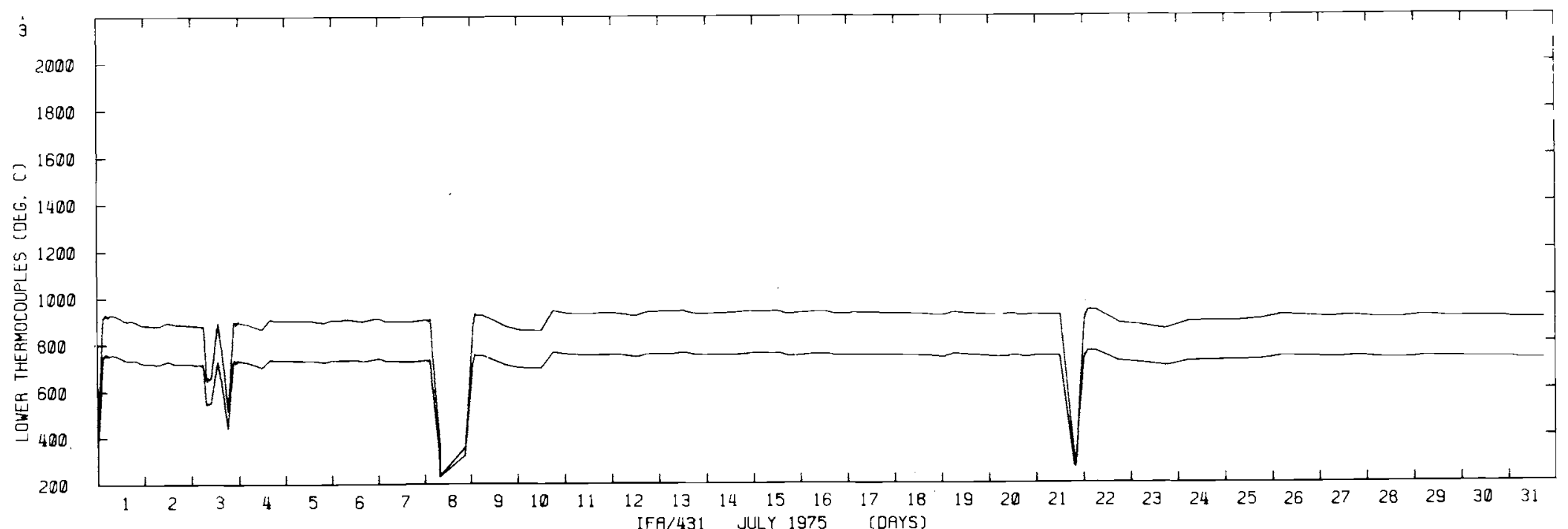

FIGURE 3.50. Lower Thermocouple Readings for Rods 1,3 of IFA 431 - July 1975 


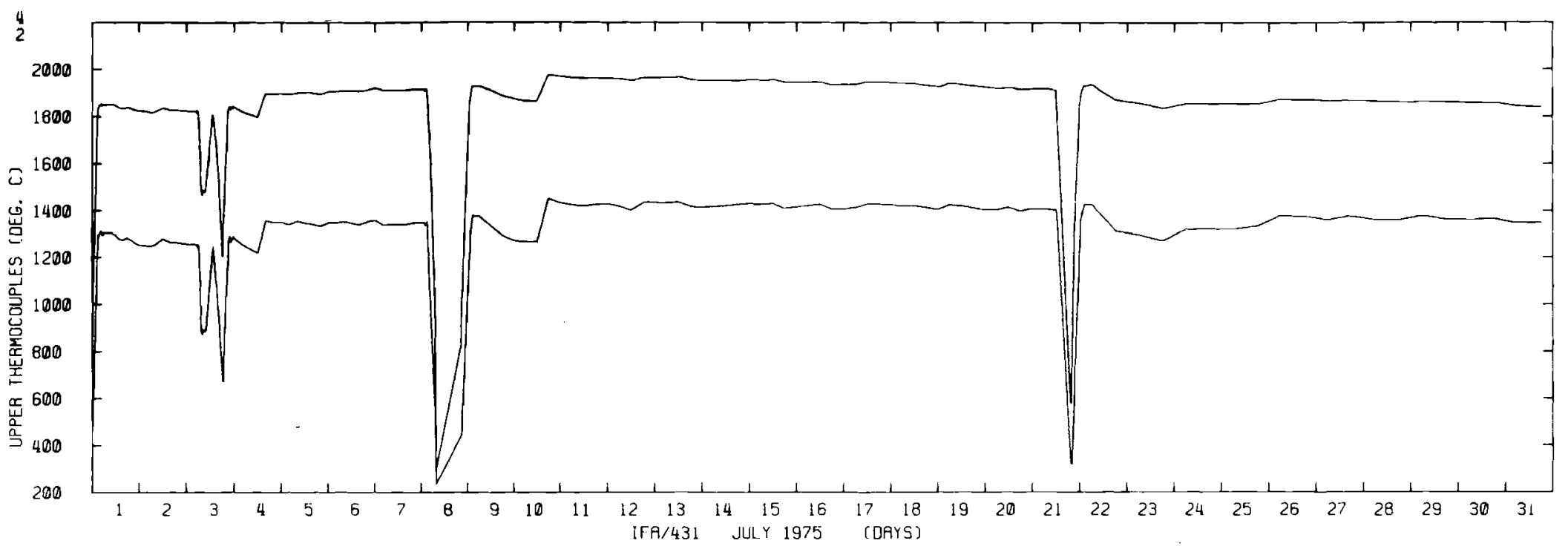

FIGURE 3.51. Upper Thermocouple Readings for Rods 2,4 of

$\omega$
$\dot{\omega}$
$\infty$
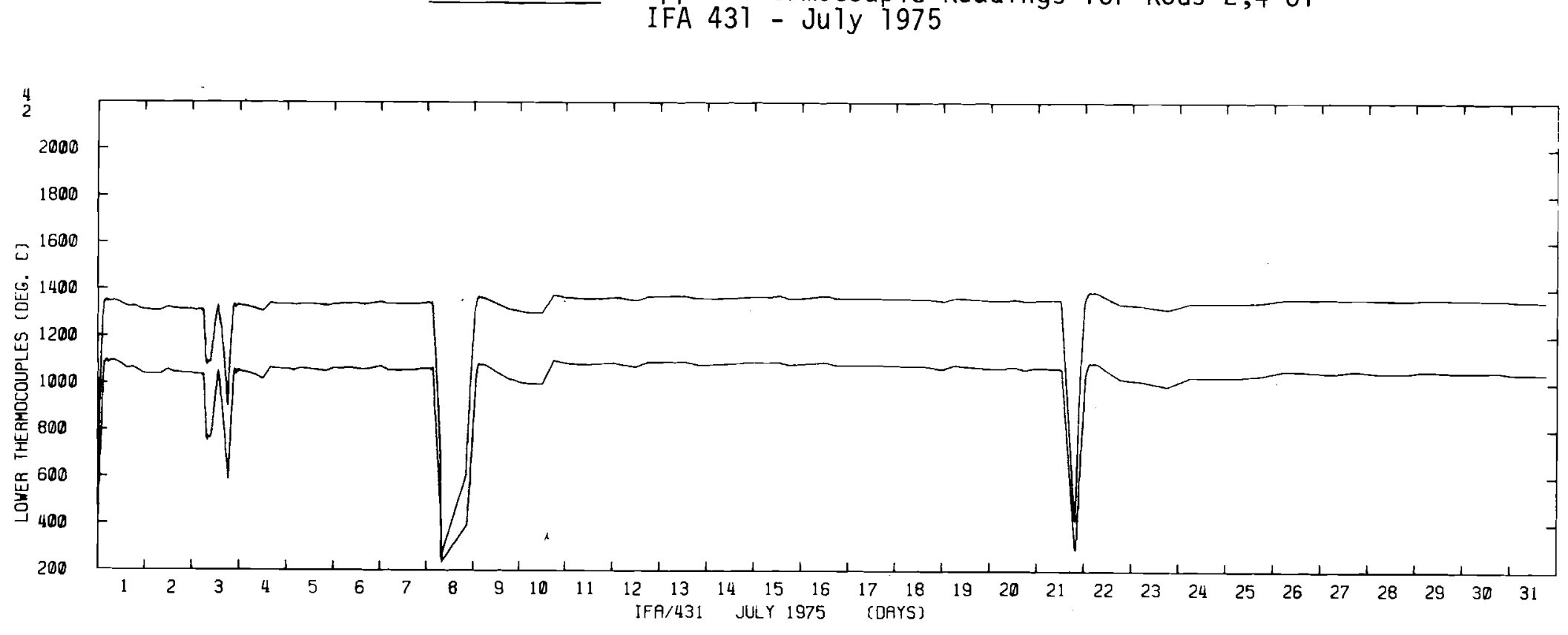

FIGURE 3.52. Lower Thermocoup le Readings for Rods 2,4 of IFA 431 - July 1975 


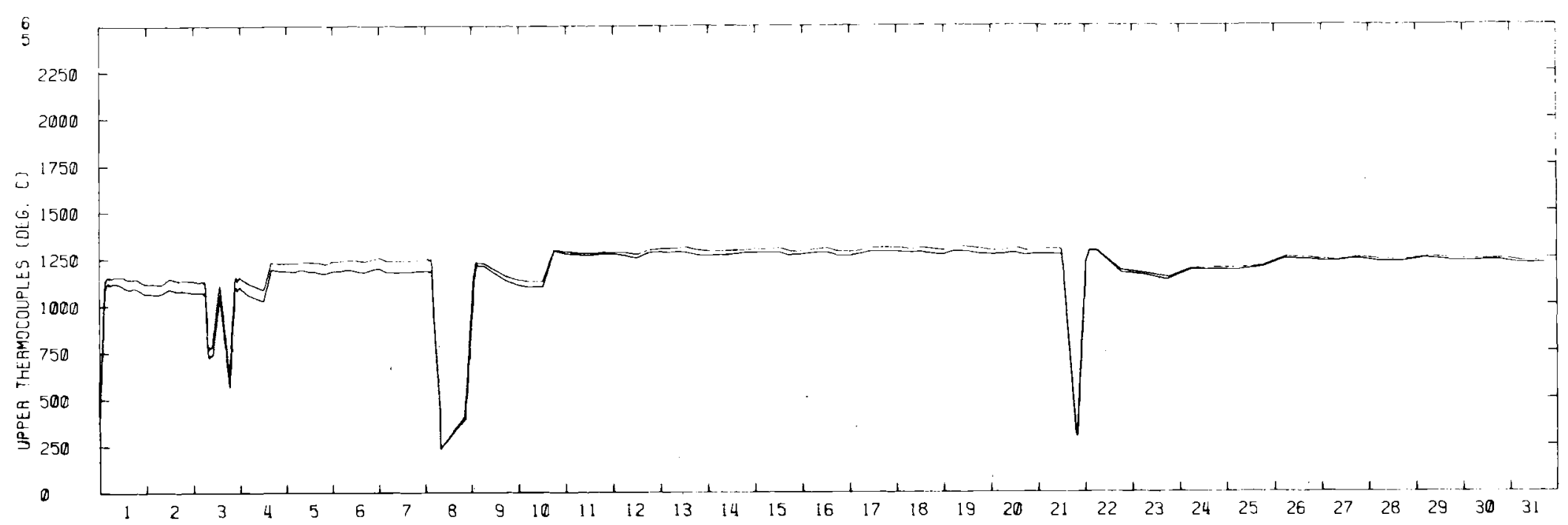

$\dot{1}$

FIGURE 3.53. Upper Thermocouple Readings for Rods 5,6 of IFA 431 - July 1975

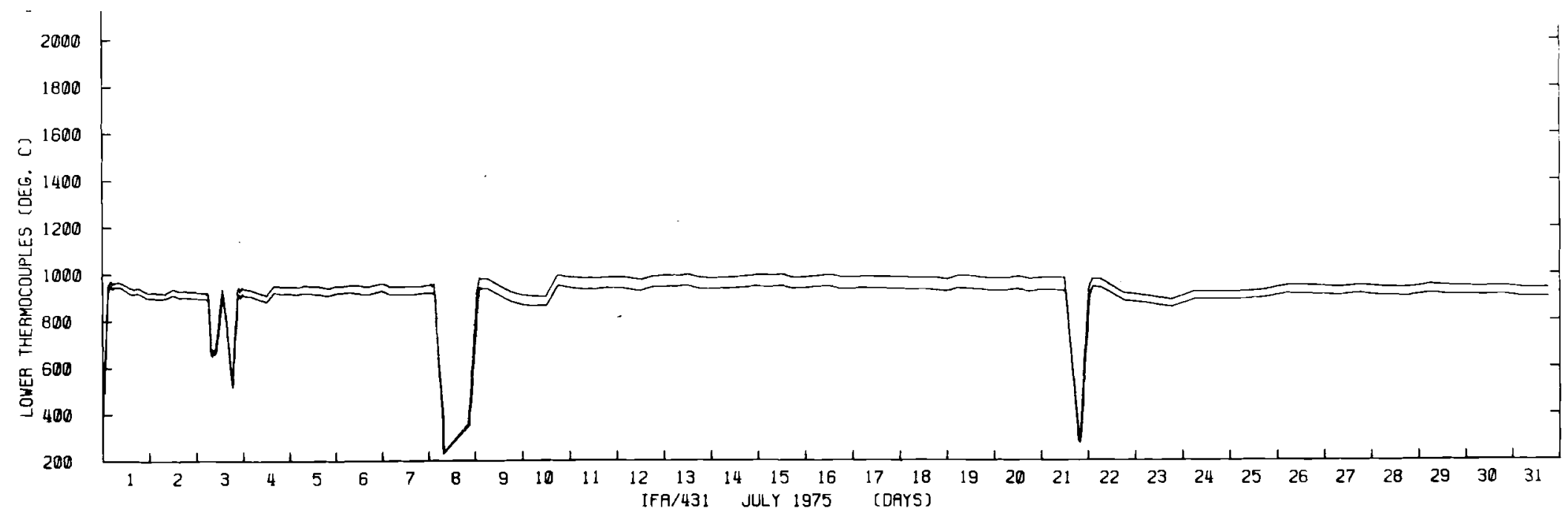

FIGURE 3.54. Lower Thermocouple Readings for Rods 5,6 of IFA 431 - July 1975 


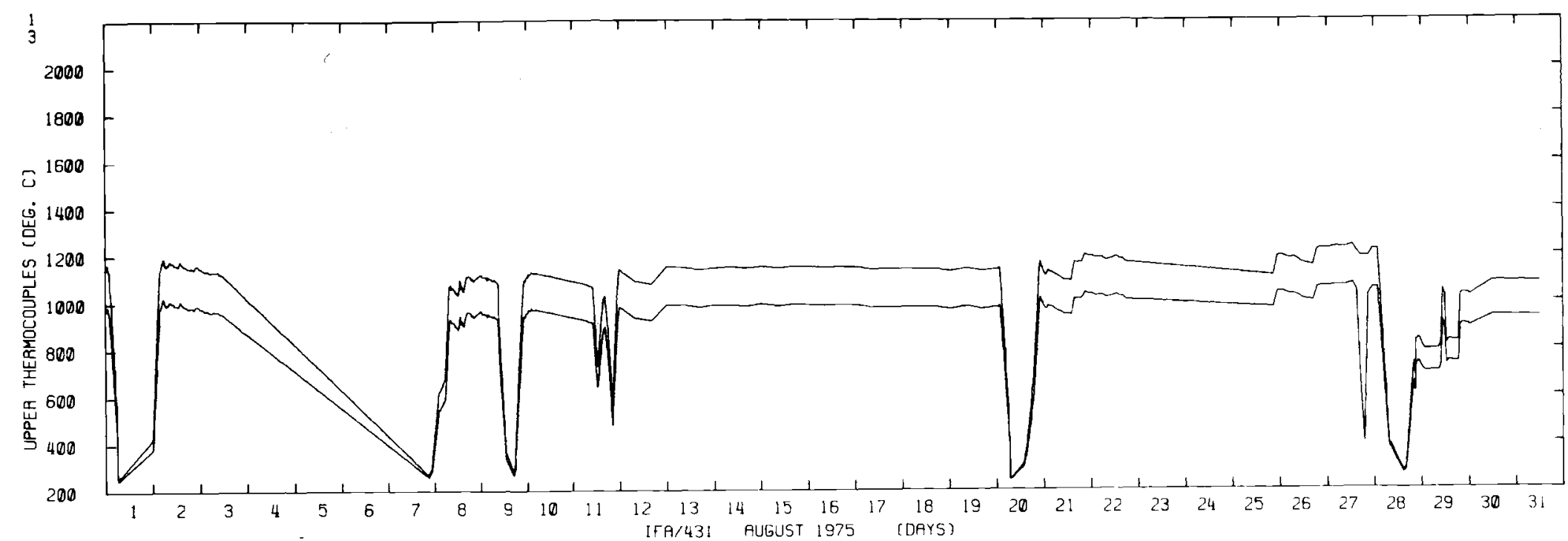

$\stackrel{\omega}{\dot{\omega}}$

FIGURE 3.55. Upper Thermocouple Readings for Rods 1,3 of IFA 431 - August 1975

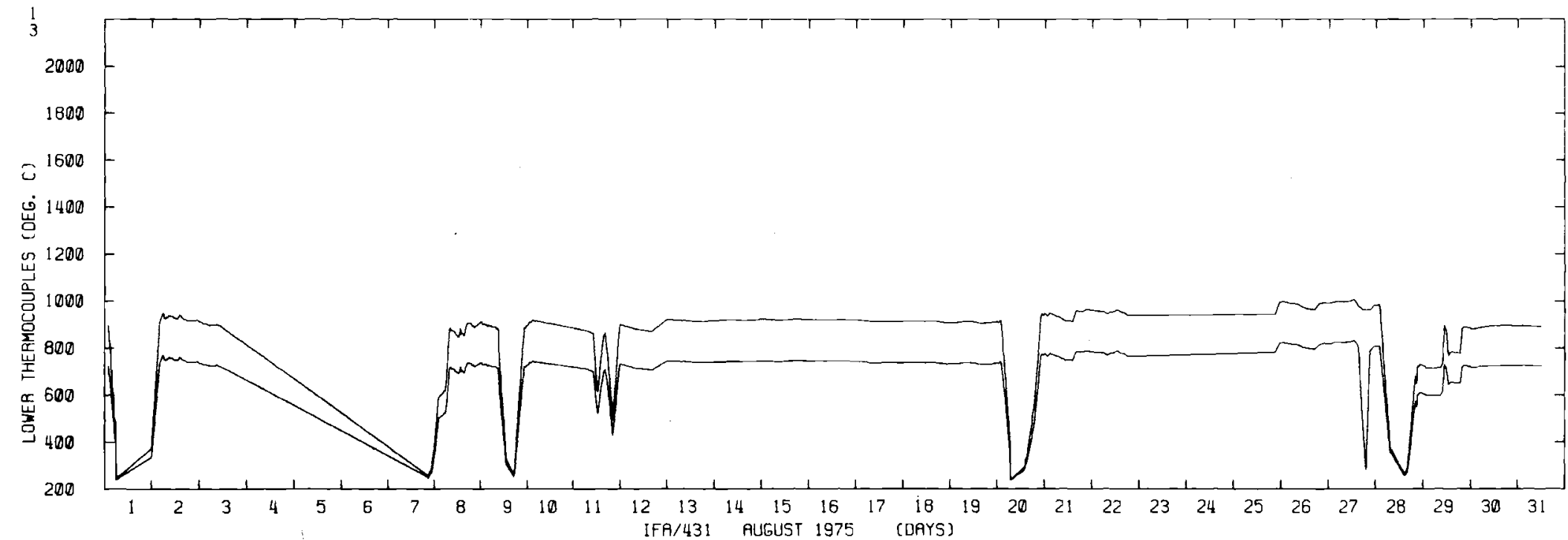

FIGURE 3.56. Lower Thermocouple Readings for Rods 1,3 of IFA 431 - August 1975 


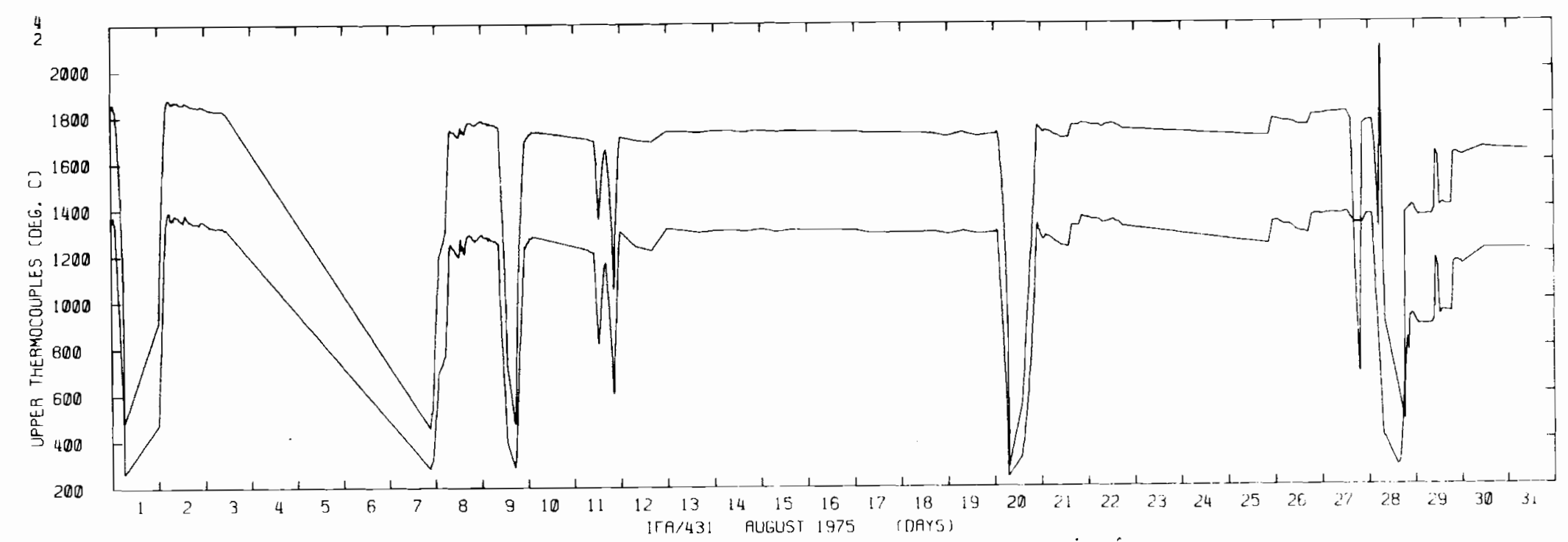

$\stackrel{\omega}{\dot{\omega}}$

FIGURE 3.57. Upper Thermocouple Readings for Rods 2,4 of IFA 431 - August 1975

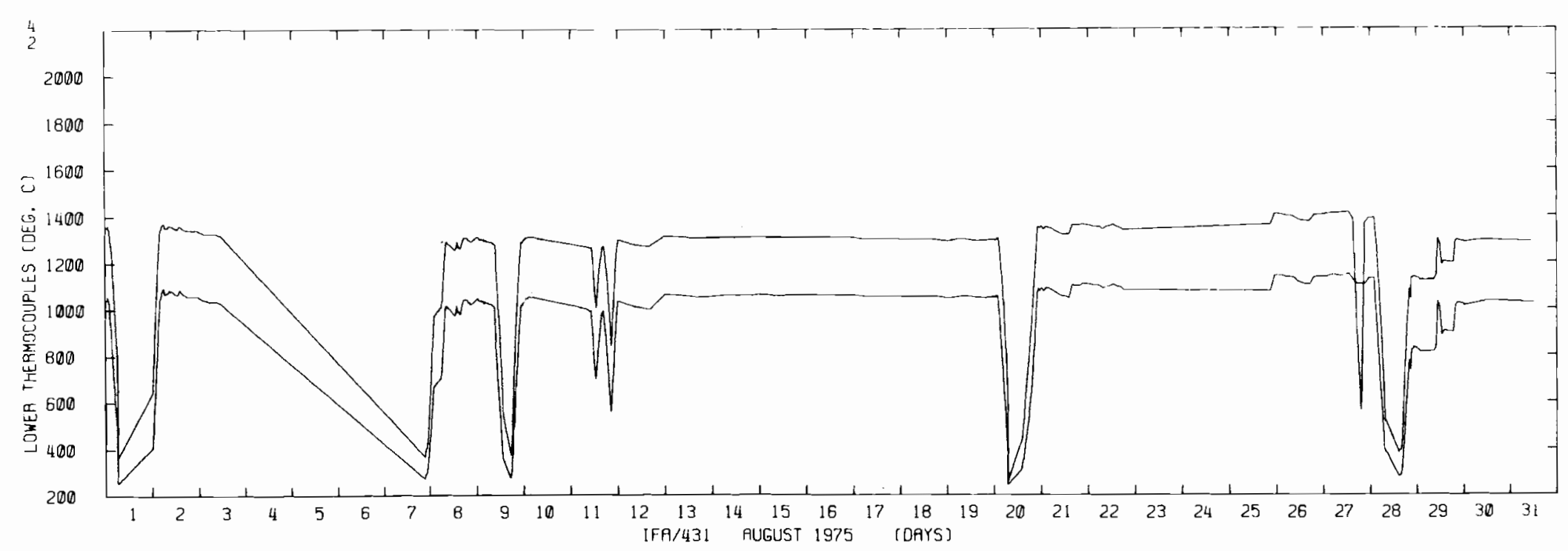

FIGURE 3.58. Lower Thermocouple Readings for Rods 2,4 of IFA 431 - August 1975 


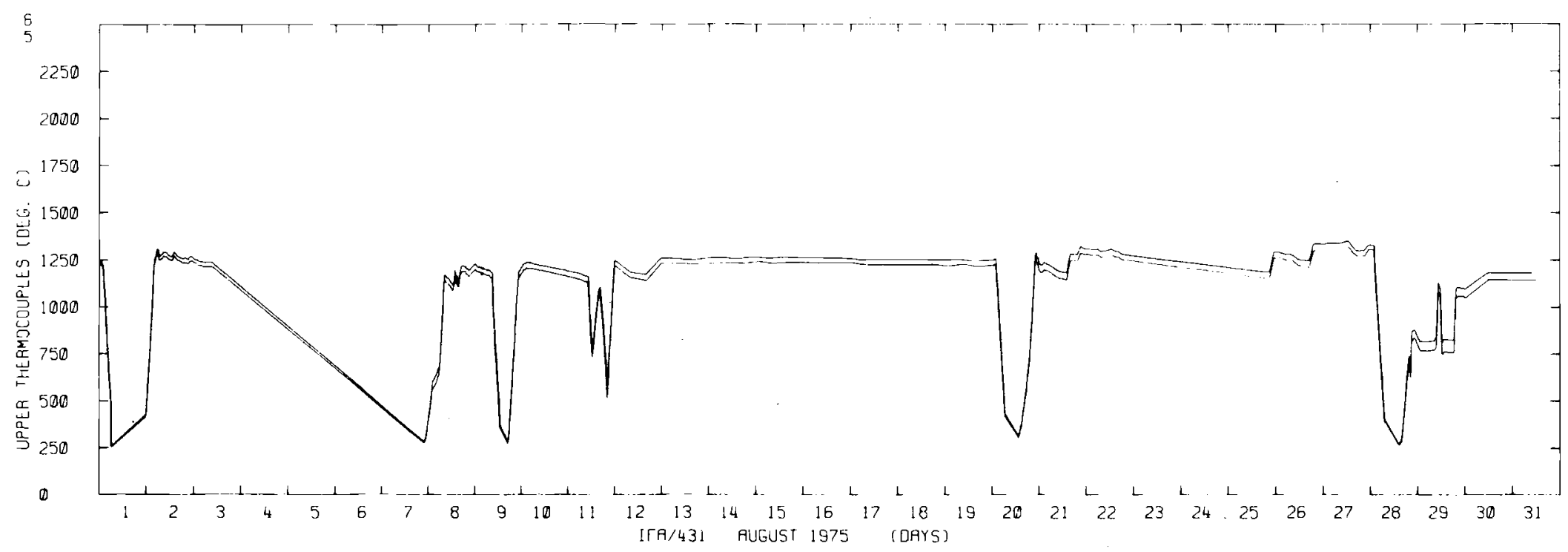

$\stackrel{\omega}{\omega}$

FIGURE 3.59. Upper Thermocouple Readings for Rods 5,6 of IFA 431 - August 1975

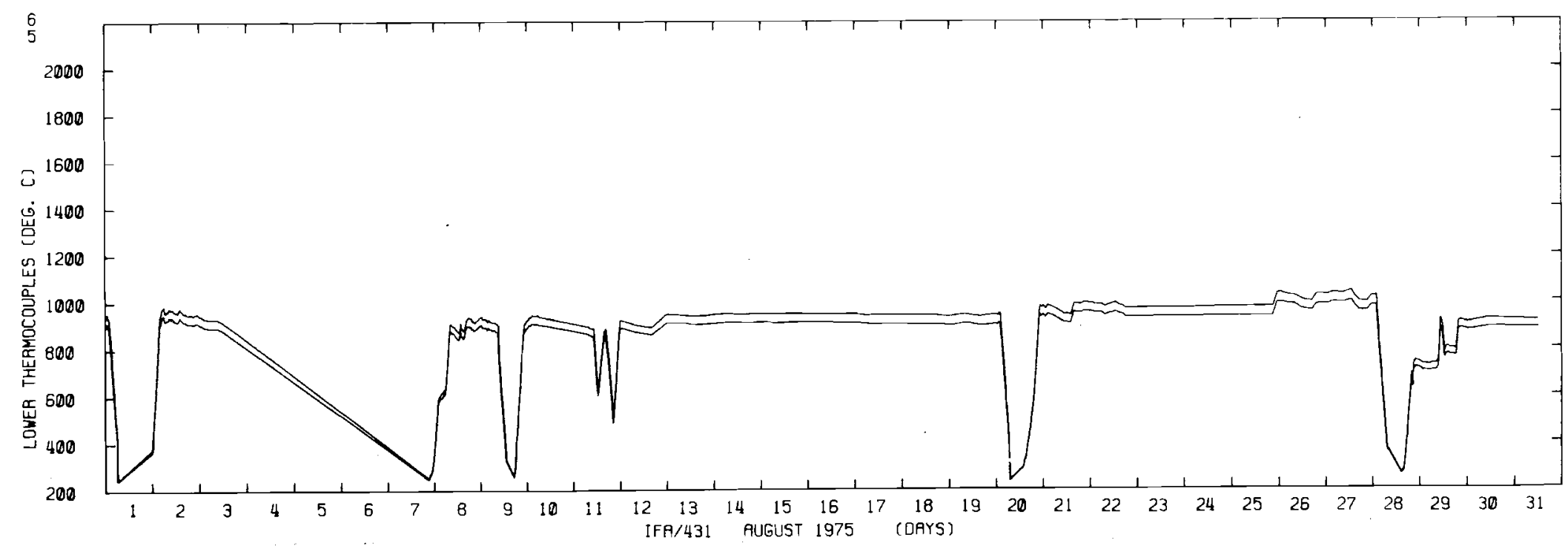

FIGURE 3.60. Lower Thermocouple Readings for Rods 5,6 of IFA 421 - Alunict 1975 


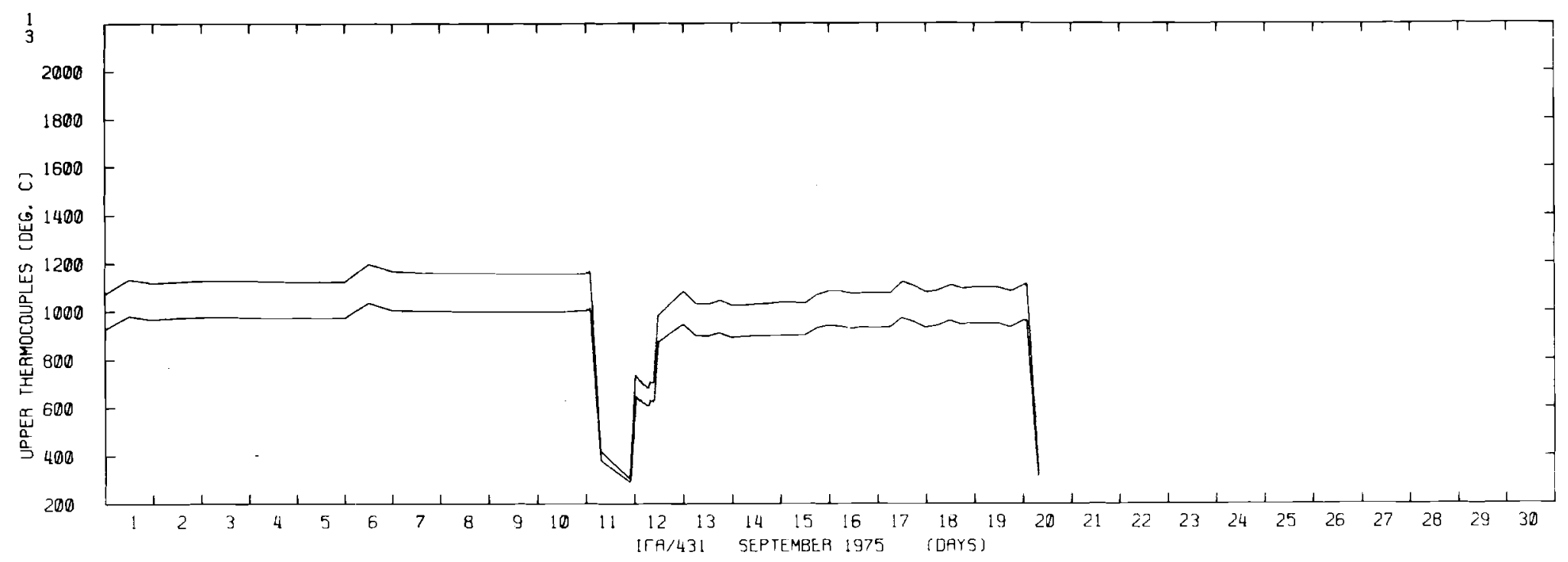

$\stackrel{\omega}{\dot{\omega}}$

FIGURE 3.61. Upper Thermocouple Readings for Rods 1,3 of IFA 431 - September 1975

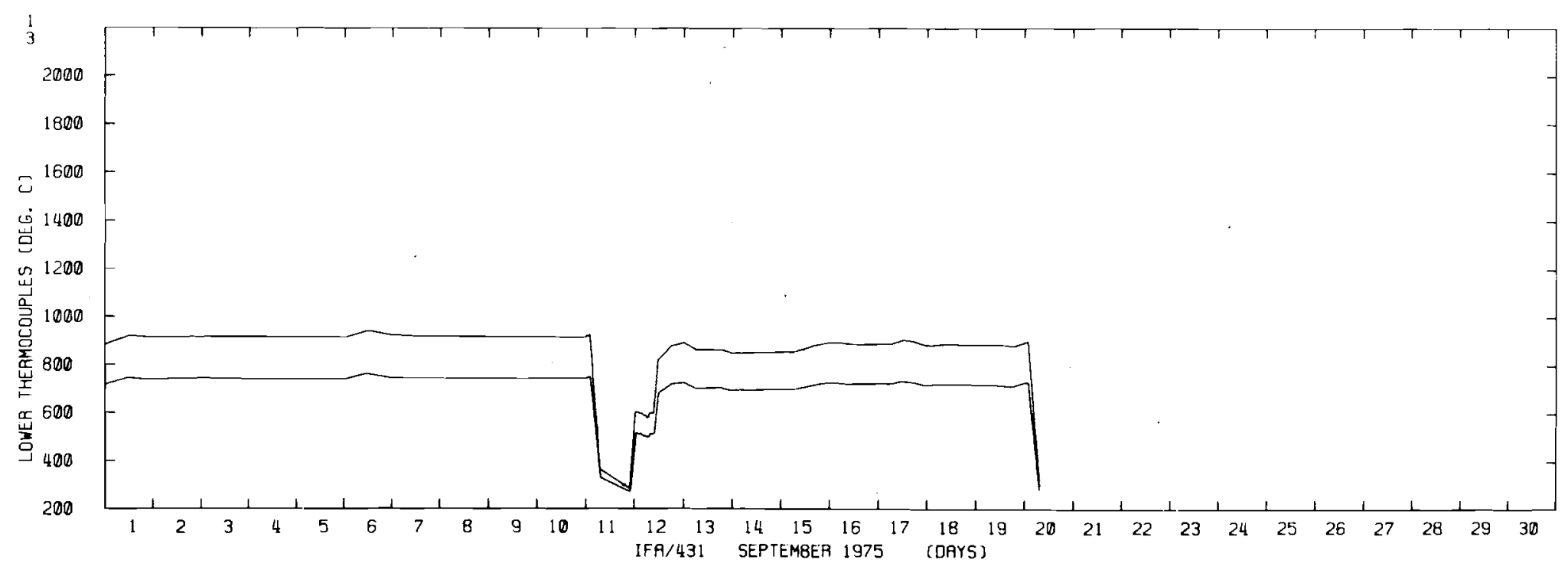

FIGURE 3.62. Lower Thermocouple Readings for Rods 1,3 of IFA 431 - September 1975 


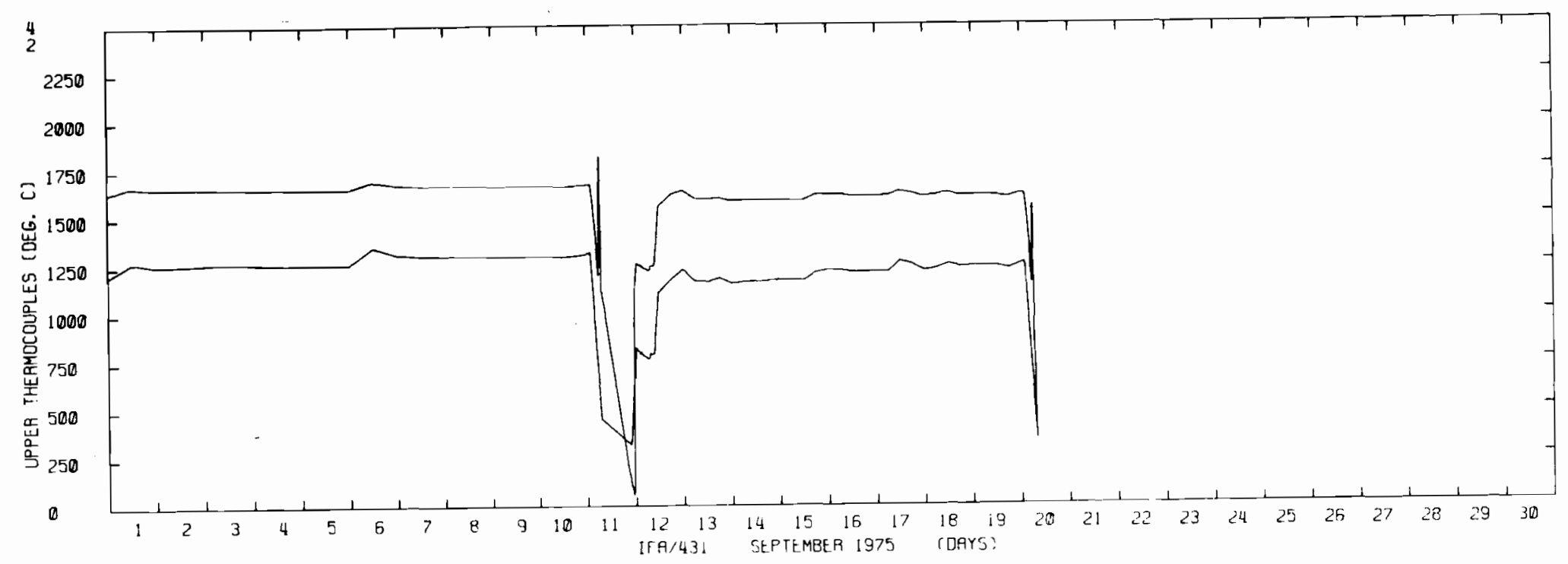

$\underset{\omega}{\omega}$

FIGURE 3.63. Upper Thermocouple Readings for Rods 2,4 of IFA 431 - September 1975

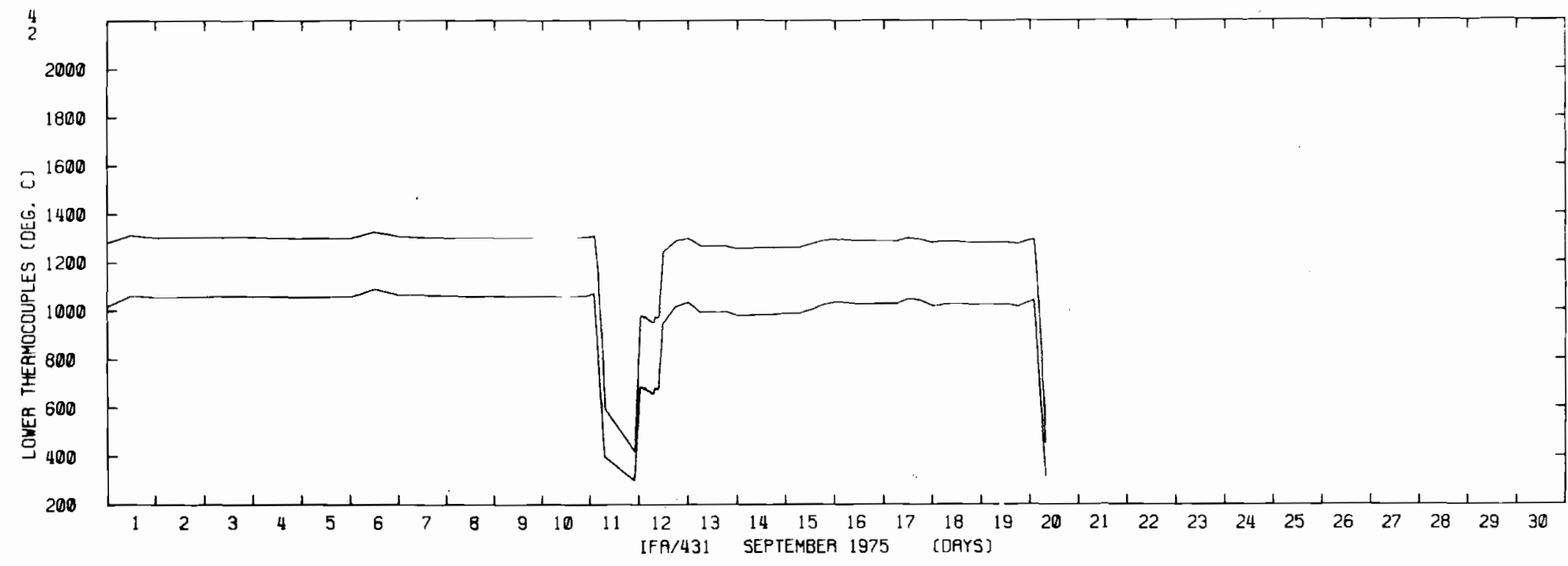

FIGURE 3.64. Lower Thermocouple Readings for Rods 2,4 of IFA 431 - September 1975 


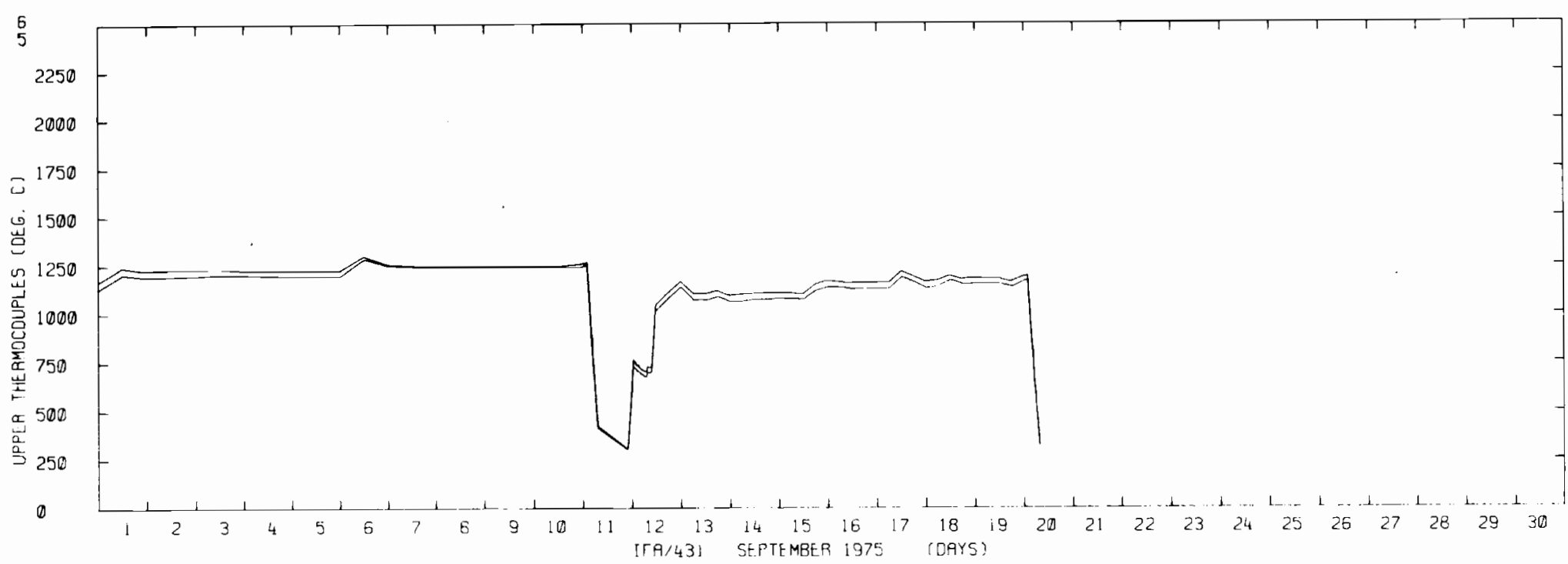

$\stackrel{\omega}{\dot{w}}$

FIGURE 3.65. Upper Thermocouple Readings for Rods 5,6 of IFA 431 - September 1975

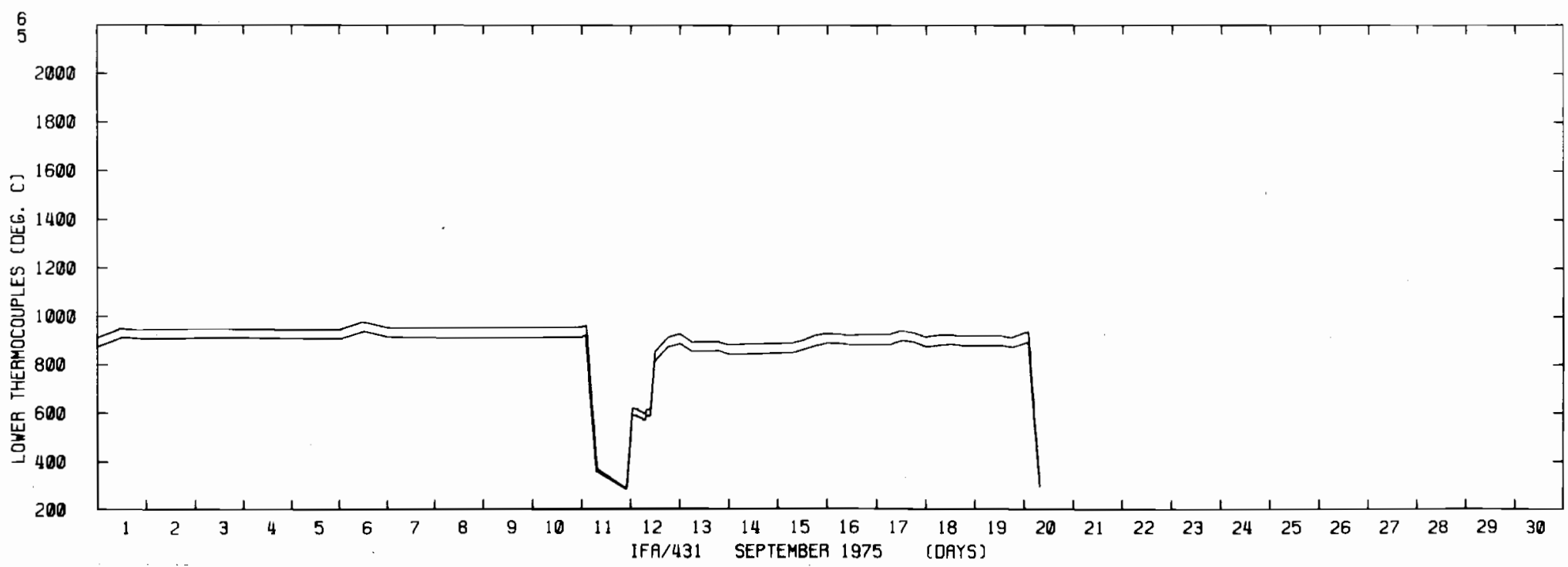

FIGURE 3.66. Lower Thermocouple Readings for Rods 5,6 of IFA 431 - September 1975 


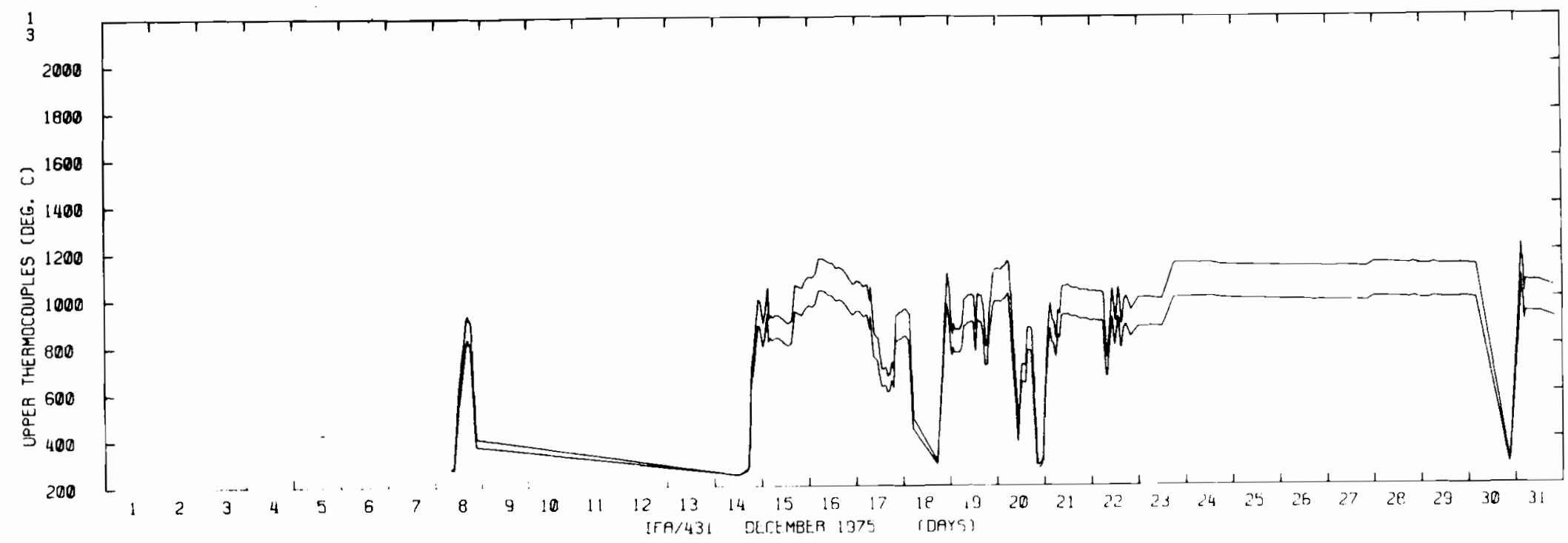

$\stackrel{\omega}{\omega}$

FIGURE 3.67. Upper Thermocouple Readings for Rods 1,3 of IFA 431 - December 1975

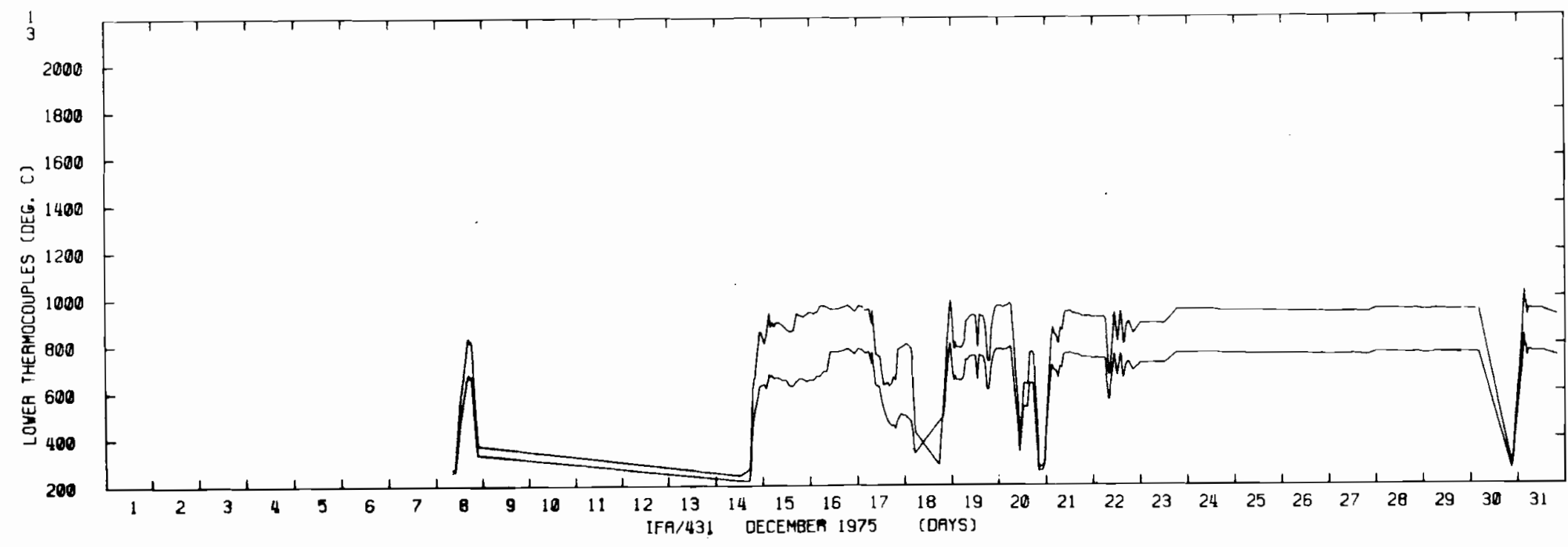

FIGURE 3.68. Lower Thermocouple Readings for Rods 1,3 of IFA 431 - December 1975 


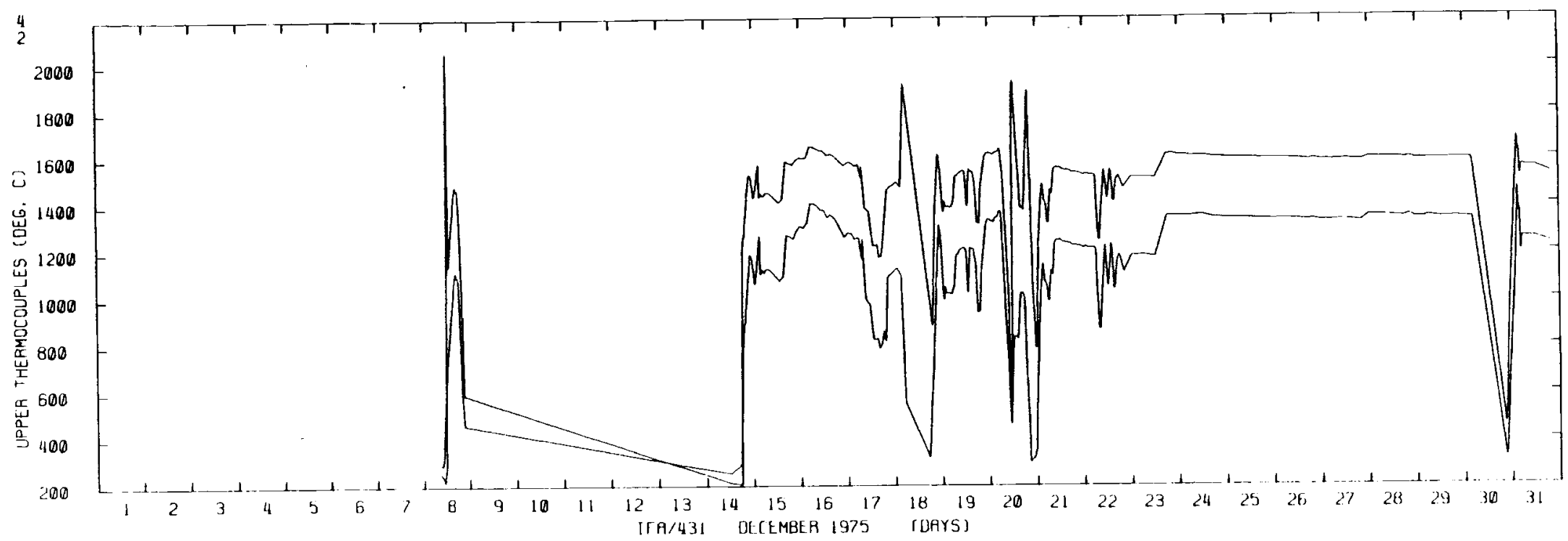

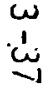

FIGURE 3.69. Upper Thermocouple Readings for Rods 2,4 of IFA 431 - December 1975

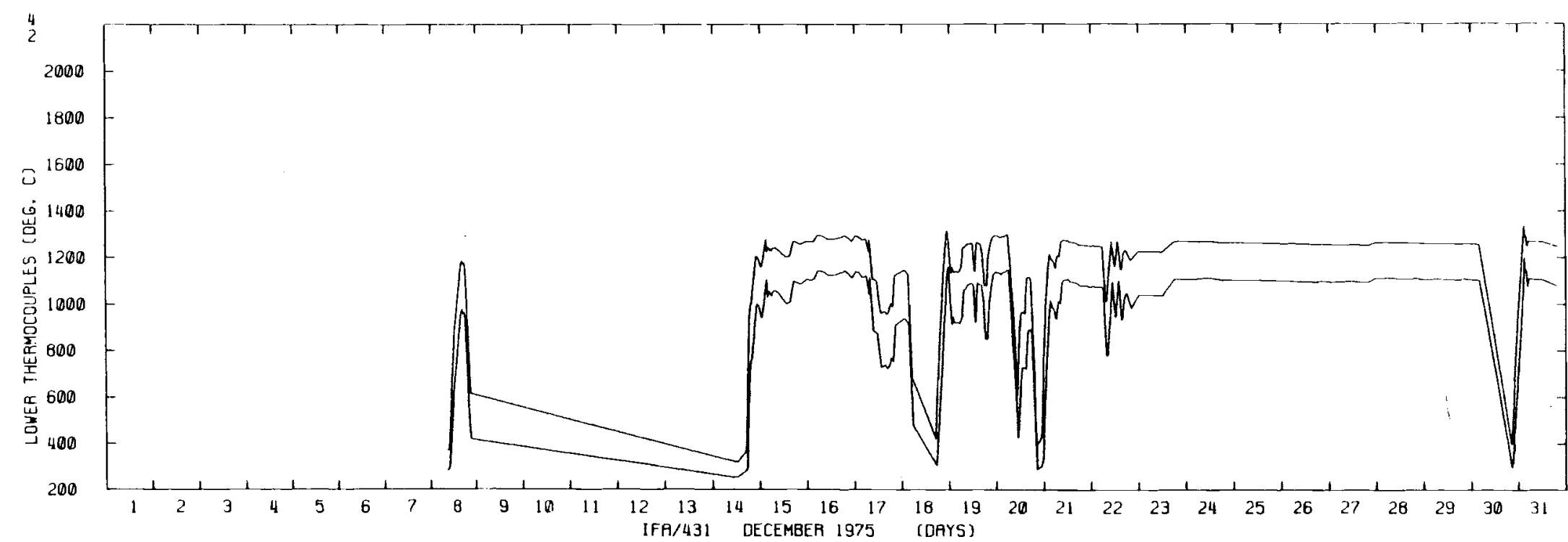

FIGURE 3.70. Lower Thermocouple Readings for Rods 2,4 of IFA 431 - December 1975 


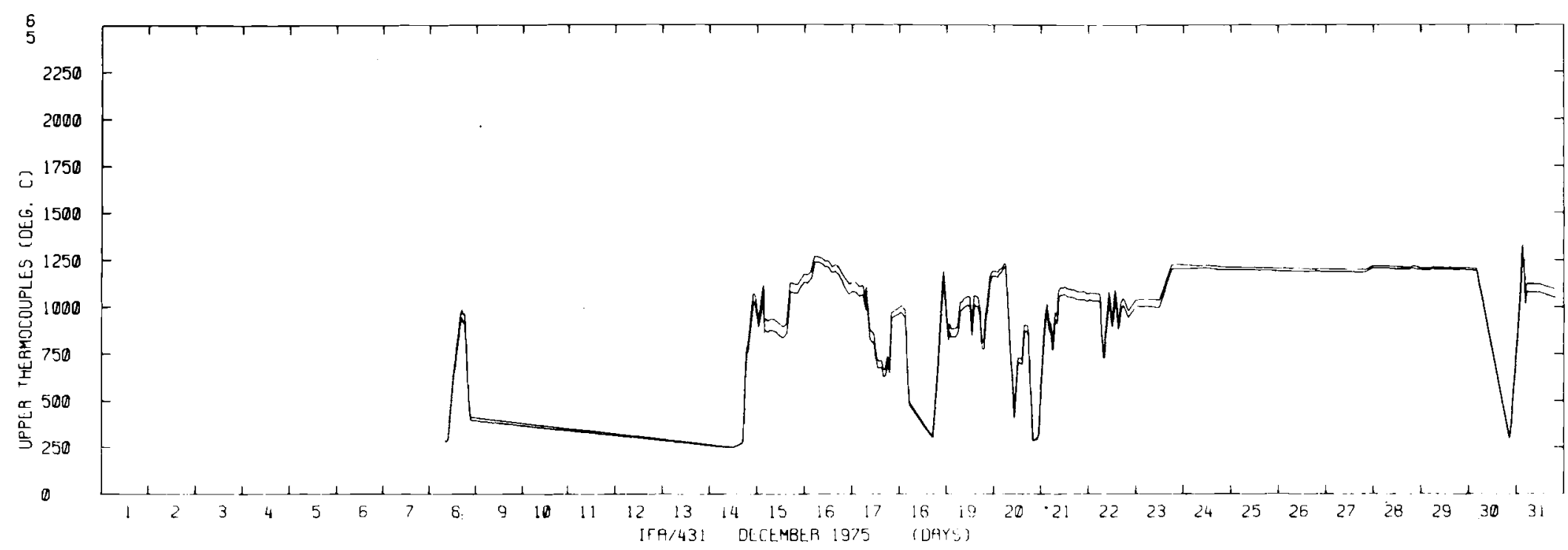

$\underset{\infty}{\omega}$

FIGURE 3.71. Upper Thermocouple Readings for Rods 5,6 of IFA 431 - December 1975

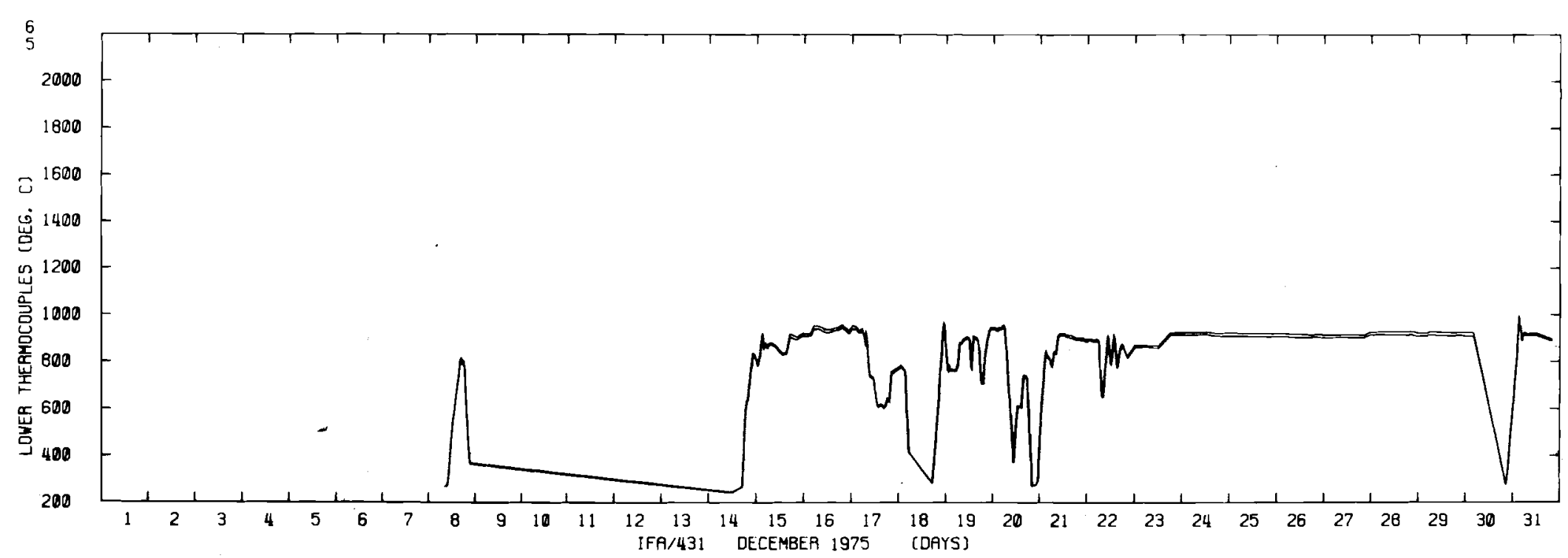

FIGURE 3.72. Lower Thermocouple Readings for Rods 5,6 of IFA 431 - December 1975 


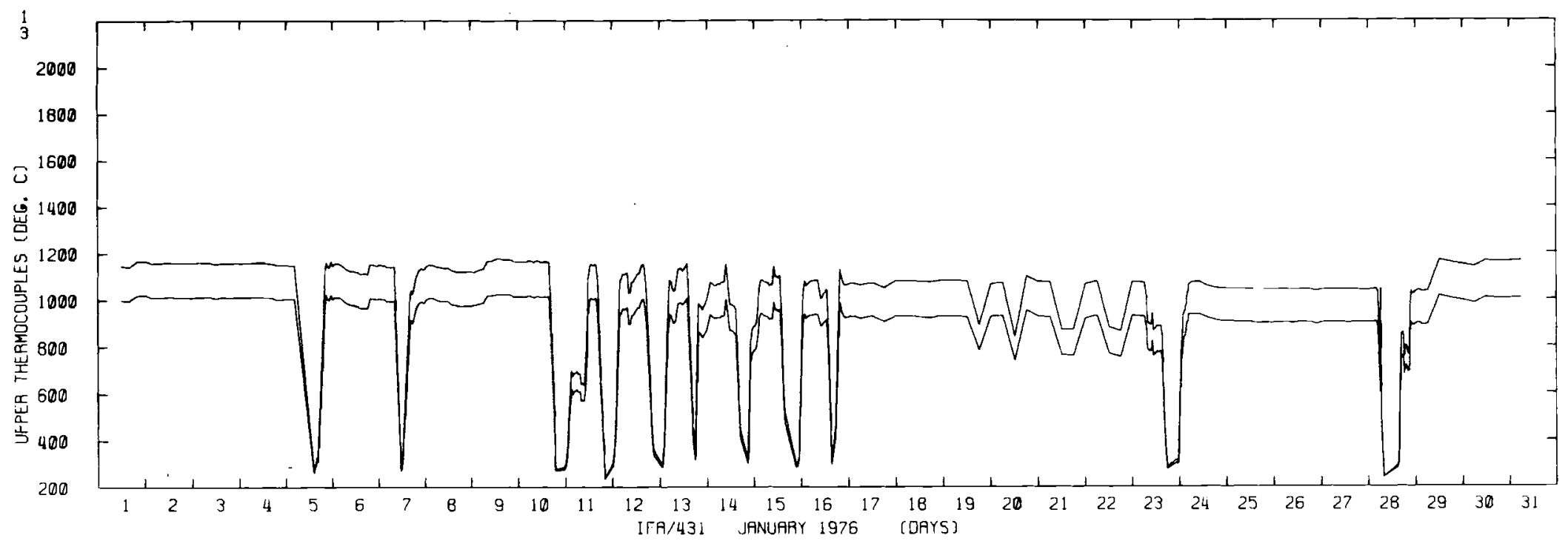

$\stackrel{\omega}{\omega}$

FIGURE 3.73. Upper Thermocouple Readings for Rods 1,3 of IPA 431 - January 1976

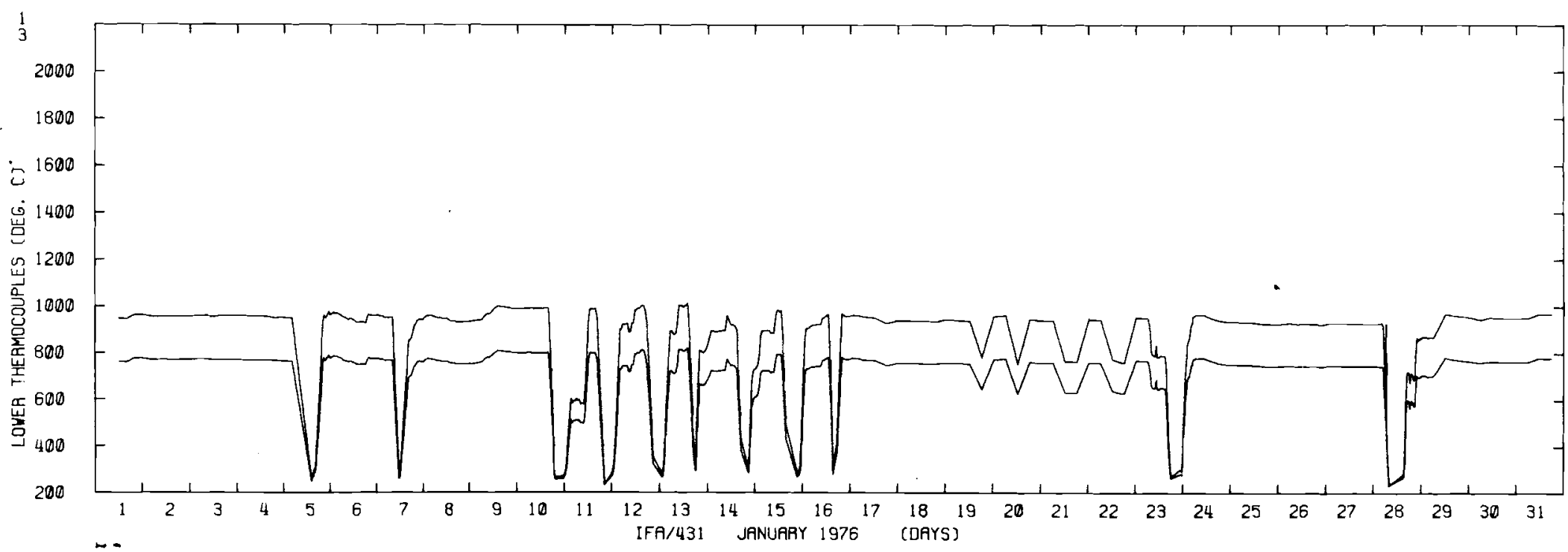

FIGURE 3.74. Lower Thermocouple Readings for Rods 1,3 of IPA 431 - January 1976 


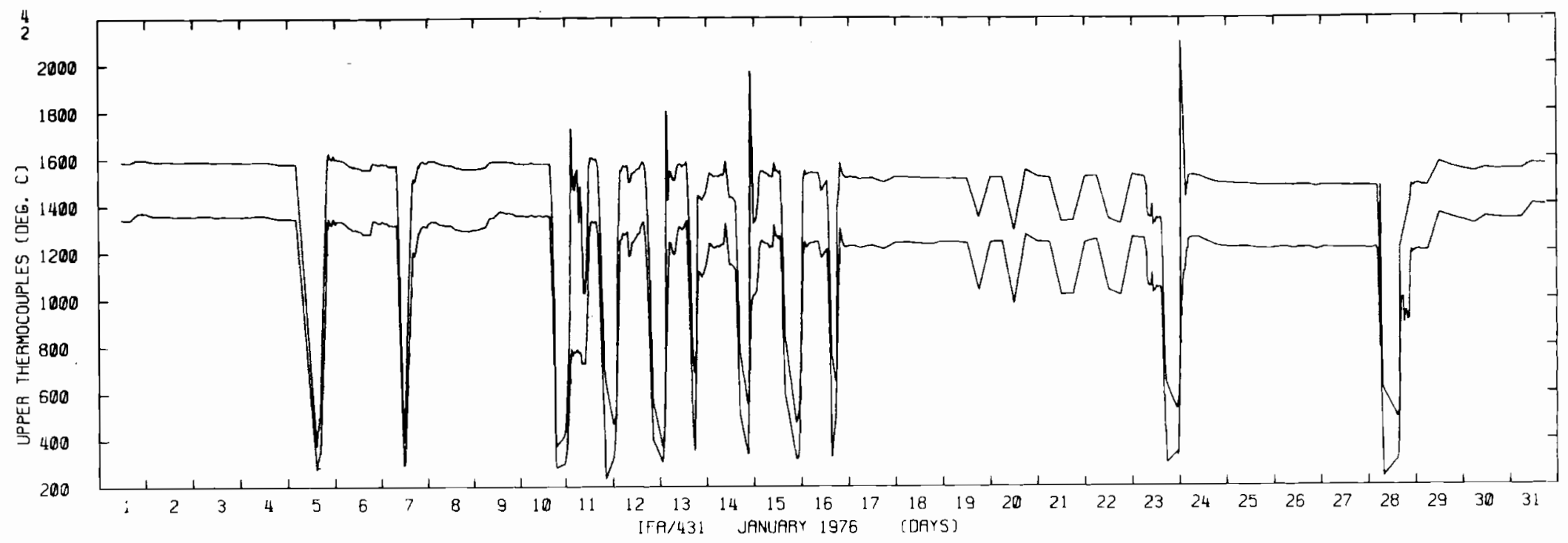

$w$
1
0

FIGURE 3.75. Upper Thermocouple Readings for Rods 2,4 of IFA 431 - January 1976

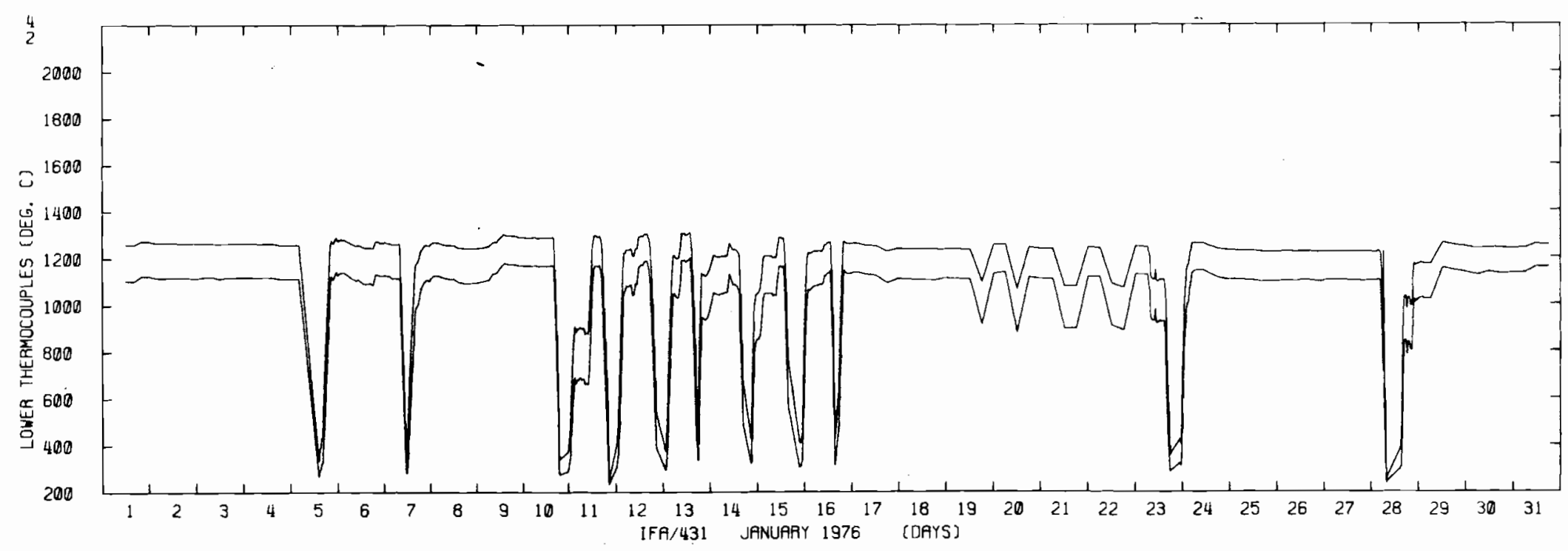

FIGURE 3.76. Lower Thermocouple Readings for Rods 2,4 of IFA 431 - January 1976 


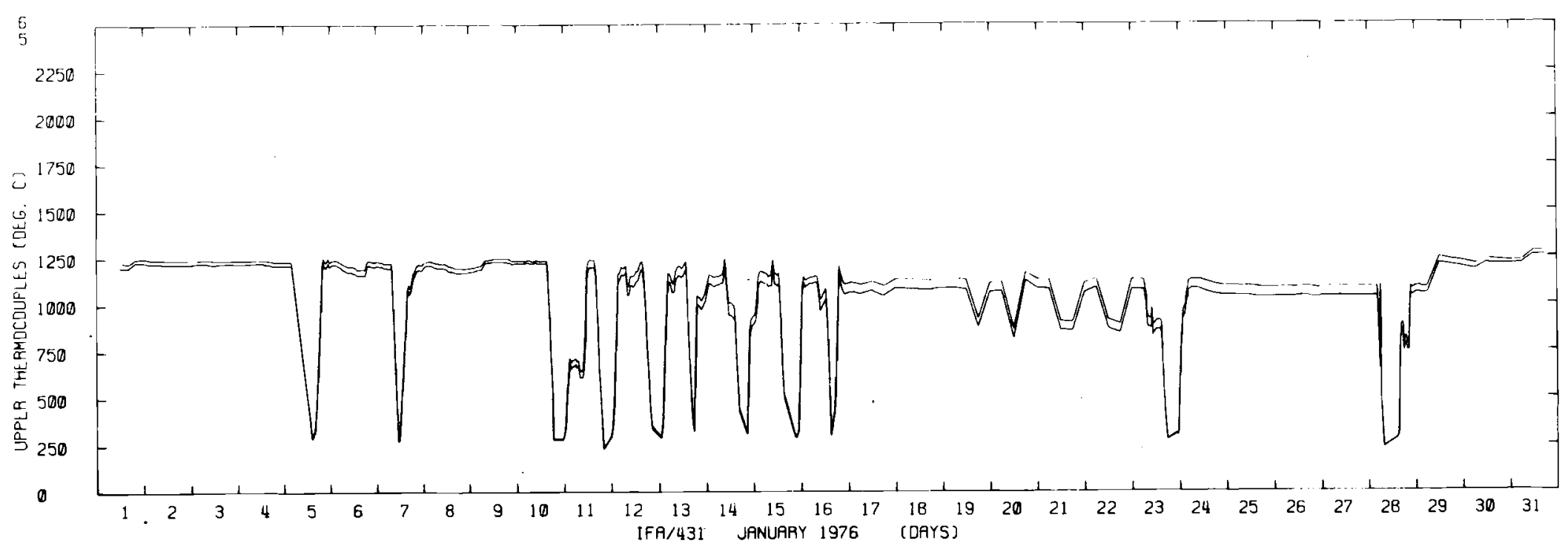

$\stackrel{w}{t}$

FIGURE 3.77. Upper Thermocouple Readings for Rods 5,6 of IFA 431 - January 1976

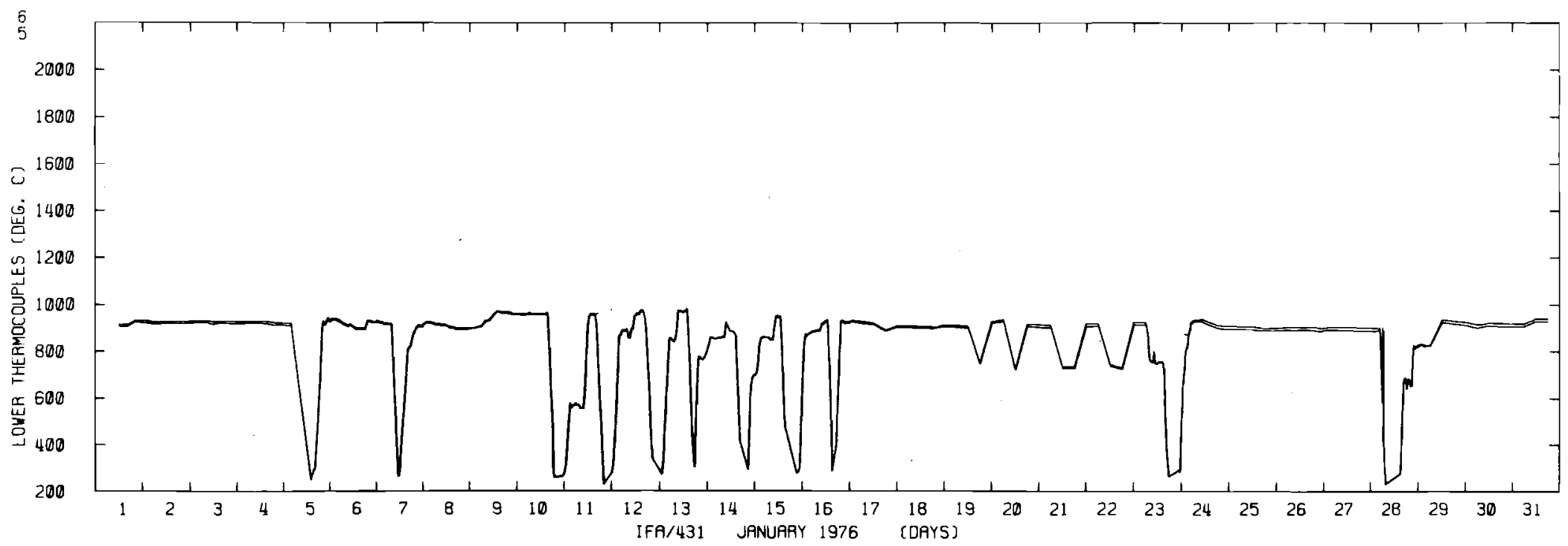

FIGURE 3.78. Lower Thermocouple Readings for Rods 5,6 of IFA 431 - January 1976 


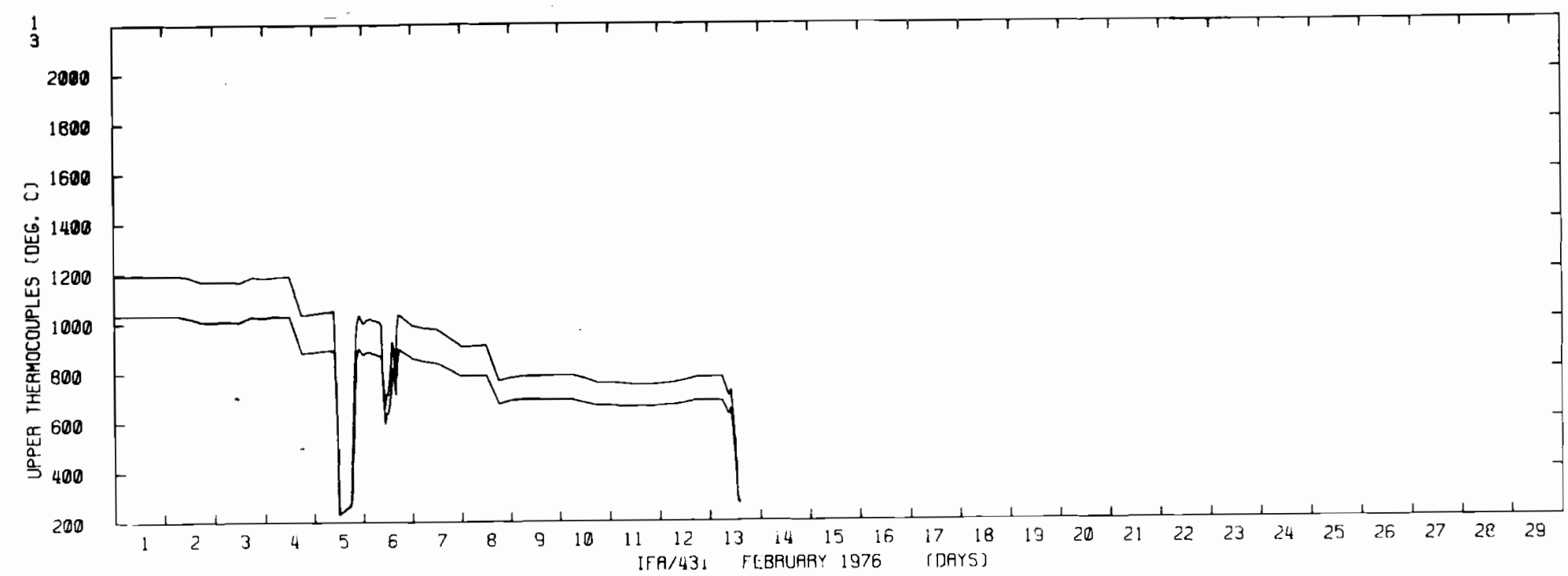

$\stackrel{w}{\stackrel{1}{n}}$

FIGURE 3.79. Upper Thermocouple Readings for Rods 1,3 of IFA 431 - February 1976

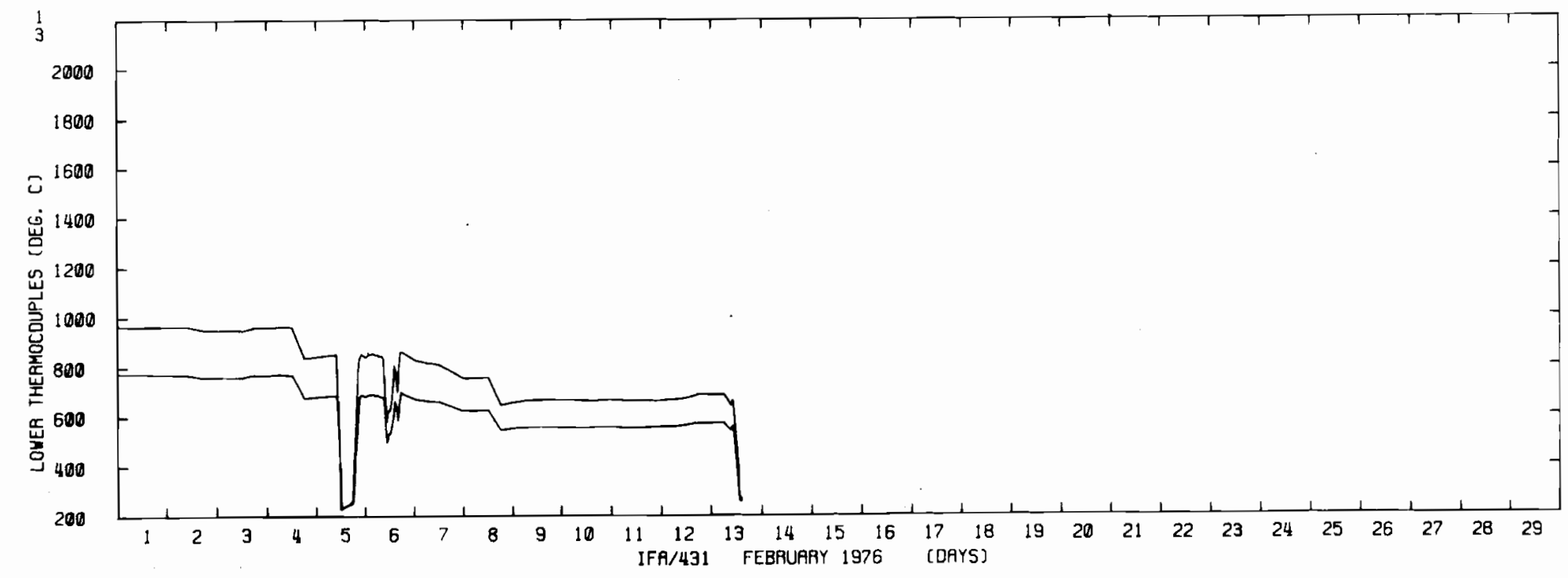

FIGURE 3.80. Lower Thermocouple Readings for Rods 1,3 of IFA 431 - February 1976 


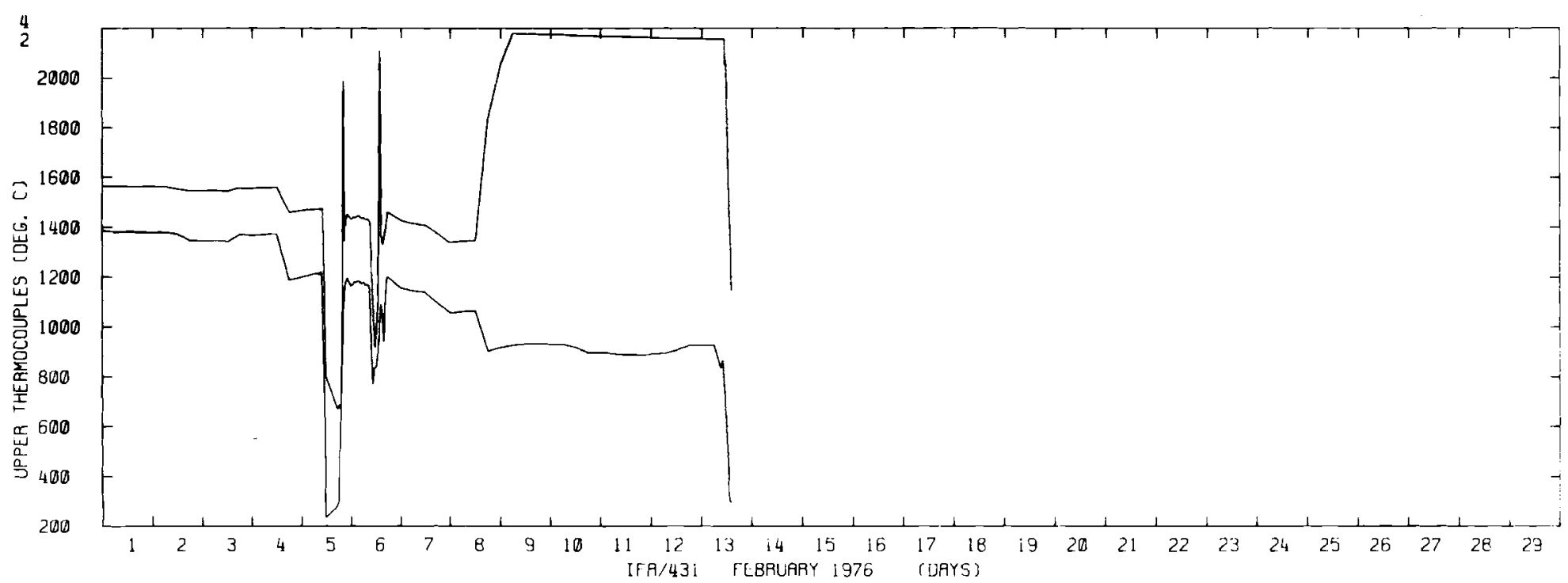

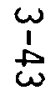

FIGURE 3.81. Upper Thermocouple Readings for Rods 2,4 of IFA 431 - February 1976

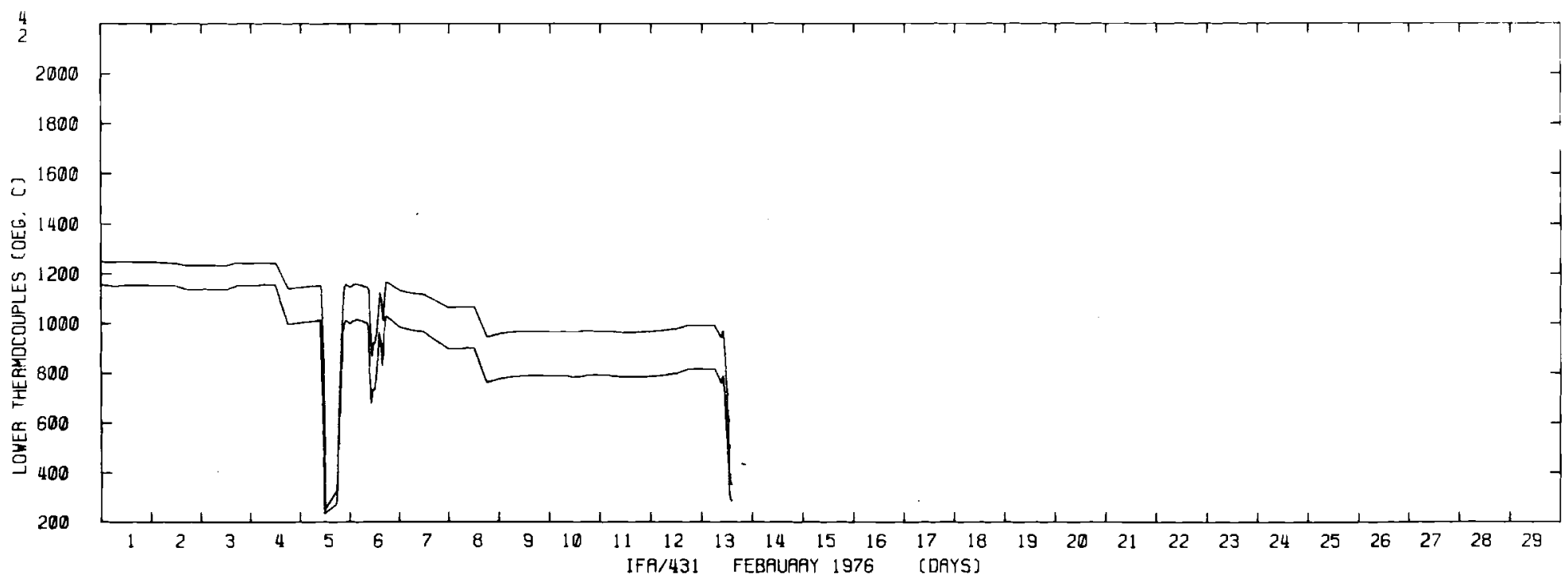

FIGURE 3.82. Lower Thermocouple Readings for Rods 2,4 of IFA 431 - February 1976 


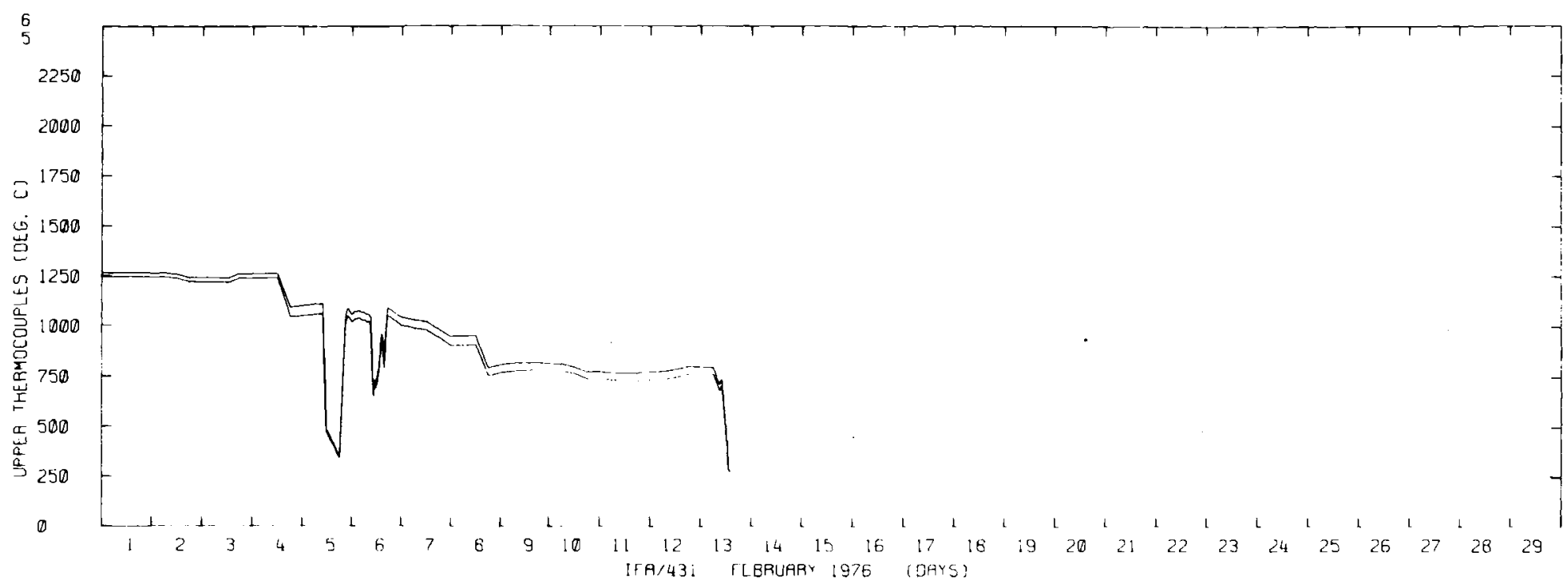

$\stackrel{w}{b}$

FIGURE 3.83. Upper Thermocouple Readings for Rods 5,6 of IFA 431 - February 1976

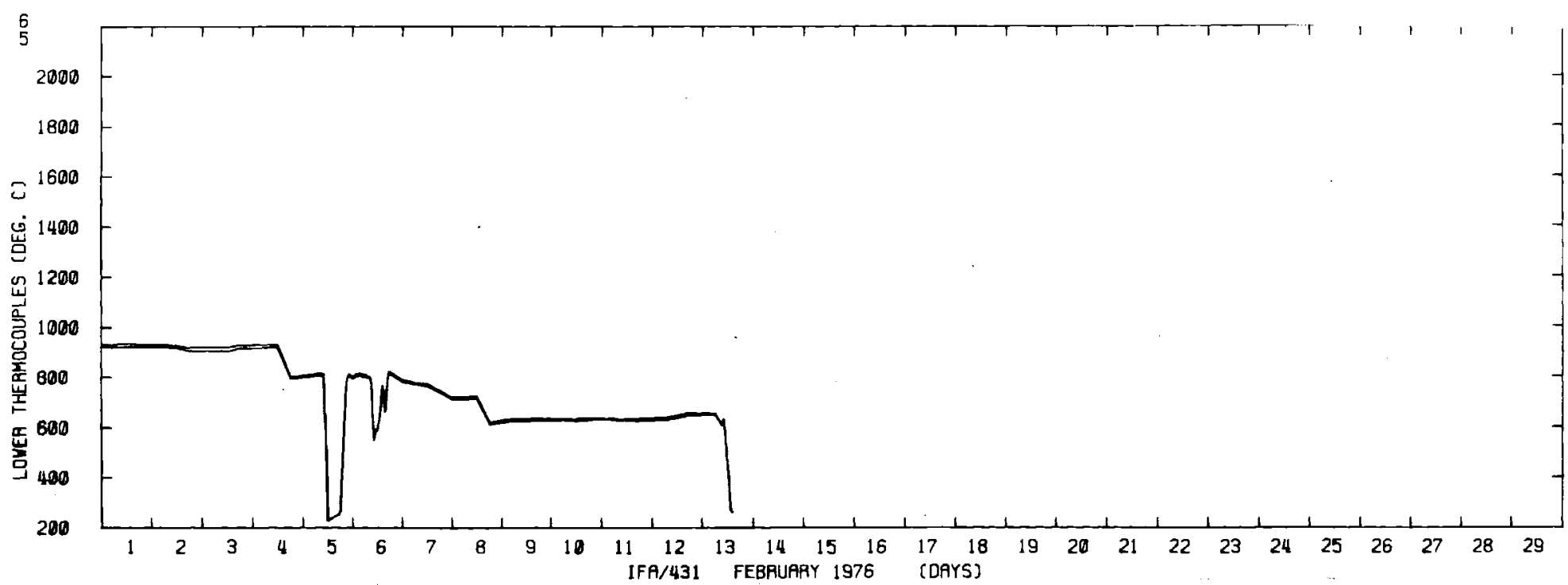

FIGURE 3.84. Lower Thermocouple Readings for Rods 5,6 of IFA 431 - February 1976 


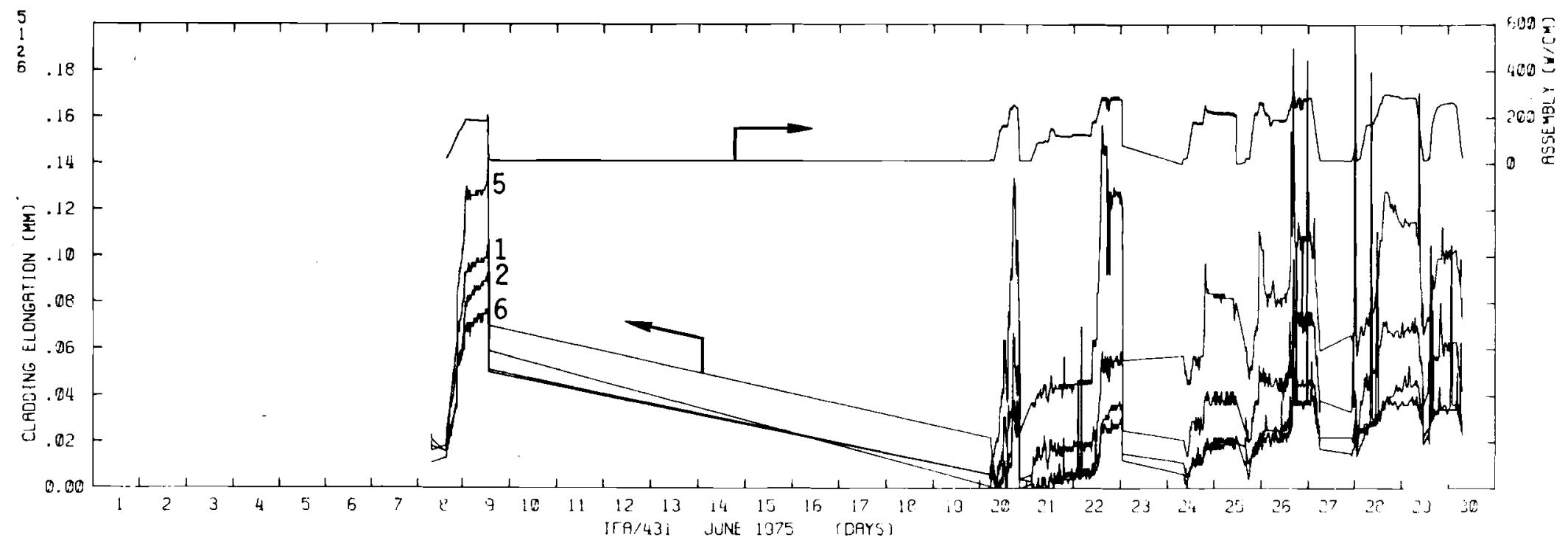

$\omega$
1
$\vdots$
0

FIGURE 3.85. Cladding Elongation Sensor Readings for Rods $1,2,5,6$ of IFA 431 - June 1975

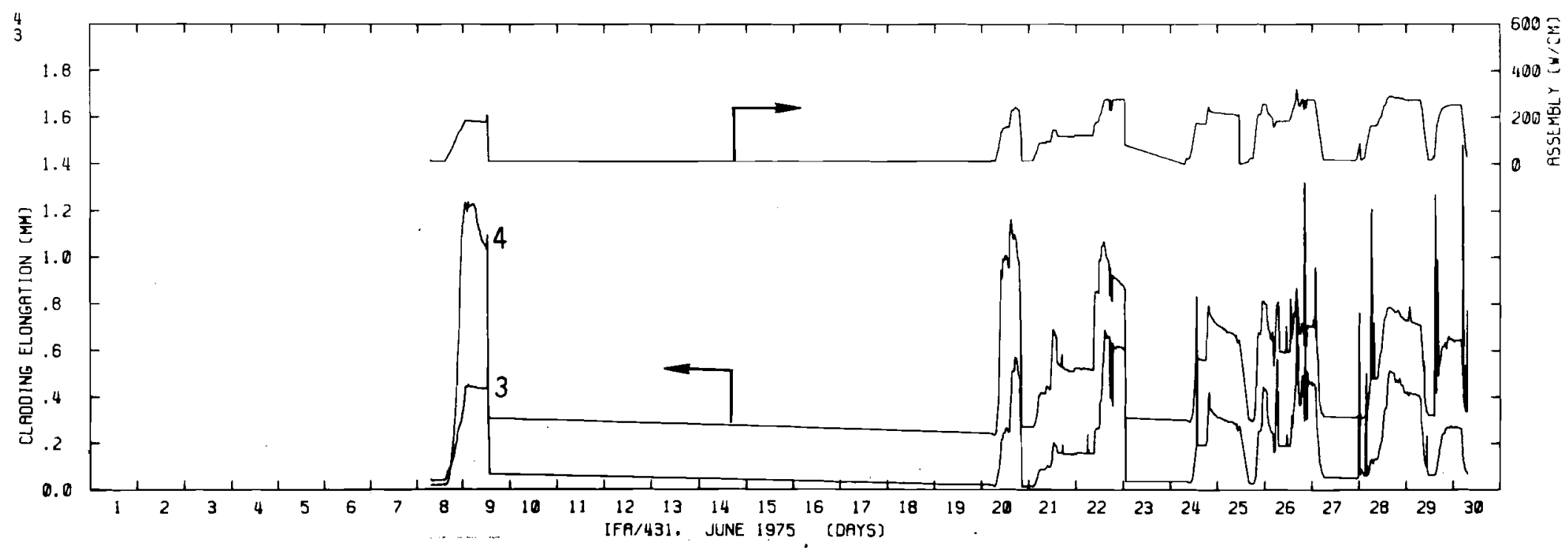

FIGURE 3.86. Cladding Elongation Sensor Readings for Rods 3,4 of IFA 431 - June 1975 


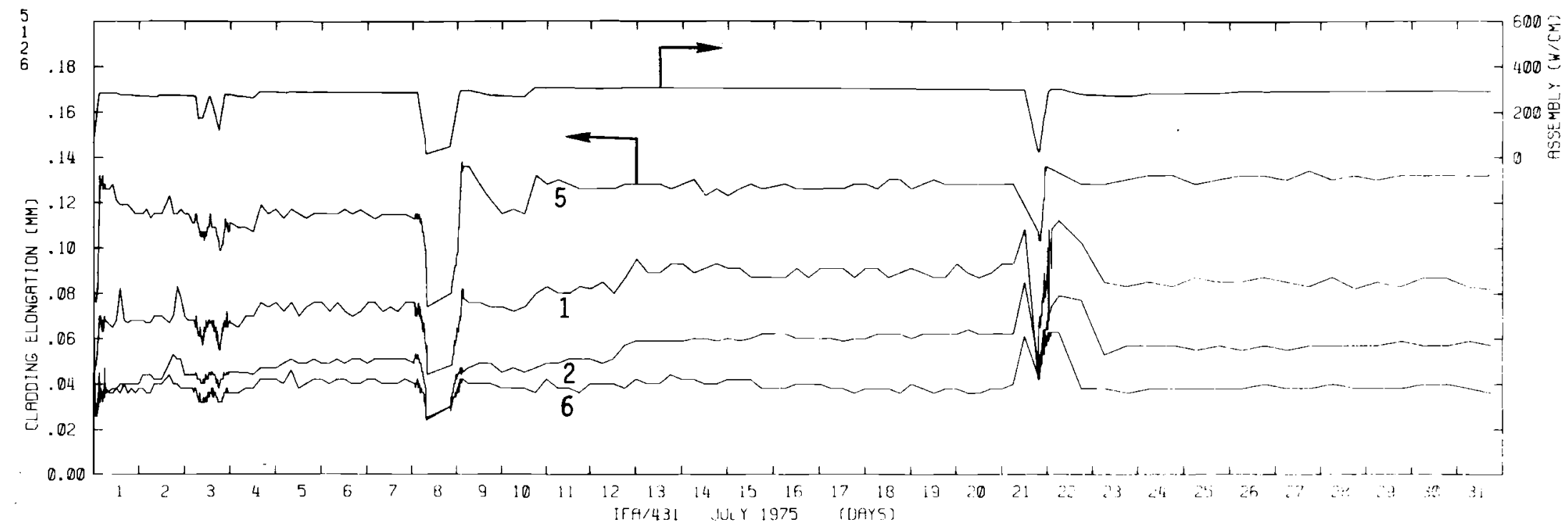

$\omega$
1
a

FIGURE 3.87. Cladding Elongation Sensor Readings for Rods 1,2,5,6 of

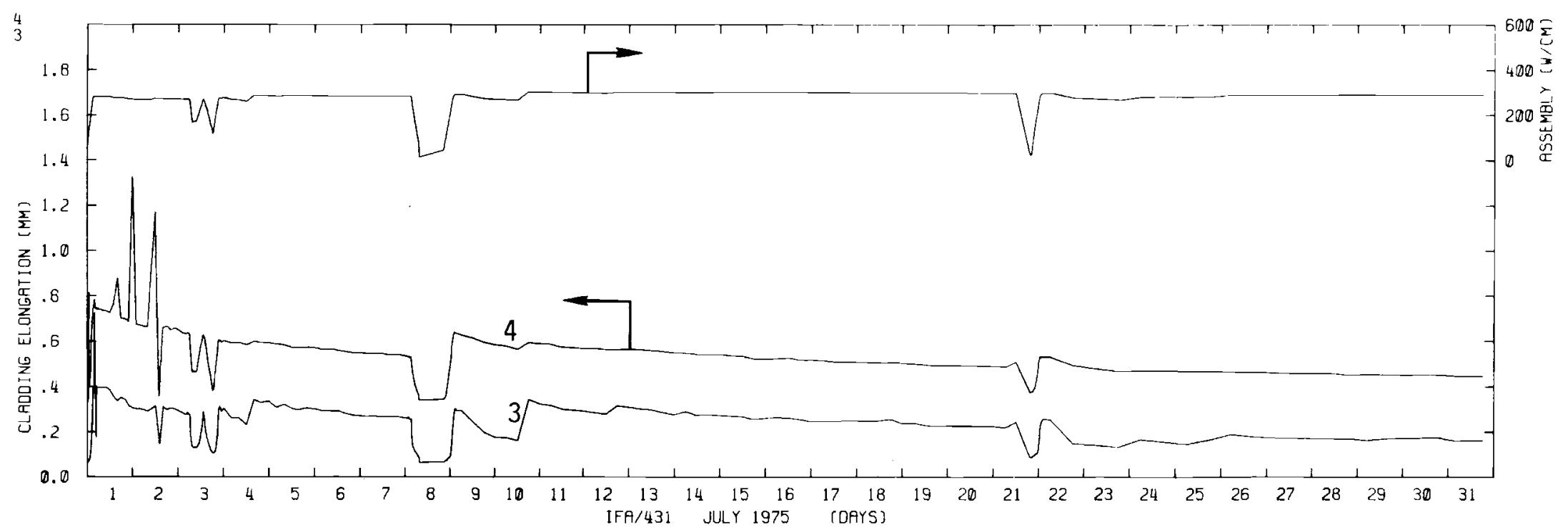

FIGURE 3.88. Cladding Elongation Sensor Readings for Rods 3,4 of IFA 431 - July 1975 


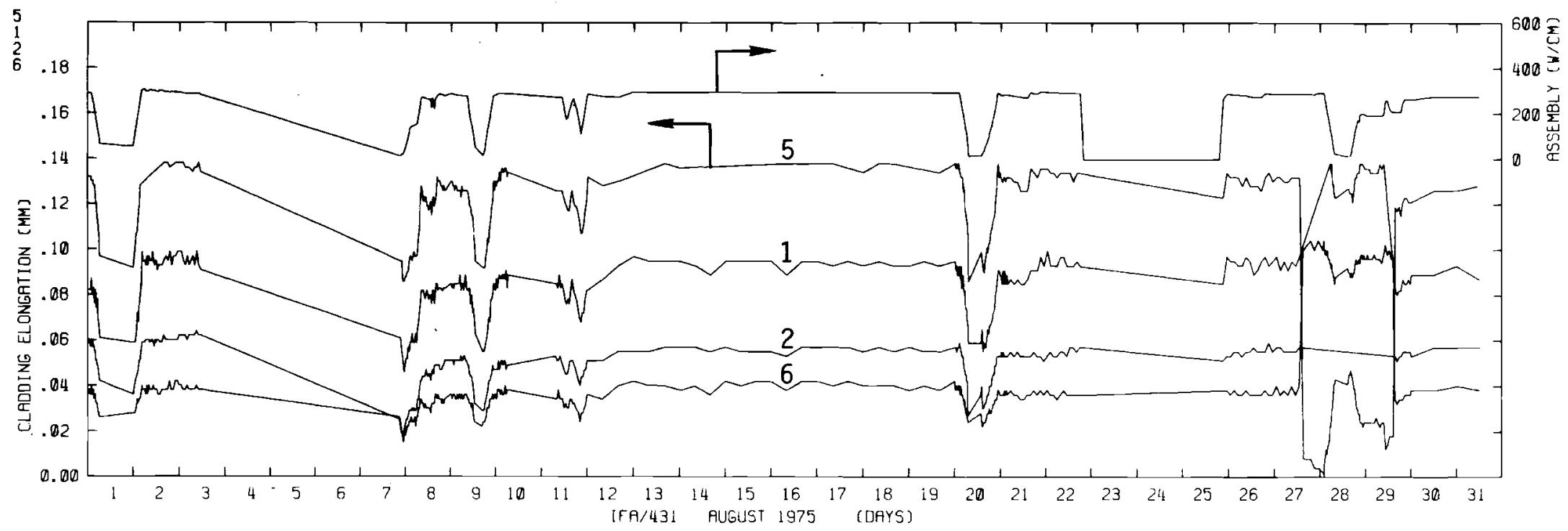

$\stackrel{\omega}{!}$

FIGURE 3.89. Cladding Elongation Sensor Readings for Rods 1,2,5,6 of IFA 431 - August 1975

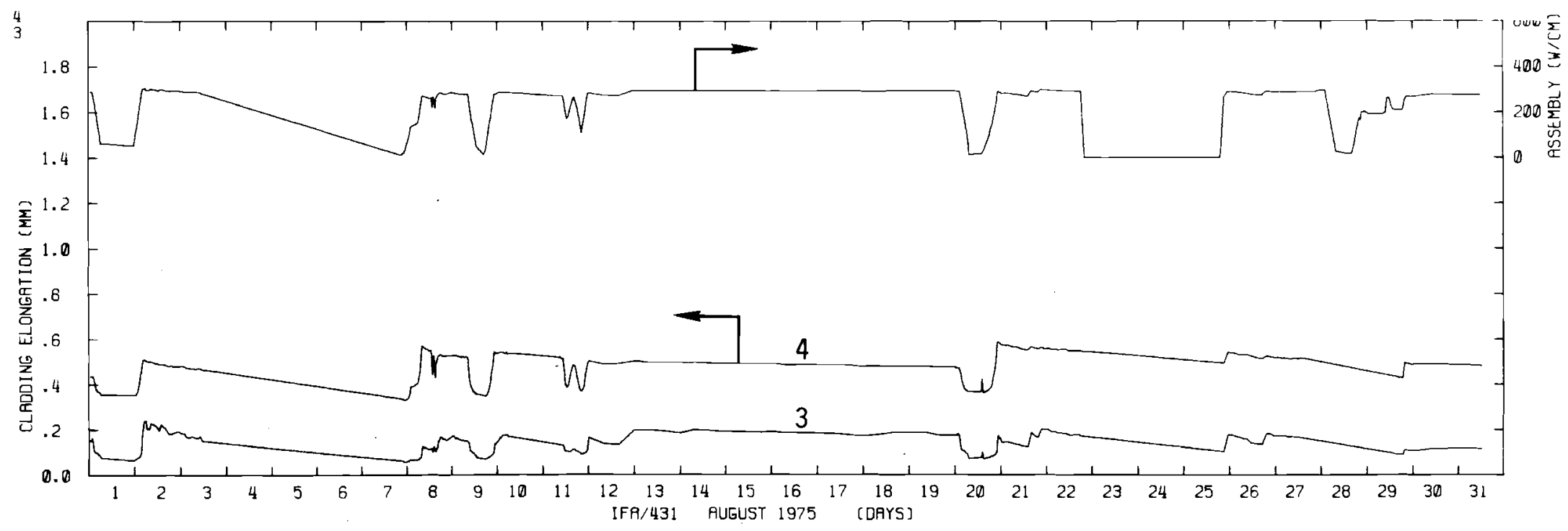

FIGURE 3.90. Cladding Elongation Sensor Readings for Rods 3,4 of IFA 431 - August 1975 


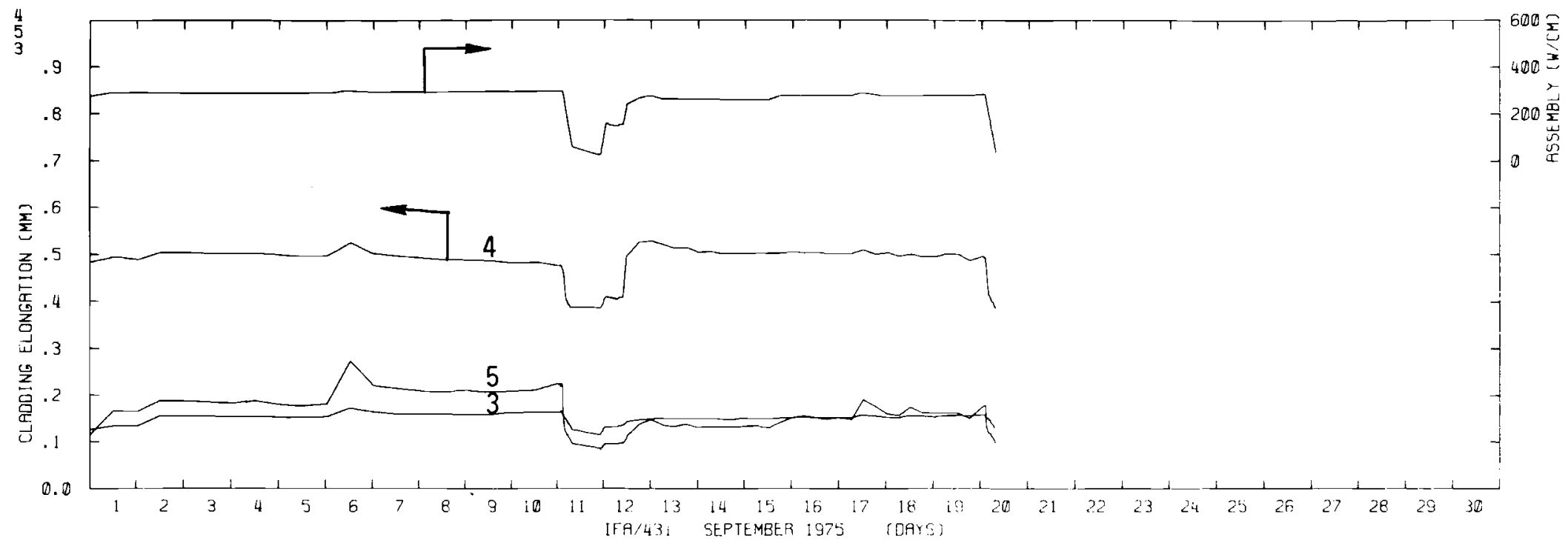

FIGURE 3.91. Cladding Elongation Sensor Readings for Rods 3,4,5 of

$\stackrel{\omega}{\vdots}$ IFA 431 - September 1975

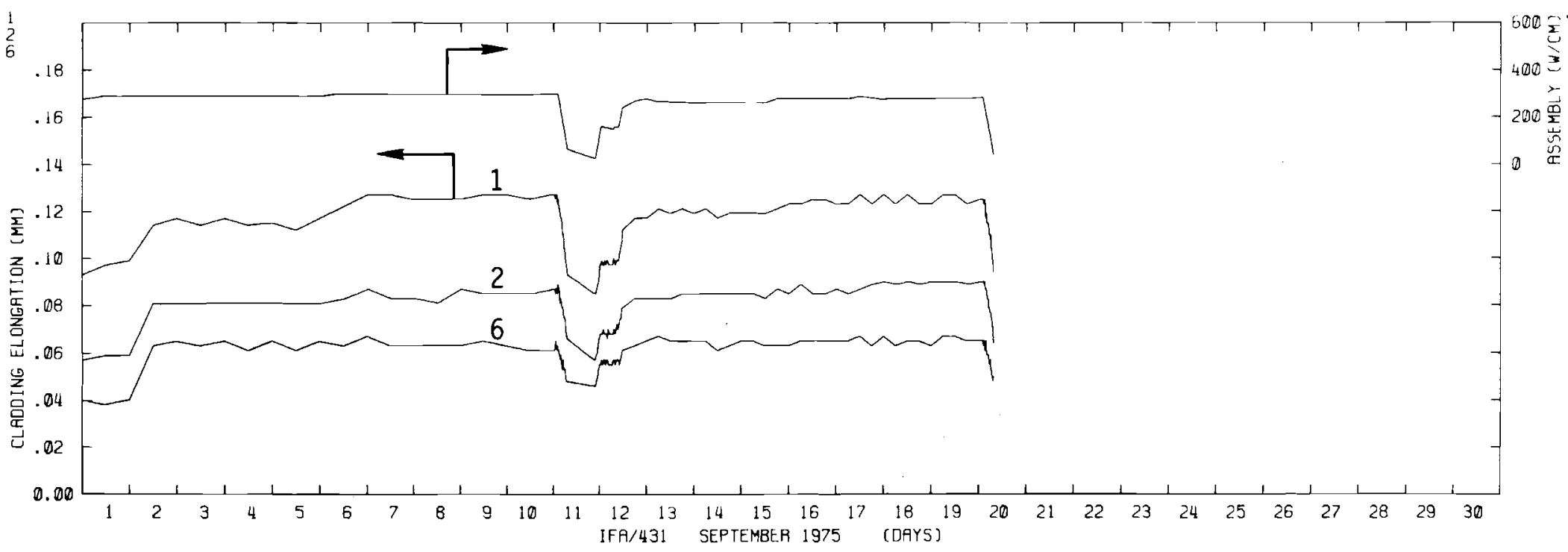

FIGURE 3.92. Cladding Elongation Sensor Readings for Rods 1,2,6 of IFA 431 - September 1975 


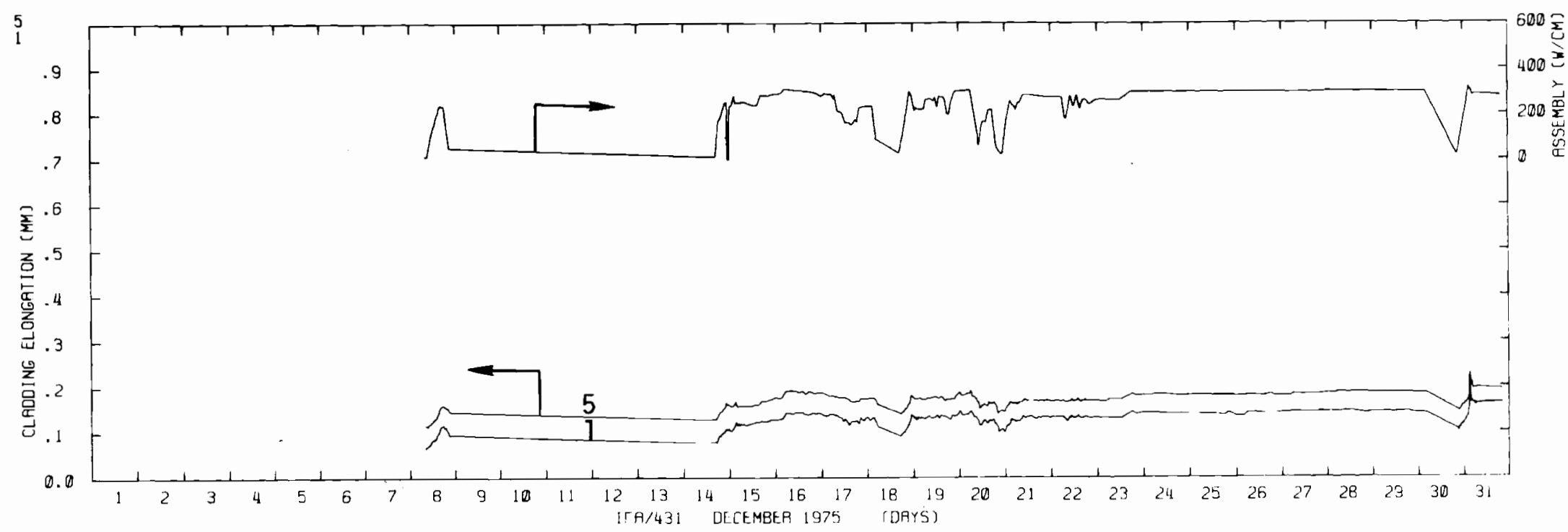

$\omega$
1
0

FIGURE 3.93. Cladding Elongation Sensor Readings for Rods 1,5 of

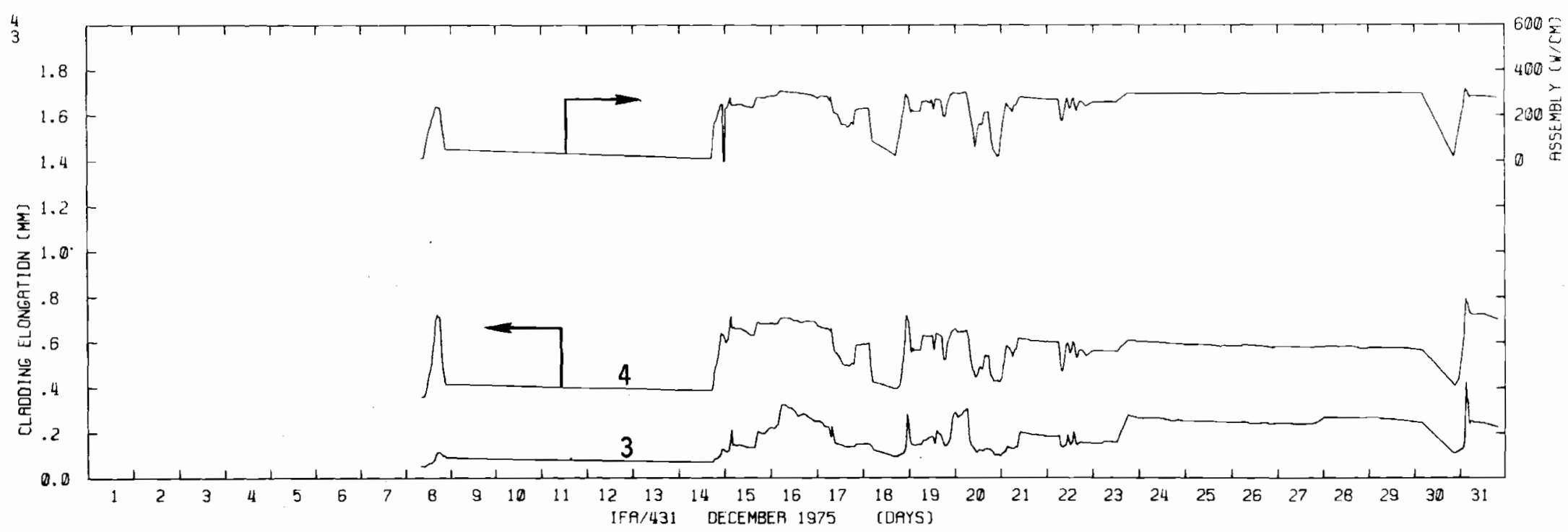

FIGURE 3.94. Cladding Elongation Sensor Readings for Rods 3,4 of IFA 431 - December 1975 


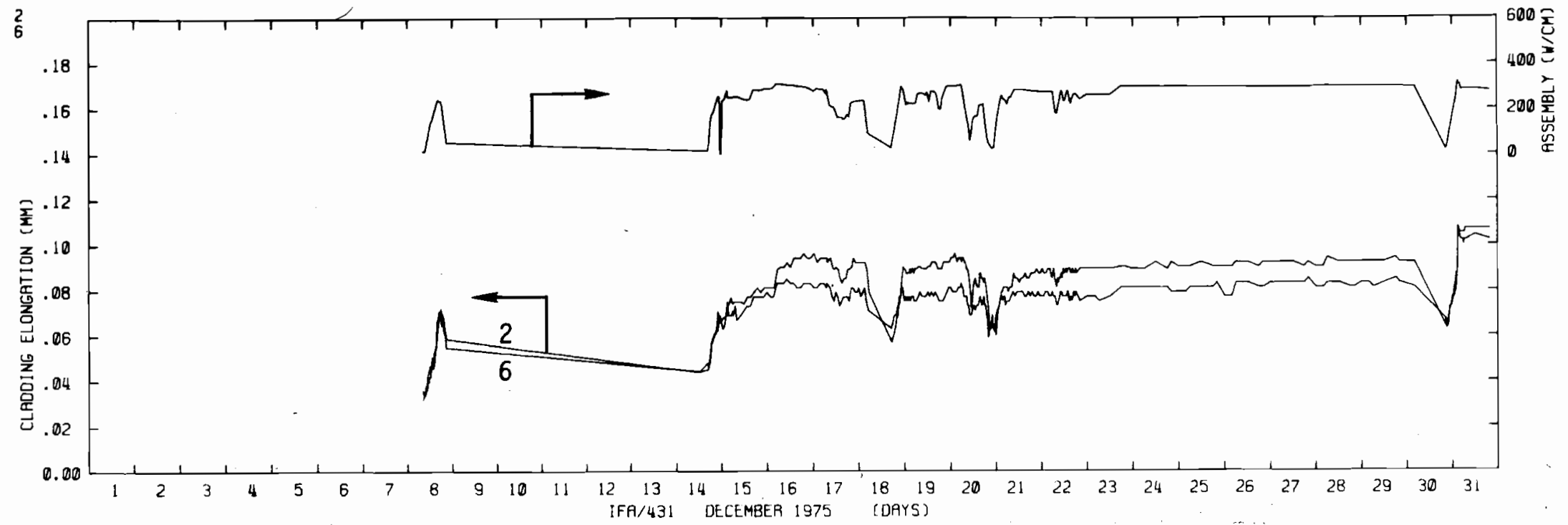

$w$
1
s.

FIGURE 3.95. Cladding Elongation Sensor Readings for Rods 2,6 of

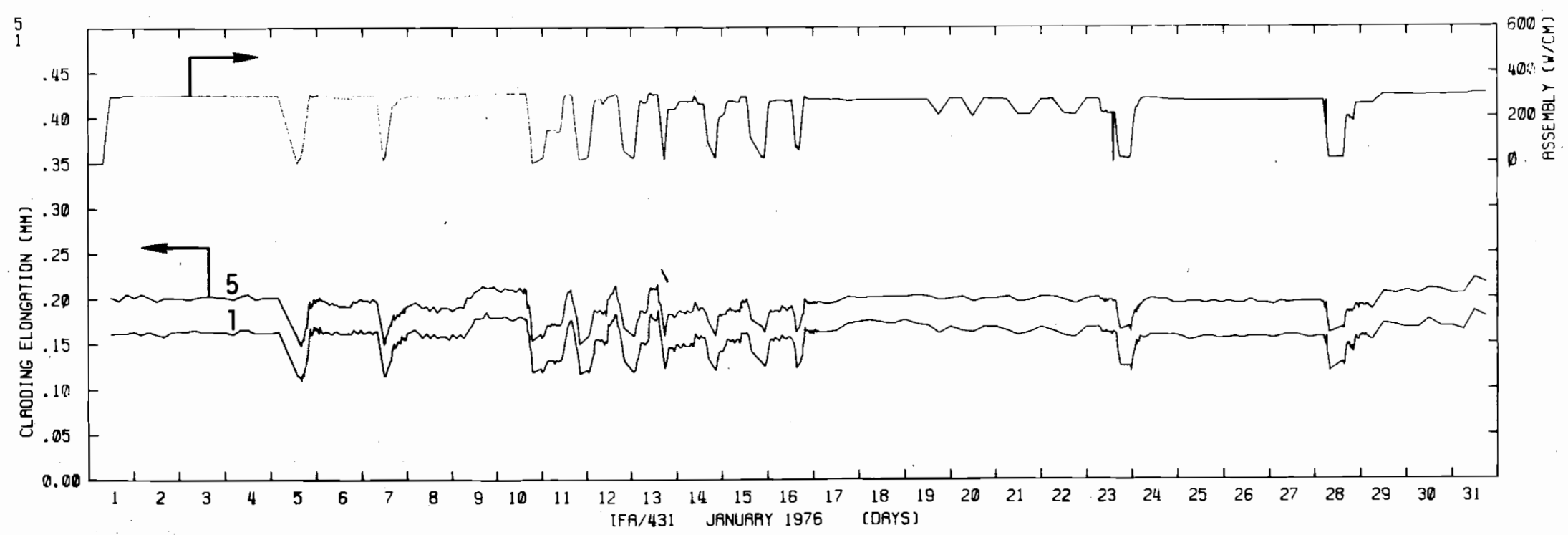

FIGURE 3.96. Cladding Elongation Sensor Readings for Rods 1,5 of IFA 431 - January 1976 


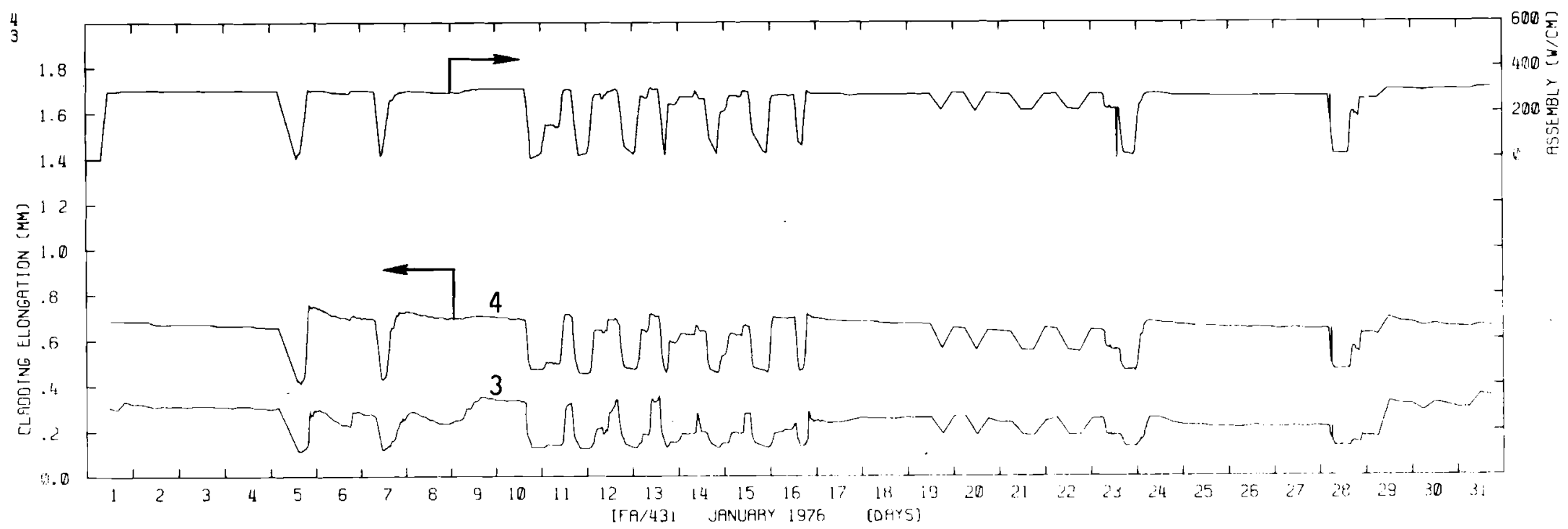

$\omega$
1
s.

FIGURE 3.97. Cladding Elongation Sensor Readings for Rods 3,4 of

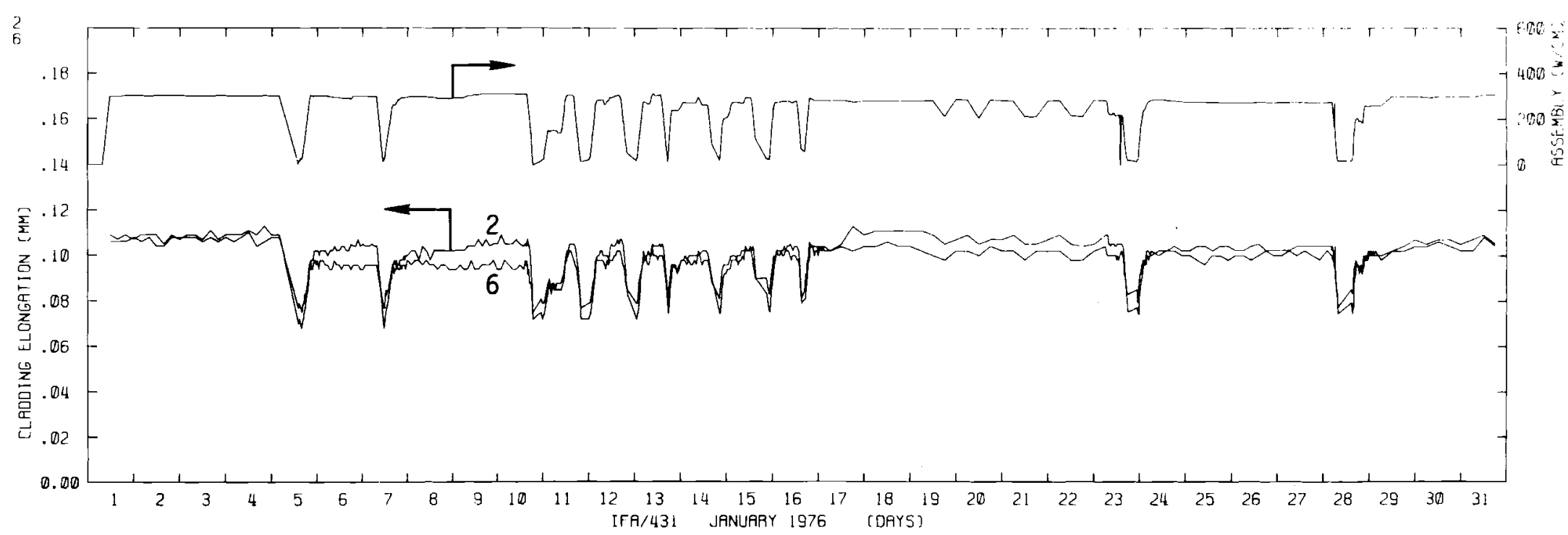

FIGURE 3.98. Cladding Elongation Sensor Readings for Rods 2,6 of IFA 431 - January 1976 


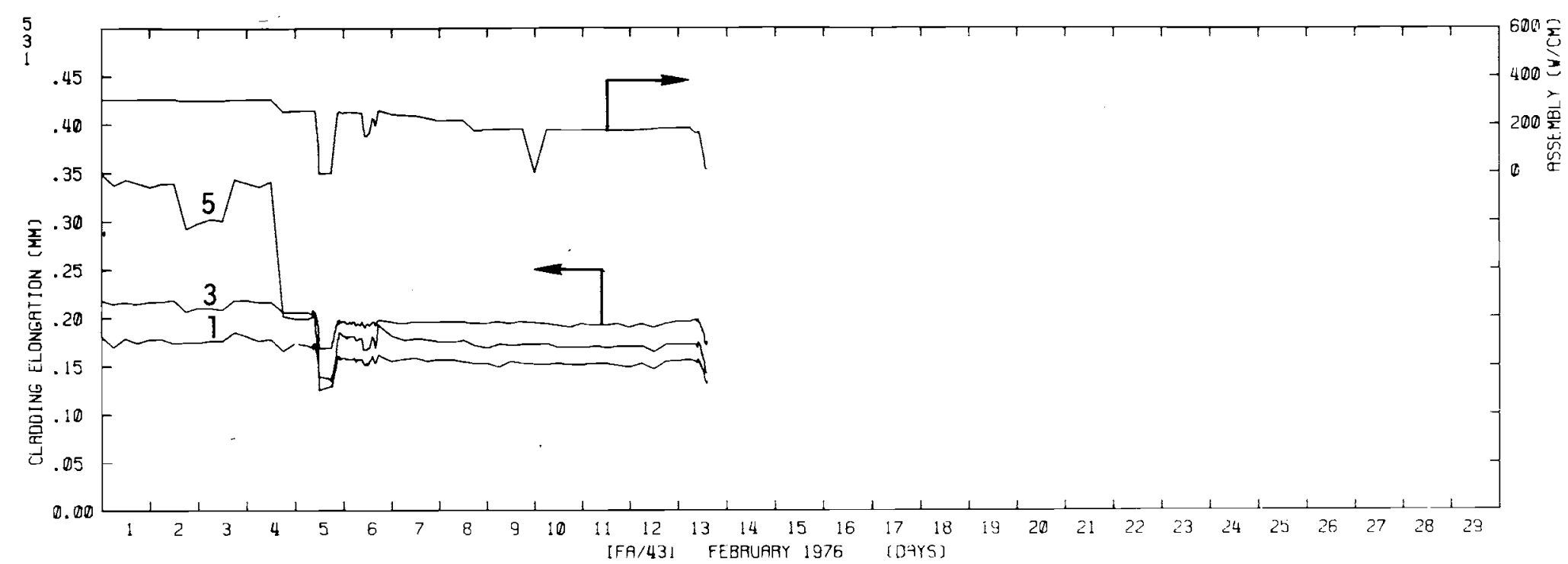

w

FIGURE 3.99. Cladding Elongation Sensor Readings for Rods 1,3,5 of IFA 431 - February 1976

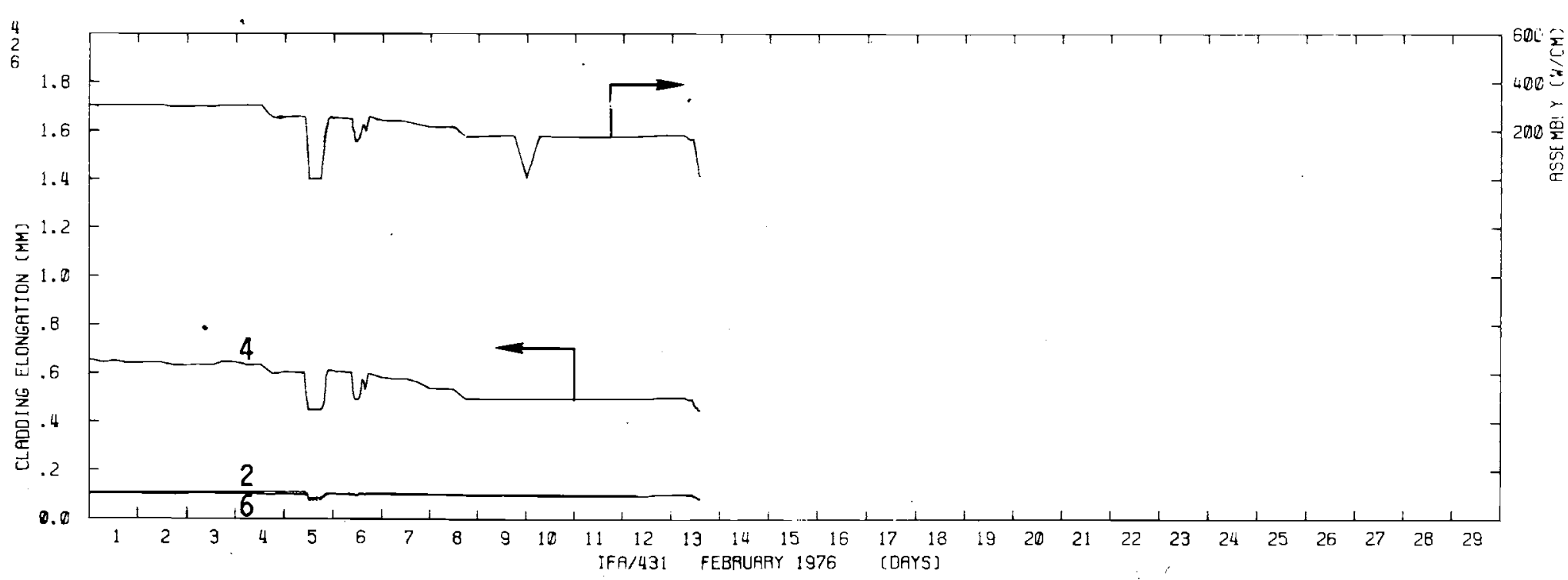

FIGURE 3.100. Cladding Elongation Sensor Readings for Rods 2,4,6 of IFA 431 - February 1976 


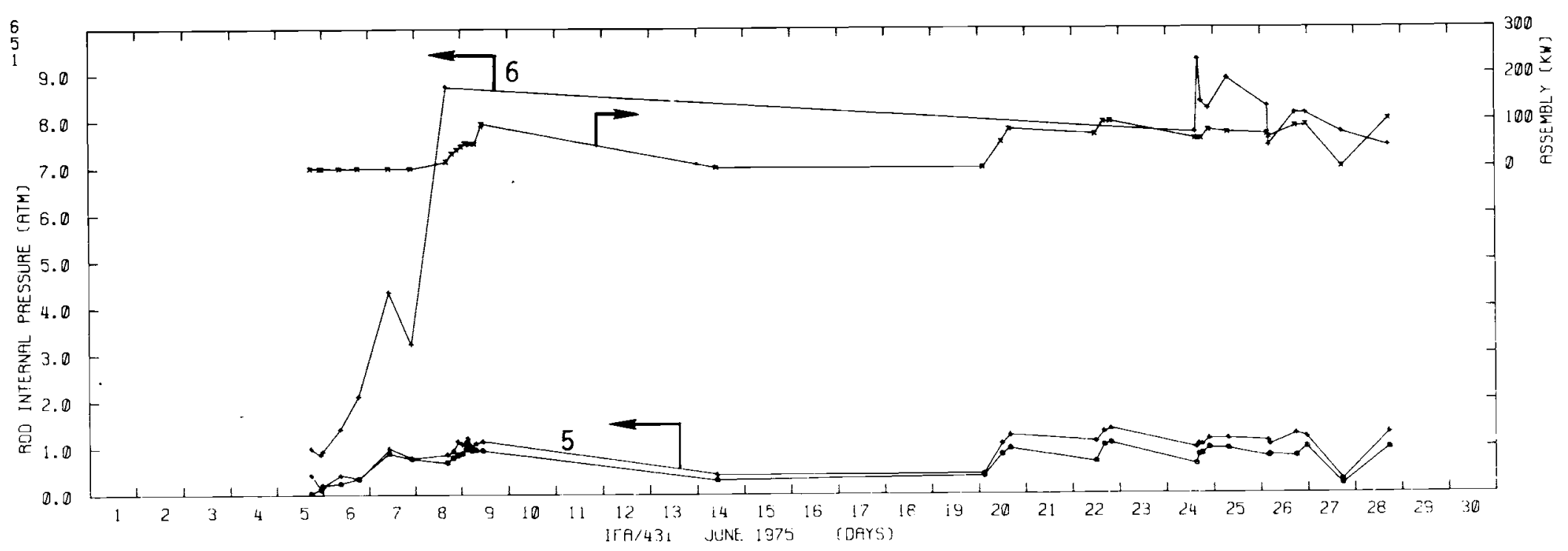

$\omega$
1
$w$

FIGURE 3.101. Internal Pressures for Rods 1,5,6 of IFA 431 - June 1975

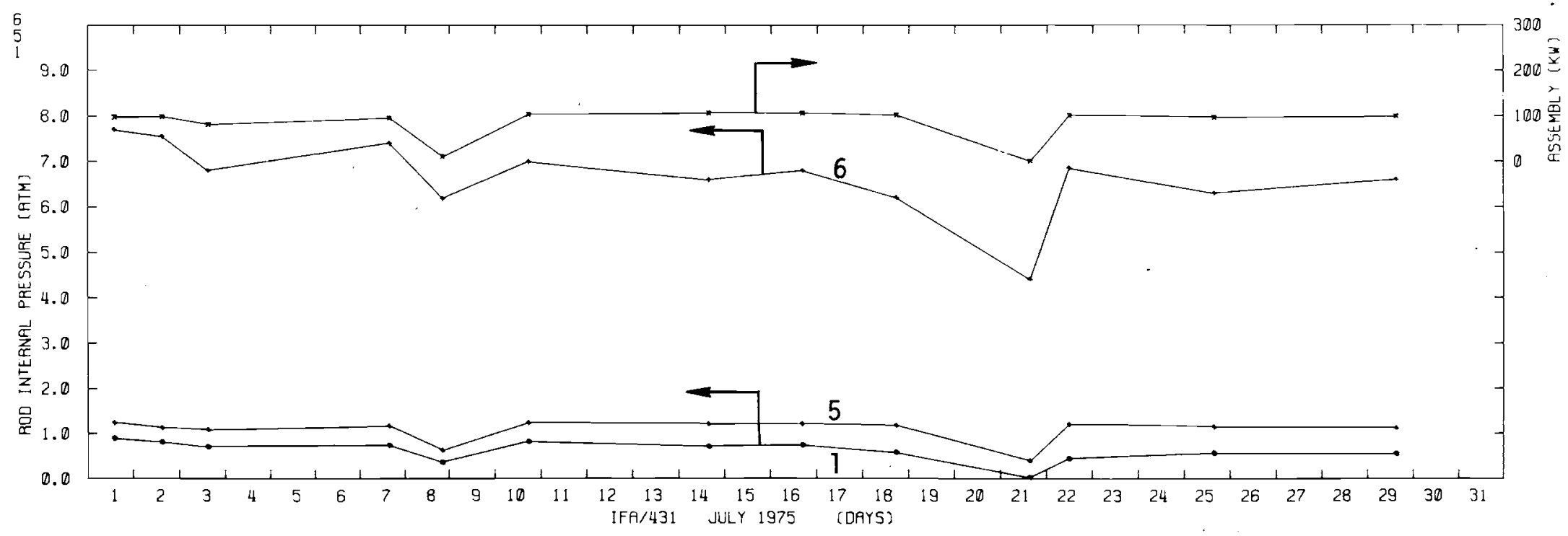

FIGURE 3.102. Internal Pressures for Rods 1,5,6 of IFA 431 - Ju1y 1975 


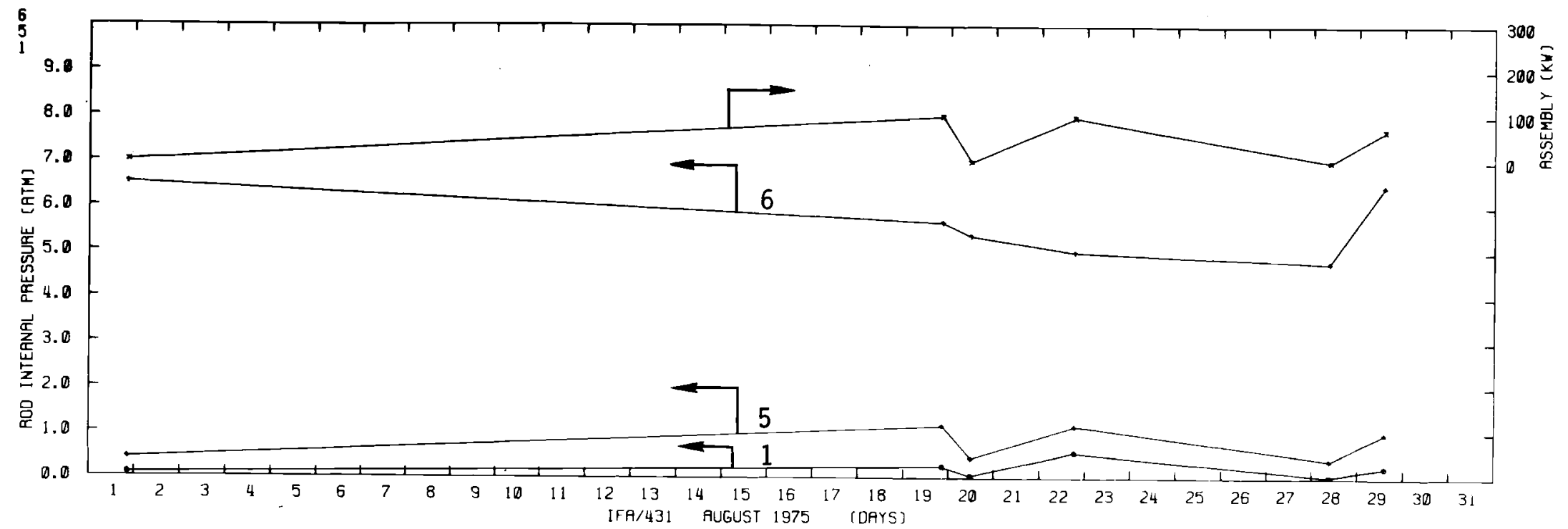

$\underset{\dot{w}}{\dot{w}}$

FIGURE 3.103. Internal Pressures for Rods 1,5,6 of IFA 431 - August 1975

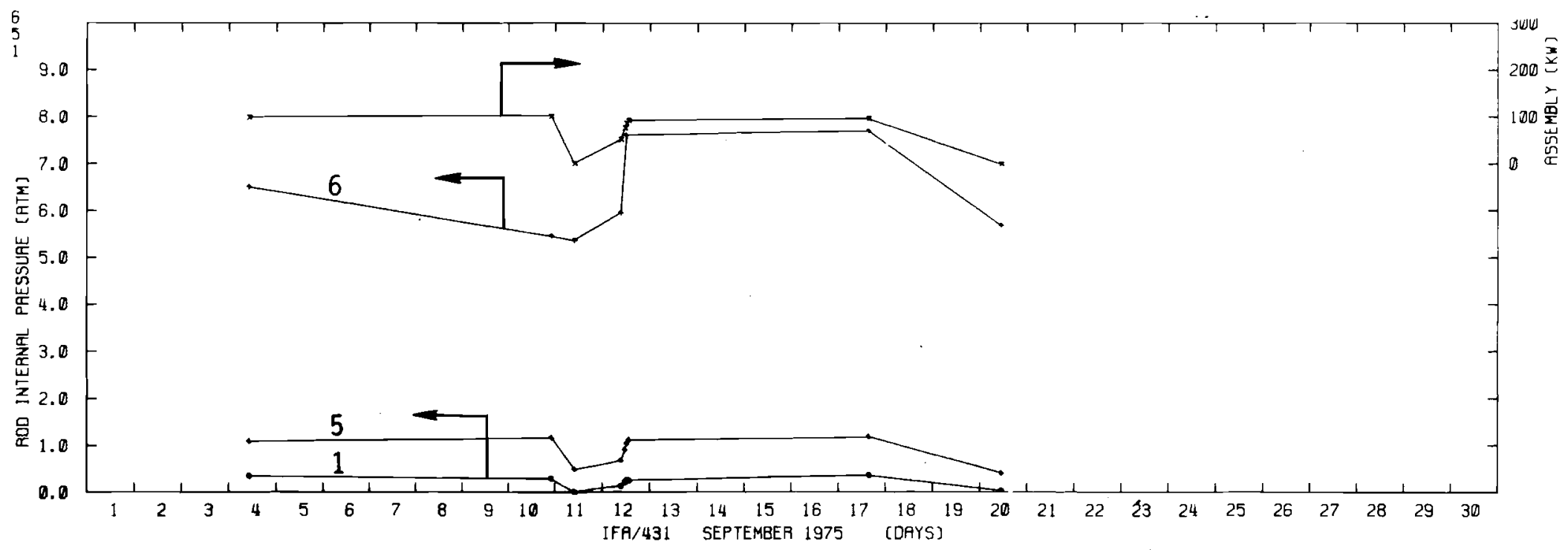

FIGURE 3.104. Internal Pressures for Rods 1,5,6 of IFA 431 - September 1975 


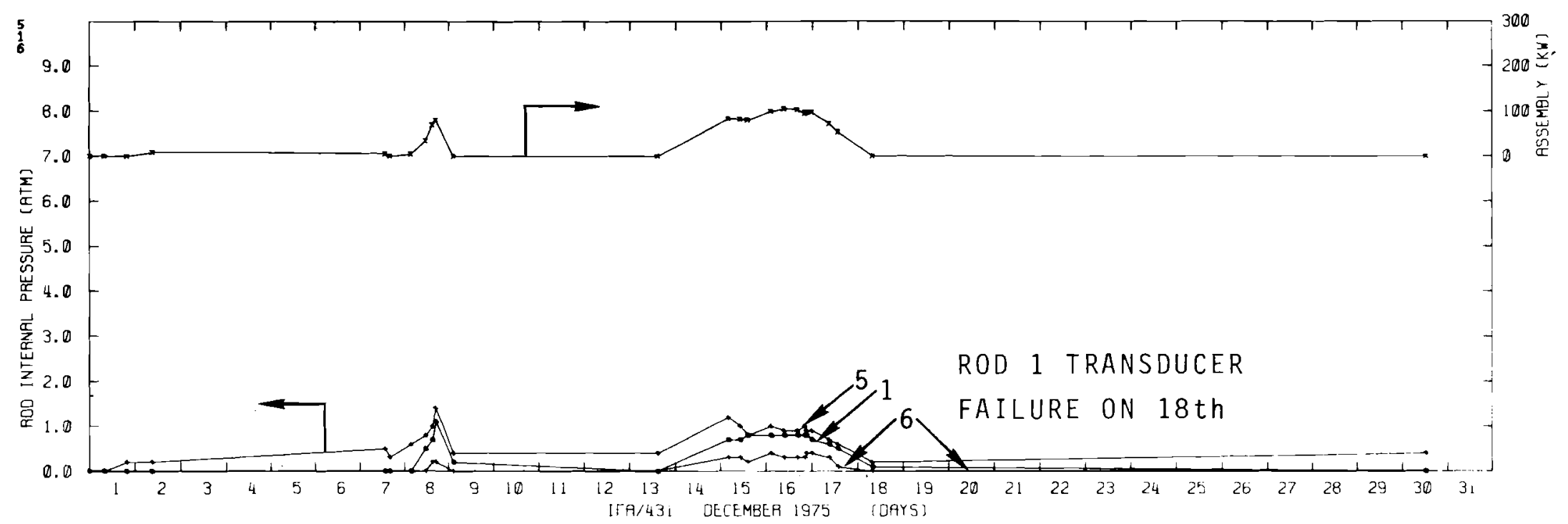

ín

FIGURE 3.105. Internal Pressures for Rods 1,5,6 of IFA 431 - December 1975

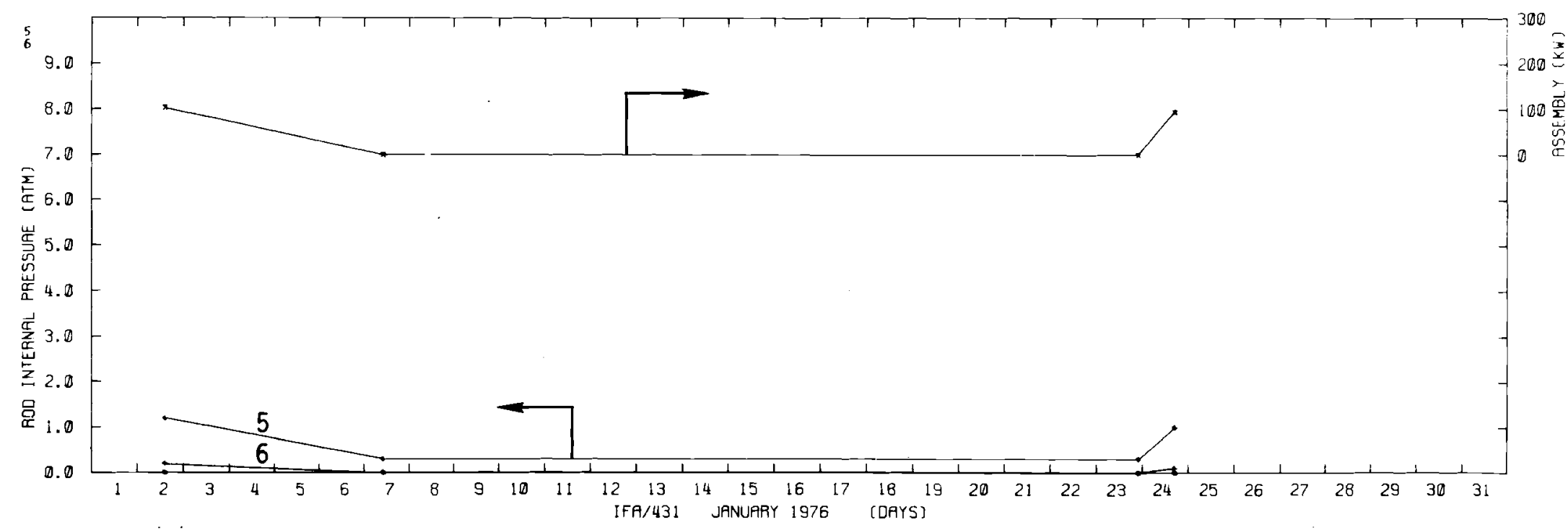

FIGURE 3.106. Internal Pressures for Rods 5,6 of IFA 431 - January 1976 


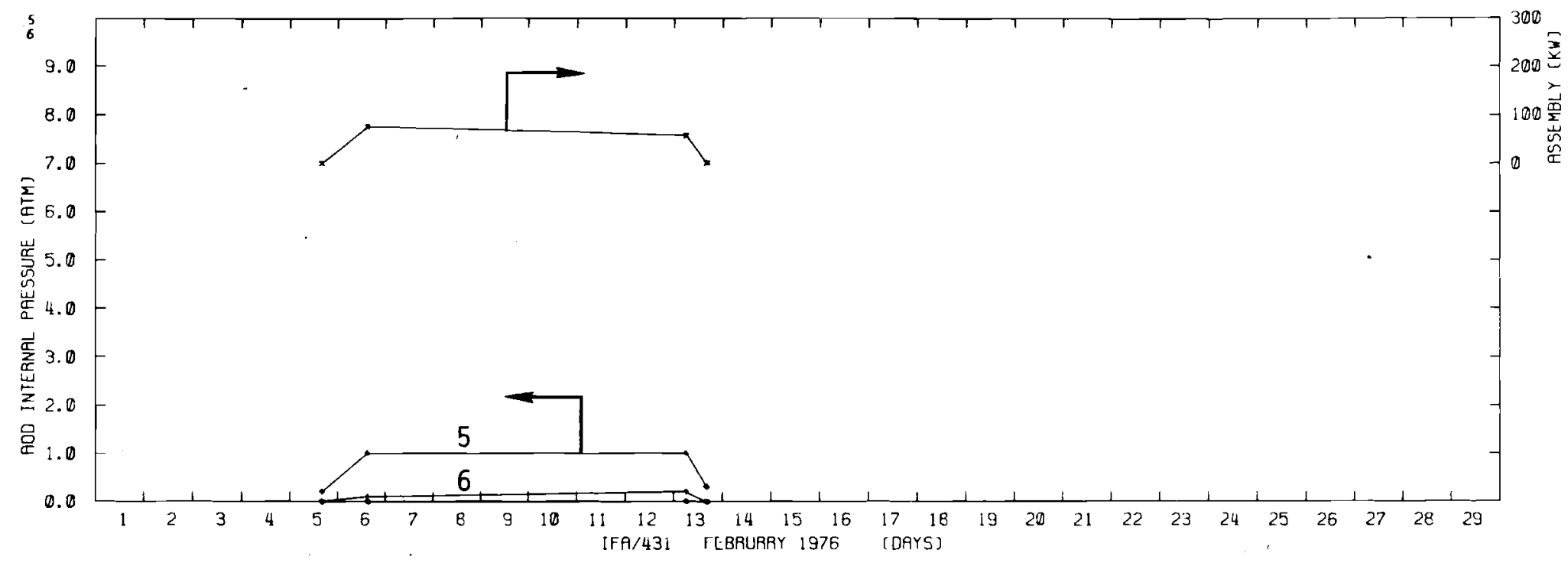

$\omega$
$\dot{d}$

FIGURE 3.107. Internal Pressures for Rods 5,6 of IFA 431 - February 1976 


\section{REFERENCES}

1. D. W. Brite, J. L. Daniel, N. C. Davis, M. D. Freshley, P. E. Hart, and R. K. Marsha11, EEI/EPRI Fuel Densification Project Research Project 131 Final Report prepared for Electric Power Research Instititue by Battelle, Pacific Northwest Laboratories, March 1975, Revised June 1975.

2. Regulatory Staff, U.S. Atomic Energy Commission, Technical Report on Densification of Light Water Reactor Fuels, WASH-1236, November 1972.

3. M. D. Freshley, P. E. Hart, J. L. Daniel, D. W. Brite, and T. D. Chikalla, "The Effect of Pellet Characteristics and Irradiation Conditions on $\mathrm{UO}_{2}$ Fuel Densification." Presented at the ANS/CNA Topical Meeting on "Commercial Nuclear Fue1 - Current Technology," Toronto, Canada, April 1975.

4. A. Hanevik, K. D. Knudsen, and P. Arnesen, "In-Reactor Measurements of Fuel Stack Shortening." Proceedings of the British Nuclear Energy Society Conference, London, England, October 1973.

5. J. A. L. Robertson, SkDe in Fuel Irradiations. CRFD-835, Chalk River, Ontario, Canada, Aprī1 1959.

6. D. D. Lanning and C. R. Hann, Verification of Fuel Centerline Thermocouple Readings Through Response to Linear Power Decreases, BNWL-2189, Batte17e, Pacific Northwest Laboratories, Richland, WA 99352, April 1977.

7. I. Cohen, B. Lustman and J. D. Eichenberg, Measurement of the Therma 1 Conductivity of Metal-Clad Uranium Oxide Rods During Irradiation. WAPD-228, Westinghouse Electric Corporation, Bettis Atomic Power Laboratory, Pittsburgh, PA, August 1960.

8. G. R.Horn, "The Effects of Xenon on Fuel-to-Cladding Gap Conductivity." Trans. ANS, Vol. 12, p. 607, 1969.

9. L. A. Lawrence, G. R. Horn and J. A. Christensen, "Fuel-Clad Gap Conductions in Fast Reactor Fuels." Trans. ANS. Vol. 13, p. 572, 1970.

10. D. J. Bradley and C. R. Hann, An Evaluation of the Discrepancies Between Predicted and Experimental Effects of Xenon and Krypton in Nuclear Fuel Rods. BNWL-1955, Batte17e, Pacific Northwest Laboratories, Richland, WA 9935?, November 1975.

11. R. E. Williford and C. R. Hann, Effects of Fill Gas Composition and Pellet Eccentricity, BNWL-2285, Battelle, Pacific Northwest Laboratories, Richland, WA 99352, July 1977.

12. P. E. Hart and J. L. Daniel, "The Role of Microstructure in Thermal and Irradiation-Induced Densification of $\mathrm{UO}_{2}$ Fuels." Presented at 77 th Annual Meeting of the American Ceramic Society, Washington, D.C., May 3-8, 1975. 
13. Core Performance Branch, U.S. Nuclear Regulatory Commission, The Analysis of Fuel Densification, NUREG-0085, July 1976.

14. "An Acceptable Model and Related Statistical Methods for the Analysis of Fuel Densification," Regulatory Guide 1.126, U.S. Nuclear Regulatory Commission, March 1977.

15. C. R. Hann, J. L. Bates, D. W. Brite, J. L. Daniel, N. C. Davis, P. E. Hart, R. K. Marsha11, G. Mellinger, and R. E. Williford, Test Design, PreCharacterization and Fuel Assembly Fabrication for Instrumented Fuel Assemblies IFA-431 and IFA-432. BNWL-1988, Battelle, Pacific Northwest Laboratories, Richland, WA 99352, November 1977.

16. M. F. Lyons, D. H. Coplin, T. J. Pashos, and B. Weidenbaum, U02 Pellet Thermal Conductivity from Irradiation with Central Melting, GEAP-4624, 1964.

17. C. E. Beyer, C. R. Hann, D. D. Lanning, F. E. Panisko and L. J. Parchen, GAPCON-THERMAL-2: A Computer Program for Calculating the Therma 1 Behavior of an 0xide Fuel Rod. BNWL-1898, Battelle, Pacific Northwest Laboratories, Richland, WA 99352, November 1975.

18. C. R. Hann and R. K. Marshal1, Comparative Analys is of Pellet-Cladding Interaction from IFA-431 and IFA-432 Halden Reactor Tests, BNWL-2240, Battelle, Pacific Northwest Laboratories, Richland, WA 99352, July 1977.

19. C. R. Hann, D. D. Lanning, R. K. Marshall, A. R. 01 sen, and R. E. Williford, A Method for Determining the Uncertainty of Gap Conductance Deduced from Measured Fuel Centerline Temperatures, BNWL-2091, Battelle, Pacific Northwest Laboratories, Richland, WA 99352, February 1977.

20. Magnetic Properties; Metallic Materials for Thermostats, Electrical Resistance, Heating, Contacts; Temperature Measurements; Illuminating Standards. 01-044077-40, 1977 Annual Book of ASTM Standards (part 44), Proposed Standard, pg. 867-873. 
APPENUIX A

FUEL ROD AND FUEL COLUMN

SCHEMATICS FOR IFA-431 


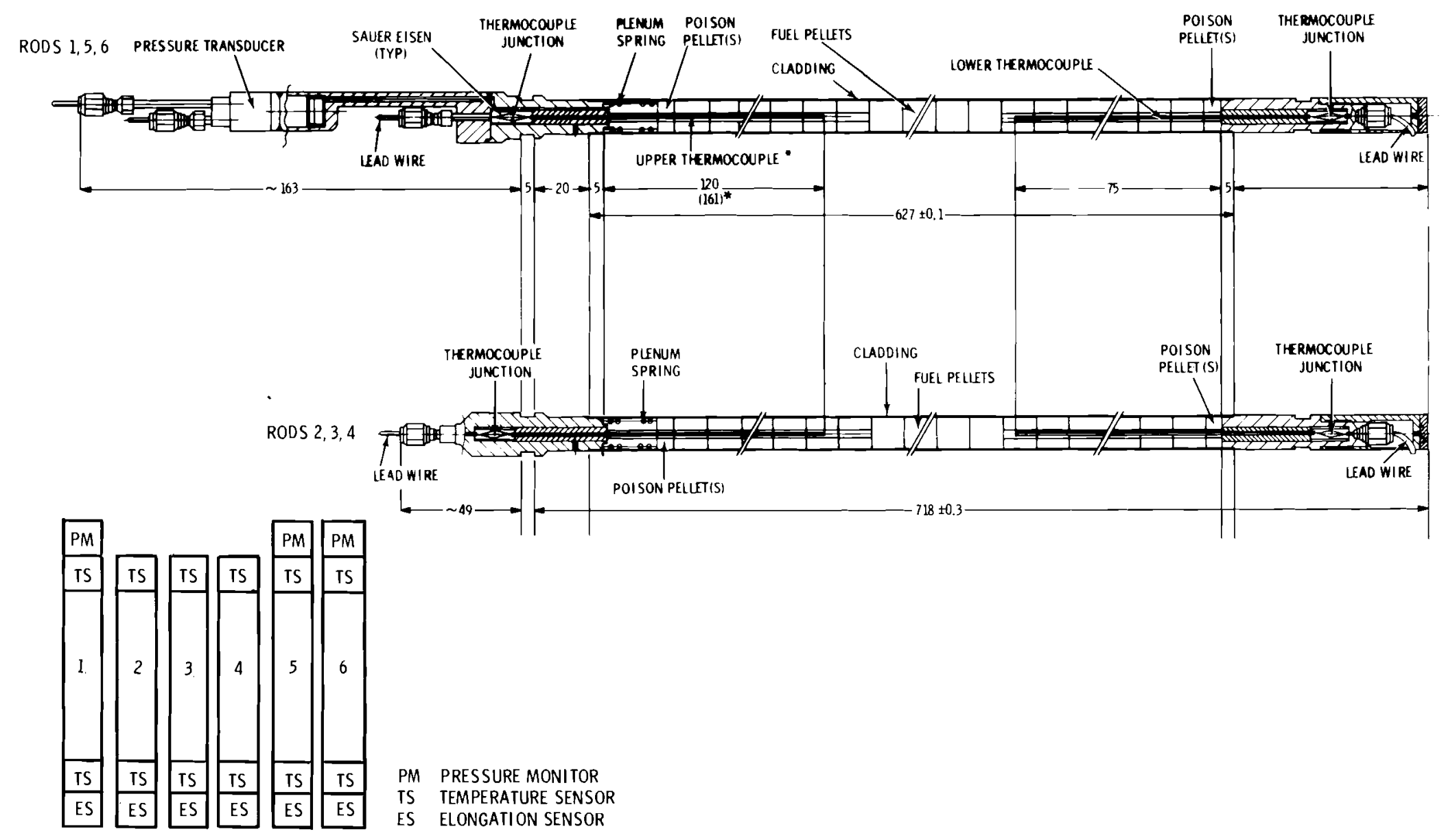

FIGURE A-1. Schematic Arrangement of Fuel Rods for IFA-431 


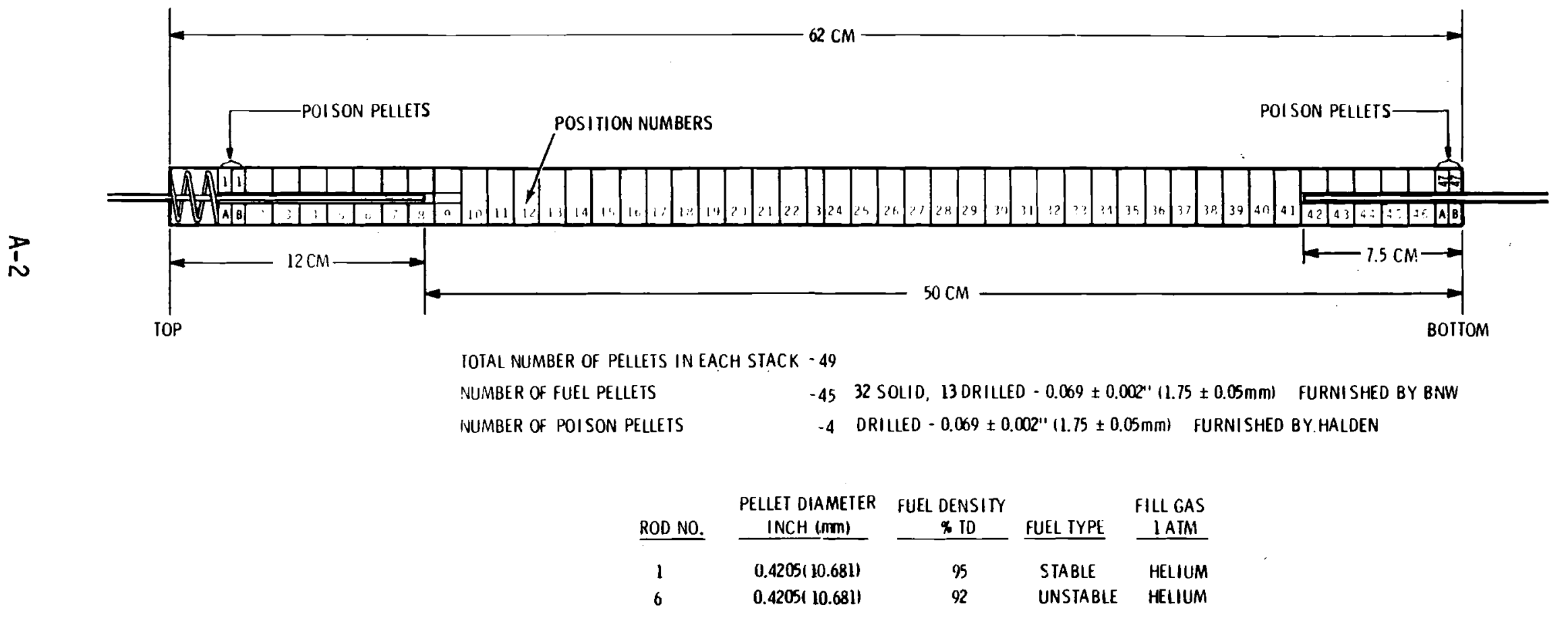

FIGURE A-2. Stack Arrangement for Rods 1 and 6 


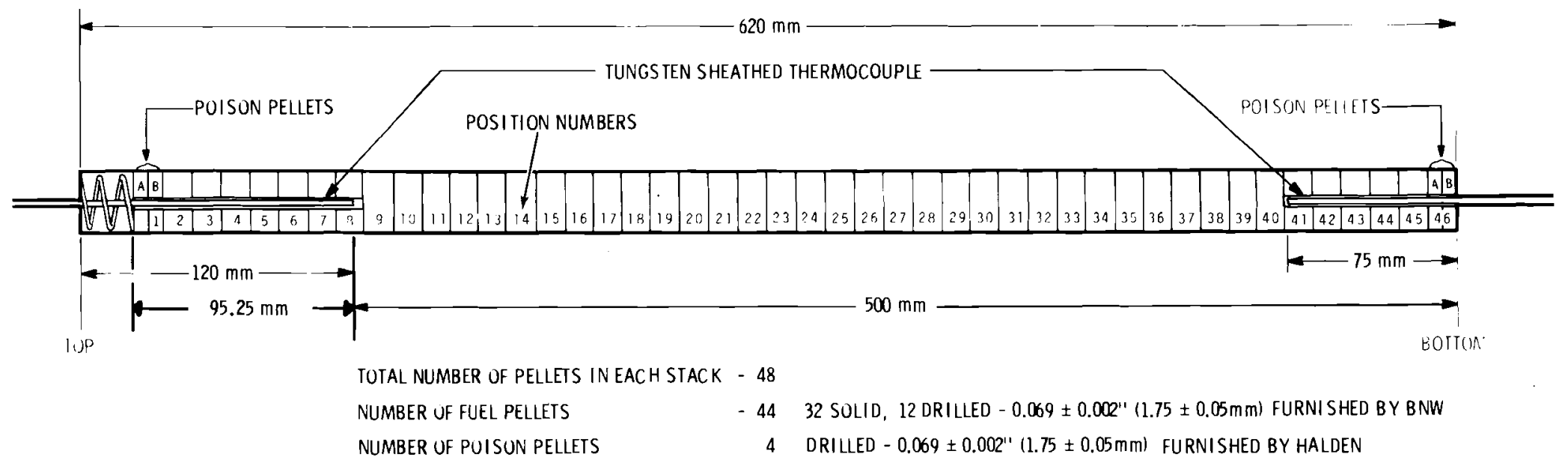

\begin{tabular}{|c|c|c|c|c|}
\hline ROD NU. & $\begin{array}{l}\text { PELLET DIAMEEER } \\
\text { INCH (mm) }\end{array}$ & $\begin{array}{l}\text { FUEL DENSITY } \\
\% \text { TD } \\
\end{array}$ & FUEL TYPE & $\begin{array}{l}\text { FILL GAS } \\
\text { IATM } \\
\end{array}$ \\
\hline 2 & $0.4145(0.528]$ & 95 & STABLE & HELIUM \\
\hline 3 & $0.4275(10.858)$ & 95 & STABLE & HELIUM \\
\hline 5 & $0.4205(10.681)$ & 92 & STABLE & HELIUM \\
\hline
\end{tabular}

FIGURE A-3. Stack Arrangement for Rods 2, 3, and 5 


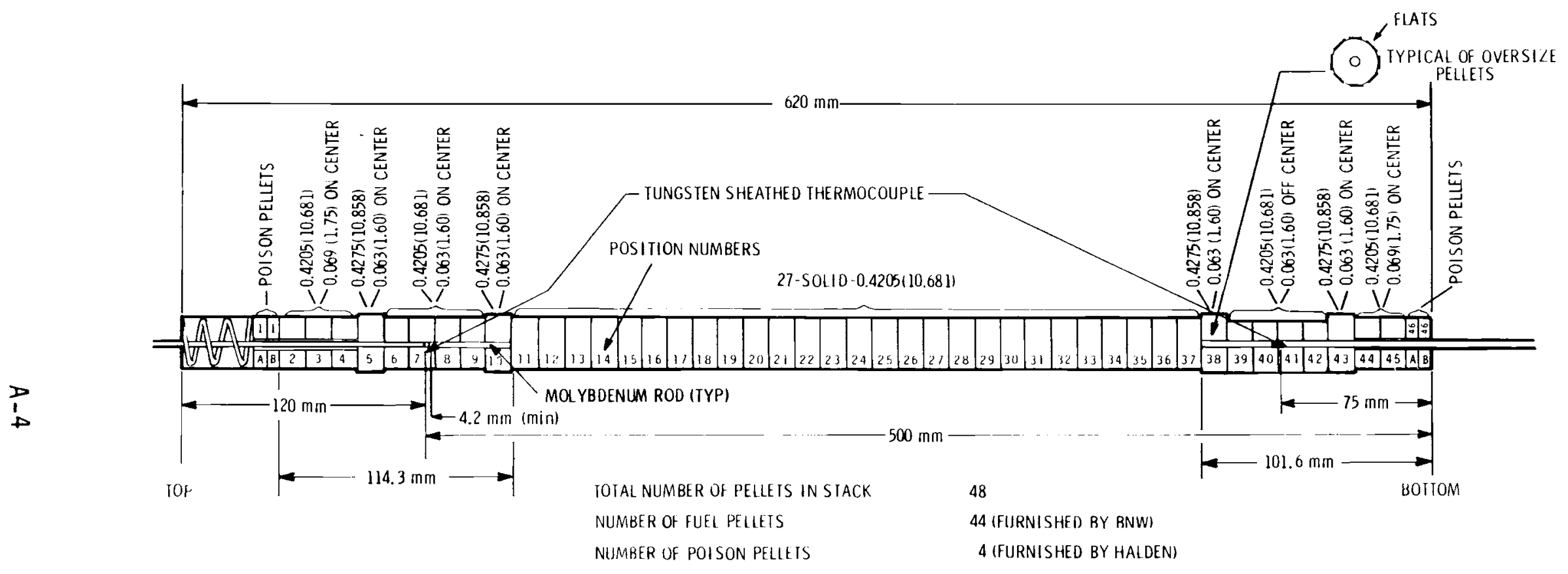

FUEL PELLET DESCRIPIION ANO QUANTITY

\begin{tabular}{|c|c|c|c|c|c|c|}
\hline SOLID & $\begin{array}{l}\text { DIAME TER } \\
\text { INCH (mm) }\end{array}$ & DRILLED & PELLET & HOLE & ON CENTER & $\begin{array}{c}0.005^{11}(0.127 \mathrm{~mm}) \\
\text { OFF CENTER } \\
\end{array}$ \\
\hline \multirow[t]{4}{*}{27} & $0.4205(10.681)$ & 5 & $0.4205(10.681)$ & $0.069 \pm 0.002(1.75 \pm 0.05)$ & YES & -- \\
\hline & & 4 & $0.4205(10.681)$ & $0.063(1.60)$ & YES & - \\
\hline & & 4 & $0.4205(10.681)$ & $0.063(1.60)$ & - & YES \\
\hline & & 4 & $0.4275(10.858)$ & $0.063(1.60)$ & YES & -. \\
\hline
\end{tabular}

FIGURE A-4. Stack Arrangement for Rod 4 - Xenon Fill Gas 
APPENDIX B

INSTRUMENT DESCRIPTIONS AND CALIBRATION 
APPENDIX B

INSTRUMENT DESCRIPTIONS AND

CALIBRATION

IFA-43? was equipped with a comprehensive array of in-pile instrumentation to collect the data. The placement of these instruments was shown in Figures 2.1 and 2.2. The most important of these instruments were:

- Six vanadium beta emitter self-powered neutron detectors

- One cobalt fast response self-powered neutron detector

- Twelve W5\%Re/W26\%Re sheathed fuel centerline thermocouples

- Six LVDT cladding elongation monitors

- Three diaphragm type rod internal pressure transducers.

Each of these is briefly discussed below. The accuracy and uncertainty of their respective outputs is discussed more completely in Reference 19.

\section{NEUTRON DETECTORS}

IFA-431 was equipped with six vanadium, self-powered, beta current neutron detectors (Figure B-1) to monitor the power in the fuel assembly after the initial thermal-hydraulic calibration. One detector failed in the IFA-431 assembly shortly after startup.

Each vanadium neutron detector was $3.93 \mathrm{in}$. (100 mm) long and was positioned so that the center of the detector and the thermocouple junction were located on essentially the same plane.

The neutron detectors used in IFA-431 were not calibrated. Their precisions were based on the results of the irradiation of 30 similar type vanadium neutron detectors in the Studsvik R2-0 Reactor in Sweden. The 30 detectors were irradiated in a thermal neutron flux of $1.1 \times 10^{10} \mathrm{n} / \mathrm{cm}^{2}-\mathrm{sec}$. The error limits for the outputs of the detectors were estimated to be $\pm 2.5 \%$ at a neutron flux of $1.1 \times 10^{10} \mathrm{n} / \mathrm{cm}^{2}-\mathrm{sec}$. 


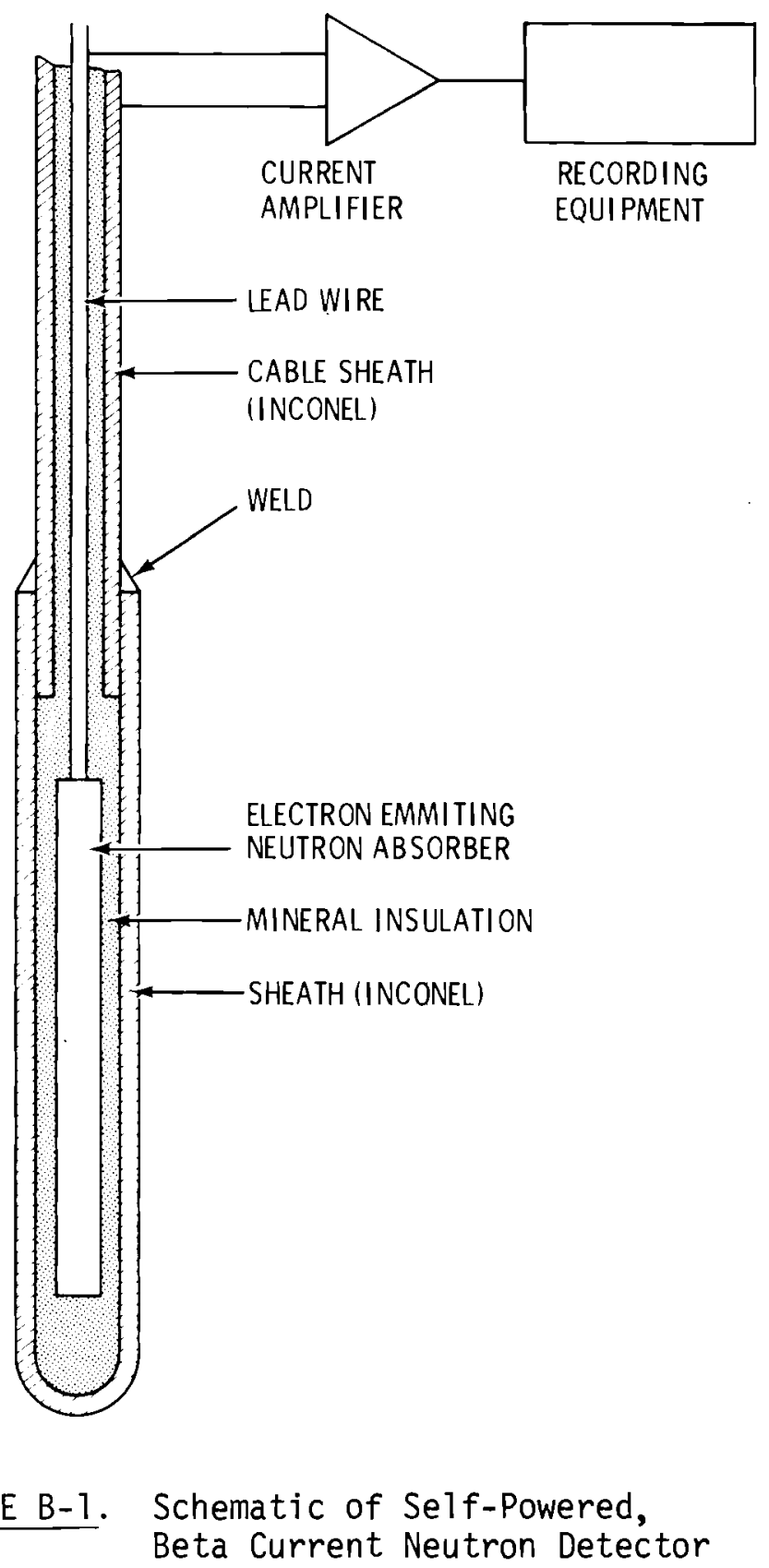


In addition to correlating the detector outputs to the neutron flux in the Studsvik reactor, Halden has conducted long-term tests of similar neutron detectors in the HBWR. These long-term tests have established the detectors as reliable and accurate instruments without a measurable change in sensitivity at the higher flux levels in the HBWR.

The sensitivities of the test assembly neutron detectors were calculated from the sensitivities of the calibrated detectors and the physical characteristics of the test assembly detectors supplied by the manufacturer. The gamma sensitivity is not measured and is considered by Halden to be negligable.

The vanadium detectors have a calculated burnup rate of $0.013 \% /$ month at a neutron flux of $1 \times 10^{13} \mathrm{n} / \mathrm{cm}^{2}-\mathrm{sec}$. Based on this rate, the neutron detector end-of-life (EOL) burnup for IFA-431 is $0.06 \%$. Because of this low value, the neutron detector outputs were not corrected for burnup.

A disadvantage of the vanadium detectors is their slow response time ( $5.5 \mathrm{~min}, 0$ to $63 \%$ ) to power changes. Consequently, during up and down power ramps, a correction factor should be considered for the output values.

The cobalt detector, similar in appearance but $20 \mathrm{~cm}$ long, was placed in the center of the assembly to monitor average assembly power during transient tests. (6)

\section{FUEL THERMOCOUPLES}

Twelve thermocouples were used in IFA-431 for measuring the central fuel temperatures. The thermocouples had grounded junctions with $0.062 \mathrm{in}$. (1.575 mm) OD tungsten/22\% rhenium sheaths and W $5 \%$ Re/W $26 \%$ Re seven-stranded thermocouple wires with beryllium oxide insulators (Figure B-2).

The thermocouples were fabricated and calibrated by the Idaho National Engineering Laboratory (INEL). The calibration curve is shown in Figure B-3. Calibration of the thermocouples over the range of use produces a brittle assembly which is fragile and subject to breakage. Consequently, only one thermocouple, which was not used in the in-reactor test, was calibrated.

The thermocouple was calibrated against a reference thermocouple of bare W $5 \% \operatorname{Re} / \mathrm{W} 26 \% \operatorname{Re}$ and an optical pyrometer as a second reference. The reference 


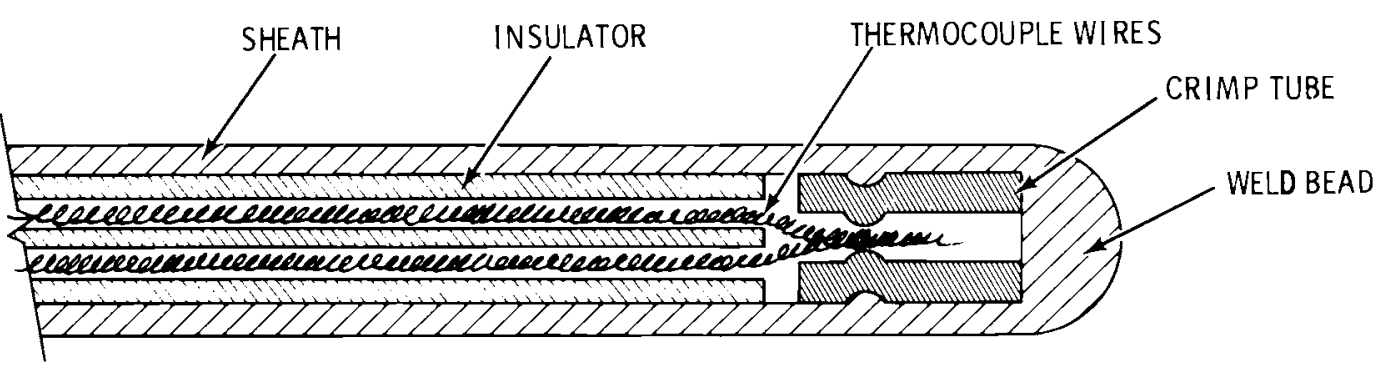

FIGURE B-2. Schematic of W $5 \% \mathrm{Re} / \mathrm{W} 26 \%$ Re Thermocouples with Grounded Junction 


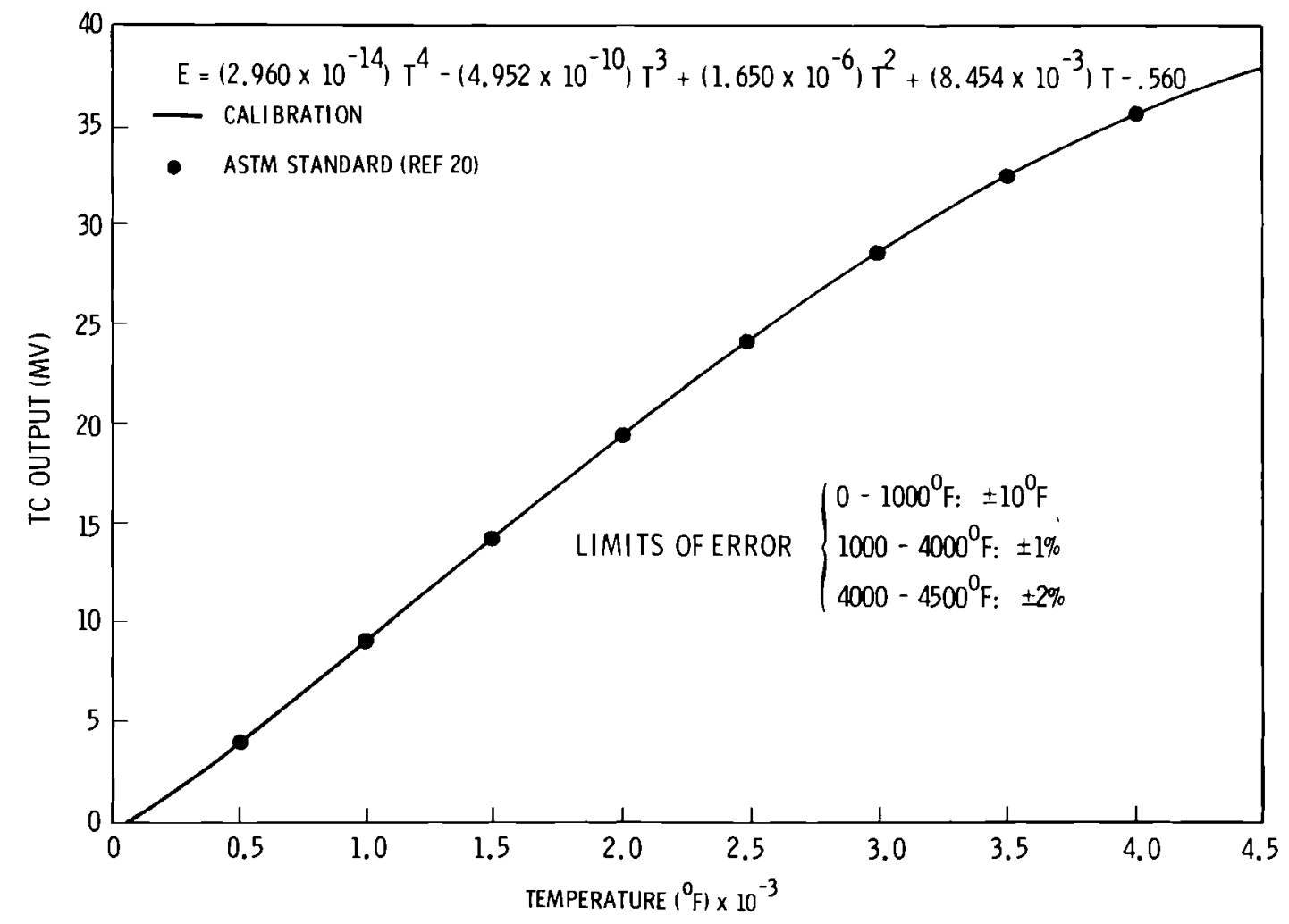

FIGURE B-3. Calibration Curve for W $5 \%$ Re/W $26 \%$ Re Thermocouples 
thermocouple and the optical pyrometer agreed within $40^{\circ} \mathrm{F}\left(22^{\circ} \mathrm{C}\right)$ up to $4000^{\circ} \mathrm{F}$ $\left(2204^{\circ} \mathrm{C}\right)$, but as the temperature approached $4500^{\circ} \mathrm{F}\left(2482^{\circ} \mathrm{C}\right)$, the two differed more widely. The optical pyrometer was thought to be closer since the $4500^{\circ} \mathrm{F}$ temperature is above that given in most calibration tables for $W /$ Re thermocouples. The calibrated thermocouple had the following limits of error:

$$
\begin{array}{ll}
\text { Ambient to } 1000^{\circ} \mathrm{F}\left(538^{\circ} \mathrm{C}\right) & = \pm 10^{\circ} \mathrm{F}\left(5.5^{\circ} \mathrm{C}\right) \\
1000^{\circ} \mathrm{F}\left(538^{\circ} \mathrm{C}\right) \text { to } 4000^{\circ} \mathrm{F}\left(2204^{\circ} \mathrm{C}\right) & = \pm 1 \% \text { of reading } \\
4000^{\circ} \mathrm{F}\left(2204^{\circ} \mathrm{C}\right) \text { to } 4500^{\circ} \mathrm{F}\left(2482^{\circ} \mathrm{C}\right) & = \pm 2 \% \text { of reading. }
\end{array}
$$

Irradiation of the thermocouples will have long term effects caused by the shunting of the EMF's by conduction across the insulators, by transmutations in the thermocouple materials, and by temperature gradients along the thermocouple wires. The insulator shunting effect was reduced to a negligible level by using beryllium oxide insulators.

The expected fluence for IFA-431 is about $1 \times 10^{20}$ nvt. This fluence would indicate a downward EMF drift of 1\% for IFA-431 at EOL. No correction factor is applied to the IFA-431 data. However, an error value of $\pm 1 \%$ is assumed for the irradiation effects.

\section{CLADDING ELONGATION MONITORS}

Figure B-4 is a schematic of the LVDT cladding elongation sensors used in IFA-431. These instruments are mounted upside down at the bottom of the assembly, the core extension contacting the lower end plug of the rod. The ferromagnetic core is attached to the extension and moves inside a coil system with the central primary coil carrying $50 \mathrm{~mA} 400 \mathrm{~Hz}$ excitation. A secondary coil consisting of two balanced halves flanks the primary coil. The output voltage is zero when the core is in its central position, and increases linearly when the cladding elongation moves the core.

Routine out-of-pile calibrations produced the curves shown in Figures B-5 through B-10. In-pile calibration consists of zeroing out the instrument output electronically during natural circulation at zero nuclear power. The coolant is electrically heated during this time. This is discussed in Reference 18. 


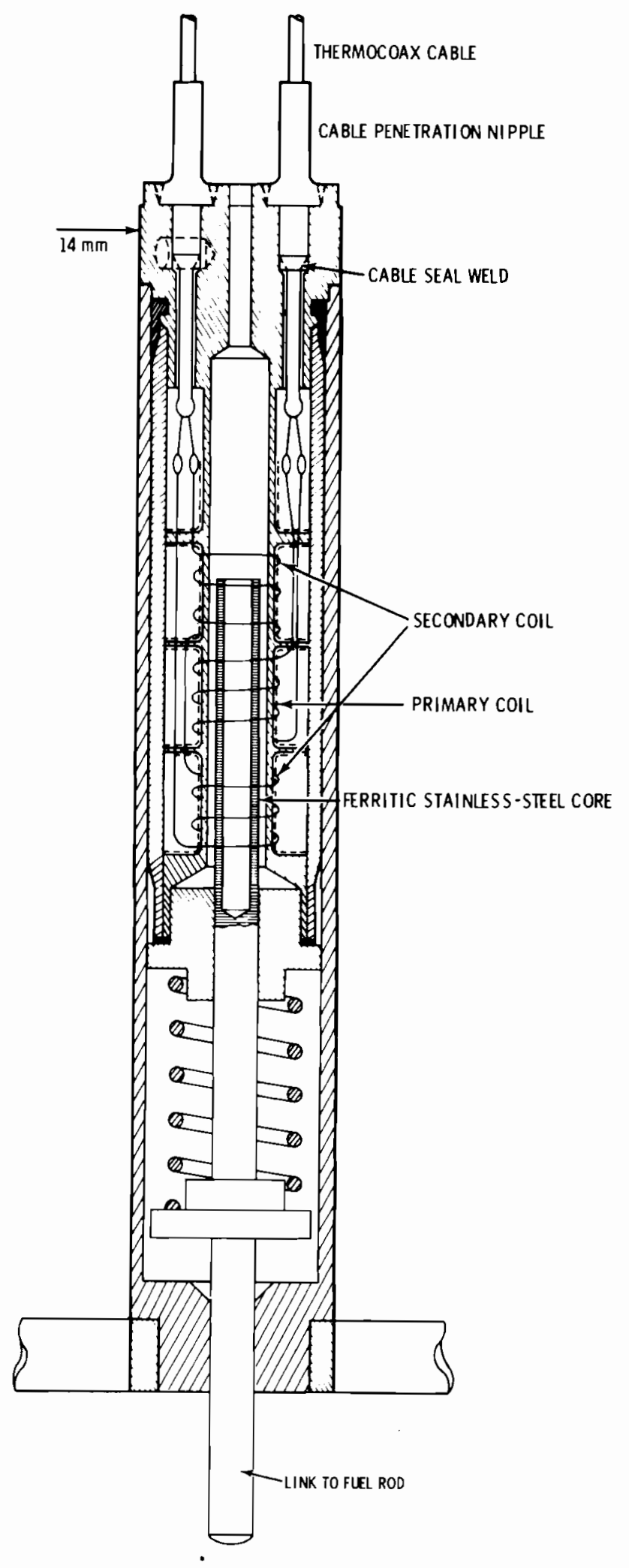

FIGURE B-4. Cladding Elongation Monitor (Ha1den Project Design) 


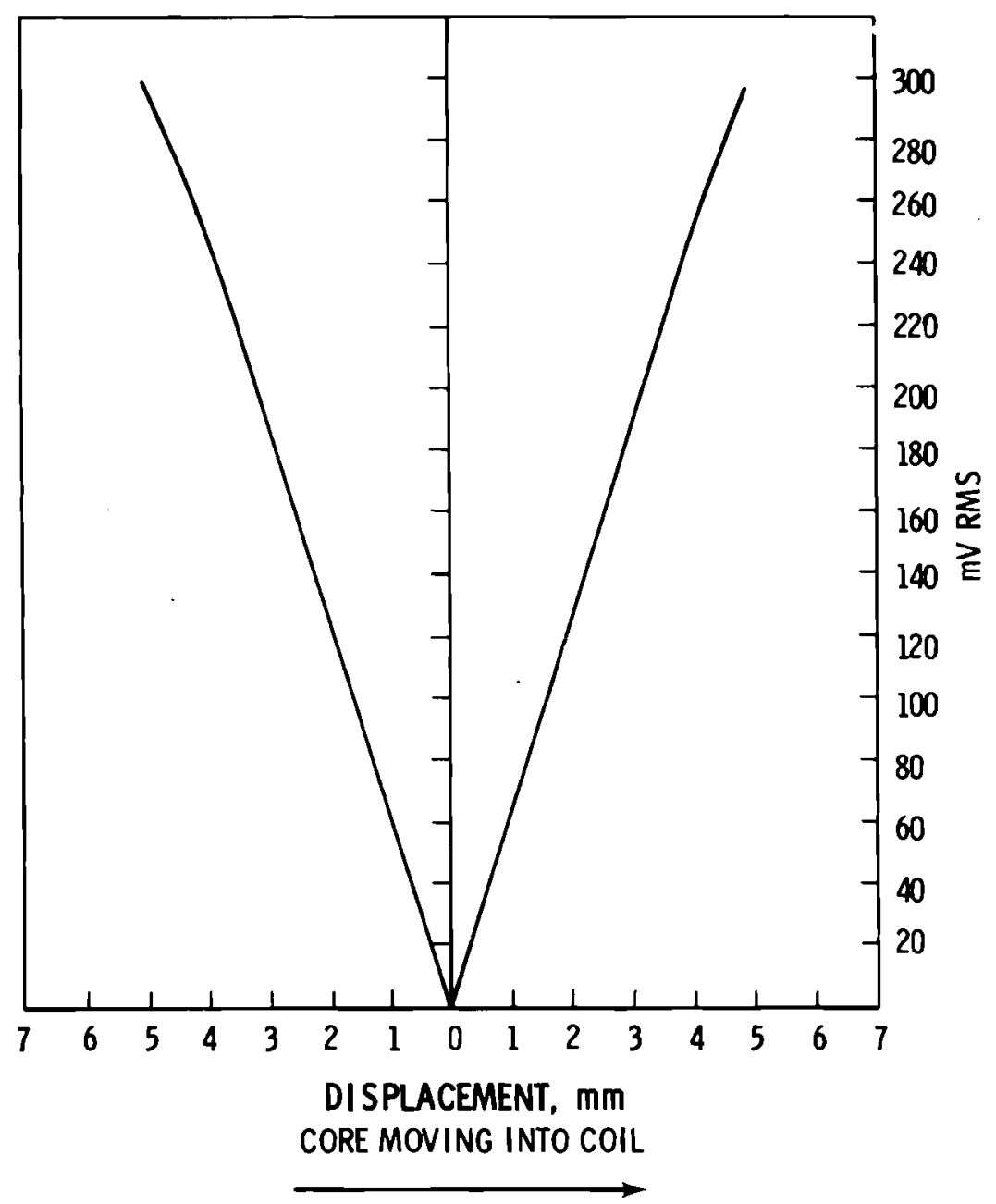

FIGURE B-5. Rod 1 Extensometer Calibration Curve 


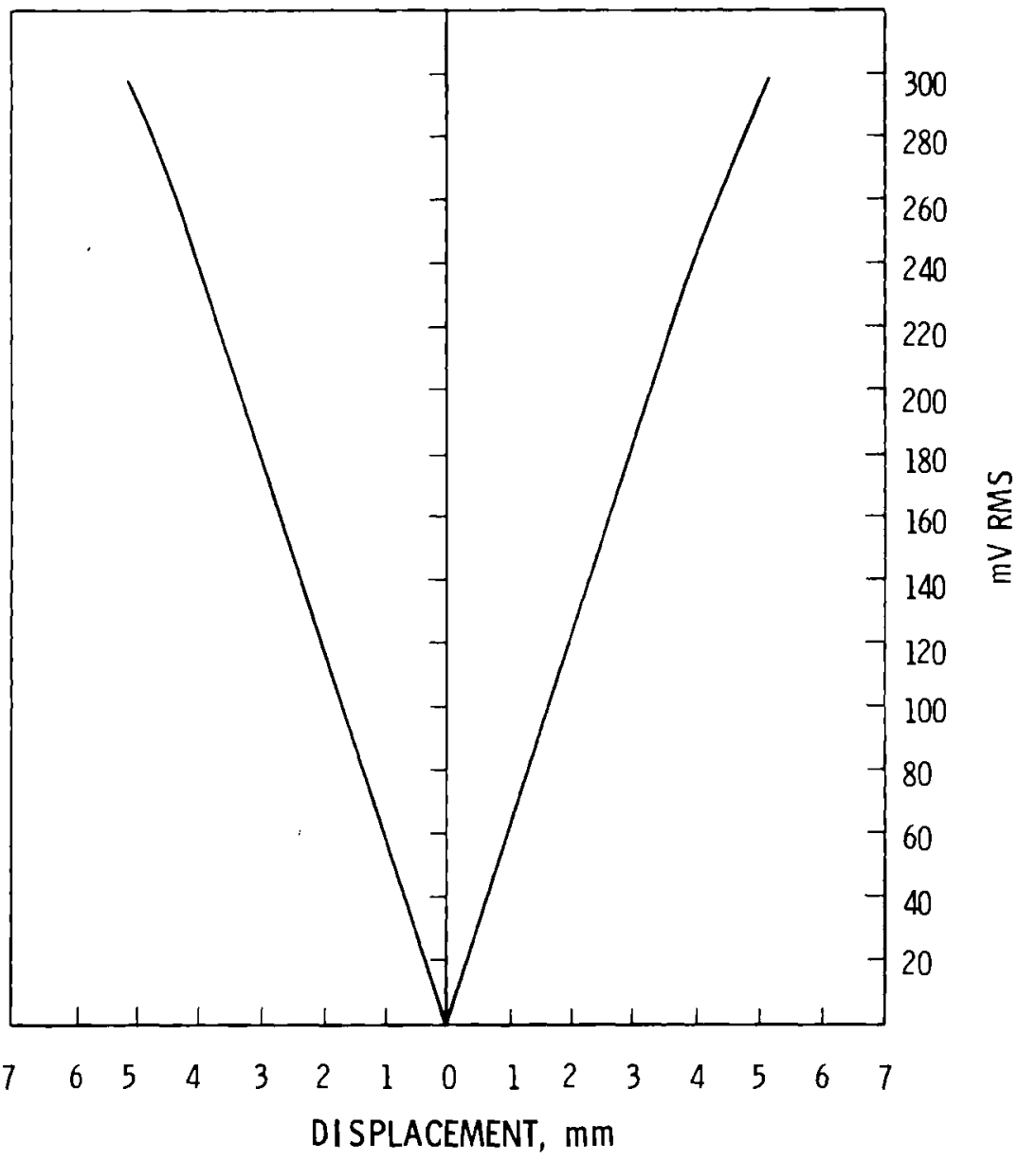

CORE MOVING INTO COIL

FIGURE B-6. Rod 2 Extensometer Calibration Curve 


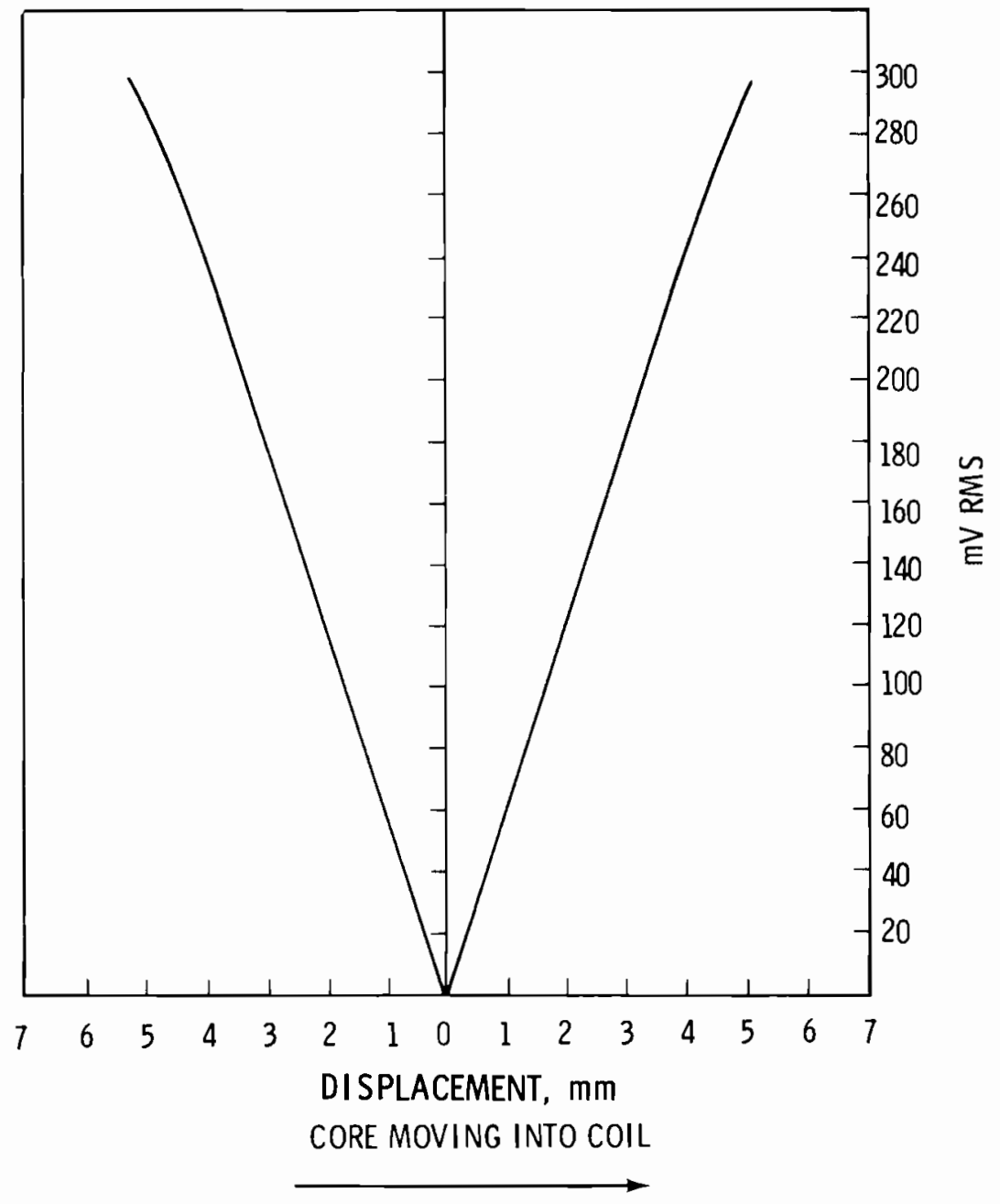

FIGURE B-7. Rod 3 Extensometer Calibration Curve 


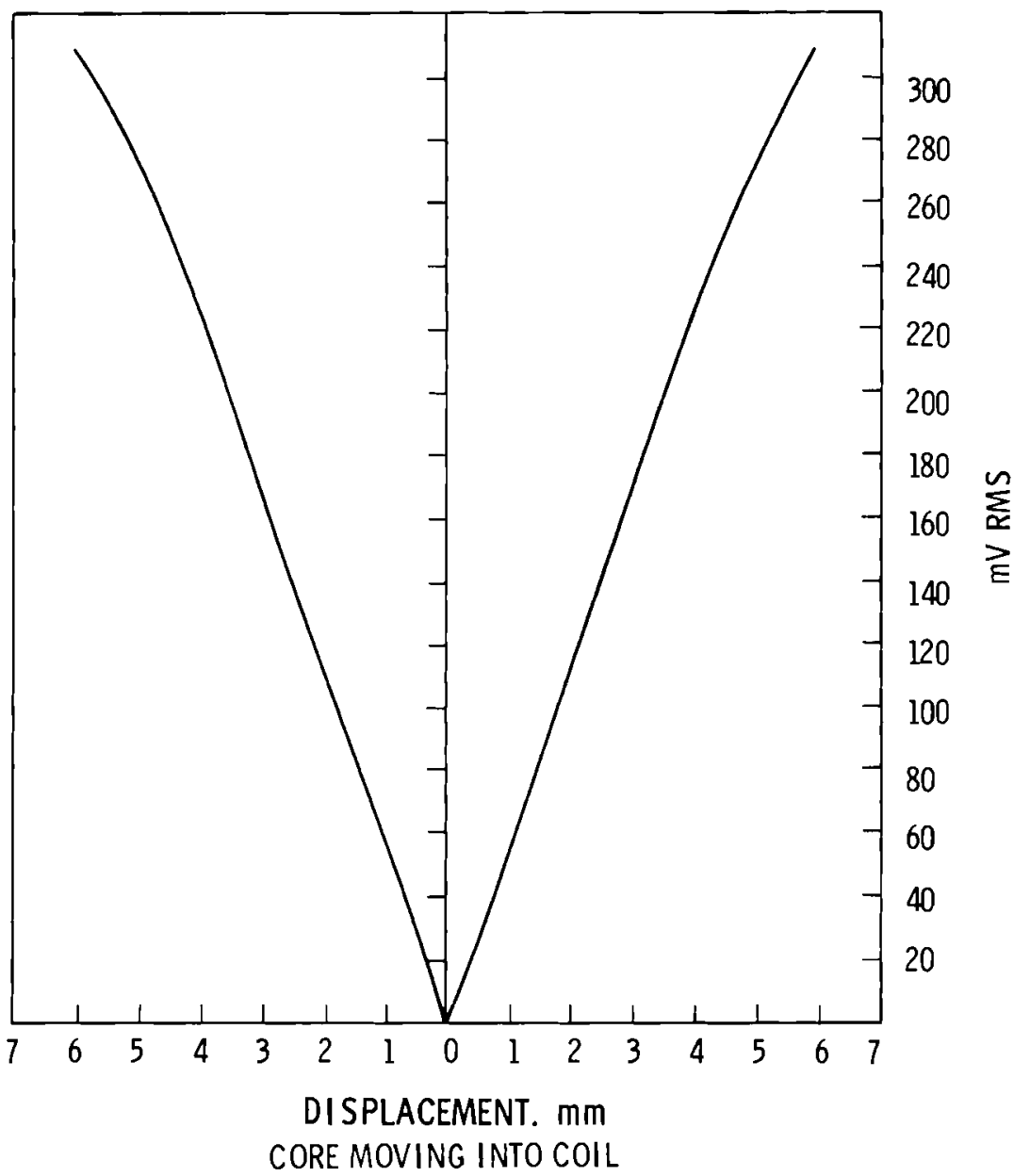

FIGURE b-8. Rod 4 Extensometer Calibration Curve 


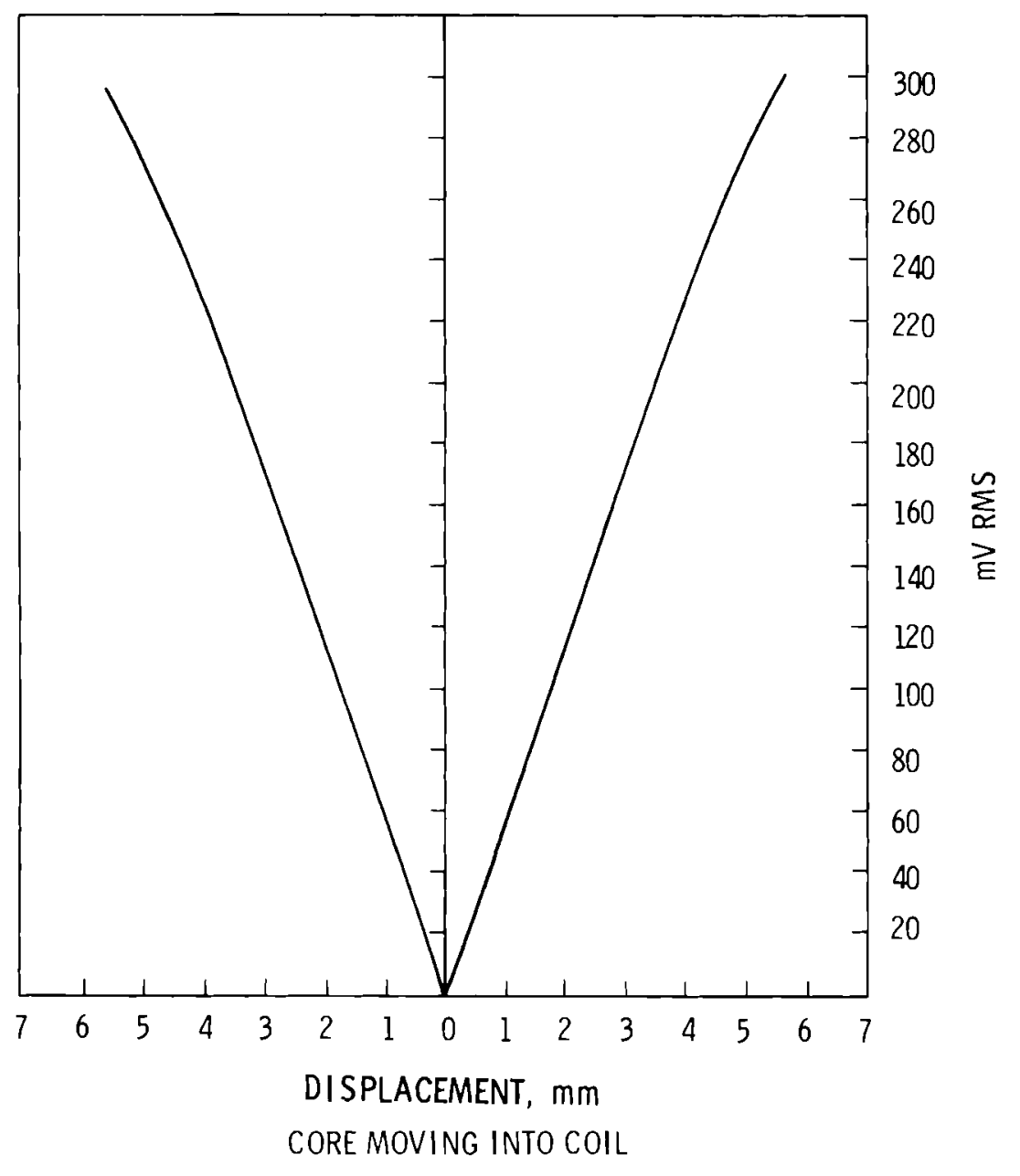

FIGURE B-9. Rod 5 Extensometer Calibration Curve 


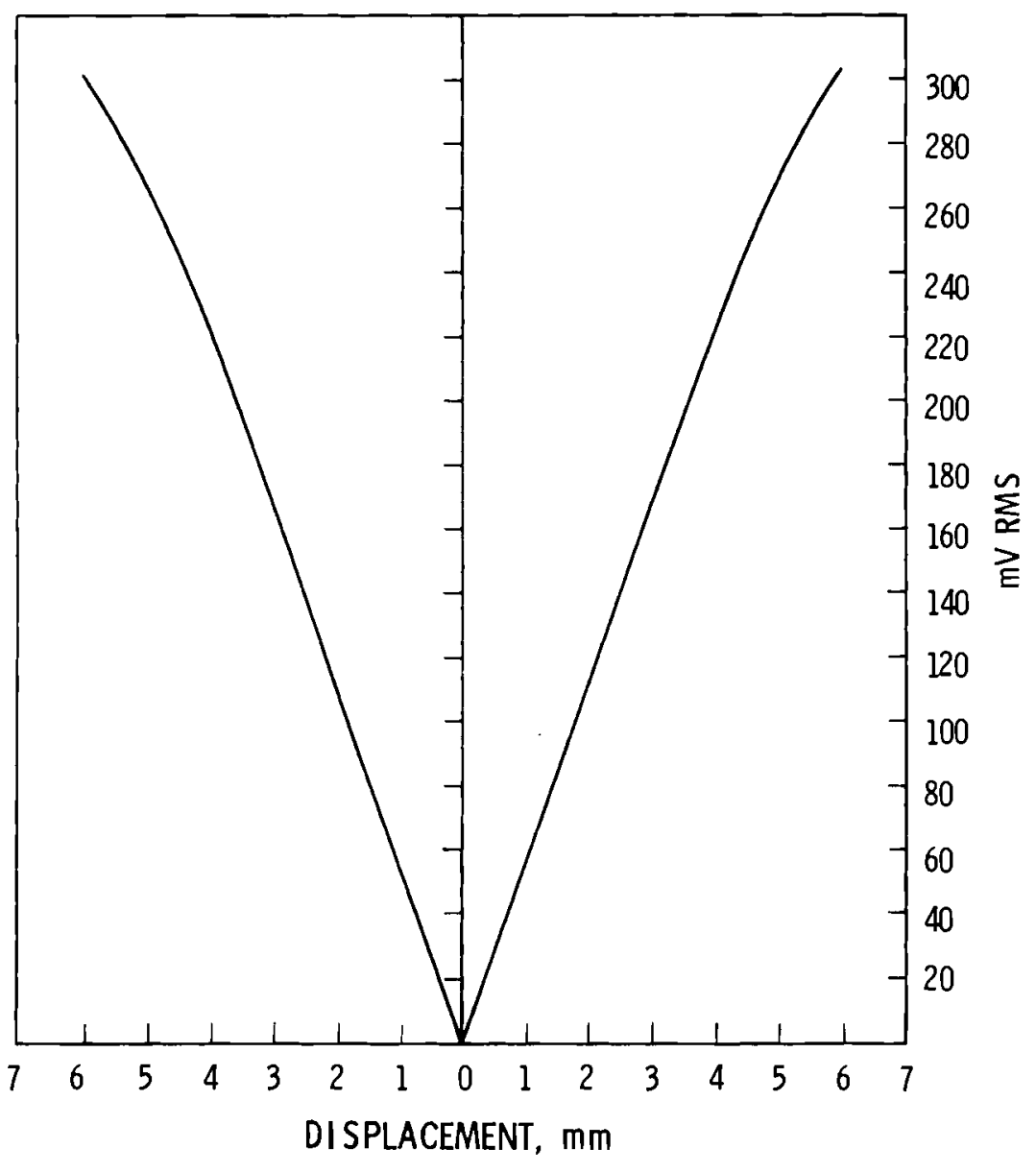

CORE MOVING INTO COIL

FIGURE B-10. Rod 6 Extensometer Calibration Curve 


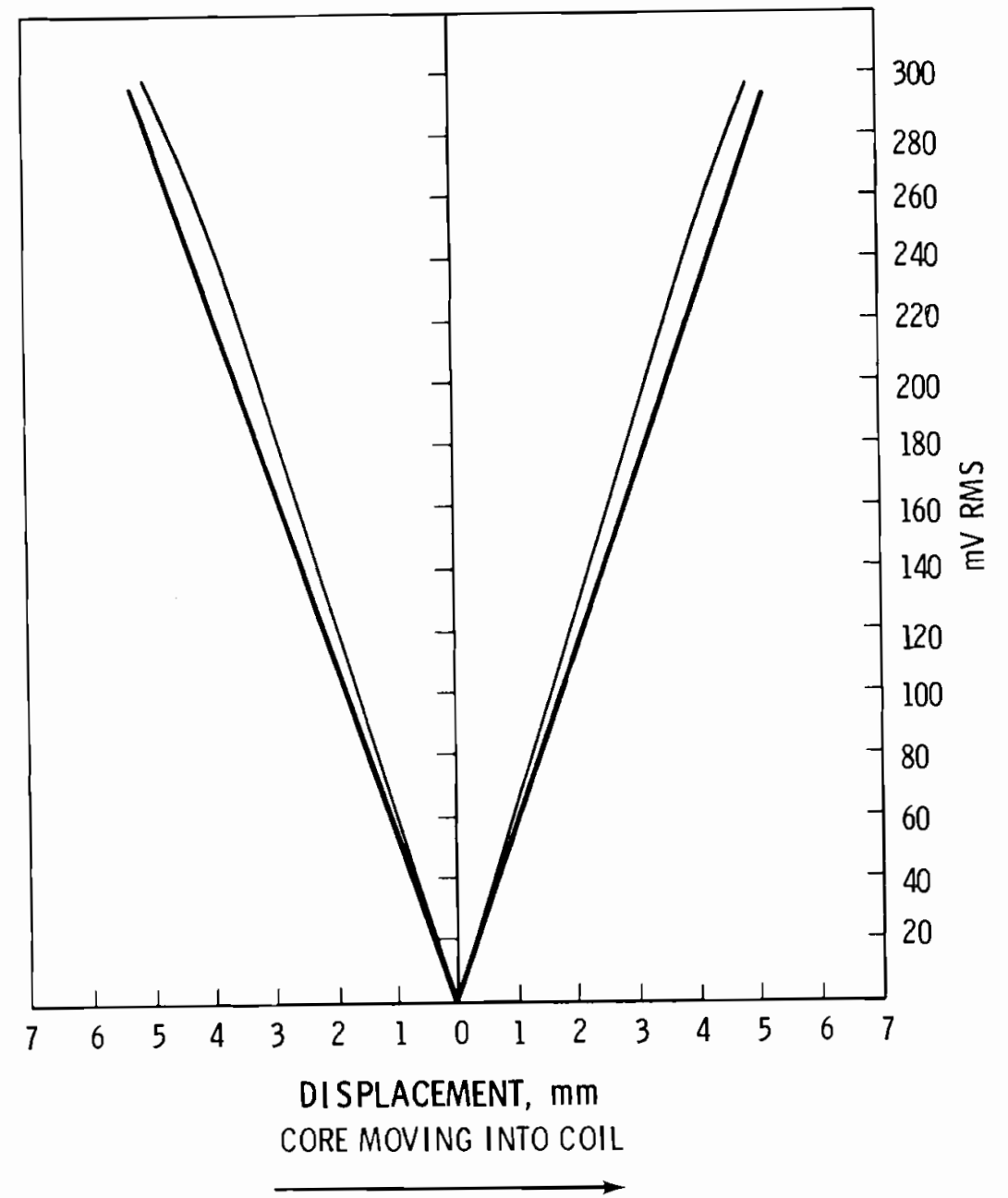

FIGURE B-11. Comparison of Rod 1 and Rod 6 Extensometers 
The non-linearity of this instrument over a range of $\pm 2.5 \mathrm{~mm}$ is $\pm 0.2 \%$ or better. Combined repeatability and accuracy is $\pm 0.6 \%$. Figure B-11 illustrates the variability between typical cladding extensometers.

\section{FISSION GAS PRESSURE TRANSDUCERS}

Figure B-12 shows a schematic of the diaphragm-type pressure transducer used to measure the internal rod pressures due to fission gas release during irradiation. This is essentially an on-off type measurement. The thin platinum alloy membrane is exposed to the rod internal gases on one side, while the other side is connected to an external pressure manifold. When the external pressure equals the internal pressure, the deflection of the membrane causes it to make an electrical contact. The step increase in voltage signals a null pressure balance. Over a range of $100 \mathrm{Kg} / \mathrm{cm}^{2}$, the instrument's sensitivity is $0.1 \mathrm{~kg} / \mathrm{cm}^{2}$. The accuracy and repeatability are $\pm 1 \mathrm{~kg} / \mathrm{cm}^{2}$ and $\pm 0.4 \mathrm{~kg} / \mathrm{cm}^{2}$, respectively.

Calibration is out-of-reactor and consists of checking the deflection sensitivity of the membrane, which does not change appreciably with pressure level. The effects of irradiation on the membrane are not known, but are assumed by Halden to be minimal. There is no temperature compensation for this instrument, but these effects are also considered negligible. 


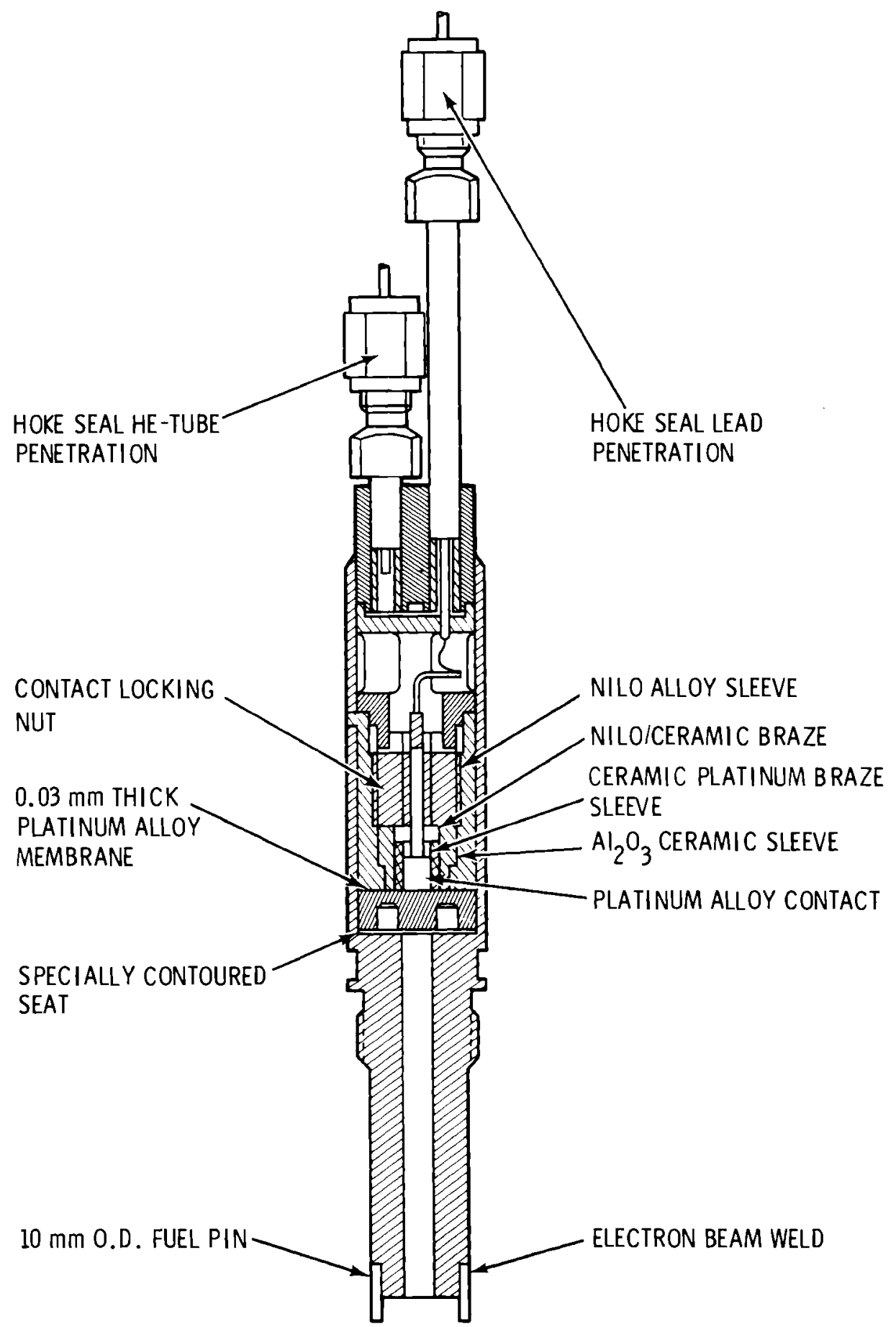

FIGURE B-12. Fission Gas Pressure Transducer (Haiden Project Design) 


\section{APPENDIX C}

ASSEMBLY POWER CAL IBRATION 
APPENDIX C

ASSEMBLY POWER CALIBRATION

\section{FUEL ASSEMBLY POWER}

At the beginning of the first irradiation cycle, the total power in the test assembly is calibrated thermal-hydraulically under forced convection cooling and is related to the average of the neutron detector currents. After this calibration the assembly is operated under natural circulation cooling, and the assembly power and individual fuel rod linear heat ratings are deduced from the neutron detector currents. The calibration is not repeated.

The test assembly inlet ports near the bottom of the assembly as shown in Figure 2.2 are closed for the forced convection calibration run by activating the calibration valve.

Forced circulation cooling is introduced from the subcooled plenum chamber and boiling is established in the channel. This is shown schematically in Figure $\mathrm{C}-1$.

The assembly is operated at constant power which is controlled by the neutron detector readings while the subcooling is varied. The boiling power is computed and plotted versus the measured subcooled power. Figure $\mathrm{C}-2$ shows a plot copied from digital computer results. The plots of boiling power versus subcooled power are very close to a straight line. The intersection of the extrapolated plots with the abscissa gives the minimum subcooled power required to suppress boiling in the channel under ideal conditions. The subcooled power is equal to the total channel power which is corrected for the moderator heating effect to give the channel power associated with the assembly.

The calibration method is based on assuming a constant slip factor during a subcooled power ramp. The results of the measurements give a plot of boiling power versus subcooled power which is very close to a straight line, indicating that the assumption is valid. 


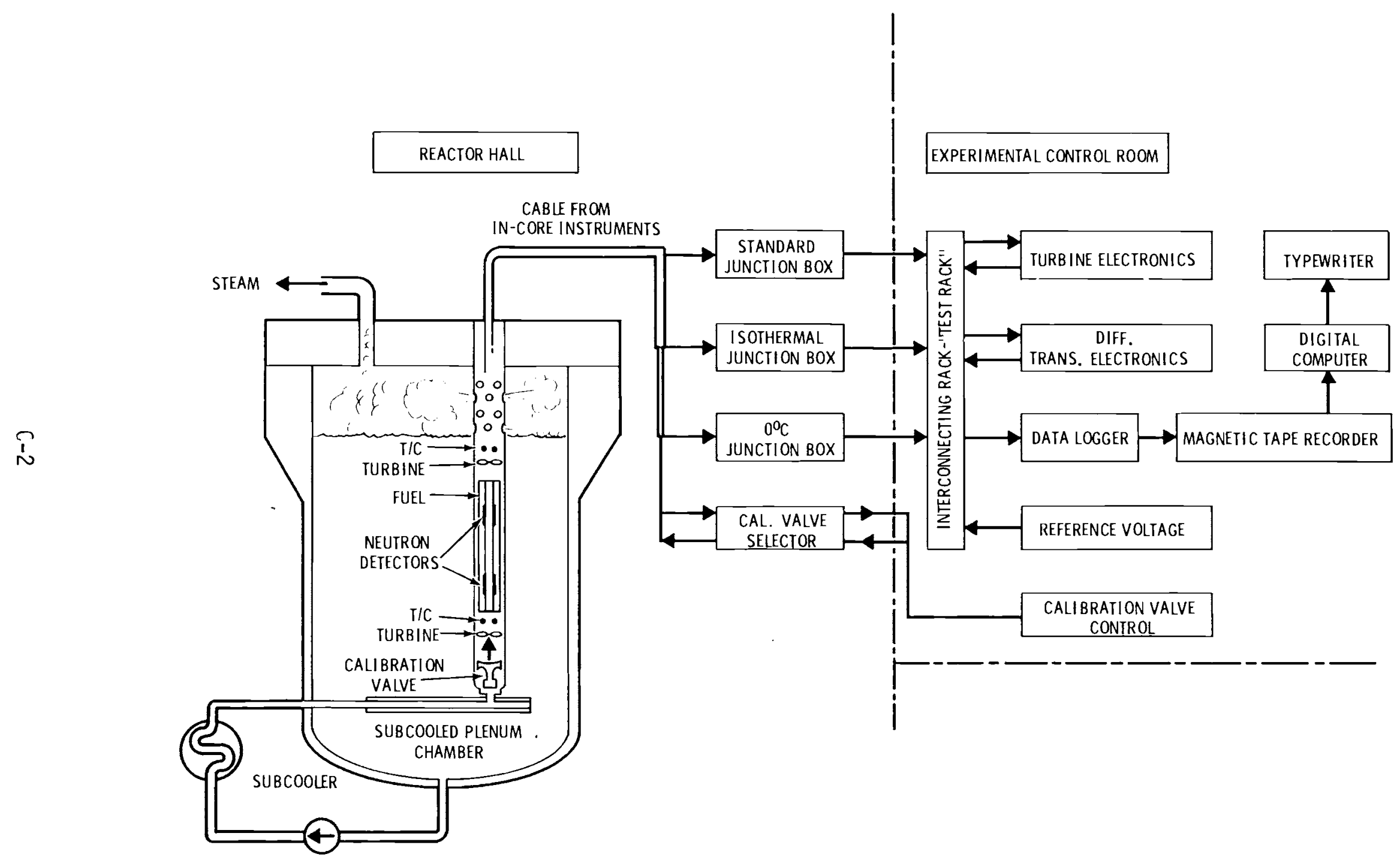

FIGURE C-1. Schematic Arrangement for Assembly Power Calibration 


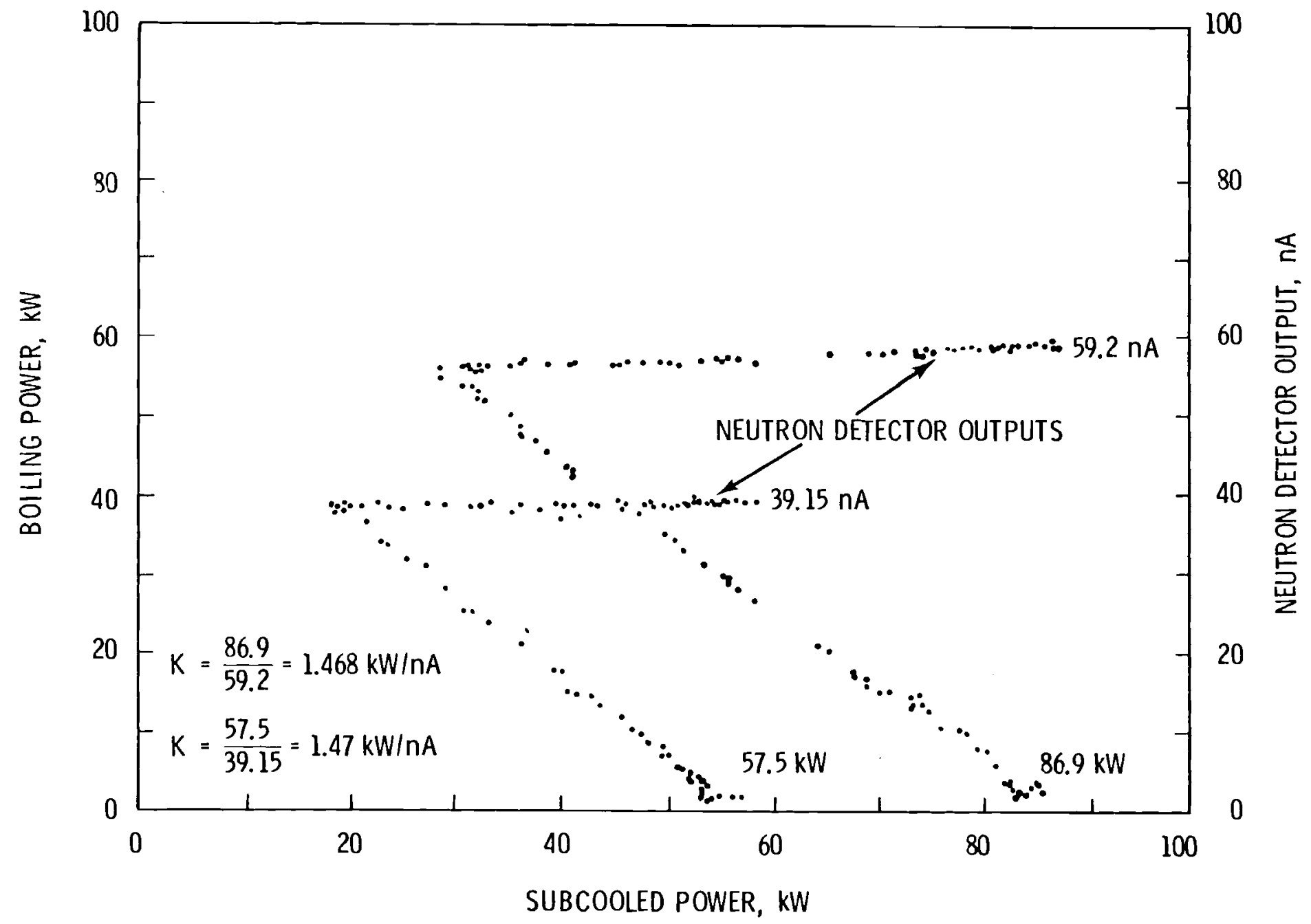

FIGURE C-2. Power Calibration Data for IFA-431 
The effects of void volume on assembly power calibration have been calculated by Halden to be $0.044 \%$ per \% void volume. This represents an increase in the $\mathrm{Kg}$ factor (ratio of thermohydraulic power to neutron detector signal) for IFA-431. The difference between the percent void volume during calibration and operation is not well known, and this factor is not included in this analysis.

The accuracy of the assembly power determination depends on the following factors:

- calibration of inlet and outlet turbine flow meters

- calibration of coolant thermocouples

- temperature profile across the coolant channel where the inlet and outlet thermocouples are located

- influx of heat from the moderator into the coolant channel

- slip factor constancy

- signal to noise ratio

- accuracy of data handling equipment.

The outlet turbine accuracy is very good, better than $\pm 0.5 \%$, while the inlet turbine calibration is more doubtful due to the short and complicated inlet section. Comparison with the outlet turbine immediately prior to measurements gives good control, however, and the accuracy obtained is estimated to be better than $\pm 2 \%$.

The calibration of coolant thermocouples is very good, about $\pm 2 \mu \mathrm{V}$. An $18^{\circ} \mathrm{F}\left(10^{\circ} \mathrm{C}\right)$ temperature rise in the channel has an accuracy of $\pm 0.5 \%$.

The nonuniform temperature distribution across the inlet to the channel is negligible because there is excellent mixing before the coolant enters the assembly. The distribution across the outlet, however, is difficult to determine as there is little information available. The best estimate is obtained by studying the consistency of the measurements and the degree of agreement between the various calibration methods. 
The influence of the heat flux from the moderator is small. It can amount to as much as $10 \mathrm{~kW}$ at low channel power and high subcooling, but it is taken into account, so even if some error is involved in determining this heat flux, the overall error contribution is very small, probably less than $\pm 0.5 \%$.

The signal to noise ratio does not normally cause any difficulty with sound instruments. The noise is easily filtered out.

There is always full control with the performance of the data handling system, so errors caused in this equipment can be neglected compared to error from other sources.

Another factor which influences the accuracy of assembly power indication by the beta current neutron detectors is the specificity of the power indicators themselves. Part of the neutron flux registered by these instruments originates in other fuel assemblies, and this portion of the signal will depend on the flux distribution in the core.

Taking the above factors into account, Halden estimates that the in-reactor assembly power measurements have accuracies in the \pm 3 to $\pm 5 \%$ range.

A value of $\pm 4-1 / 2 \%$ was selected for the IFA-431 assembly power accuracy. 
APPENDIX D

DATA PROCESSING 
APPENDIX D

DATA PROCESSING

Processing of the data received from Halden on magnetic tape proceeds as shown in Figure D-1. After reception of the data tape, it must be translated from the Halden IBM/1800 language (EBCDIC) to the PDP11/45 language (ANSI), and the translated version stored on tape. Then this tape is reformatted so that all the data from a particular time on a particular date is in one block. This is simultaneously stored on a disc file.

Once the raw data is stored on disc, another program (Figure D-2) is applied to each block of data to correct the rod local heat ratings at the thermocouple locations for radial flux tilt across the assembly. This was necessary for IFA-431 since the powers on the original data tape actually represented the powers at the neutron detector locations and not at the thermocouple locations (Figure 2.2). Rod local and assembly powers are also corrected for axial flux shape and heat losses to the moderator. Corrections for local mass distributions of fissile material for each rod are also made. Table D-1 indicates typical values for these correction factors.

While this is being done, other checks are being made on the data. For instance, in IFA-431, neutron detector number six failed during startup, and a correction factor is applied to the calibration factor for the assembly. Also, a value for this detector is calculated assuming that the upper and lower flux planes defined by the two sets of neutron detectors are parallel. The impact that the failure of this detector has on the rod and assembly power uncertainties is discussed in Reference 19.

For the assembly and rod average powers, a total heat balance check is made. This is done during application of the axial correction factor to account for the difference between the average and true mean of the axial flux distribution. The first attempt at this uses an axial profile that represents normal operating conditions. If the heat balance for this profile does not 


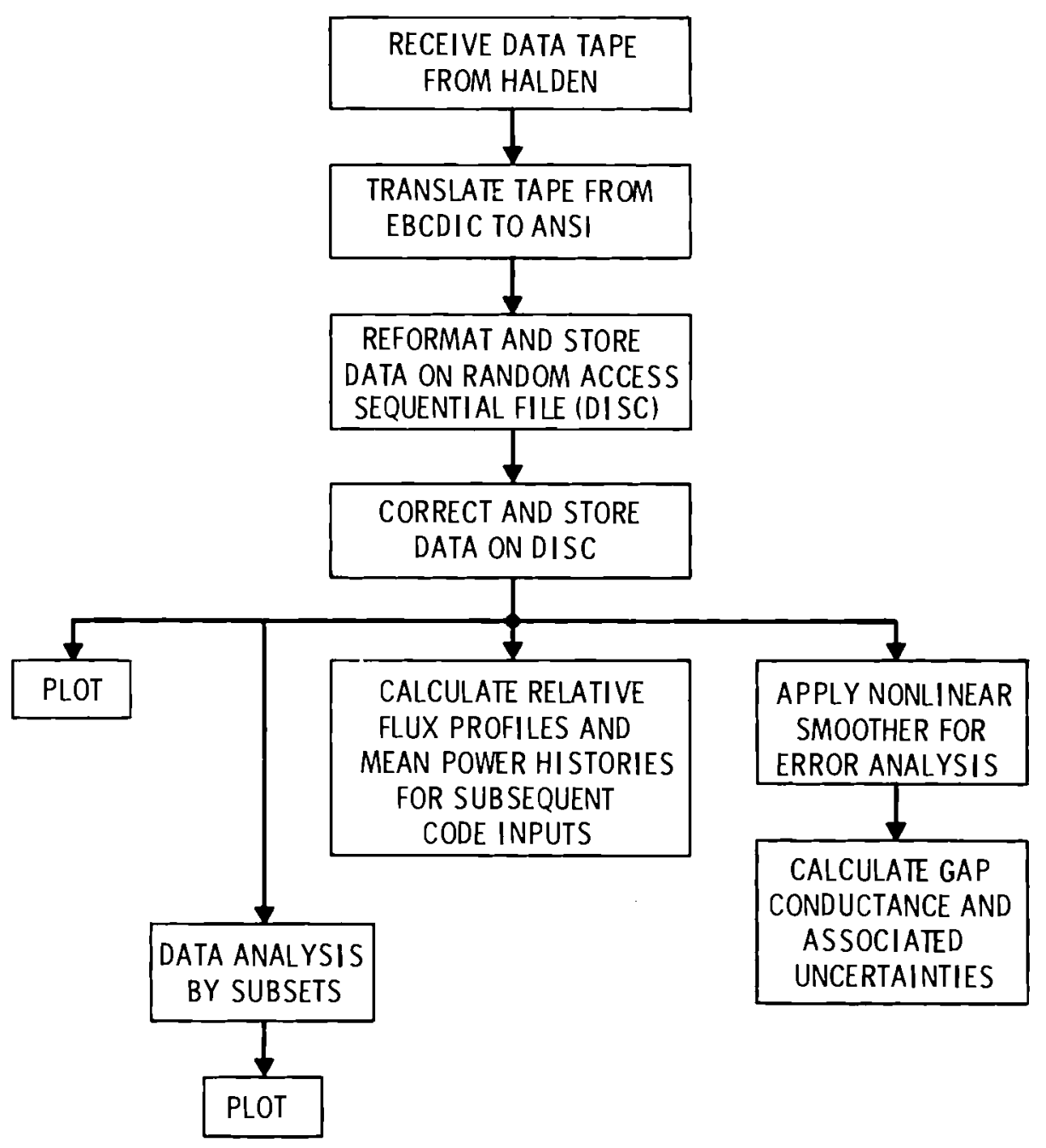

FIGURE D-1. Flow Diagram for Processing Halden Data

TABLE D-1. Typical Power Correction

Factors for IFA-431

\begin{tabular}{|c|c|c|c|c|c|c|}
\hline \multirow[t]{4}{*}{ Rod } & \multirow[t]{4}{*}{ Fuel } & \multirow[t]{4}{*}{$\begin{array}{c}\text { Radial } \\
\text { Ti1t } \\
\end{array}$} & \multicolumn{3}{|c|}{ Calibration Factor } & \multirow[t]{4}{*}{ Total } \\
\hline & & & & Neutron & & \\
\hline & & & Axial & Detector & Gamma & \\
\hline & & & Shape & Average & Heating & \\
\hline 1 & 1.0190 & 1.106 & 0.952 & 1.038 & 0.988 & 1.1003 \\
\hline 2 & 0.9628 & 0.945 & 0.952 & 1.038 & 0.988 & 0.8883 \\
\hline 3 & 1.0614 & 0.926 & 0.952 & 1.038 & 0.988 & 0.9596 \\
\hline 4 & 1.0044 & 1.125 & 0.952 & 1.038 & 0.988 & 1.1032 \\
\hline 5 & 0.9791 & 0.987 & 0.952 & 1.038 & 0.988 & 0.9435 \\
\hline 6 & 0.9878 & 0.957 & 0.952 & 1.038 & 0.988 & 0.9229 \\
\hline
\end{tabular}

Burnup Correction $=-0.66 \%$ per 1000 MWD/MTM 


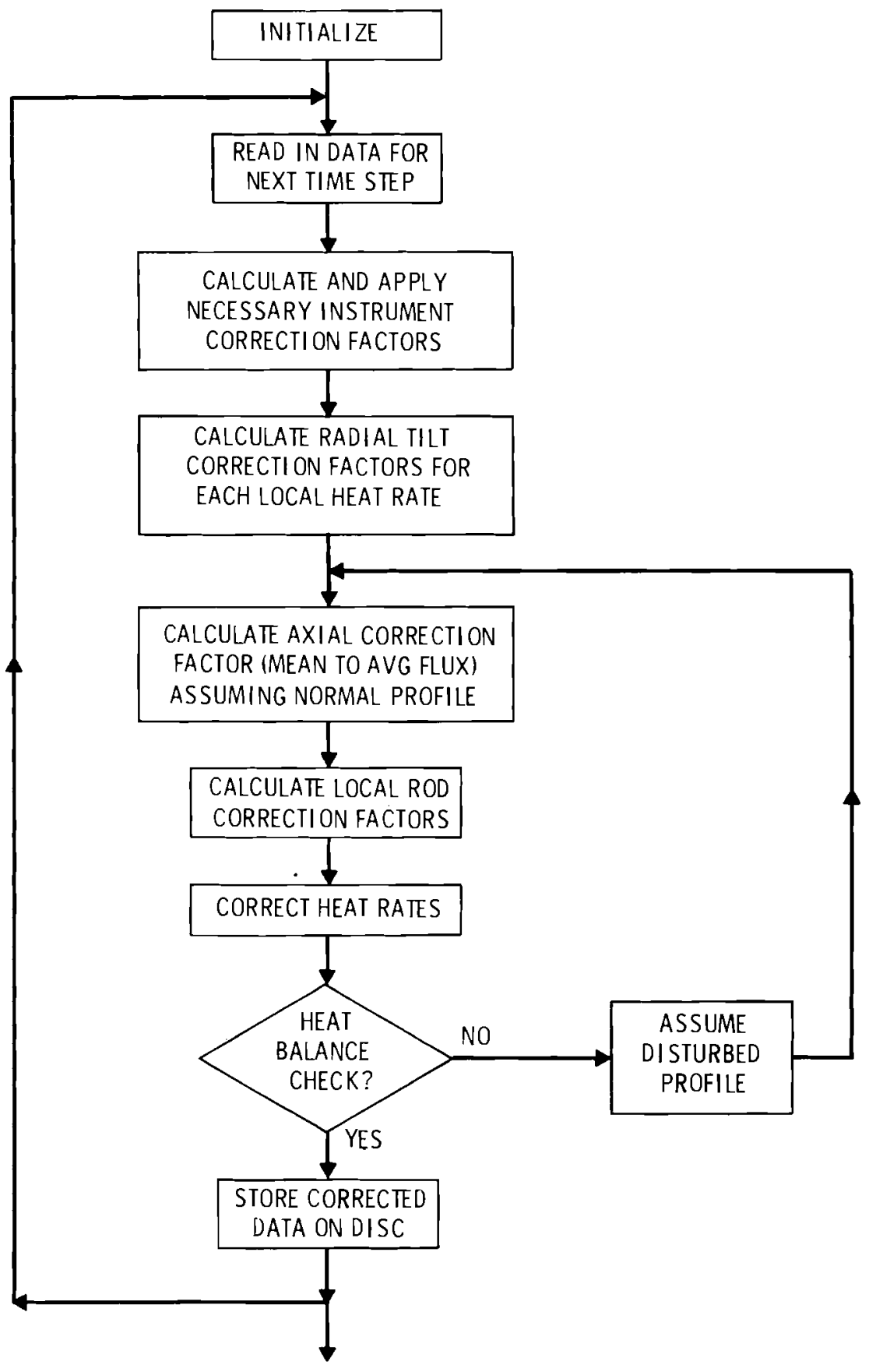

FIGURE D-2. Flow Diagram for Correction of Halden Rod Local Powers 
check, an error message is printed and a second attempt is made with an axial flux shape that represents a disturbed flux profile. This occurs when a nearby control rod is partially inserted. In nearly all cases, the normal profile produces a heat balance that checks to within less than $1 / 2 \%$.

When this step is complete, another program corrects the burnups and heat ratings for depletion of ${ }^{235} \mathrm{U}$. Plutonium buildup is not taken into account. Both of these factors are smal1 for the low burnup reached by IFA-431 (4300 MWd/MTM average).

After the data are corrected, four paths are possible and usually are executed simultaneously. The data are plotted, relative flux profiles and mean power histories are calculated for input to safety related codes, an error analysis is performed on the corrected data, and the data is analyzed by subsets (i.e., transient, steady state) to separate out the effects of the major variables. A sample of the relative axial power profile seen by the assembly is shown in Figure D-3. Figure D-4 is a flow diagram of the gap conductance and uncertainty calculations performed. (19) 


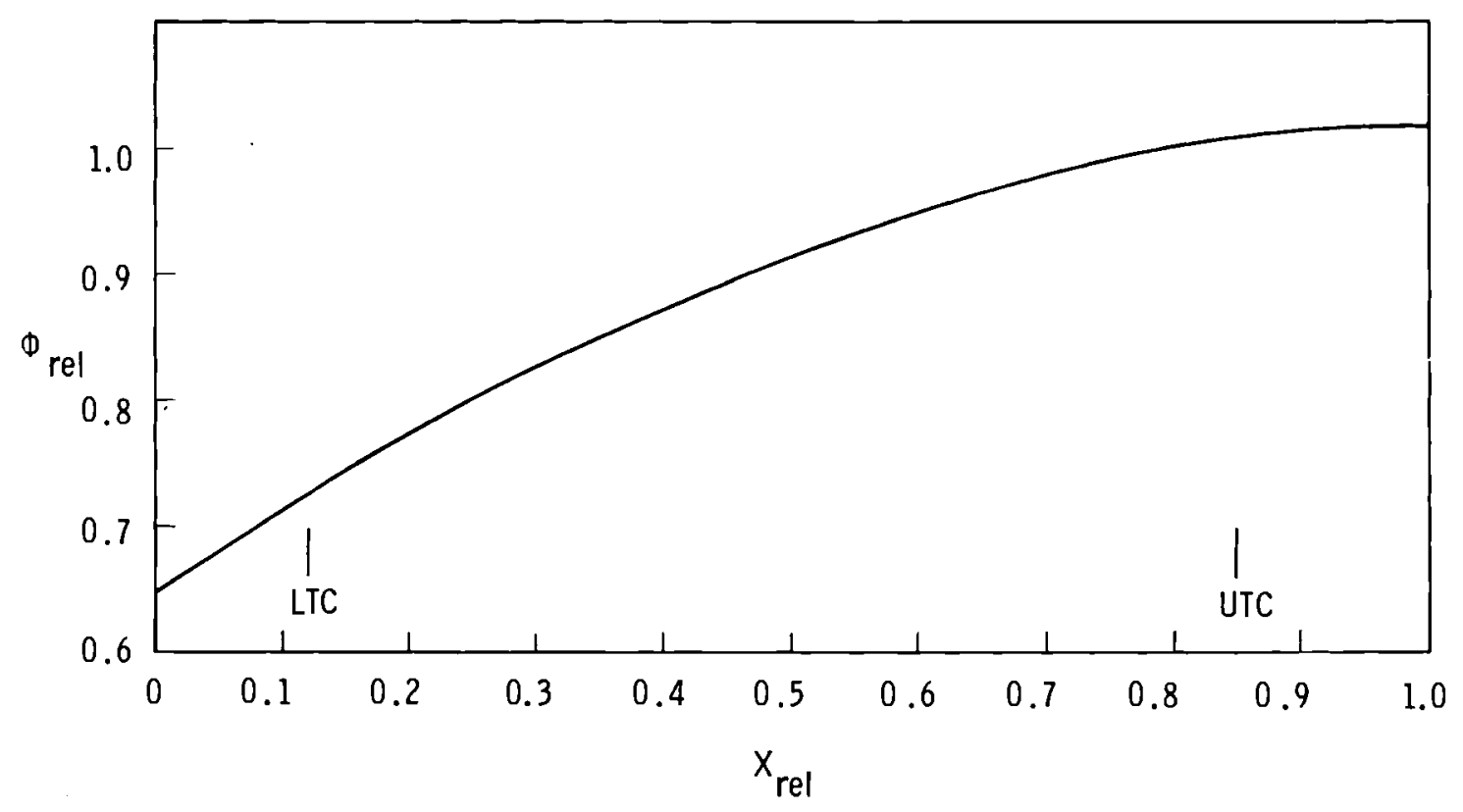

FIGURE D-3. Typical Axial Power Profile for IFA-431 


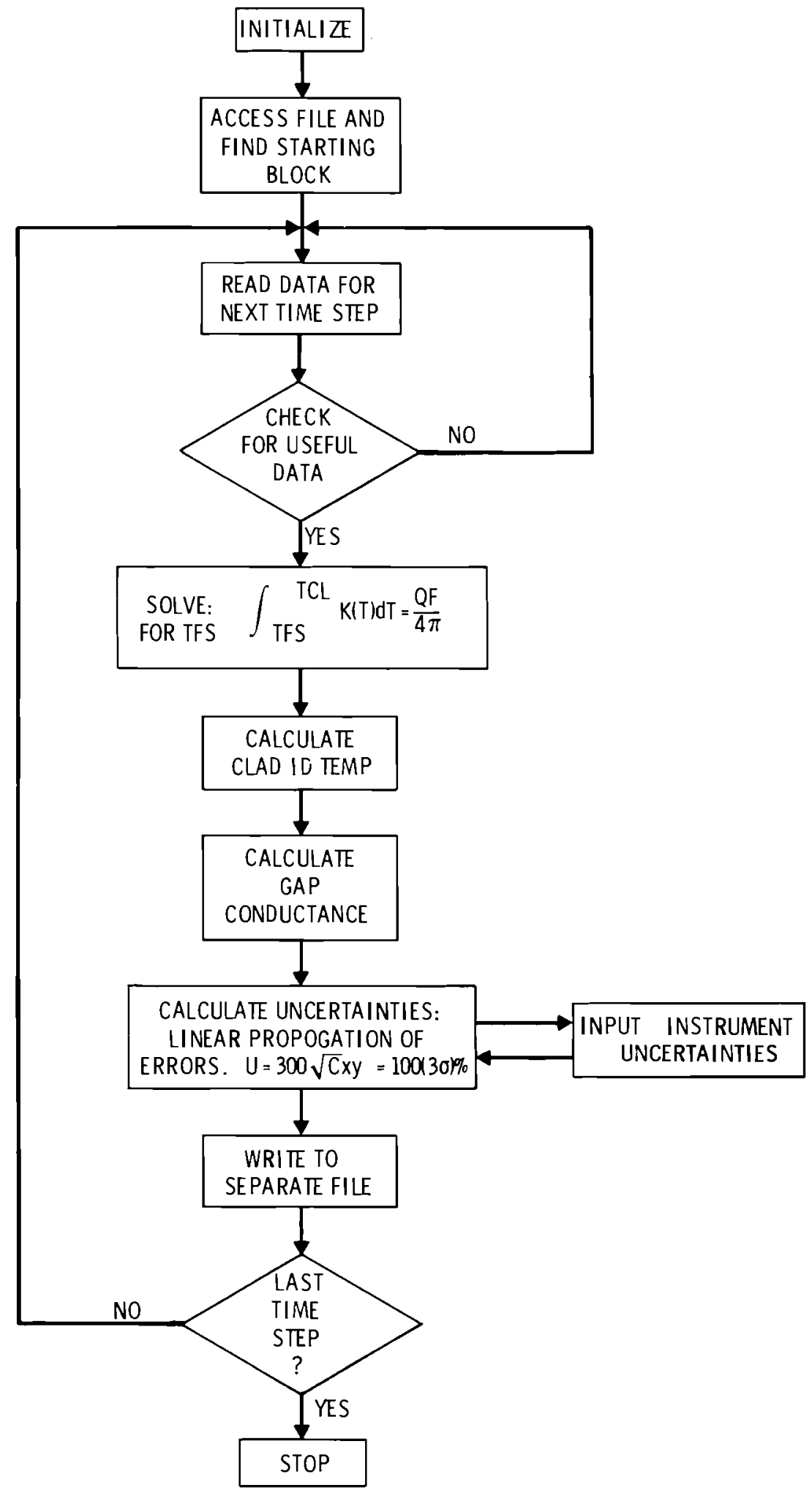

FIGURE D-4. Flow Diagram for Gap Conductance and Uncertainty Calculations 


\section{DISTRIBUTION}

\section{OFFSITE}

No. of

Copies

1 ERDA Chicago Patent Group

9800 S. Cass Avenue

Argonne, Illinois 60439
A. A. Churm

245 Basic Distribution Under NRC-1

61 Supplementary NRC-3 Distribution List

3 ERDA Technical Information

Chief Mail \& Files

US NRC Central Files

Washington, D.C. 20555

M. Jinks

10 Nuclear Regulatory Commission, Division of Reactor Safety Research

Chief, Fuel Behavior Research Branch

ONSITE

1 ERDA Richland Operations Office

Program Division

38 Battelle-Northwest
W. J. Bailey
J. 0. Barner
R. P. Marshall
D. W. Brite
J. A. Christensen
C. L. Mohr
F. E. Panisko
E. L. Courtright
P. J. Pankaskie
M. D. Freshley
A. M. Sutey
C. R. Hann (15)
D. S. Trent
D. D. Lanning
S. R. Wagoner
R. K. Marsha 11
R. E. Williford
Technical Information Files (5)
Technical Publications 
